Edited by

Zvi Bodie, Dennis McLeavey, CFA, and Laurence B. Siegel

\title{
The Future of Life-Cycle Saving and Investing
}

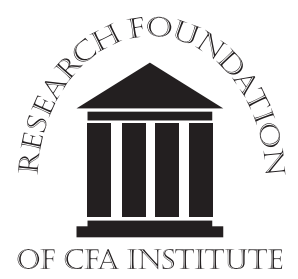




\title{
Statement of Purpose
}

\section{The Research Foundation of CFA Institute is a not-for-profit organization established to promote the development and dissemination of relevant research for investment practitioners worldwide.}

\begin{abstract}
Neither the Research Foundation, CFA Institute, nor the publication's editorial staff is responsible for facts and opinions presented in this publication. This publication reflects the views of the author(s) and does not represent the official views of the Research Foundation or CFA Institute.
\end{abstract}

The Research Foundation of CFA Institute and the Research Foundation logo are trademarks owned by The Research Foundation of CFA Institute. CFA ${ }^{\circledR}$, Chartered Financial Analyst ${ }^{\circledR}$, AIMR-PPS $^{\circledast}$, and GIPS ${ }^{\circledast}$ are just a few of the trademarks owned by CFA Institute. To view a list of CFA Institute trademarks and the Guide for the Use of CFA Institute Marks, please visit our website at www.cfainstitute.org.

(C) 2007 The Research Foundation of CFA Institute

All rights reserved. No part of this publication may be reproduced, stored in a retrieval system, or transmitted, in any form or by any means, electronic, mechanical, photocopying, recording, or otherwise, without the prior written permission of the copyright holder.

This publication is designed to provide accurate and authoritative information in regard to the subject matter covered. It is sold with the understanding that the publisher is not engaged in rendering legal, accounting, or other professional service. If legal advice or other expert assistance is required, the services of a competent professional should be sought.

ISBN 978-0-943205-96-0

26 October 2007

\section{Editorial Staff}

Maryann Dupes

Book Editor

David L. Hess

Kara H. Morris

Assistant Editor

Production Manager

Lois Carrier

Production Specialist 


\section{Authors}

David Blitzstein, as special assistant for multiemployer plans for the United Food and Commercial Workers International Union (UFCW), currently serves as a trustee for five Taft-Hartley pension funds and two health funds representing one-quarter of a million plan participants. In addition, he advises the UFCW international leadership on employee benefit policy issues. Between 1990 and 2006, Mr. Blitzstein served as the director of the negotiated benefits department of the UFCW and was responsible for providing collective bargaining advice on health insurance and pension issues. He represents the UFCW as a member of the steering committee of the National Coordinating Committee for Multiemployer Plans (a lobbying group for multiemployer plans), a member of the Employee Benefits Research Institute, a member of the National Academy of Social Insurance, and a director of the Pension Research Council of the Wharton School of the University of Pennsylvania. Mr. Blitzstein is a graduate of the University of Pennsylvania and holds a master of science in labor studies from the University of Massachusetts in Amherst.

Zvi Bodie is Norman and Adele Barron Professor of Management at Boston University's School of Management. Professor Bodie has served on the finance faculty of the Harvard Business School and the Massachusetts Institute of Technology (MIT) Sloan School of Management. He has published widely on pension finance and investment strategy in leading professional journals. His books include Foundations of Pension Finance, Pensions in the U.S. Economy, Issues in Pension Economics, and Financial Aspects of the U.S. Pension System. He is the author of Investments, a leading textbook used in certification programs of CFA Institute, the Financial Planning Association, and the Society of Actuaries, and is co-author with Nobel Prize winning economist Robert C. Merton of the textbook Finance. His latest book is Worry Free Investing: A Safe Approach to Achieving Your Lifetime Financial Goals. Professor Bodie holds a PhD from MIT.

Jeffrey R. Brown is William G. Karnes Professor of finance in the College of Business of the University of Illinois at Urbana-Champaign. Professor Brown is also a research associate of the National Bureau of Economic Research and associate director of the NBER Center for Retirement Research. He is a member of the Social Security Advisory Board and has previously served as senior economist for the White House Council of Economic Advisers (2001-2002). He was a founding co-editor of the Journal of Pension Economics and Finance. Professor Brown's primary research focus is on the interaction of public and private insurance markets, including annuities, life insurance, long-term care insurance, pensions, and Social Security. He has also investigated such issues as stock market participation, dividend taxation, and the effect of inheritances on labor supply. Professor Brown holds a BA from Miami University, an MPP from Harvard University, and a PhD in economics from Massachusetts Institute of Technology. 
George Chacko is a managing partner and chief investment officer of 6S Capital, a managing director of Trinsum Group, an associate professor at Santa Clara University, and an active board member for several companies. He was previously a professor at Harvard Business School and a managing director of fixed income at State Street Bank in Boston. Professor Chacko has also held positions at Prudential Investments and Accenture. He has published in academic journals, practitioner journals/magazines, and books on portfolio construction, complex financial securities, and the microstructure of financial markets. He holds a BS in electrical engineering from Massachusetts Institute of Technology, an MBA from the University of Chicago, and an MA and $\mathrm{PhD}$ in business economics from Harvard University.

Jeffrey J. Diermeier, CFA, is president and CEO of CFA Institute. Previously, he served as global chief investment officer at UBS Global Asset Management, where he oversaw the management of more than $\$ 400$ billion in assets and a staff of 435 investment professionals in 10 countries. Mr. Diermeier has received two Graham and Dodd Scroll Awards for research articles published in the Financial Analysts Journal. He has also received a Roger Murray Award from the Institute for Quantitative Research in Finance and the distinguished Business Alumnus Award from the University of Wisconsin, where he served on the dean's advisory board of the business school and endowed the Jeffrey J. Diermeier Chair in Finance. Mr. Diermeier is a member of the board of the University of Wisconsin Foundation, the National Association of Corporate Directors' Not-for-Profit Advisory Council, and XBRL International's Board of Advisors. He also serves on the board of Stairway Partners, an investment management organization, and is a trustee of the Diermeier Family Foundation. Mr. Diermeier holds a BBA and an MBA from the University of Wisconsin at Madison.

Philip H. Dybvig is Boatmen's Bancshares Professor of Banking and Finance at Washington University in St. Louis. Professor Dybvig previously served on the faculties of Princeton and Yale universities. His research interests are primarily in portfolio theory, the analysis of financial markets, and banking. A former Sloan and Batterymarch research fellow, Professor Dybvig has published more than 30 articles in leading journals as well as two textbooks. Professor Dybvig is associate editor of the Journal of Economic Theory and the Journal of Applied Finance and has also previously served as editor of the Review of Financial Studies and president of the Western Finance Association. He holds a BA from Indiana University as well as MA, Master of Philosophy, and PhD degrees from Yale University.

Jim Finnegan, CFA, was the publisher and owner of Financial Engineering Nerws. He holds a Bachelor of Science degree in chemical engineering from Clarkson University, an MBA with a concentration in finance from Harvard Business School, and a master of science in investment management from Boston University. 
François Gadenne, CFA, is co-founder and chairman of the Retirement Income Industry Association, which serves as a think tank to analyze retirement income issues. He is also president and CEO of Retirement Engineering, Inc., a research and development company that designs insurance and investment products geared to meeting the retirement income needs of Baby Boomers, and serves as a lecturer at Boston University's School of Management. Additionally, Mr. Gadenne co-founded Rational Investors, an independent provider of investment education and advice products for the defined-contribution market. He has worked with Standard \& Poor's Retirement Services Group, Bank of Boston (now Bank of America), Braxton (the strategy arm of Deloitte), and Arthur D. Little. Mr. Gadenne is a graduate of the École Supérieure de Commerce de Paris (France) and an MBA recipient from the Kellogg School of Management at Northwestern University.

Jerome S. Golden is president of the Income Management Strategies Division of MassMutual Financial Group, which in 2005 acquired Golden Retirement Resources, Inc. (GRR), the company that he founded in 1999. At GRR, Mr. Golden and his team spent six years developing and implementing the patentpending RetireMentor ${ }^{\circledR}$ system and the Flexible Benefits Annuity. RetireMentor is an integrated income-planning and management system that addresses the unique financial issues of retirement, including the need to receive secure lifetime income benefits, maintain purchasing power over time, and adjust to life events. Mr. Golden was previously an executive vice president at the Equitable Life Assurance Society of the United States, the principal insurance subsidiary of AXA Financial. He was also president of BT Variable, originally named the Golden Financial Group, which he founded in 1987. Mr. Golden is a fellow of the Society of Actuaries. He holds a BA from the University of Michigan.

Laurence J. Kotlikoff is professor of economics at Boston University. He is also a research associate at the National Bureau of Economic Research and president of Economic Security Planning, Inc. (a company that specializes in financial planning software). Professor Kotlikoff has served on the economics faculties of the University of California, Los Angeles, and Yale University, and he was a senior economist for the President's Council of Economic Advisers. He has served as a consultant to a variety of domestic and international organizations and corporations, including the Swedish and Norwegian ministries of finance and the central banks of Italy, Japan, and England. Professor Kotlikoff is the author or co-author of 11 books and hundreds of professional journal articles. He also writes extensively in newspapers and magazines on issues of deficits, generational accounting, tax structure, Social Security, Medicare, health reform, pensions, saving, insurance, and personal finance. Professor Kotlikoff holds a BA from the University of Pennsylvania and a $\mathrm{PhD}$ in economics from Harvard University. 
Deborah J. Lucas is Donald C. Clark/Household International Professor of Finance at the Kellogg School of Management at Northwestern University. Professor Lucas is also a research associate at the National Bureau of Economic Research and has been a visiting assistant professor at the Sloan School of Management at Massachusetts Institute of Technology. Her primary research interests include dynamic asset pricing, corporate finance, and applications of finance in public policy. Professor Lucas is currently working on questions relating to measuring and accounting for risk in federal credit programs, pension liabilities, and Social Security. She is a co-editor of the Journal of Money, Credit, and Banking. She earned BA, MA, and PhD degrees in economics from the University of Chicago.

Robert C. Merton is John and Natty McArthur University Professor at the Harvard Business School. He currently serves as chief science officer of Trinsum Group, an advisory firm that provides strategic consulting, corporate finance investment banking advice, asset management, and pension solution systems. Professor Merton is past president of the American Finance Association and a member of the National Academy of Sciences. He received the 1997 Alfred Nobel Memorial Prize in Economic Sciences (with Myron Scholes) for a new method to price derivative securities. Professor Merton also received the inaugural Financial Engineer of the Year Award from the International Association of Financial Engineers. He has written numerous books and articles on finance, including optimal lifetime consumption and portfolio selection, equilibrium asset pricing, derivative securities, credit and corporate liability pricing, financial innovation, and system design. A graduate of Columbia University in engineering mathematics, Professor Merton holds an MS from California Institute of Technology in applied mathematics, a $\mathrm{PhD}$ in economics from Massachusetts Institute of Technology, and honorary degrees from the University of Chicago and seven foreign universities.

Alicia H. Munnell is the director of the Center for Retirement Research at Boston College and Peter F. Drucker Professor of Management Sciences at Boston College Carroll School of Management. Previously, Professor Munnell was a member of the President's Council of Economic Advisers and served as assistant secretary for economic policy at the U.S. Treasury. She spent most of her professional career at the Federal Reserve Bank of Boston, where she became senior vice president and director of research. Professor Munnell was co-founder and first president of the National Academy of Social Insurance. She is currently a member of the American Academy of Arts and Sciences, the Institute of Medicine, the Pension Research Council at Wharton, the Century Foundation, the National Bureau of Economic Research, and the Pension Rights Center. Professor Munnell's research interests focus on retirement issues, including tax policy, Social Security, public and private pensions, productivity growth, infrastructure, and general monetary and fiscal policy. She holds a BA from Wellesley College, an MA from Boston University, and a $\mathrm{PhD}$ in economics from Harvard University. 
James Poterba is Mitsui Professor of Economics and head of the department of economics at Massachusetts Institute of Technology (MIT). Professor Poterba is also director of the Public Economics Research Program at the National Bureau of Economic Research, a fellow of the American Academy of Arts and Sciences, and a fellow of the Econometric Society. He has served as a director of the American Finance Association, a member of the executive committee of the American Economic Association, and a former Sloan and Batterymarch research fellow. Professor Poterba's research focuses on how taxation affects the economic decisions of households and companies. His recent work has emphasized the effects of taxation on the financial behavior of households, particularly regarding their saving and portfolio decisions. Professor Poterba is a trustee of the College Retirement Equity Fund and a former member of the MIT 401(k) Plan Oversight Committee. He is a member of the advisory board of the Journal of Wealth Management and co-author of The Role of Annuity Markets in Financing Retirement. Professor Poterba holds a BA from Harvard University and a Doctor of Philosophy in economics from Oxford University.

Anna Rappaport is the founder and president of Anna Rappaport Consulting, a firm specializing in strategies for better retirement systems. Ms. Rappaport is a past president of the Society of Actuaries. She is a senior fellow on pensions and retirement for the Conference Board. She was a delegate to the 1998 and 2002 National Summits on Retirement Savings, and she chairs the Committee on Post Retirement Needs and Risks of the Society of Actuaries. She has been a major driving force in the consumer education efforts of the Actuarial Foundation. She was a member of the 2003 technical panel of the Social Security Advisory Board. Ms. Rappaport is a frequent speaker and contributor to business and trade publications and is the co-author of three books on the topics of demographics, retiree medical benefits, and retirement. For many years, she wrote a column on postemployment benefits for the Employee Benefit Plan Review. She was a worldwide partner of Mercer Human Resources Consulting before founding her firm. Ms. Rappaport holds an MBA from the University of Chicago.

Dallas L. Salisbury is president and CEO of the Employee Benefit Research Institute (EBRI), which provides objective information regarding employee benefit systems and related financial security issues. Prior to joining EBRI, Mr. Salisbury held positions with the Washington State legislature, the U.S. Department of Justice, the Employee Benefits Security Administration of the U.S. Department of Labor, and the Pension Benefit Guaranty Corporation. He is a fellow of the National Academy of Human Resources and currently serves on the board of directors of the NASD Investor Education Foundation. Mr. Salisbury is a member of the U.S. Government Accountability Office's Advisory Group on Social Security 
and Retirement and a member of the advisory committee to the Comptroller General of the United States. He has written and lectured extensively on economic security topics. Mr. Salisbury holds a BA from the University of Washington and an MA in public administration from the Maxwell School at Syracuse University.

Paul A. Samuelson is institute professor and professor of economics, emeritus, at Massachusetts Institute of Technology. His work in economic theory is extensive, including, but not limited to, work in modern welfare economics, linear programming, Keynesian economics, economic dynamics, international trade theory, logic choice, and maximization. Professor Samuelson has authored or co-authored hundreds of books and articles covering these and other topics, and he is the author of the best-selling economics textbook of all time. He was awarded the David A. Wells Prize by Harvard University in 1941, and the American Economic Association awarded him the John Bates Clark Medal in 1947 as the living economist under 40 years old "who has made the most distinguished contribution to the main body of economic thought and knowledge." Professor Samuelson is the recipient of the 1970 Nobel Prize in economics. He served as economic adviser to President John F. Kennedy and has been president of the International Economic Association, the American Economic Association, and the Econometric Society. Professor Samuelson received a BA from the University of Chicago and MA and $\mathrm{PhD}$ degrees from Harvard University.

John B. Shoven is Charles R. Schwab Professor of Economics at Stanford University and Wallace R. Hawley Director of the Stanford Institute for Economic Policy Research. Professor Shoven's research interests include corporate finance (dividend behavior, mergers and acquisitions, and share repurchase); Social Security and private pensions; stock and bond returns; mutual funds; federal, personal, and corporate income taxation; international cost-of-capital comparisons; and applied general equilibrium analysis. His current research focuses on interactions between government behavior and consumer investment, specifically in the areas of asset allocation and asset location theory, the effect of taxes on the relative performance of mutual funds, the long-run future of pension fund saving, and public policy toward pensions. A fellow of the Econometrics Society, Professor Shoven received a BA in physics from the University of California, San Diego, and a $\mathrm{PhD}$ in economics from Yale University.

Paul Solman has been business and economics correspondent for PBS's The News Hour with Jim Lehrer since 1985. The founding editor of the alternative Boston weekly, The Real Paper, Mr. Solman began his career in business journalism as a Nieman fellow, studying at Harvard Business School in 1976. He has been a business reporter for public broadcasting since 1977, and he was the co-originator and executive editor of PBS's business documentary series, Enterprise. His reporting 
has won numerous Emmys, as well as two Peabody awards, the most recent in 2004 for his reporting on the undercounting of unemployment. Mr. Solman has served on the faculty of Harvard Business School, where he has taught courses in media, finance, and business history. He has written for numerous publications, including Forbes and Mother Jones magazines. A one-time cab driver, kindergarten teacher, and management consultant, Mr. Solman holds a BA from Brandeis University.

John Turner is a senior policy adviser of the Public Policy Institute at AARP. Previously, he was affiliated with the International Labour Organization of the United Nations in Geneva, Switzerland, where he co-edited the book Social Security Pensions: Development and Reform. Mr. Turner has also worked in research offices at the U.S. Social Security Administration and the U.S. Labor Department, where he was deputy director of the pension research office for nine years. A member of the National Academy of Social Insurance, he has published more than 100 articles in professional journals concerning pension and Social Security policy. Mr. Turner serves on the board of directors of the European Network for Research on Supplementary Pensions, is a fellow at the Pensions Institute (United Kingdom), serves on the editorial board for Benefits Quarterly, and is the U.S. private pension correspondent to the International Social Security Association. The author or editor of 12 books, Mr. Turner holds a $\mathrm{PhD}$ in economics from the University of Chicago.

Mark J. Warshawsky is director of retirement research at Watson Wyatt Worldwide, a global human capital consulting firm, where he conducts and oversees research on employer-sponsored retirement programs and policies. He is also a member of the Social Security Advisory Board and the Pension Research Council. From 2004 to 2006, Mr. Warshawsky served as assistant secretary of the U.S. Treasury for economic policy. As the Treasury's top economist, he led the department's efforts to develop and advance economic policies and was responsible for the review and analysis of domestic and international economic matters as well as developments in financial markets. In particular, he led the department's efforts in pension and Social Security reform. Previously, as deputy assistant secretary for microeconomic analysis, from 2002 to 2004, Mr. Warshawsky oversaw research focused on terror risk insurance, financial reporting, health spending, retirement income security, and the Trustees' Reports for Social Security and Medicare. Before joining the Treasury, he was director of research at the TIAA-CREF Institute, senior economist in the employee plans division of the U.S. Internal Revenue Service, and senior economist at the U.S. Federal Reserve Board. Mr. Warshawsky has authored three books and more than 60 professional articles. His research has been influential in reforms of minimum distribution requirements for retirement plans. He received a BA from Northwestern University and a $\mathrm{PhD}$ in economics from Harvard University. 



\section{Contents}

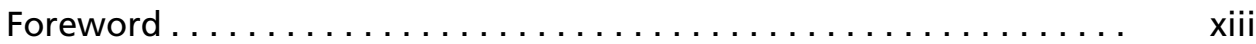

Laurence B. Siegel

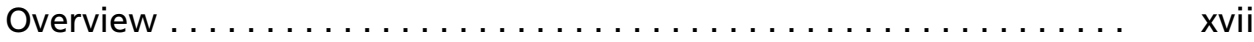

Zvi Bodie

\section{Keynote Addresses}

Is Personal Finance a Science? . . . . . . . . . . . . . . . . . .

Paul A. Samuelson

The Future of Retirement Planning . . . . . . . . $\ldots \ldots \ldots \ldots \ldots$

Robert C. Merton

\section{Session 1: Bodie Presentation}

The Theory of Optimal Life-Cycle Saving and Investing . .

Zvi Bodie

Jonathan Treussard

Paul Willen

Session 1 Comments by Deborah Lucas...................

Deborah J. Lucas

Session 1 Comments by Philip Dybvig . .

Philip H. Dybvig

\section{Session 2: Laibson Presentation}

Session 2 Comments by Jeffrey Brown ................. 44 Jeffrey R. Brown

Session 2 Comments by James Poterba $\ldots \ldots \ldots \ldots \ldots \ldots \ldots$ James Poterba

\section{Session 3: Kotlikoff Presentation}

Is Conventional Financial Planning Good for Your Financial Health? .

Laurence J. Kotlikoff

Session 3 Comments by John Turner . . . . . . . . . . . . . John Turner

Session 3 Comments by George Chacko 


\section{Session 4: Innovative Products Panel}

Perspective of the Retirement Income Industry Association ........

François Gadenne, CFA

Innovative Retirement Income and Old-Age Insurance Products:

Insurance and Income Annuity Solutions . . . . . . . . . . . .

Jerome S. Golden

Sustaining Retirement Income-Barriers and Dreams ...........

Anna Rappaport

The Life Care Annuity.

Mark J. Warshawsky

\section{Session 5: Munnell Presentation}

The Role of Government in Life-Cycle Saving and Investing . . . . . . . .

Alicia H. Munnell

Session 5 Comments by John Shoven. .

John B. Shoven

Session 5 Reply by Alicia Munnell

Alicia H. Munnell

\section{Session 6: What Everyone Should Know about . . . Panel}

Introduction.

Paul Solman

The Crisis in Retirement Plans ..

David Blitzstein

The Need to Save More

Dallas L. Salisbury

The Role of CFA Institute

Jeffrey J. Diermeier, CFA

The Challenges of Investor Education

Zvi Bodie

\section{Postconference Summaries}

The Future of Life-Cycle Saving and Investing: A Review. . . . . . . .

Jim Finnegan, CFA

An Actuary's View of the Future of Life Cycle Saving and Investing:

A Report and Some Discussion on Key Issues

Anna Rappaport

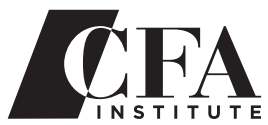




\section{Foreword}

Life-cycle finance is the branch of finance that affects everybody. It deals with the questions faced by individuals seeking to get ahead: How much should I save, and what should I invest in to build wealth? When I retire or if I become unemployed, how much of my savings can I spend each year? Is there something I can do to make sure I do not outlive my savings? What can my spouse and children expect to inherit?

Despite the urgent needs represented by these questions, financial researchers have devoted relatively little attention to most of them. "What should I invest in?" has received the lion's share of the attention, and as a result, a well-accepted body of theory exists that says how to build optimal portfolios out of securities or asset classes. Mainstream finance has evolved pretty much in a straight line as a series of progressively more sophisticated answers to this question. The seeds planted by Irving Fisher and Frederick Macaulay gave rise to the trunk wood of Harry Markowitz, Franco Modigliani, Merton Miller, and the incomparable William Sharpe. ${ }^{1}$ The more modern explorations launched by Fischer Black have been carried on by successors too numerous to mention. This progression has produced an integrated body of theory that is taught in business schools and that most finance practitioners and academics agree on, at least in broad outline.

But this body of work does not say (or at least it does not say very clearly) how much to save, how quickly to spend down one's assets, or how to insure against untoward events. It does not answer the central question of life-cycle finance: How can I spread the income from my working life over my entire life? To address these questions, we need to look outside mainstream finance-in particular, at actuarial science and the theory of insurance.

In fact, the lead role in life-cycle finance has historically been played by actuaries, working mostly in obscurity for insurance companies. Their contribution is critical because life-cycle finance depends on the ability to estimate how many people will undergo a life change-be born, have children, get a job, retire, become disabled, or die-in a given period, which is what actuaries do. By combining the experiences of large groups of people for whom each of these events would arrive almost randomly, they turn chaos into order, unpredictability into predictability.

\footnotetext{
1Sharpe, to his credit, turned his attention to life-cycle finance, both as an academic and as an entrepreneur, later in life. See the discussion on pages 96-99 of Peter L. Bernstein's Capital Ideas Evolving (Hoboken, NJ: John Wiley \& Sons, 2007). Franco Modigliani and Milton Friedman also studied the life cycle, from the consumption and/or saving and investment viewpoints, and these accomplishments were noted by the Nobel Prize committee (Modigliani won the Nobel Prize in economics in 1985, and Friedman won it in 1976). The classic literature on insurance and risk pooling is generally considered to begin with Menahem E. Yaari, "Uncertain Lifetime, Life Insurance, and the Theory of the Consumer," Review of Economic Studies, vol. 32, no. 2 (April 1965):137-150. Emily N. Zeitz, in "An Examination of the Demand for Life Insurance," Risk Management E Insurance Review, vol. 6, no. 2 (September 2003):159-191, provides an excellent bibliography of this literature.
} 
Perhaps most importantly, actuaries create the knowledge gained by combining the law of large numbers with the pooling of risk. Through these powerful tools, they are able to estimate with substantial accuracy the probability that someone will die in a particular period of time; and death is the event that causes a life insurance policy to pay off or that causes pension or annuity payments to stop. Armed with this foreknowledge, financial institutions can issue safe instruments that have payoffs linked to the longevity of the buyer. Guaranteed pensions, life annuities, and life insurance are thus added to the tool kit of finance, and these are the tools that make life-cycle finance-the spreading of income over time-possible.

Our understanding of life-cycle finance has been enriched by the usual suspects: professors of finance, insurance professionals, and risk managers as well as investment managers and other financial institution executives. But there are many other characters in this complex story. Lawmakers, lawyers, regulators, and accountants have played major roles. So have pension plan executives - a broad category that includes corporate managers, government officials, labor union representatives, and so forth. Trade associations, and their leaders and resident scholars, have likewise made important contributions.

In this spirit, the Research Foundation of CFA Institute teamed with Boston University and the Federal Reserve Bank of Boston to present a conference exploring the frontiers of life-cycle finance from the perspective of the many disciplines mentioned above. The event was called "The Future of Life-Cycle Saving and Investing" and was held at Boston University on 25-27 October 2006. This volume presents the proceedings of this extraordinary gathering of minds. It is unique among the books presented by the Research Foundation of CFA Institute in that it includes contributions from people in just about all the fields mentioned above. It is a testament to the creativity of the conference organizers that the contributors have such a wide variety of backgrounds. Insights from such leading thinkers as Paul Samuelson, Robert Merton, and Zvi Bodie are captured in this single volume, which we hope our readers will treasure for a long time.

This book is yet another in a series of efforts by the Research Foundation of CFA Institute to educate investors and advisers on the challenges of planning and saving for life. We believe it serves as a useful complement to our recent publication Lifetime Financial Advice: Human Capital, Asset Allocation, and Insurance, by Roger G. Ibbotson, Moshe A. Milevsky, Peng Chen, CFA, and Kevin X. Zhu, and continues to build on our other recent book and literature review efforts in private wealth management. We encourage you to visit the Research Foundation area at www.cfapubs.org for more information.

The remarkable cohesion of this collection of readings-which includes speeches, written papers, and discussions-is attributable in large part to the organizational effort of Professor Bodie, of the Boston University School of 
Management, who designed the conference. We owe him a large debt of gratitude. Financial support for the conference was provided by the Boston University School of Management and the Federal Reserve Bank of Boston as well as by the Research Foundation of CFA Institute.

This is the first conference proceedings that we have considered important and cohesive enough for the Research Foundation to publish. We are truly delighted to present it.

Laurence B. Siegel Research Director The Research Foundation of CFA Institute 



\section{Overview}

\section{Zvi Bodie}

\section{Norman and Adele Barron Professor of Management Boston University Boston}

On 25-27 October 2006, Boston University School of Management hosted a unique conference on the future of life-cycle saving and investing. Its aim was to create a cross-functional dialogue among the key players in the industry about how best to meet the goal of serving the public with valuable investment and planning options in a manner that leverages the power of the marketplace. Co-sponsored by the Federal Reserve Bank of Boston's Research Center for Behavioral Economics and Decision-Making and the Research Foundation of CFA Institute, the conference was based on the premise that economic science provides a useful analytical framework for designing and producing the next generation of saving and investment solutions for households. The emphasis in this inaugural conference was on retirement, which is now a pressing policy concern in the United States. Future conferences will deal with other aspects of personal finance.

The conference brought together academic economists, financial planning practitioners, suppliers of financial products, actuaries, and government officials to address the following questions:

- What are the most important insights of economic theory for making life-cycle financial choices?

- What does every consumer need to know in order to make rational choices about saving and investing for retirement and other life-cycle goals?

- How can employers help employees make more rational choices by setting better default options in benefit plans?

- Can computer-based personal financial planning models that conform to the principles of economics help consumers make better decisions, be widely adopted, and be commercially viable?

- What new life-cycle products and services are private-sector providers of consumer financial services bringing to market?

- What is the appropriate role for the government in life-cycle saving and investment?

The papers addressing these questions were written, presented, reviewed, and discussed by prominent academic economists and leading experts on employee benefits, personal financial planning, investment management, and government programs for providing and regulating life-cycle saving products. In total there were 150 conference participants, representing business, government, and academia. In addition to the sponsors of the event, the other professional organizations represented 
were the Retirement Income Industry Association (RIIA), the Society of Actuaries (SOA), the Employee Benefits Research Institute (EBRI), and the National Association of Personal Financial Advisors. Although the discussions focused on policies and practices in the United States, there were also some participants from the Netherlands, who talked about the Dutch experience.

In his opening speech, Paul A. Samuelson, the 1970 Nobel laureate in economic science, set out the theme of the conference- the relationship between economic science and the conventional advice provided to households about investing over the life cycle. In his own scholarly research, in his world-famous textbook Econom$i c s,{ }^{1}$ and in his columns in the popular press, Samuelson has consistently devoted much of his effort to understanding and communicating the practical implications of economics for household decision making. Samuelson reminded his audience that the first edition of his introductory textbook, published in 1948, contained sections on personal finance, including how much a person should save for retirement and how to invest these savings. ${ }^{2}$

Samuelson went on to say that, in 1969 , he published a scholarly article that examined a generally accepted principle of life-cycle investing: that the young should invest more heavily in equities than the old. ${ }^{3}$ In the article, using a mathematical model he developed that had a single risky asset and a risk-free asset, he proved that the usual reasons given to justify this principle were logically flawed. Assuming a particular type of welfare or utility function (called "constant relative risk aversion"), he proved that the rational welfare-maximizing individual would invest exactly the same fraction of his or her total wealth-human capital plus financial wealth - in the risky asset at every age. The model developed in that article has become the standard base-case model in the scientific literature on rational lifetime financial planning. ${ }^{4}$

However, Samuelson did not conclude that the conventional wisdom about life-cycle investing was necessarily wrong. He believes that other factors not considered in his model could reconcile the generally accepted age-based investing

1 Paul A. Samuelson, Economics: An Introductory Analysis (New York: McGraw-Hill Book Company, 1948).

2For example, Chapter 5 contains a section titled Is College Worthwhile? and Chapter 10 is entitled "Personal Finance and Social Security." The subheadings for Chapter 10 in the table of contents include Budgetary Expenditure Patterns, Income Patterns of Saving and Consumption, How People Borrow Money, Government Bonds as a Form of Saving, Investing in Securities, Economics of Home Ownership, Buying Life Insurance, and Social Security and Health.

3 Paul A. Samuelson, "Lifetime Portfolio Selection by Dynamic Stochastic Programming," Review of Economics and Statistics, vol. 51, no. 3 (August 1969):239-246.

${ }_{4}^{4}$ Robert C. Merton developed the continuous-time version of the model in parallel with Samuelson's discrete-time model. Both were published side by side in the same issue of the Review of Economics and Statistics. Robert C. Merton, "Lifetime Portfolio Selection under Uncertainty: The ContinuousTime Case," Review of Economics and Statistics, vol. 51, no. 3 (August 1969):247-257. 
rule with economic theory. Since 1969, Samuelson and other scholars have explored how modifying the assumptions of the original model affects the conclusions. Samuelson himself has modified the assumption that equity returns follow a random walk and has explored the effect of mean reversion on the optimal age profile of equity investment. But this line of research has yielded ambiguous results. Samuelson's most recent conclusion is that the reconciliation of theory with practical advice is not to be found in the long-run behavior of equity returns but, rather, in an individual's lifetime pattern of work/leisure opportunities and choices. 5

In the first session after Samuelson's speech, the conference addressed the question: What are the most important insights of economic science for making household financial decisions? In their paper, Zvi Bodie, Jonathan Treussard, and Paul Willen maintain that the core principle of the economic theory of consumer choice over the life cycle is to reallocate consumption of goods and leisure from those life stages and contingent states in which they are relatively "high" to stages and states where they are relatively "low." This principle, known as "consumption smoothing," underlies rational decision making with respect to career choice, retirement, insurance, saving, and investing. But implementing the principle is extremely complicated in practice. Among the many complicating factors are the absence of markets for some important types of insurance and the reality that individuals rarely have the knowledge or self-discipline to act rationally in their own best long-term interest.

Discussants Deborah Lucas and Philip Dybvig focused on many of the realworld complications that exist in dealing with these issues. Lucas pointed out that there are many life uncertainties that affect the ability of people to plan well. Lucas also acknowledged that although the markets for many derivative products have grown, seemingly useful financial products, such as inflation and catastrophe futures, have failed. Dybvig suggested that life-cycle models need to place more emphasis on the risks of mortality (fear of outliving savings) and unemployment (reduced wages) and noted that for consumers, marketing and pricing of products matter a great deal. In line with themes raised by the discussants, the question and answer session continued to highlight various practical issues that exist for consumers (e.g., life-cycle funds do not provide guarantees that they will deliver on their implied promises, and current regulatory rules for financial services products and pensions need further reform).

The second session addressed the question: How can employers and government regulators help employees make more rational decisions about life-cycle saving and investing? The paper by John Beshears, James Choi, David Laibson, and

5This line of research began with Zvi Bodie, Robert C. Merton, and William F. Samuelson, "Labor Supply Flexibility and Portfolio Choice in a Life Cycle Model," Journal of Economic Dynamics and Control, vol. 16, no. 3-4 (July-October 1992):427-449. William Samuelson, who is one of the coauthors of this article, is Paul Samuelson's son. 
Brigitte Madrian summarized the results of empirical studies on the effect of default options on consumer choices in the United States. ${ }^{6}$ In particular, default settings for $401(\mathrm{k})$ contribution rates have a huge influence on plan participants' choices. This paper is one of a number of sources that documents a lack of informed decision making and disciplined action in retirement planning. The discussion that followed focused on how employers and the U.S. Department of Labor could set better "safe harbor" default options in employee retirement saving plans. The paper's findings are unsettling, in particular the finding that people tend to discount even the near future at a remarkably high rate. Other conference participants emphasized that personal financial decisions tend to be ill informed. A related theme, one that Bodie emphasized, was that individuals are not getting good advice from financial institutions and that the bad advice is being echoed by the financial regulators. Bodie took particular issue with the view that "stocks are safe in the long run" because it runs counter to the basic principles of finance.

The discussion of default settings focused primarily on appropriate settings for withdrawals from retirement saving plans and for rates of annuitization. Jeffrey Brown and Anna Rappaport both argued that default options for payouts should encourage a focus on annuitization, the phasing of annuitization, and the selection of the optimal age at which to annuitize in order to reduce the risks of overannuitization and "buyer's remorse" and to mitigate interest rate risk. Rappaport suggested a default option that would provide for annuitization of 50 percent of plan proceeds and would defer the start date of phased annuitization to age 70 . This topic seems particularly timely given the decline in annuitization that is resulting automatically from the shift away from defined-benefit plans.

The third session addressed the question: Can computer-based personal financial planning models that conform to the principles of economics be both helpful and commercially viable? The paper by Laurence Kotlikoff describes a commercial product called ESPlanner that was launched several years ago with the goal of being useful and viable. Kotlikoff s major theme was that the conventional rules of thumb used in retirement planning-notably, replacement rates for pre-retirement income-are without a sound conceptual foundation and can result in large losses in welfare. John Turner, in his comments on the paper, defended the notion of using replacement rates in planning for retirement but agreed that a unique replacement rate was not a helpful tool for retirement planning. The planning model on which Kotlikoff based his analysis incorporates a life-cycle consumption-smoothing approach to retirement planning and produces very different recommendations about saving, insurance, and portfolio allocations from conventional financial planning. George Chacko criticized Kotlikoffs model for not adequately considering the impact of investment strategy and investment return.

6In S.J. Kay and T. Sinha, eds. Lessons from Pension Reform in the Americas (New York: Oxford University Press: forthcoming). 
The fourth session addressed the question: What new life-cycle products are financial services firms bringing to market, or likely to bring to market, in the future? The panel that presented answers to this question comprised François Gadenne, CFA, Anna Rappaport, Jerome Golden, and Mark Warshawsky. They spoke about how the retirement income market is segmented and about the challenges faced by middle- and lower-income Americans in maintaining an adequate standard of living in old age. Gadenne noted that the Baby Boomers' move into retirement years will put trillions of dollars of assets into motion and that current financial services income-generating products (as well as insurance industry capacity) may not be able to meet this demand. He also noted the importance of downside asset protection in early retirement years. Rappaport discussed many of the practical barriers to income solutions in retirement, including very complex regulations that discourage employers from including income options in defined-contribution plans. The discussion on practical barriers complemented the discussion about potential future roles of government in Session 5. Warshawsky offered a proposal about how to meet these challenges with a product that combines income annuities with long-term care insurance. Golden illustrated a new product solution that considers both investments and an income annuity. How individuals, government, and the financial services industry are going to cope with longevity risk were themes raised in the audience discussion.

In his speech at the conclusion of the first day of the conference, Robert C. Merton, Nobel laureate in economic science (1997), analyzed and forecasted the likely directions for the next stage of financial innovation in life-cycle products for consumers. He cited the accelerating pace of technological progress in finance during the decades since he and Paul Samuelson published their 1969 companion articles on optimal life-cycle consumption and portfolio choice, and he expressed his strong conviction that the innovations that have revolutionized the practice of finance in banking and international trade can be adapted to satisfy consumer financial needs over the life cycle. He gave several examples of how new consumer financial products can be designed and produced to overcome some of the obstacles that lead to blatantly irrational or suboptimal behavior.

The fifth session, which opened the second day of the conference, addressed the question: What is the appropriate role for government in life-cycle saving and investment? Alicia Munnell presented an overview of the central role played by Social Security and Medicare in the U.S. system of life-cycle consumption and risk sharing. In her view, 401(k) plans are not generating the saving they should because of a lack of incentives to participate, save enough, and diversify wisely. She and her discussants, Lans Bovenberg and John Shoven, laid out a set of principles and practical examples of the role that government and nongovernmental institutions should play in the future evolution of that program. In particular, Bovenberg argued that relying entirely on employers to provide retirement income is unnecessary and inefficient. 
Shoven emphasized the need for a policy based on planning many years ahead so as to make hard choices politically palatable. He noted that the 1983 National Commission on Social Security Reform (the Greenspan Commission) succeeded in raising the normal retirement age by delaying its implementation date until the year 2000. As an example of such a hard choice, he suggested indexing benefits to life expectancy to help deal with higher costs resulting from longer life spans.

In the final session of the conference, a panel of four speakers-David Blitzstein, Jeffrey Diermeier, CFA, Dallas Salisbury, and Zvi Bodie-all expressed their views on what ordinary U.S. citizens need to know to make rational choices about saving and investing for retirement and other life-cycle goals. They also discussed what their organizations are doing currently and might do in the future to help make this happen.

The panelists agreed that Americans are not well informed about the changes that have been occurring in the way pensions are provided, and partly as a result, they are not saving enough on their own to maintain a decent standard of living in old age. American workers are especially uninformed about how to invest their retirement savings, and the guidance generally provided by investment firms and professional advisers has not been completely trustworthy. As an example, consumers are being told that the way to protect themselves against inflation in retirement is to invest in stocks. In fact, U.S. Treasury inflation-protected bonds are a far better hedge against the risk of inflation. Indeed, the reason given by the U.S. Treasury, in 1997, for starting to issue these bonds was to provide consumers with a safe way to invest for retirement. Although many investment companies offer these bonds-called TIPS - as a choice in their 401(k) plans, the bonds are offered in the form of a mutual fund, which greatly diminishes their effectiveness as a safe investment alternative.

At the conclusion of the conference, several participants expressed optimism that increased awareness of the need for product innovation and advances in financial technology that make such innovation possible would enable consumers to cope successfully with the risks they will face to their standard of living in the future. The conference organizers promised that there would be more conferences like this one to identify problems, analyze possible solutions, and encourage innovation to implement those solutions.

\section{Postscript}

In the weeks following the conference, several excellent summaries of the conference were written. We are pleased to be able to republish two of them in this book with permission, and a third can be found online at www.fpanet.org/journal/articles/ 2007_Issues/jfp0507-art-six.cfm. 


\section{KEYNOTE ADDRESSES}

\section{Is Personal Finance a Science?}

\section{Paul A. Samuelson}

Institute Professor and Professor of Economics, Emeritus

Massachusetts Institute of Technology

Cambridge, Massachusetts

My assigned presentation title is ill expressed. Its wording might seem to be asking, "Is personal finance an exact science?" And, of course, the answer to that is a flat no. If this disappoints anyone in the audience, now is a good moment to rectify your miscalculation by leaving.

What I do hope to address is what kind of inexact science personal finance is. Actually, the earliest political economy-in Aristotle or even the Holy Scripturesbegan as the management of the household. You cannot be more low-down personal than that.

My Harvard mentor Joseph Schumpeter, in a crescendo of brainstorming, went so far as to claim that solving the numerical problems of economics-one pig for three hens rather than two or four-was the effective Darwinian evolutionary selection force that made humans become human. Descartes opined, "I think; therefore, I am." Schumpeter out-opined Descartes by asserting, "Because we humanoid primates had to struggle with personal finance, we became human."

In our introductory economics textbooks, Robinson Crusoe always played a starring role - and rightly so. Some 10,000 years ago, agriculture broadly defined was the only existent industry. Each farm and hunting family had little reason to trade with their 20-50 known neighbors-neighbors who were virtual clones of themselves.

I do not jest. As recently as around 1970, one of my innumerable sons spent his summer away from Milton Academy with his "new" temporary mother on a farm in lower Austria. That is a region where no marriage took place before the female candidate proved her fertility by becoming pregnant. Virtually all that the family consumed was grown on their peasant farm. Slaughtering the hog was the big event of the summer-pure personal finance once again.

But alas, devil nicotine ended that bucolic scenario of self-sufficiency. My son's "new" brother became hooked on cigarette smoking. This requires cash. And to get cash, you must shift to some cash crop for the first time. That is how and why personal finance became perforce market oriented as it is today almost everywhere. 
I spoke of elementary textbooks. My McGraw-Hill bestseller, Economics: An Introductory Analysis, came out back in $1948 .{ }^{1}$ For the 50 -year celebration of it, I had to reread this brainchild. What I discovered was that, apparently, mine was the first primer ever to devote a full chapter to personal finance-including Series E savings bonds, diversified mutual funds, and how much more income sons-in-law earned who were doctors and lawyers as compared with clergymen, dishwashers, cabdrivers, or stenographers. Fifty years later, I was pleasantly surprised to reread much in the new facsimile edition of that 1948 original, like the following words:

Of course America's post-1935 social security system, which was formulated in depression times to intentionally discourage saving and to coax into retirement job-hoggers, will have to be abandoned in the future as a pay-as-you-go nonactuarial financial system. Such systems begin with seductively favorable pension rates that are transitional only, and must mandate stiffer contributions in future stationary or declining demographic states.

This was apparently one of my first initiations into overlapping-generation economics. You might say that in my small way, I was then being John the Baptist to latter-day Larry Kotlikoff, who is known deservedly around Central Square as "Mr. Generational Accounting."

Life-cycle finance à la Franco Modigliani recognizes that as mammals, we all do begin with a free lunch. As mortals, we are all going to die. But prior to that event, with few exceptions, we will need to be supported in retirement years by personal finance. And as we used to think before Reagan and the two Bushes, oldage pensions might come partly out of Social Security public finance.

My brief words here will focus on personal life-cycle finance. That is a domain full of, shucks, ordinary common sense. Alas, common sense is not the same thing as good sense. Good sense in these esoteric puzzles is hard to come by.

Here is a recent example. Life-cycle retirement mutual funds are a current rage. Fund A is for the youngster in this audience who will be retiring in 2042; Fund B is for 2015 retirees. Funds A and B both might begin with, say, 65 percent in risky stocks and 35 percent in allegedly safer bonds. But even without anyone having to make a phone call, Fund B will move earlier than Fund A to pare down on risky stocks and goose up exposure to safe bonds.

The logic for this is simple-as simple as that $2+2=4$ and that the next 9 years is a shorter horizon period than the next 36 years. The law of averages, proven over and over in Las Vegas or even at the ballpark, allegedly tells us that riskiness for a pooled sample of, say, 36 items is only half what it is for a pooled sample of only 9 horizon items - the well-known $\sqrt{n}$ verity, or maybe fallacy.

1 Paul A. Samuelson, Economics: An Introductory Analysis (New York: McGraw-Hill Book Company, 1948). 
Milton Friedman is assuredly no dummy. Just ask him. Maybe he would recall from his course in statistics that the ratio of $\sqrt{9}$ (i.e., 3) to $\sqrt{36}$ (i.e., 6) measures how less risky stocks are, in the sense that the long-horizon portfolio endures only half the stock riskiness of the short-horizon portfolio. Do not copy down my fuzzy arithmetic. It is only blue smoke, sound, and fury signifying nothing.

I have triplet sons. I will call them Tom, Dick, and Harry to protect their privacy. All three are risk-averse chips off the old block: Unless the mean gains of a portfolio exceed its mean losses, they will avoid such an investment. However, Tom is less paranoid than Dick, whereas Harry is even more risk averse than Dick. Nevertheless, all three will shun life-cycle funds. For each of their 25 years until retirement, each will hold constant the fractional weight of risky equities. Tom's constant is $3 / 4$; Dick's is $1 / 2$; suspicious Harry stands at only $1 / 4$.

How do I know that? Because in my family we eat our own cooking. I have written numerous learned papers denying that the correct law of large numbers vindicates the commonsense erroneous notions about risk erosion when investment horizons grow from 1 to 10 or from 100 to 10,000 .

Mine has been the Lord's work. But it has brought me no second Nobel Prizenot even when I go on to write articles using only one-syllable words to rebut the many pure mathematicians who believe that all of us should seek only to maximize our portfolio's long-term growth rates. ${ }^{2}$ Georges Clemenceau said that wars are too important to leave to generals. I say, applied math is too important to be left to pure math types!

I do not seem to have made many converts saved from error, however. I console myself by repeating over and over Mark Twain's wisdom: "You will never correct by logic a man's error if that error did not get into his mind by logic."

With Zvi Bodie on this program, I can hurry on to new personal finance topics. Housing will be one. Why housing in a personal finance seminar? I will leave it to Yale University's Bob Shiller or Wellesley College's Karl (Chip) Case, but not before articulating my 1958 point that, money aside, people's homes are an ideal contrivance for converting working-age savings into retirement-day dissaving.

President George W. Bush has advocated—so far unsuccessfully-that those of us covered by Social Security should be allowed to transfer into our own accounts our fair share of what has been paid into the public fund on our account. That way, the long-term sure-thing surplus yield of common stocks over bonds can be a wind at our back augmenting our golden years of retirement. Besides, as Libertarians say, "It's our money, not the government's."

2Paul A. Samuelson, "Why We Should Not Make Mean Log of Wealth Big Though Years to Act Are Long," Journal of Banking Eं Finance, vol. 3, no. 4 (December 1979):305-307. 
Do not shoot the piano player-I am only quoting from White House handouts.

I am not a prophet. I cannot guarantee that, risk corrected, stocks will outperform bonds from 2006 to 2050 . However, if the U.S. electorate wants to drink from that whiskey bottle and bet on that view, private accounts are not the efficient way to implement such a plan. Ask Massachusetts Institute of Technology's Peter Diamond for sermons on this topic.

A century of economic history about private and public financial markets strongly nominates that one huge public diversified indexed Social Security fund, using both stocks and bonds and both domestic and foreign holdings, will produce for the next generations better retirement pensions along with better sleep at night. One of its unique virtues is beneficial mutual insurance-reinsurance among adjacent generations.

Of course, this sensible - "good sense" sensible — proposal is too efficient ever to be adopted. To adopt it would free some millions of financial employees to transfer into useful plumbing, beer brewing, and barbering jobs.

Never forget the old saw, "Insurance is sold, not bought." The same goes for stocks, bonds, and lottery coupons. Borrowing from Abraham Lincoln, I can say that God must love those common folk that behavior scientist economists write about because She made so many of them.

Fortunately, there have been some good social inventions. If the poet Browning were to ask me, "Did you once see Shelley plain?" I would have to answer no. But I did see up close my Harvard graduate school buddy Bill Greenough. It was his Harvard $\mathrm{PhD}$ thesis that invented for TIAA-CREF the variable lifetime annuity invested efficiently in common stocks. And early on, I did write blurbs for Jack Bogle's successful launching of Vanguard's no-load rock-bottom fee S\&P 500 Index stock mutual funds.

Along with the hero who invented the wheel and the heroes who discovered how to make cheese cheese and how to make cider hard cider, in my Valhalla of famous heroes, you will find the names of Greenough and Bogle.

My final words are cut short by this audience's well-fed drowsiness. I will leave as a question for later discussion: Will hedge funds make our golden years more golden, or will the new concoctions of option engineers, instead of reducing risks by spreading them optimally (in fact, by making possible about 100 to 1 over leveraging), result in microeconomic losses for pension funds and, maybe someday, even threaten the macro system with lethal financial implosions?

Good teachers always end their lectures with a question. 


\section{The Future of Retirement Planning}

Robert C. Merton

John and Natty McArthur University Professor

Harvard Business School

Boston

With the move to defined-contribution plans, we, the financial services industry, are asking individuals to make complex financial management decisions that they have not had to make in the past and that, for the most part, they are not adequately prepared to make. In addition, I believe we are presenting these decisions in formats that make them difficult for individuals-even those who are generally well educated-to resolve.

I will begin this presentation with a few remarks about defined-benefit retirement plans, particularly how they went wrong and what we can learn from their flaws. I will then discuss defined-contribution plans, which have become the de facto alternative to defined-benefit plans. Unfortunately, traditional defined-contribution plans have a number of features that prevent them from being the long-term answer for employer-sponsored retirement plans. Thus, I will discuss a next-generation solution deriving from defined-contribution plans. Finally, I will discuss financial management technology and the tools available today that can be used to address and help solve the shortcomings of current retirement products.

\section{Defined-Benefit Retirement Plans}

Most expert observers agree that corporate defined-benefit (DB) plans are on their way out. The trend in that direction was emphasized in particular when IBM announced in early 2006 that it intended to close its defined-benefit plan to both existing and new employees. IBM is an employee-centric, financially strong company with an overfunded DB plan, and yet the DB plan is being shut down. Some observers say that defined-benefit plans have become too expensive for the corporations to maintain; others say they are too risky. I think the simplest explanation for what happened to defined-benefit plans is that they were mispriced, not three or five years ago but from the outset.

For example, assume that the liabilities in a defined-benefit pension plan have the equivalent duration of 10 years and a risk-free rate of 5 percent. Assume, too, that the plan used a blended expected return on the asset portfolio of 9 percent, not risk adjusted (with assets including risky securities). If liabilities that should have been discounted at 5 percent with a 10-year life span are instead discounted at 9 percent, the result is two-thirds of the present value. Thus, for every $\$ 1.00$ of cost a corporation is expecting from a plan, the cost is actually $\$ 1.50$. 
If a corporation is negotiating with its employees and it offers what it mistakenly believes is $\$ 1.00$ of benefits that are really worth $\$ 1.50$, then employees are likely to choose the benefits offered over cash, even if they do not know the actual value of the benefits. As an analogy, consider a corporate automobile perk that allows employees to choose either a Toyota Camry or a Bentley. Which will they choose? Will the outcome be random? I do not think so. Even if they have no idea of the actual cost of each, most people are likely to pick the $\$ 300,000$ Bentley over a $\$ 30,000$ Camry, and just so with generous benefits versus cash compensation.

From the very beginning, providers and sponsors should have recognized that the accounting treatment of these plans was systematically underpricing the cost of benefits. Because of this underpricing, I can say with confidence that we will not go through a cycle that brings us back to defined-benefit plans, at least not to plans with such a pricing structure. Defined-benefit plans have some admirable features, and they may be used again, but we will not return to them with these benefits at this price.

Although defined-benefit plans have been underpriced from the beginning, the reason they are being shut down now rather than 10 years ago is path dependent. During the 1990s, the stock market was up 9 out of 10 years. Therefore, funding for such underpriced plans appeared not to be an issue. But the 2000-02 market crash combined with globally falling interest rates changed that unrealistic outlook, which is why the plans are being reconsidered now.

\section{Defined-Contribution Retirement Plans}

The use of defined-contribution plans has become the default strategy following the decline in defined-benefit plans. Although defined-contribution plans solve the problem for the plan sponsor by (1) making costs predictable and (2) taking risk off the balance sheet, they place a tremendous burden of complex decision making on the user.

For example, assume the objective function is that employees hope to maintain the same standard of living in their retirement that they enjoyed in the latter part of their work lives. If that is the goal, then a defined-benefit type of payout is quite attractive. In a defined-contribution scenario, however, a 45-year-old will have contributions coming in for 20 years or more and a 35-year-old for 30 years prior to retirement, and each will need to decide the size of these contributions, as well as the types of investments to make with these funds, in order ultimately to provide the required standard of living at the age of 65 .

Finding and executing a dynamic portfolio strategy to achieve such a goal is an extremely complex problem to solve, even for the best financial minds. Yet, through the use of defined-contribution plans, the financial services industry is, in effect, asking employees of all sorts-from brain surgeons, to teachers, to assembly line workers - to solve just such a problem. The situation is not unlike that of being a surgical patient who, while being wheeled into the operating room, has the surgeon 
lean down and say, "I can use anywhere from 7 to 17 sutures to close you up. Tell me whatever number you think is best, and that is what I will do." Not only is that a frightening decision for a patient to be faced with, but it is one that most patients are, at best, poorly qualified to make.

The Next Generation of Retirement Planning. Let me turn to what I think might be a good next generation for defined-contribution plans. If we accept that one of the prospects that most frightens individuals is the possibility of outliving their assets, then the objective function of establishing a standard of living in retirement that approximates the standard of living individuals enjoyed in the latter part of their careers is an appropriate one. Furthermore, if we consider the behavior of most participants in defined-contribution plans, we realize that most people do not enjoy financial planning. After all, most participants do not change their contribution allocations after first establishing them. Therefore, considering individuals' fear of outliving assets and their disinclination to do financial planning, how should the next generation of plans be designed?

First, if the objective function is an appropriate standard of living in retirement, then the plan should be a system that integrates health care, housing, and inflationprotected annuities for general consumption. Health and housing are substantial factors in the retiree's standard of living that are not well tracked by the U.S. Consumer Price Index or by any other simple inflation index and should be treated as separate components in providing for an overall standard of living. Furthermore, in order to receive a real annuity at the time of retirement, individuals must expect to pay real prices. Thus, during the accumulation period, real mark-to-market prices should be used. But where do we find such mark-to-market prices? Well, we can approximate them. Insurers, in particular, have the expertise to develop them. What I suggest is that, rather than establishing arbitrary interest rates for the long run, plan developers should use actual market prices derived from actual annuities and mortality experience and mark them to market with respect to real interest rates and not to arbitrary projections. For example, if a plan is based on a 4 percent interest rate and the actual rate turns out to be 2 percent, then the retirees will not have the amount of money they had counted on.

In addition, plans need to be portable. They need to be protected against all credit risks, or at least against the credit risk of the employer. Plans also need a certain degree of robustness, and that robustness must be appropriate to the people who use them. Consider another analogy. If I am designing a Formula 1 race car, I can assume that it will be driven by a trained and experienced Formula 1 driver, so I can build in a high degree of precision because I know the car will not be misused in any way. But if I am designing a car that the rest of us drive every day, I have to be more concerned about robustness than a sophisticated level of precision. When designing a car for the rest of us, I have to assume that the owner will sometimes forget to change the oil or will sometimes bang the tires into the curb. I have to 
assume that it will be misused to some degree, so its design must be robust enough to withstand less than optimal behavior and yet still provide the intended outcomes. In applying this analogy to financial plan design, one probably should not assume that users will revise their savings rates in the optimal or recommended fashion.

Qualities of Plan Design: Simplicity and Constancy. What I have in mind is a defined-contribution plan that satisfies the goals of employers while also providing the outcomes of defined-benefit plans, which do such a good job of meeting the needs of retirees. Users should be given choices, but the choices should be ones that are meaningful to them, not the choices that are typically given today, such as what mixture of equities and debt to include in a portfolio. I do not think such choices are helpful for most people.

To use the automobile analogy again, we should be designing plans that let people make their decisions based on a car's miles per gallon, a factor that makes sense to them, rather than an engine's compression ratio, which is a degree of information that most people cannot use effectively. We need to design products that are based on questions that most people find reasonable, such as the following: What standard of living do you desire to have? What standard of living are you willing to accept? What contribution or savings rate are you willing or able to make? Such questions embed the trade-off between consumption during work life and consumption in retirement, and they make more sense to people than questions about asset allocation-or compression ratios.

Besides creating a simple design with only a handful of choices-but choices that are relevant - we need a design that does not change, at least in the way that users interact with it. An unchanging design leads to tools that people will be more likely to learn and use. In fact, a design that is unchanging is almost as important as a design that is simple.

For example, I have been driving for almost 50 years, and during that time the steering wheel in cars has not changed, even though automobile designers could have replaced steering wheels with joysticks. They have been careful to keep the car familiar so that users like me do not have to relearn how to drive each time we buy a new car.

The design of the accelerator is also emblematic of this constancy in design. Depressing and releasing the accelerator requires the same action and provides the same tactile experience that it did 50 years ago. But the technology triggered by the accelerator is entirely different today. Fifty years ago when a driver pressed on the accelerator, that action actually forced metal rods up to the carburetor, opening up passages to allow air and gas to mix and combust and thus send more energy through the engine. Today, the tactile experience is the same for the driver, but the accelerator is not moving metal rods. The processes activated by the accelerator are now electronic. And yet, automobile manufacturers have spent large sums of money making that accelerator feel the same as it did 50 years ago. 
The lesson to be learned is that something simple and consistent is easier for people to learn and remember than something complicated and changing. The goal is to be innovative without disturbing the user's experience because planning for retirement is a complicated matter that should not be made more difficult by providing tools that are difficult to use.

Let me return to my automobile analogy. Driving a car is a complex problem. If I wrote down all the information needed to operate a car so that a driver could go from the financial district in Boston to Logan International Airport, I would have a tome full of instructions. It would have to explain the use of the wheel, the gearshift, the accelerator, the brakes, the mirrors, the turn signals, and more. Just getting the car in motion and onto a busy thoroughfare is a complicated coordination problem. Getting to the airport is another level of complexity altogether. And the journey itself is filled with uncertainties. The driver must be alert at all times because, for example, a pedestrian may try to cross the street against the light or a portion of the route may be closed for repairs, and the driver must be prepared to react to each of these uncertainties.

The trip to the airport is difficult enough as it is, but what if the driver is told at the beginning of the drive to the airport, "You must aim the car in the right direction at the start of your trip. After that, you cannot turn the wheel." Knowing the complexities involved in the trip ahead, such constraints make it almost inconceivable that the driver will reach the destination in a satisfactory manner. And yet, most of the models that are used to develop defined-contribution plans implicitly assume that numerous decisions are fixed. That is not an optimal design at all.

We must, therefore, design a system that is user friendly, one that people, given time, can become familiar with and thus willing to use-a system in which the designers do the heavy lifting so that users need only make lifestyle decisions that they understand and that the system then translates into the investment actions needed to achieve the users' goals. The optimal strategies of the system should guide users to arrive at their target retirement goals smoothly. The system will maximize the prospects of achieving a desired standard of living subject to a risk constraint of a minimum life income amount in retirement, but optimization is not simply about ensuring a desired level of retirement income but also about the efficiency or effectiveness in achieving that goal. Just as it is possible to save too little for retirement, it is also possible to save too much and face the regret of forgone consumption opportunities during the many years before retirement. Despite these complexities, I am optimistic that such systems are doable, not with futuristic tools but with technology and tools that are available today.

How do I think this next generation of defined-contribution plans will be developed? For one thing, I foresee them developing as corporate plans through plan sponsors because, although the defined-benefit plans are a legacy, I believe 
employers will continue to provide retirement assistance in some manner, whether that assistance comes in the form of a 403(b) or a 401(k). One important role employers can play is that of gatekeepers.

Despite the doubts that are sometimes expressed by employees about their employers, when it comes to retirement planning and life-cycle products, people tend to trust their employers far more than they do third-party financial service providers. And employers, despite the criticism sometimes aimed at them, generally want the best for their employees. So, employers can perform a crucial function as reliable gatekeepers when it comes to providing retirement products for their employees.

\section{Technology and Tools for Creating Products}

The paradox of the type of system I have just described is that the simpler and easier it is for retirees to use, the more complex it is for its producer. The dynamic trading and risk assessment needed for the next-generation plan require sophisticated models, tools, and trading capability, none of which needs to be explained to the individual.

Interestingly, the mean-variance portfolio model is still the core of most professional investment management models, even for sophisticated institutions. Certainly, it has been updated since its first use in the 1950s, but it is a tribute to Harry Markowitz and William Sharpe that it is still at the core of thinking about risk and return in practice. But to design the next generation of retirement products, designers must consider explicitly some of the other dimensions of risk.

Human Capital. The first dimension is human capital, and the response to include it may seem obvious. But it becomes less obvious how it should be done the more closely it is observed. For example, assume that a university professor and a stockbroker have the same present value of their human capital and the same financial capital. Their risk tolerance is also the same. When deciding which of the two should hold more stocks in their portfolio, most people intuitively respond that the stockbroker should. After all, stockbrokers typically know a lot more about stocks than professors do. But if we consider their situations more closely, we realize that the stockbroker's human capital is far more sensitive to the stock market than the professor's. Therefore, to achieve the same total wealth risk position, the stockbroker should actually put less of his or her financial wealth into stocks. Most models today take into account the value of human capital, but few consider the risk of human capital or how human capital is related to other assets, and that situation needs to change.

Wealth vs. Sustainable Income Flows. The second dimension that needs to be considered is the use of wealth as a measure of economic welfare. To illustrate, consider two alternative environments faced by the individual: One has assets worth $\$ 10$ million; the other has assets worth $\$ 5$ million. The environment with $\$ 10$ million can earn an annual riskless real rate of 1 percent; the one with $\$ 5$ 
million can earn an annual riskless real rate of 10 percent. Which environment is preferable? Of course, if all wealth is to be consumed immediately, the $\$ 10$ million alternative is obviously better. At the other extreme, suppose the plan is to consume the same amount in perpetuity. A few simple calculations reveal that the $\$ 5$ million portfolio will produce a perpetual annual real income of $\$ 500,000$ and that the $\$ 10$ million portfolio will produce only $\$ 100,000$. So, with that time horizon for consumption, the $\$ 5$ million environment is equally obviously preferable. The "crossover" time horizon for preference between the two is at about 10 years. Thus, we see that wealth alone is not sufficient to measure economic welfare.

How many advice engines, even sophisticated ones, take this changing investment-opportunity environment dimension into account? Many such engines quote an annuity (i.e., an income amount) as an end goal, but in doing so, they take an estimated wealth amount and simply apply the annuity formula with a fixed interest rate to it, as if there were no uncertainty about future interest rates. In other words, they do not distinguish between standard of living and wealth as the objective. Sustainable income flow, not the stock of wealth, is the objective that counts for retirement planning.

Imagine a 45-year-old who is thinking in terms of a deferred lifetime annuity that starts at age 65 . The safe, risk-free asset in terms of the objective function is an inflation-protected lifetime annuity that starts payouts in 20 years. If interest rates move a little bit, what happens to the value of that deferred real annuity? It changes a lot. If I report the risk-free asset the way typical 401(k) accounts are reportednamely, as current wealth - the variation reported in wealth every month will be tremendous. But if I report it in annuity (or lifetime income) units, it is stable as a rock.

Peru has developed a Chilean-type pension system. A large percentage of the assets - between 40 and 60 percent - are held in one-year (or less) Peruvian debt, with limited international investment. Such a structure does not make much sense for a pension plan. For one, the duration of the bonds should be considerably longer. But every month, the balance is reported on a mark-to-market basis to all plan participants. Imagine the communication challenge of investing in a bond with a 40-year duration, instead, and reporting the resulting enormously volatile monthly balance and explaining why it is actually risk free.

How plans are framed and how their values are reported (wealth versus annuity income units) is thus not trivial. The proper unit of account selected is essential for conveying what is risky and what is not.

Prepackaged Liquidity. Derivative securities can be designed to replicate the payoffs from dynamic trading strategies in a retirement plan. This is done by, in effect, running the Black-Scholes derivation of option pricing "backwards." Thus, instead of finding a dynamic trading strategy to replicate the payout of a derivative, the financial services firm creates a derivative that replicates the dynamic strategy 
desired and then issues that derivative as a prepaid liquidity and execution contract for implementing the strategy. As an example, the dynamic trading strategy for which such prepackaged trading liquidity can be created might be a systematic plan for changing the balance between equity and debt holdings in a prescribed way over time.

Housing Risk. Housing and housing risk are another important dimension, and reverse mortgages are entirely pertinent to this topic. If one is trying to lock in a standard of living for life, owning the house he or she lives in is the perfect hedge. In implementing this aspect of the retirement solution, a reverse mortgage provides an importantly useful tool. A reverse mortgage works within the U.S. tax code to strip out that part of the value of a house not needed for retirement-housing consumption without putting the user at any leveraged risk with respect to the consumption of that house. It is a practical way to decompose a complex asset and use the value to enhance one's standard of living in retirement. It can also be a far more efficient way of creating a bequest than holding onto a house and leaving it to heirs. After all, one does not have to be an expert to know that it is probably far from optimal bequest policy, from the point of view of the heirs' utility, to receive the value of the house as a legacy at some uncertain time in the future-perhaps next year, perhaps in 30 years. I am hopeful that this market will continue to grow rapidly in size and efficiency.

Behavioral Finance and Regret Insurance. For those who believe in its findings, behavioral finance also belongs in the design of life-cycle products. As an example, consider loss aversion, or fear of regret: It appears that loss aversion dysfunctionally affects investors' choices. It inhibits them from doing what is in their best interests. How might we mitigate this problem? Is it possible to create a new financial product, called "regret insurance?" If such a thing is possible, what would it look like?

Consider the following scenario. Assume that a person is broadly invested in the stock market but, for some rational reason, decides to sell. The investor, however, fears that immediately after she sells, the market values will rise. She is frozen by her fear of regret, the regret of selling too low and missing an opportunity to enhance her assets. Fortunately, she can mitigate this situation by purchasing regret insurance. In this case, she buys a policy that guarantees the sale of her stock portfolio at its highest price during the following two years. After two years pass, the investor and the insurer will examine the daily closing price for the portfolio, and the insurer will buy the portfolio for its highest daily closing price during the two years. For the cost of a set premium, the investor is guaranteed an absolute high and is thereby freed of uncertainty and the likelihood of regret. 
Such insurance can work for buyers as well as sellers. Suppose an investor wants to buy into the stock market, but he fears that prices will fall after the purchase and he will miss out on better prices. To mitigate his regret, he purchases an insurance policy that allows him to buy the market at the lowest price recorded during the previous two years.

Some people might say that this idea of regret insurance sounds too complicated to produce. How, they might ask, would an insurer determine the risk and then establish a reasonable price? I would submit that such products are already being used in the form of lookback options, which provide exactly the kind of insurance just described. In the exotic options industry, which is quite large, lookback options are frequently issued, which illustrates my general point that the technology and the mathematical tools are already in place to develop the next generation of retirement products. The learning-curve experiences of nearly three decades of trading, creating, pricing, and hedging these types of securities are in place for someone entering the retirement solutions business. It is simply a matter of using market-proven technology in a way that it is not now being used.

\section{Concluding Illustration}

One can see from the previous hypothetical example how the identified dysfunctional financial behavior induced by behavioral regret might be offset by the introduction of a well-designed financial product (regret insurance). And if successful, the impact of that cognitive dysfunction on an individual's financial behavior and on equilibrium asset prices can be offset. Note that this change occurs not because of "corrective" education or other means of modifying the individual's internal behavioral makeup but, instead, because an external means is introduced that causes the "net" behavior of the individual to be "as if" such a correction had taken place.

I want to close with a personal, real-world example that illustrates the same dynamics of interplay between the cognitive dissonance of the individual and the corrective effect of the creation and implementation of a financial product or service designed to offset the distortions in financial behavior that would otherwise be obtained, in this case with respect to efficient refinancing of housing mortgages, instead of regret.

In 1999, I took out a mortgage on my apartment, although I do not remember what the interest rate was. Three years later, the same broker who handled my mortgage called me and offered to reduce my mortgage payments by $\$ 400$ a month. The offer sounded too good to be true, so I asked what the closing costs would be. He replied that the lender would cover all the closing costs. I then surmised that there must be an embedded option to refinance in my mortgage and that now the lender was trying to get that option out of the mortgage by its generous refinance offer. But the broker assured me that the new mortgage would give me the identical right to 
refinance whenever I wanted. Furthermore, the lender was not extending the payment period, and all the other terms of the old mortgage would remain intact, except that I would now be paying $\$ 400$ less per month. Even though the deal sounded too good to be true, he convinced me that it was on the level, so I agreed to the refinancing. He came to my office, we signed and he notarized the contract (without my attorney being involved), and the deal has been just as beneficial as he had said.

My guess is that the broker had been given incentives to monitor mortgages like mine for possible refinancing because if he did not get to me, a competitor would. Better to cannibalize your own business by pursuing refinancing than to have the business taken away altogether. Furthermore, my mortgage was probably sold into the capital markets, so his employer, as the originator, would not lose. Certainly, this supposition does not go counter to the way the world works, and thus I ended up being a beneficiary of the competition of the system.

The point of my story is that I turned out to be an excellent illustration of behavioral finance in action. After all, how can someone who does not know the interest rate on his mortgage determine whether he should optimally refinance it? But because of the way the market has developed, the same company that gave me the mortgage gave me a better deal at no cost. I thus ended up behaving like Rational Man in refinancing my mortgage but not because I became "educated" about optimal refinancing models (which I already knew), learned what my interest rate was (which I still do not know), and then optimally exercised. Instead, innovation of financial services together with technology for low transaction costs and market competition allowed me to act "as if" I had. In the process, capital market prices for mortgages were being driven closer to those predicted by the efficient market hypothesis of neoclassical finance. The next generation of retirement products will surely be designed to accommodate and offset such typically suboptimal human behavior.

\section{BIBLIOGRAPHY}

Merton, Robert C. 2003. "Thoughts on the Future: Theory and Practice in Investment Management." Financial Analysts Journal, vol. 59, no. 1 (January/February):17-23.

-2006. “Allocating Shareholder Capital to Pension Plans.” Journal of Applied Corporate Finance, vol. 18 , no. 1 (Winter):15-24.

- 2006. "Observations on Innovation in Pension Fund Management in the Impending Future." PREA Quarterly (Winter):61-67.

Merton, Robert C., and Zvi Bodie. 2005. "The Design of Financial Systems: Towards a Synthesis of Function and Structure." Journal of Investment Management, vol. 3, no. 1 (First Quarter):1-23. 


\section{Question and Answer Session}

\section{Robert C. Merton}

Question: How do you see us moving from defined-benefit plans to something more sophisticated than today's simple defined-contribution plans?

Merton: Most companies want to provide good benefits for their employees. After all, providing efficient benefits is an effective way to pay people, besides its reflecting on a company's reputation. The compensation system of the company is a key strategic issue, and benefits are becoming an ever-larger element of compensation.

That is why such decisions are moving from the CFO to the CEO. They are strategic, and they have considerable implications for the success of the company. Furthermore, companies do not want "smoke and mirrors" for solutions. They do not want to be told that a plan solution will take care of retirement by earning equity market returns virtually risk free, at least over the long run, or by beating the market itself by 1,2 , or 5 percentage points. There are no simple-fix "free-lunch" solutions. That is how we got into trouble with the defined-benefit plans.

Employees, too, need to be told to adjust their expectations. Get used to driving a Camry, not a Bentley, or be prepared to spend $\$ 300,000$ to get the Bentley instead of $\$ 30,000$ for the Camry. Contribution rates will be whatever is required to achieve goals, and individuals will have to make choices-for example, accept lower wages and higher contribution rates or plan to pay supplemental amounts for additional retirement benefits. They should also expect to make some substitution between the level of retirement consumption and consumption in their working years.

Question: You mentioned that mean-variance is still the norm for modeling, yet the new products you describe have returns that are not normally distributed. Do you believe that many future financing concerns will be addressed by these complex, nonnormally distributed products?

Merton: Yes. But individuals do not need to be aware of this sea change. Individuals do not have to understand the nonlinearities and complexities of option investment strategies or regret insurance. All they are doing is buying a contract that allows them to achieve their targeted replacement of income.

Like the driver of an automobile, individuals do not have to know how the product works. But someone has to know because someone has to be a gatekeeper. Such products cannot be black boxes into which money is poured. But the surgeon, the teacher, and the assembly line worker will not be doing the due diligence. If the plan sponsor is not the one to look under the hood and find out how a product works and decide that it is legitimate, then some other similar mechanism must be established. 
Mean-variance portfolio theory is, as I said, at the core of what's done with asset management for personal finance, asset allocation, mutual funds, and so forth. But the technology to do risk assessment, valuation, and the dynamic strategies I have alluded to, including trying to replicate a 20 -year deferred real annuity that is not publicly traded, is market-proven technology that is used every day by Wall Street firms, fixed-income trading desks, capital markets groups, hedge funds, and so forth. Such financial technology is not something that I have plucked off a professor's idea list. It is in use, and more of it is being created all the time. What I am talking about is a new application of market-proven technologies, and that is why I am confident that the products that I have mentioned are implementable. To be truly an effective solution, the design of such systems, however, must be scalable and cost-effective.

Question: Are you proposing that this new generation of individual retirement investors do not need to understand the risks involved in their plans?

Merton: I am not opposed to people being informed about the investments in their plans, but I think they ought to be informed about things that are useful to them. Disclosing the details of financial technology to nonprofessionals is unlikely to make them any better prepared. What they need to know is that gatekeepers have been established to assure the quality of a plan's design.

Question: So, you believe a gatekeeper has to be established? In the definedbenefit scenario, corporations did not play that role.

Merton: Plan sponsors did play that role in defined-benefit plans, although not always well. They are still playing that role, and I think they view themselves as such. I do not think they are walking away and closing their defined-benefit plans and telling their employees to go open an IRA.

Corporations have a certain fiduciary duty. Any company that creates a 401(k) plan needs to assure that it is not bogus. If it is, the company is responsible. The company does not guarantee returns, but it must perform due diligence to assure that the plan is sound. One of the strengths of a defined-benefit plan is that it is managed in-house, and the company is responsible for the payouts promised. Definedcontribution plans are outsourced, so plan sponsors have to be more diligent. The one thing I know that does not work is to send surgeons, teachers, and assembly line workers back to school to teach them about duration, delta hedging, and other financial technical details so that they can have a retirement account. Someone else has to take that role. The plan sponsor is probably the natural gatekeeper.

Question: If we need some instruments that are currently not traded, is there a role for government to issue, for example, longevity bonds, so we can derive more information on that type of instrument? 
Merton: Absolutely. The creation of TIPS (Treasury Inflation-Protected Securities) and their equivalents was an enormous event, especially for those of us who lived through the big inflation problems with retirement accounts in the late 1970s and early 1980s. As far as I know, only one company-I think it was Aetna working with the Ford Motor Company pension program-wrote an index instrument back then, but it capped the protection at a specific level. Having government-sponsored TIPS and the inflation swap markets that have developed around them means that there will be a lot of ways to develop underlying instruments. Government can play a role.

Certainly, it would be delightful if we had some way of trading longevity efficiently and observing the pricing functions for it. We are not yet there. Still, given the existing environment, I think it is better to use the best estimates from the markets on the cost of longevity risk. In the case of inflation indexing, even though long-dated deferred annuities are not, as far as I know, available at any kind of reasonable prices, one can use well-known dynamic strategies to approximate the returns to such annuities. Such strategies are used all the time in capital market transactions and are done on the other side of these swap transactions to come close to replicating that.

But even if our level of precision for such replications were eight digits, if much of the actual data for other elements of the retirement solution are accurate only to one digit, we do not accomplish a lot by imposing that extra precision. If we get one piece of this problem to a rather precise point, then we know at least one of the elephants in the parlor. For example, in the early phase of retirement accumulation, people do not know what their income will be during the next 30 or so years before they retire. They do not know whether they will be married or divorced. They do not know how many children they will have. They do not know how the tax code will change. We all deal with a host of uncertainties. The idea that we should spend enormous resources making precise one dimension out of all those uncertainties is neither efficient nor cost-effective.

People do, however, need greater precision as they approach retirement because that is when they know much more accurately what they need. They know their income, their marital status, their dependent status. That is also when lifetime annuities become available. Could annuities be more efficient in design and price? No question about it. But they are available, and both design and cost will improve considerably.

Consider another analogy. If you intend to sail from Southampton, United Kingdom, to New York City, you want to aim the boat so that you are not going to Miami, but you do not need a lot of precision at the outset because you can tack as needed to keep a reasonable course. But as you approach New York Harbor, you do not want to be off even by 50 yards. The same concept applies with life-cycle products. A lot of things happen to people during the 30 years leading up to 
retirement-many more than they, or we, can predict in advance. What individuals need is a mechanism that allows their retirement planning to adjust to all of these uncertainties as they impinge on them. With the right mechanism, they can adjust their retirement planning and make it more precise as they approach their destination so that, at the end, they can have a lifetime, guaranteed annuity in the amount needed to sustain their lifestyle in retirement.

Now, the guarantee may be, in effect, that of a AA insurance company rather than that of a AAA company. But the guarantee of a AA insurance company is almost always good enough. I am proposing a model that is different from one in which an individual approaches retirement and purchases a variable annuity about which the insurer says, "If the stock market earns 4 percent a year over the Treasury bond yield for the next 15 years, you will be in fat city." Market risks are a far bigger factor than AA credit risk.

If a stronger guarantee is worth it, institutions may effectively collateralize it. I see such immunization occurring in the United Kingdom, and it may be headed to the United States. Perhaps we will have longevity bonds that are used to immunize against systematic longevity risks. If there is enough worry about the credit of an insurance company, then the annuity need not be run from the general account. The insurer can create SPVs (special-purpose vehicles) in which it can fund the annuities with the right-duration real bonds or with longevity bonds, if those appear.

Although retirement planning today presents a big, challenging problem, it also offers big opportunities. I am excited and optimistic about the prospects ahead. A lot of financial technology exists to help us address the problem. 


\section{Session 1: Bodie Presentation}

\section{The Theory of Optimal Life-Cycle Saving and Investing}

Zvi Bodie

Norman and Adele Barron Professor of Management

Boston University

Boston

Jonathan Treussard

PhD Candidate

Boston University

Boston

\section{Paul Willen}

Senior Economist, Research Department

U.S. Federal Reserve Bank of Boston

Boston

Life-cycle saving and investing are today a matter of intense concern to millions of people around the world. The most basic questions people face are

- How much of their income should they save for the future?

- What risks should they insure against?

- How should they invest what they save?

Many of these questions are answered for people - in whole or in part-by government, trade unions, employers, and other institutions. In this paper, we argue that economic theory offers important insights and guidelines to policymakers in government, to the financial services firms that produce life-cycle financial products, to the advisers who recommend to their clients which products to buy, and to educators who are trying to help the public make informed choices.

The literature is vast and complex, and we will not attempt to survey or summarize it all in this paper. Instead, we lay out the basic analytical framework using a few relatively uncomplicated models and focus on several key concepts. This analytical framework could serve as a valuable guide to financial services firms in helping them to develop and explain products in terms that are understandable to the layman.

In the first section of this paper, we introduce the life-cycle model of consumption choice and portfolio selection. We emphasize the central role of consumption in life-cycle planning, and we highlight the use of financial assets as means to 
transfer consumption from points in the individual's life cycle when consumption has relatively little value to points when consumption has relatively more value. The second section highlights five concepts from the life-cycle model that are directly relevant to the practice of life-cycle planning: (1) the notion of a lifetime budget constraint, (2) the relevance of contingent claims in life-cycle planning, (3) the trade-off imposed by varying costs of consumption over one's lifetime, (4) the role of risky assets, and (5) the asset allocation decision over the life cycle. In the third section, we recognize the complexity of life-cycle planning and the relevance of financial frictions at the individual level, and accordingly, we argue that it is the role of specialized firms to engineer and deliver life-cycle products that meet the needs of households. The final section contains our concluding remarks.

\section{Theoretical Introduction}

The starting point for analysis of life-cycle portfolio choice is a model of the evolution of an investor, which one can think of as an event tree. ${ }^{1}$ Figure 1 illustrates an event tree for a fictional investor who lives for three periods: youth, prime earning years, and retirement. In addition to aging, events occur that affect the investor. In Period 2, he earns either high or low income, and in Period 3, he enjoys either good or bad health. Figure 1 shows income and, in retirement, expenses associated with the different outcomes. We assume that our investor earns no income in retirement and faces no health expenses before retirement. A financial plan, in this context, tells an investor how much to save or borrow, how to invest any savings-not just today (in Period 1) but in the future (in Period 2)-and how much the investor should withdraw in retirement (Period 3). That plan could also depend on contingencies: Along the high-income path, our investor may want to save more; along a bad health path, our investor may want to withdraw less to prepare for high bills.

Suppose, for simplicity, that the only investment opportunity is to save or borrow at 0 percent interest. The lines labeled "advice" in Figure 1 reflect a simple proposed financial plan: Save $\$ 10,000$ a year when young, save $\$ 20,000$ a year during prime earning years, and withdraw $\$ 50,000$ a year in retirement. It is easy to verify that this plan works. Savings at retirement equal $\$ 750,000$, which, divided up over the remaining 15 years, allows withdrawals of $\$ 50,000$ a year.

How good is this proposal? Standard approaches to financial planning would focus on whether the investor could afford to save enough or whether the $\$ 50,000$ would be enough in retirement. What does the life-cycle theory say about this proposal? We distill the following three principles from the life-cycle approach.

1In finance, the event tree has become a workhorse tool-most importantly, the Cox-RossRubinstein (1979) binomial model. 
Figure 1. The Life-Cycle Model: An Event Tree

(1)

Youth

(21-35)
(2) Prime

Earning Years

(36-65)

(H) High Income

Income: $\$ 100,000$

a year

Advice: Save $\$ 20,000$

a year

Consumption: $\$ 80,000$ a year

(L) Low Income

Income: $\$ 50,000$

a year

Advice: Save \$20,000

a year

Consumption: $\$ 30,000$ a year
(3)

Retirement

(66-80)

(HG) Good Health

Expenses: $\$ 5,000$

a year

Advice: Withdraw \$50,000

a year

Consumption: $\$ 45,000$

a year

(HB) Bad Health

Expenses: $\$ 15,000$

a year

Advice: Withdraw \$50,000

a year

Consumption: $\$ 35,000$ a year

(LG) Good Health

Expenses: $\$ 5,000$

a year

Advice: Withdraw \$50,000

a year

Consumption: $\$ 45,000$

a year

(LB) Bad Health

Expenses: $\$ 15,000$

a year

Advice: Withdraw $\$ 50,000$

a year

Consumption: $\$ 35,000$

a year

Principle 1: Focus not on the financial plan itself but on the consumption profile that it implies. In this example, we can easily calculate consumption (shown in Figure 1) because it equals income less savings during working years and withdrawals less health expenses in retirement. ${ }^{2}$

Principle 2: Financial assets are vehicles for moving consumption from one location in the life cycle to another. Suppose, for example, our investor wanted to increase consumption in youth. By reducing savings in youth and leaving it unchanged in prime earning years, our investor can transfer consumption from retirement to youth.

2This insight goes back to Fisher (1930) and Modigliani and Brumberg (1954, 1979). 
By reducing savings in youth and raising savings in middle age, our investor can transfer consumption from prime earning years to youth. ${ }^{3}$

\section{Principle 3: A dollar is more valuable to an investor in situations where consumption is low than in situations where consumption}

is high. In Figure 1, for example, the life-cycle model says that if we offered to give a dollar to our investor but said he must choose when he wanted it, our investor would want the money in youth, when his consumption is lowest. The law of diminishing returns is at work here: An additional dollar is a lot more valuable to a recent college graduate than to a 55-year-old executive.

So, what does the life-cycle model tell us about the advice in Figure 1? Looking at the implied consumption over the life cycle, we notice huge variations. According to our third principle above, a dollar is much more valuable when consumption is low than when it is high. And so we can improve on this plan by trying to move consumption from situations with high consumption to situations with low consumption.

- Consumption in youth $(\$ 20,000)$ is much lower (and thus more valuable) than it is on average in prime earning years $(\$ 55,000)$. By saving less in youth and more in prime earning years, our investor could transfer consumption from lowvalue situations to high-value situations and make himself better off.

- Consumption in situations $H G$ and $H B$ ( $\$ 40,000$ on average) is much lower (and thus more valuable) than in situation $H(\$ 80,000)$. By saving more in situation $H$, our investor could transfer consumption from low-value situations to high-value situations and make himself better off.

- Consumption in situations $L G$ and $L B$ ( $\$ 40,000$ on average) is higher (and thus less valuable) than in situation $L(\$ 30,000)$. By saving less in situation $L$, our investor could transfer consumption from low-value situations to high-value situations and make himself better off.

Now, suppose we introduce health insurance. And suppose health insurers offered a contract that says that for every dollar you invest, you receive $\$ 2$ if your health is bad in retirement. If you borrow a dollar in prime earning years and invest in this stylized form of health insurance, what happens? Your consumption in prime earning years remains the same but falls by $\$ 1$ when your health is good (because you have to repay the loan) and increases by $\$ 1$ when your health is bad (because you receive the $\$ 2$ for having bad health less the loan repayment). Thus, health insurance transfers consumption resources from situations where your health is good

${ }^{3}$ Moving consumption over the life cycle is at the heart of life-cycle planning. As Irving Fisher put it, the intent of life-cycle planning theory is to "modify [the income stream received by the individual] by exchange so as to convert it into that particular form most wanted by [this individual]" (Fisher 1930, Chapter 6). 
to situations where your health is bad. For example, in Figure 1, consumption is higher (and thus less valuable) in good health situations than in bad ones, so our investor can make himself better off by buying insurance.

\section{Five Key Concepts}

With the overview of the life-cycle model complete, we now highlight five of the most important insights produced by the theory of life-cycle planning: (1) the notion of a lifetime budget constraint, (2) the relevance of contingent claims in life-cycle planning, (3) the trade-off imposed by varying costs of consumption over one's lifetime, (4) the role of risky assets, and (5) the asset allocation decision over the life cycle.

Insight 1: The Lifetime Budget Constraint. One of the great early insights in financial planning follows directly from Principle 2 above: Under certain conditions, household consumption over the life cycle depends entirely on the present discounted value of lifetime income and not on the evolution of income itself. More specifically, suppose two investors have some financial wealth and also expect some stream of labor income over their remaining working life. ${ }^{4}$ Now, calculate the discounted present value of their future income, which we call "human wealth," and add it to their savings and call the sum "total wealth." According to the life-cycle model, under certain conditions, if two investors have the same total wealth, then their consumption decisions over the life cycle will be the same, regardless of the shape of their actual income profile.

To understand why we can ignore the profile of income across dates and random outcomes, return to Principle 2, which says that we can use financial assets to transfer consumption from one situation to another. A loan is a financial asset that allows you to increase consumption today in exchange for reducing consumption by the amount of the loan plus interest at a future date. What is the maximum amount an investor can consume today? It is her current savings plus the maximum amount she can borrow. What is the maximum amount she can borrow? It is, theoretically, the present discounted value of her future labor income. Thus, total wealth, as defined in the previous paragraph, measures the maximum amount an investor can transfer to the present. Now that our investor has transferred everything to the present, she can decide when to spend it, and using the same technology, she can transfer her wealth to the situations where she wants to consume. It is important to stress that the idea of transferring all lifetime income to the present is purely a hypothetical construct used as a way to measure lifetime resources using a single metric.

4The lifetime budget constraint is presented in Fisher (1930), Modigliani and Brumberg (1954), and Modigliani (1986). This concept of a lifetime budget constraint has been generalized and successfully applied to life-cycle planning under uncertainty, starting most notably with Cox and Huang (1989), and has been central to the development of finance theory over the past decade or so. 
The importance of the lifetime budget constraint is that it shows that financial wealth is only one part of the wealth that matters to an investor. Total wealth equals the sum of both financial wealth and human wealth. For most householdsbasically for almost all households in which the income earner is not old-human wealth dwarfs financial wealth. Table 1 shows the ratio of human wealth to income measured using real-world data for various groups in the population. To see the importance of human wealth, consider a 35-year-old male college graduate earning $\$ 100,000$ and owning $\$ 400,000$ in financial wealth. Consider also an heir who plans to remain out of the labor force his entire life and has $\$ 3$ million in financial wealth. One might think that these two investors have nothing in common, but according to one version of the life-cycle model, they should, in fact, consume exactly the same amounts. Note that according to Table 1, the college graduate's human wealth is 25.9 times his current income, or in this case, $\$ 2.59$ million, to which we add financial wealth of $\$ 400,000$ to get total wealth of $\$ 2.99$ million, almost exactly the same as the heir.

We can also incorporate future expenses into the lifetime budget constraint. For example, suppose an investor knows that she will send two kids to college at given dates in the future. If we know how much that education will cost, we can simply subtract the present value of future education costs from current total wealth, just as we added future income. 5

\section{Insight 2: The Importance of Constructing "Contingent} Claims." Previously, we argued that investors can use financial assets to transform their income and expense streams into the equivalent of financial wealth, but we were unspecific as to how. Now, we focus on how investors can actually affect these transformations. First, the easy case: If future income and expenses are certain, then investors can transform them into additions and subtractions from current wealth by simply borrowing and/or saving the appropriate amount. For example, if one knows that one will earn $\$ 100,000$ five years from now and the interest rate is 5 percent, one can raise current liquid financial wealth by borrowing $\$ 78,350$ and paying back the money plus $\$ 21,650$ in interest from future earnings.

But in practice, things are not so easy. The main problem with calculating the lifetime budget constraint is random outcomes. To see why random outcomes are a problem, return to Figure 1. Following the logic above, our investor can convert his future labor income into current financial wealth by borrowing. But how much should he borrow? Along the "high-income" path, he earns $\$ 100,000$ a year. So, if we assume an interest rate of zero, he could borrow $\$ 100,000$ today and pay it back, say, at age 45. But suppose he does not get the high-income outcome but, instead,

${ }^{5}$ See, for instance, CollegeSure savings funds. 


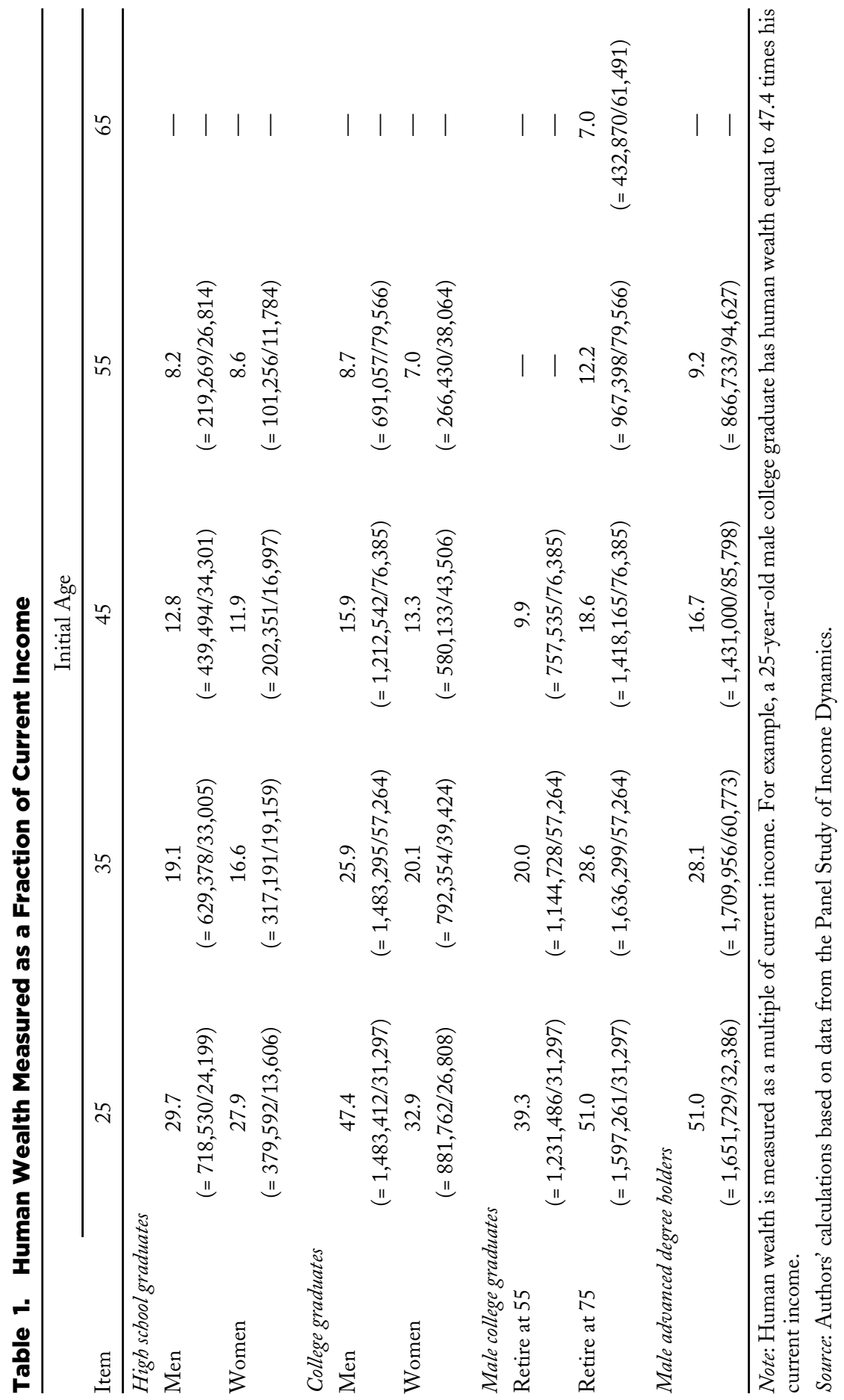


earns "low income." Then, at age 45, his income would not be sufficient to pay off the loan. Another alternative would be to borrow $\$ 75,000$, the average of his two income draws, but he would still have insufficient funds.

What if financial markets offered a security that paid off $\$ 1$ only if our investor got the low-income outcome and another security that paid off $\$ 1$ only if our investor got the high-income outcome? Then, our investor could convert his future income along the low-income path into current income by shorting $\$ 50,000$ of the low-income asset and similarly convert his income along the high-income path using the high-income asset. We call these assets that pay off contingent on some future event "contingent claims."6

If contingent claims are so useful, one might ask why we do not observe them. And the answer is that we do, although they rarely ever appear in the form we described. Let us revisit the case of health insurance. Earlier, we described a stylized contract that paid off only in bad health states. In its most familiar form, however, health insurance is a contract that pays the investor's medical bills both in good and bad health states in exchange for a payment today. Accordingly, health insuranceas we observe it - is not a contingent claim per se because it pays off in both outcomes. Nonetheless, it is easy to construct a contingent claim using this common form of health insurance and the riskless bond. For example, if you want a claim contingent on the bad health outcome, then borrow $\$ 5,000$ and buy health insurance. In the bad health event, you receive $\$ 10,000$ ( $\$ 15,000$ less the loan repayment), and in the good health event, you get nothing because the health insurance payoff and the loan repayment cancel each other out. One can similarly construct a claim contingent on the good outcome. ${ }^{7}$

Contingent claims help with another serious problem: inflation. Suppose our investor knows for sure that he will earn $\$ 100,000$ next year, but he is uncertain about inflation. Suppose that inflation could either be zero or 10 percent. Thus, our investor's real income next year actually does vary randomly: Along one path, he receives $\$ 100,000$ in real spending power, and along the other, he receives $\$ 90,000$. According to Principle 2, our investor will want to shift consumption from the lowinflation event to the high-inflation event. If we create inflation-contingent claims, our investor will be able to do just that. It is for this reason that economists have long advocated and spearheaded the creation of inflation-indexed bonds, marketed as TIPS or Treasury Inflation-Protected Securities. ${ }^{8}$

${ }^{6}$ Also called Arrow-Debreu securities after the seminal work of Arrow (1953) and Debreu (1959). See also Arrow (1971) and the recent work by Sharpe (2006).

7This type of reasoning is the essence of production technology supporting the creation of contingent claims, in theory and in practice, going back to Black and Scholes (1973), Merton (1973), and Cox, Ross, and Rubinstein (1979). This is the core of modern financial engineering as it applies to life-cycle planning.

8 See, for instance, Fischer (1975) and Bodie (2003) for the role of inflation-protected bonds in lifecycle plans. 
We have now, we hope, convinced the reader of the value of contingent claims in life-cycle financial planning. But before we go on, we should discuss the limits to the use of contingent claims. First, contingent claims work well when both parties can verify the event in question and neither party can affect or has better information about the likelihood of the event occurring. For example, it is easy to verify the price of General Motors Corporation (GM) stock. And for the most part, investors who either have better information or who can affect the price are legally forbidden from trading, so we see a large variety of claims contingent on the level of GM stock (futures, options, etc.). But earlier, we proposed that an investor would buy claims contingent on the level of his labor income. First, because income is not always easy to verify (the investor would have an incentive to hide some income and claim that he earned only $\$ 50,000$ when he actually earned $\$ 100,000$ so as to allow him to pay back only $\$ 50,000$ ) and because a worker has some control over how much he earns (again, our investor has an incentive to earn less because he would then have to repay less), income-linked contingent claims present practical problems. ${ }^{9}$ Second, the creation of contingent claims requires that we clearly understand the risks investors face, and neither record keeping nor econometric techniques have yet rendered measurement of these risks trivial.

Insight 3: The Prices of Securities Matter! In discussing contingent claims, we have shown how households can eliminate variation in consumption across different random events by transferring consumption from outcomes with high consumption to outcomes with low consumption by buying and selling consumption in those different outcomes using contingent claims. But we have said nothing about the price of contingent claims, and as everyone knows, prices usually play a central role in determining how much of something someone wants to buy or sell.

To illustrate some of the issues with the pricing of contingent claims, we consider an investor who faces two equally probable outcomes in the future: In outcome $H$, she consumes $\$ 100,000$, and in outcome $L$, she consumes $\$ 50,000$. Table 2 provides information for this example. To analyze this problem, we will need two concepts from probability theory. First, we measure the "expected" level of consumption, which we get by weighting different outcomes by their probability and summing. The expected consumption for our investor is $\$ 75,000$. But many different consumption profiles yield the same expected consumption (for example, $\$ 75,000$ with certainty), and risk-averse investors are not indifferent among them. Our investor, if risk averse, would certainly prefer $\$ 75,000$ with certainty. But we can go further and actually measure how much she prefers other consumption

\footnotetext{
9These problems are related to moral hazard and the resulting borrowing constraint literature, such as He and Pages (1993) and El Karoui and Jeanblanc-Picque (1998), who extended the study of human capital in life-cycle planning to address the important real-world problems caused by the limited ability of people to borrow against future income.
} 
Table 2. Understanding the Role of the Prices of Contingent Claims

\begin{tabular}{|c|c|c|}
\hline Item & $H$ & $L$ \\
\hline \multicolumn{3}{|l|}{ Scenario } \\
\hline Probability & $50 \%$ & $50 \%$ \\
\hline Initial consumption & $\$ 100,000$ & $\$ 50,000$ \\
\hline Expected consumption & \multicolumn{2}{|c|}{$\$ 75,000$} \\
\hline Certainty equivalent & \multicolumn{2}{|c|}{70,710} \\
\hline \multicolumn{3}{|l|}{ Baseline prices } \\
\hline Price of contingent claim & $50 \$$ & $50 \$$ \\
\hline Strategy & Sell $\$ 25,000$ & Buy $\$ 25,000$ \\
\hline Cost & $-\$ 12,500$ & $\$ 12,500$ \\
\hline New consumption & 75,000 & 75,000 \\
\hline Expected consumption & \multicolumn{2}{|c|}{$\$ 75,000$} \\
\hline Certainty equivalent & \multicolumn{2}{|c|}{75,000} \\
\hline \multicolumn{3}{|l|}{ Alternative prices } \\
\hline Price of contingent claim & $40 \phi$ & $60 \$$ \\
\hline Strategy 1 & Sell $\$ 25,000$ & Buy $\$ 25,000$ \\
\hline Cost & $-\$ 10,000$ & $\$ 15,000$ \\
\hline New consumption & 75,000 & 75,000 \\
\hline Expected consumption & \multicolumn{2}{|c|}{$\$ 75,000$} \\
\hline Certainty equivalent & \multicolumn{2}{|c|}{75,000} \\
\hline Strategy 2 & Sell $\$ 30,000$ & Buy $\$ 20,000$ \\
\hline Cost & $-\$ 12,000$ & $\$ 12,000$ \\
\hline New consumption & 70,000 & 70,000 \\
\hline Expected consumption & \multicolumn{2}{|c|}{$\$ 70,000$} \\
\hline Certainty equivalent & \multicolumn{2}{|c|}{70,000} \\
\hline Strategy 3 & Sell $\$ 12,500$ & Buy $\$ 8,333$ \\
\hline Cost & $-\$ 5,000$ & $\$ 5,000$ \\
\hline New consumption & 87,500 & 58,333 \\
\hline Expected consumption & \multicolumn{2}{|c|}{$\$ 70,833$} \\
\hline Certainty equivalent & \multicolumn{2}{|c|}{71,440} \\
\hline
\end{tabular}

profiles by measuring the "certainty equivalent consumption level"-the level of certain consumption that would make her as happy as the random consumption in question. For a particular level of risk aversion, we calculate that our investor would be as happy with $\$ 70,710$ with certainty as with the $\$ 100,000$ and $\$ 50,000$ with equal probability. 10

10This type of calculation, known as certainty equivalent analysis, is explained at http:// en.wikipedia.org/wiki/Certainty_equivalent. Certainty equivalent measures have been used to compare investment strategies since at least Merton and Samuelson (1974). 
Now, a financial planner comes along to help her out. The financial planner has at his disposal a set of contingent claims, one paying $\$ 1$ in outcome $H$ and another paying $\$ 1$ in outcome $L$. What strategy should he propose to the investor? Let us start with a baseline case where both contingent claims cost the same: 50 cents. The financial planner proposes to the investor that she short $\$ 25,000$ of outcome $H$ income by shorting the contingent claim and that she go long $\$ 25,000$ of outcome $L$ income by purchasing the outcome $L$ contingent claim. The cost of the state $L$ contingent claims $(\$ 12,500)$ is exactly offset by the gains from shorting the outcome $L$ contingent claim, meaning that the long-short portfolio costs nothing. What happens to consumption? The investor now consumes $\$ 75,000$ in both outcomes. This strategy, therefore, shifts consumption from the high outcome to the low outcome- just what we said financial assets were supposed to do. And the certainty equivalent level of consumption, trivially equal to the actual level of consumption, $\$ 75,000$, is much higher than the initial level. So, the financial planner provided good advice.

Now, we change the world a little and set the prices of the contingent claims unequally at 40 cents for the $H$ outcome and 60 cents for the $L$ outcome. Suppose the planner provides the same advice (called "Strategy 1" in the table). The plan still provides the same certain level of consumption, but a slight problem exists: Because the price of the $H$ state consumption has fallen relative to the $L$ state, the revenue from the sale of $H$ state consumption no longer offsets the cost of the added $L$ state consumption. The investor now needs to come up with $\$ 5,000$ to execute the strategy. We assume that the investor does not have that money and confine ourselves to self-financing strategies. The planner regroups and provides Strategy 2 , a self-financing strategy that yields certain consumption of $\$ 70,000$. By selling more of the cheap state $H$ claims and buying fewer of the expensive state $L$ claims, our investor can achieve certain consumption of $\$ 70,000$ without adding any money. Has the planner earned his money? No. Recall that certainty equivalent consumption for the initial consumption profile exceeded $\$ 70,000$.

Not all investors will respond to asset prices in the same way. Differences in risk aversion, for example, play a big role. Risk aversion measures the willingness of an investor to tolerate variation in consumption across random outcomes. In Strategies 2 and 3, we argue that our investor is willing to accept a substantial increase in variation of consumption in exchange for a small increase in expected consumption. But that conclusion follows only because of the specific choice of risk aversion that we made. A household with higher risk aversion might opt for the sure consumption. Another issue that has drawn significant attention from economists is "habits." Some have argued that households are particularly unwilling to tolerate reductions in consumption. In this case, for example, suppose that our investor currently consumes $\$ 70,000$ a year and is unwilling to tolerate any reduction in consumption. Then, for her, the only plausible option would be to accept the 
lower expected level of consumption that accompanies the strategy of achieving riskless consumption. To add to the challenge of portfolio choice in this situation, we point out that the investor knows that higher consumption may restrict her choices in the future and, therefore, may restrict consumption now so that she can take risky bets in the future. 11

So far, both strategies proposed by the planner have caused problems-one because it required substantial additional funds and the other because it did not provide any benefit. Does this mean that financial planning cannot help this investor? No. Strategy 3 offers a bundle of contingent claims that manages to raise the investor's certainty equivalent consumption without requiring additional investment. What is unique about this plan among the ones we have looked at so far is that it does not provide a certain level of consumption.

The earlier examples illustrate that the optimal plan depends on the prices of the contingent claims. With either set of prices, it was possible to eliminate variability from consumption. But in only one of the cases was this advisable. The difference between the two scenarios is that in the baseline, there was no risk premium (and thus no incentive for the investor to take on risk) and in the alternative, there was a risk premium. To see the difference, calculate the returns on a riskless bond that pays $\$ 1$ in both outcomes and an equity-type security that pays $\$ 1$ in state $L$ and $\$ 2$ in state $H$. In the baseline scenario, the price of this bond would be $\$ 1$, making the return zero; the price of this equity would be $\$ 1.50$ with an expected payoff of $\$ 1.50$, so it also has a return of zero. In the alternative scenario, the return on the riskless bond is still zero, whereas the equity security now costs $\$ 1.40$ with the same expected payoff of $\$ 1.50$, meaning that it returns 7 percent more than the riskless bond.

Insight 4: Risky Assets in the Life-Cycle Model. One of the most important insights of the life-cycle model concerns the benefits of risky assets. In the life-cycle model, we view risky assets as a way to move money across different outcomes at a given time, not as a way to transfer resources across time. Let us illustrate this point with an example.

Consider an investor who lives for two years, this year and a "next year" in which there are two possible outcomes: "good times" and "bad times." Our investor can invest in a bond that pays 5 percent regardless of the outcome and a stock that increases 30 percent in good times and falls 5 percent in bad times. Figure 2 illustrates this event tree. Standard investment advice would view the two assets as different ways to save for the future - to transfer money to the future. In the lifecycle model, we divide their roles. We do so by constructing a portfolio composed

11For a discussion of these issues, see Dybvig (1995). 
Figure 2. The Role of Risky Assets in the Life-Cycle Model

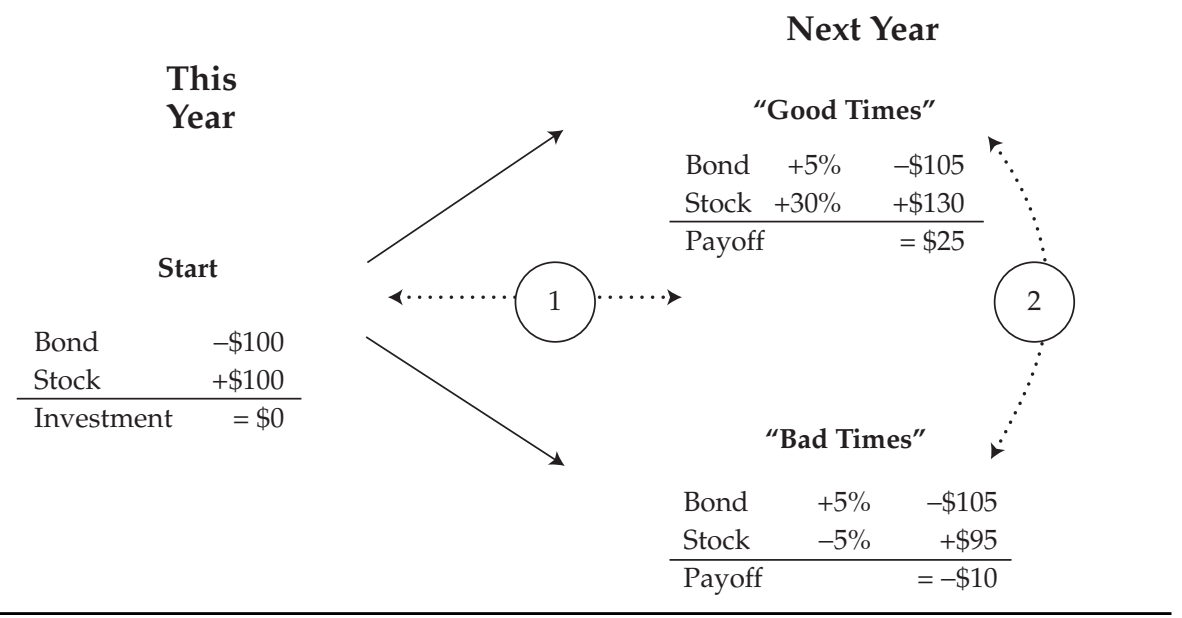

of $\$ 100$ of stock financed by a $\$ 100$ short position in the bond. This portfolio costs nothing today and, as Figure 2 shows, pays $\$ 25$ in good times and $-\$ 10$ in bad times. In other words, one can use this portfolio to convert $\$ 10$ in bad times into $\$ 25$ in good times (circled Transaction 2 in the figure). To transfer money across time, one uses the bond that, for example, allows the investor to transfer $\$ 100$ today for $\$ 105$ in both states in the future (circled Transaction 1 in the figure).

Suppose our investor wants to decide whether to invest $\$ 100$ in the stock or bond. Our analysis shows that a $\$ 100$ investment in the stock is a combination of a $\$ 100$ investment in the bond and the portfolio described above. In other words, the investor is exchanging $\$ 100$ today for $\$ 105$ in the future and exchanging $\$ 10$ in bad times for $\$ 25$ in good times. According to our logic, we view investing $\$ 100$ in the bond as exchanging $\$ 100$ today for $\$ 105$ next year but transferring nothing from bad times to good times. Thus, the difference in the two investment options has to do not with transferring resources across time- - both investments achieve that - but with transferring resources across outcomes.

Therefore, the decision to invest in the stock revolves around whether the investor is willing to give up $\$ 10$ in bad times in exchange for $\$ 25$ in good times. If we imagine, for the purposes of discussion, that the two outcomes are equally probable, then this seems like an exceptionally good deal. But we should recall that a goal of financial planning is to smooth consumption across outcomes, so we need to know whether our investor wants to transfer income from bad times to good times. At first glance, one might imagine that our investor would want to transfer income just the opposite way if, for example, "good times" meant employment and "bad times" meant joblessness. 
Insight 5: Asset Allocation over the Life Cycle. One of the great early discoveries of the theory of life-cycle financial planning was an understanding of the evolution of the optimal level of risk exposure as an investor ages. Despite the prevailing folk wisdom (and advice from some practitioners and academics) that investors should reduce the proportion of their portfolio invested in risky assets as they age, Merton (1969) and Samuelson (1969) showed that, for standard preferences, 12 it is optimal for individuals to maintain a constant fraction of their total wealth (human capital plus financial wealth) invested in equities at all ages.

The above may suggest that the life-cycle theory has little advice on asset allocation other than to choose the right proportion once. In fact, because of the influence of labor income, the proportion of financial wealth invested in risky assets can vary dramatically over the life cycle. This issue was taken up by Bodie, Merton, and Samuelson (1992), who considered life-cycle investors with risky wages and a degree of choice with respect to the labor-leisure decision. The model's results indicate that the fraction of an individual's financial wealth optimally invested in equity should "normally" decline with age for two reasons. First, because human capital is usually less risky than equity and because the value of human capital usually declines as a proportion of an individual's total wealth as one ages, an individual may need to invest a large share of his or her financial wealth in risky assets to get sufficient overall risk exposures. Second, the flexibility that younger individuals have to alter their labor supply allows them to invest more heavily in risky assets. The opposite result, however, is also possible. For people with risky human capital, such as Samuelson's businessmen or stock analysts, the optimal path may be to start out early in life with no stock market exposure in one's investment portfolio and increase that exposure as one ages.

\section{New Financial Products}

In this section, we map the key concepts from the life-cycle model into a methodological framework for the successful production of consumer-oriented structured life-cycle contracts. This approach, which recognizes that individuals do not have the ability to engineer for themselves contingent claims packaged in the form they most desire, owes much to Merton's development of the theory of financial intermediation. 13 The production of life-cycle products is successful if

1. the state-contingent consumption promised by the life-cycle product effectively satisfies the needs of the individual and

2. the financial intermediary has the adequate production/risk management infrastructure in place for the consumer-oriented life-cycle product to be technologically feasible.

12In particular, Samuelson (1969) and Merton (1969) studied individuals with constant relative risk aversion. For more details, see http://en.wikipedia.org/wiki/Risk_averse\#Relative_risk_aversion.

13This approach is exposed in Chapter 14 of Merton (1992). 
An analogy is that of the automobile industry. The customer is offered a standard product with optional features. Then, it is the automobile manufacturer's responsibility to fill the order received. Similarly, the development of financial products should start with designing standard products that serve primarily to secure a certain standard of living in retirement with various options.

In particular, the technology applied to this approach is entirely nested within the contingent claims analysis (CCA) framework developed by Merton (e.g., 1992). In accordance with the CCA methodology, the process that allows a financial intermediary to successfully engineer, market, and deliver optimal life-cycle products to its customers is best viewed as a production process that consists of three sets of tasks, as illustrated in Figure 3.

\section{Figure 3. Using the Life-Cycle Model to Address} Consumer Needs

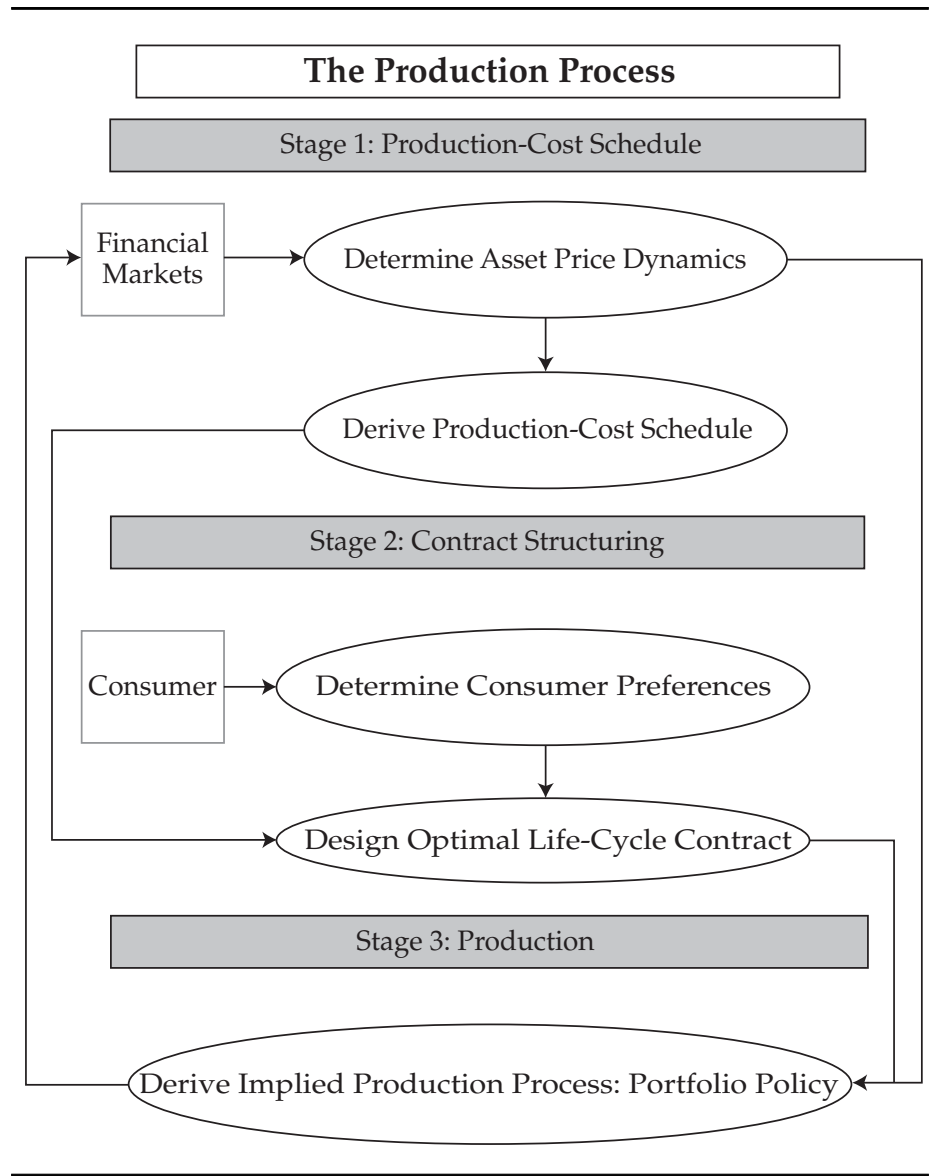


Stage 1. This stage requires the financial firm to determine its productioncost schedule (i.e., the cost of state-contingent consumption). These costs fall under two categories: the cost of certain future consumption provided by the market prices of inflation-protected bonds and the cost of state-specific consumption implied by the market prices of such securities as options (e.g., Breeden and Litzenberger 1978). State-contingent prices, also known as Arrow-Debreu prices (Arrow 1953; Debreu 1959), allow one to gauge the objective trade-off of consuming in different states of the world; thus, they are critical inputs in the process of designing optimal life-cycle consumption programs. These prices are instrumental in guaranteeing that the life-cycle contract satisfies the individual's budget constraint. A critical aspect of this stage is that it requires no knowledge of the financial intermediary's future customers and their preferences.

Stage 2. This is a contract-structuring stage during which, using the schedule of state prices, the financial firm structures the product that best satisfies the customer's tastes given the individual's lifetime wealth and planning horizon. For anticipated spending items with a well-defined time structure, and for which successful funding is a high priority — such as securing a comfortable standard of living in retirement and being in a position to send children to college- the financial firm should guarantee a floor given a particular flow of contributions. To the extent that the individual has wealth in excess of that required to finance necessities, modern finance theory (e.g., Vasicek 1977; Cox and Huang 1989; and Merton 1992) indicates that optimal discretionary spending over the life cycle is functionally identical to a derivatives contract on the growth-optimum portfolio. ${ }^{14}$ By acknowledging the effects of consumption habit formation (e.g., Dybvig 1995; Bodie, Detemple, Otruba, and Walter 2004) on individual well being, "consumption ratcheting" features may play a central role in the design of consumer-oriented life-cycle products.

Stage 3. After the contract is finalized, the financial intermediary initiates production by dynamically replicating the payoffs promised to the customer. This is done via hedging in financial markets. 15 Although the financial intermediary replicates the guaranteed payments as closely as possible, it must also raise risk capital from investors to assure customers that their payments will not be subject to residual risk (e.g., the risk that the intermediary may default on its obligation to deliver the promised amounts). 16 Consumers should not have to become investors in the debt or equity of the financial intermediary.

14The growth-optimum portfolio minimizes the expected time to reach a prespecified wealth target under the assumption of continuously reinvested gains. The composition of the growth-optimum portfolio is subjective in that it depends on expected rates of return on stocks.

15 For example, Detemple, Garcia, and Rindisbacher (2003, 2005) offer a flexible mathematical technology to determine the precise portfolio policy supporting optimal life-cycle products.

16Risk capital is defined in Merton and Perold (1993). 


\section{Conclusion}

As products and services for addressing the financial risks of retirement change, so do the varieties of institutions available to provide support to the elderly. Today, many diverse retirement income systems coexist around the world, each relying in varying proportions on one or more of the following institutional forms:

- support from family or community,

- pension plans sponsored by employers and/or labor unions,

- social insurance programs run by governments, and

- personal savings in the form of real and financial assets-equity in one's home or business, savings accounts, insurance contracts, mutual funds, and so on.

Many experts agree, however, that the mix of these institutional forms will change significantly in the next few years. Change is particularly to be expected in the industrialized countries, such as the United States, the United Kingdom, Australia, Western Europe, and Japan, where the rapid aging of the population reflects both that people are living longer and that they are having fewer children. In these economies, people will find they can rely less on family and government support than in the past and must, instead, turn to financial markets and related institutions by saving and investing for their own retirement. Even in emerging markets, new demographic and economic realities have prompted the beginning of widespread retirement system reforms, as seen in the pension reform movements of Latin America, Eastern Europe, and more recently, Asia.

In response to global population aging and financial deregulation, governments and financial firms are seeking to create new institutions and services that will provide the desired protection against the financial consequences of old age, illness, and disability and will insulate people against both inflation and asset price fluctuations. New opportunities are to be expected for older persons to continue employment, perhaps on a part-time basis, and to convert their assets, particularly housing wealth, into spendable income. For better or for worse, these developments mean that people are being given more individual choice over their own asset accumulation and drawdown processes. Because these new financial instruments transfer more responsibility and choice to workers and retirees, the challenge is to frame risk-reward trade-offs and to cast financial decision making in a format that ordinary people can understand and implement.

The authors thank Phil Dybvig, Debbie Lucas, and participants at this conference for helpful comments and suggestions. 


\section{REFERENCES}

Arrow, K. 1953. "The Role of Securities in the Optimal Allocation of Risk-Bearing." Econometrie [translated and reprinted in Review of Economic Studies (1964), vol. 31, no. 2:91-96].

- 1971. "Insurance, Risk, and Resource Allocation," Chapter 5 in Essays in the Theory of RiskBearing. Chicago: Markham Publishing Company.

Black, F., and M. Scholes. 1973. "The Pricing of Options and Corporate Liabilities." Journal of Political Economy, vol. 81, no. 3 (May/June):637-654.

Bodie, Z. 2003. "Thoughts on the Future: Life-Cycle Investing in Theory and Practice." Financial Analysts Journal, vol. 59, no. 1 (January/February):24-29.

Bodie, Z., R. Merton, and W. Samuelson. 1992. "Labor Supply Flexibility and Portfolio Choice in a Life Cycle Model." Journal of Economic Dynamics and Control, vol. 16:427-449.

Bodie, Z., J. Detemple, S. Otruba, and S. Walter. 2004. "Optimal Consumption-Portfolio Choices and Retirement Planning." Journal of Economic Dynamics and Control, vol. 28:1115-1148.

Breeden, D., and R. Litzenberger. 1978. "Prices of State-Contingent Claims Implicit in Option Prices.” Journal of Business, vol. 51, no. 4 (October):261-651.

Cox, J., and C. Huang. 1989. "Optimal Consumption and Portfolio Policies When Asset Prices Follow a Diffusion Process.” Journal of Economic Theory, vol. 49, no. 1 (October):33-83.

Cox, J., S. Ross, and M. Rubinstein. 1979. “Option Pricing: A Simplified Approach.” Journal of Financial Economics, vol. 7, no. 3 (September):229-263.

Debreu, G. 1959. Theory of Value. New Haven, CT: Yale University Press.

Detemple, J., R. Garcia, and M. Rindisbacher. 2003. "A Monte Carlo Method for Optimal Portfolios.” Journal of Finance, vol. 58, no. 1 (February):401-446.

- 2005. "Intertemporal Asset Allocation: A Comparison of Methods." Journal of Banking and Finance, vol. 29, no. 11 (November):2821-2848.

Dybvig, P. 1995. "Dusenberry's Ratcheting of Consumption: Optimal Dynamic Consumption and Investment Given Intolerance for Any Decline in Standard of Living." Review of Economic Studies, vol. 62, no. 2 (April):287-313.

E1 Karoui, N., and M. Jeanblanc-Picque. 1998. "Optimization of Consumption with Labor Income.” Finance and Stochastics, vol. 2, no. 4:409-440.

Fischer, S. 1975. “The Demand for Index Bonds.” Journal of Political Economy, vol. 83, no. 3 (June):509-534.

Fisher, I. 1930. The Theory of Interest. New York: Macmillan Company.

He, H., and H. Pages. 1993. "Labor Income, Borrowing Constraints, and Equilibrium Asset Prices.” Economic Theory, vol. 3, no. 4:663-696.

Merton, R. 1969. "Lifetime Portfolio Selection under Uncertainty: The Continuous-Time Case." Review of Economics and Statistics, vol. 51, no. 3 (August):247-257. 
- 1973. "Theory of Rational Option Pricing." Bell Journal of Economics and Management Science, vol. 4, no. 1 (Spring):141-183.

1992. Continuous-Time Finance. Malden, MA: Blackwell.

Merton, R., and A. Perold. 1993. "Management of Risk Capital in Financial Firms." In Chapter 8 of Financial Services: Perspectives and Challenges. Edited by S.L. Hayes III. Cambridge, MA: Harvard Business School Press:215-245.

Merton, R., and P. Samuelson. 1974. "Fallacy of the Log-Normal Approximation to Optimal Portfolio Decision-Making over Many Periods.” Journal of Financial Economics, vol. 1, no. 1 (May):67-94.

Modigliani, F. 1986. "Life Cycle, Individual Thrift, and the Wealth of Nations." American Economic Review, vol. 76, no. 3 (June):297-313.

Modigliani, F., and R. Brumberg. 1954. "Utility Analysis and the Consumption Function: An Interpretation of Cross-Section Data." In Post Keynesian Economics. Edited by K. Kurihara. New Brunswick, NJ: Rutgers University Press.

- 1979. "Utility Analysis and Aggregate Consumption Functions: An Attempt at Integration." In Collected Papers of Franco Modigliani, vol. 2, Edited by A. Abel. Cambridge, MA: MIT Press.

Samuelson, P. 1969. "Lifetime Portfolio Selection by Dynamic Stochastic Programming." Review of Economics and Statistics, vol. 51, no. 3 (August):239-246.

Sharpe, W. 2006. "Retirement Financial Planning: A State/Preference Approach.” Working paper.

Vasicek, O. 1977. "An Equilibrium Characterization of the Term Structure.” Journal of Financial Economics, vol. 5, no. 2 (November):177-188. 


\section{Session 1 Comments by Deborah Lucas}

Deborah J. Lucas

Donald C. Clark/Household International Professor of Finance

Kellogg School of Management at Northwestern University Evanston, Illinois

A longtime concern of mine has been to find ways to make theory relevant to practice, and I assume that doing so is also a purpose of this conference. Thus, we must consider the important but simple points embodied in theory in a world that is complicated. My intention, therefore, is to sort out the lessons I believe to be learned from this paper and to identify which ones have practical significance and which do not.

\section{Theory vs. Reality}

In the stationary environment of a standard life-cycle model, it is easy to characterize an optimal plan for consumption and saving. But when young people look to the future, myriad possibilities exist, each with different implications for financial planning. Will they get married, and if so, when? Will they divorce? Will they have children? How much will education and health care cost? What if they decide not to work for a corporation but, rather, want to start their own business? These uncertainties make it difficult to predict future earnings or to decide on an optimal saving strategy.

As people move toward retirement, financial planning is still complicated. Health becomes an important issue, but many other factors will also affect target savings levels. Do they own a home? Will their children help them out in times of trouble, or will they need to help their children? Will the social institutions they have been counting on continue to exist throughout their retirement? What must they save to have enough money to last throughout their lifetimes?

Taking these complexities into account, I cannot help but wonder whether optimal life-cycle saving and investing is more compelling in theory than in practice, at least in its most literal form. It is clearly impractical for people to write a contingent consumption plan that takes into account all the possibilities that might lie ahead. Therefore, it seems sensible that people do indeed focus on financial plans rather than consumption plans; financial planning provides people with a target level of resources that can support a range of not yet fully specified consumption plans.

\section{Six Concepts in a Complex World}

The authors organize the implications of the life-cycle model into six concepts, which I think offer a useful framework for discussing their paper. Although three of the concepts seem difficult to operationalize, the other three are both relevant 
and useful. Note that, although I assert that the first three-lifetime budget constraint, asset allocation over the life cycle, and phases of the life cycle-are less relevant in a practical sense, I recognize that they are the same concepts that helped Franco Modigliani win the Nobel Prize in economics. Thus, they are intellectually essential but nevertheless difficult to put into practice.

Less Relevant Concepts. Conceptually, the lifetime budget constraint highlights the fact that people possess not only their financial wealth but also their own human capital. In a perfect market, people can capitalize that human capital and think of it as being part of the resources available to them. Unfortunately, in an uncertain environment with incomplete markets, each person's lifetime budget constraint is poorly defined. People cannot forecast what they will do with their careers or how much money they are likely to earn, nor can creditors be assured of future repayment were people to try to borrow against future earnings. Hence, although it is worthwhile for financial planners to encourage people to be broadly forward looking in financial planning, the formal concept of a lifetime budget constraint may have few practical implications for behavior.

How to allocate assets over the life cycle is a decision that most people must contend with. In structuring my portfolio, should I put a greater proportion in stocks or bonds? To what extent should I invest in alternative assets? How should these allocations change as I age? These are critical questions in theory and practice, but theory offers little guidance to help people decide what they should do because what theoretically constitutes optimal asset allocation is sensitive to small changes in assumed preferences or circumstances (e.g., tax status and transaction costs). The theory is not wrong; it is simply not robust. Recognition of the heterogeneity of people's circumstances and preferences suggests caution in offering dogmatic advice based on simple theory. Financial advisers, therefore, must be very precise when trying to understand their clients' goals and constraints and avoid one-size-fits-all advice based on overly stylized theories.

My categorization of the third concept - phases of the life cycle - as having limited practical relevance is likely to raise eyebrows among many of my colleagues. After all, when people are young, and again when they are old, they generally have much less labor income than they have during middle age. Therefore, to smooth consumption, it is natural when earnings are high to save for retirement. My concern is that emphasizing the phases of the life cycle can lead to an oversimplified view of why people save and thereby to investment products that are insufficiently flexible. Certainly, people need to begin saving money while they are working so they will have money when they are old. But the theory too often neglects people's liquidity needs before they retire and the desire for flexibility in deciding when to retire. 
Highly Relevant Concepts. The three concepts from the paper that I find especially relevant to practice are (1) the importance of contingent claims, (2) the prices of securities, and (3) the role of portfolio constraints.

Although it is impractical to formulate a financial plan that assures smooth consumption over a lifetime, it is both important and feasible to identify and insure against many of the largest risks to financial security. The insights gained from contingent claims analysis are fundamental to creatively designing and pricing such risk management products. Insurance against contingent events has become increasingly available to commercial enterprises, and much can be learned from that experience. Many seemingly useful products, such as inflation futures and catastrophe futures, failed because they did not insure specific risks well enough (a property casualty insurer in the mid-Atlantic faces different risks from one in Florida). I think this reality will be even more important in personal financial markets. That is, because personal financial risks can vary significantly from person to person, creating standardized products with wide appeal is one of the biggest challenges.

Price is important for two reasons. First, for a financial product to be viable, it must be affordable. Although in theory the cost of sharing certain risks should be negligible, in practice, the price of insurance is often prohibitive. Financial engineers are adept at customization, but specialized consumer products often come with high markups. Such innovations are likely to be less attractive than simpler but more affordable products. The lesson that affordability is critical also can be learned from the commercial derivatives market. Even among sophisticated clients, such as financial institutions, the commercial derivatives products that gain wide acceptance are simple, competitively priced, multipurpose products, such as swaps and index options. Therefore, just a handful of derivatives products account for a large portion of the derivatives market. I think this situation will carry over to personal financial markets; only a few products will be broadly viable. Furthermore, specialized products in the commercial market are expensive and illiquid; only a few companies use them. That is likely to be the case in the consumer world too.

Another important aspect of price is that a financial service provider must have a good idea what a new product is worth before offering it. Heterogeneity of expectations about risk and return affects demand and makes pricing difficult, even for the specialists who build financial products. The tools of modern finance, particularly methods to value contingent claims, have been essential in providing a common basis for understanding value.

Finally, portfolio constraints, and market incompleteness more generally, limit the usefulness and availability of many products that may appear theoretically attractive. For instance, most consumers do not make use of strategies that require taking short positions or trading in thin markets. Furthermore, many of the hazards that individuals would like to insure against are fraught with moral hazard and adverse selection, causing the market for such protection to be restricted or nonexistent. Such constraints must be taken into account to make portfolio theory relevant. 


\section{Lessons from the Life-Cycle Theory}

Financial service vendors already use many of the theory's concepts in their day-today businesses, both to structure and to market their products. Indeed, advice and products for high-end clients have become increasingly sophisticated. The real challenge, then, is to provide products that are useful for less wealthy investors and to educate them so that they can evaluate those investment alternatives. Because commercial vendors always have an incentive to sell anything that is profitable and their advice is difficult to evaluate, it is not surprising that less informed investors are wary of good ideas as well as bad ones. Unfortunately, skepticism and confusion might also prevent many people from following the simple and valuable precepts that emerge from the life-cycle model.

Because it is likely that the government will continue to play the largest role in shaping the saving and retirement decisions of most people, the theory is especially valuable in providing guidance for the design and reform of social institutions. The obvious areas where the theory is relevant are in the structuring of public pensions, private pension regulation, and the design of social insurance contracts. For example, life-cycle theory suggests that continuing erosion of the defined-benefit pension system may have some undesirable consequences, such as increasing the risk of inadequate income in retirement. Clearly, there are many bad features of the current defined-benefit system - to name a few, its coverage is limited and uneven, it lacks portability, and the ERISA restrictions are burdensome. Nevertheless, definedbenefit pension plans offer a basic level of insurance not otherwise obtainable in financial markets today. Life-cycle theory offers insights into how defined-benefit plans could be restructured to best meet the needs of workers and retirees.

\section{Final Thoughts}

It is often the case that observed behavior differs markedly from the most basic predictions of the life-cycle theory, which may indicate that people are making big mistakes. Alternatively, it may be that the theory needs to be refined to better reflect people's preferences and constraints. One of the most basic ideas to arise from lifecycle theory is that people will want a smooth stream of consumption. Therefore, a big challenge for life-cycle theory is to determine why, when people have a choice between annuitizing and not, they tend not to annuitize. Are annuities too expensive? Do people think that annuities do not afford them enough access to their money if they need it? Or are the annuities they already have, such as Social Security, Medicare, and a fully paid home, sufficient? Or do people avoid annuities because they are short sighted? Answering such questions will shed light on how both theory and practice can be improved. 


\section{Session 1 Comments by Philip Dybvig}

Philip H. Dybvig

Boatmen's Bancshares Professor of Banking and Finance Washington University in St. Louis

St. Louis

I agree with most of the assertions of "The Theory of Optimal Life-Cycle Saving and Investing," and I certainly appreciate its goal, which is to make the results of theoretical literature in this area more accessible to a general audience. My intention, therefore, is to offer some constructive amendments that I hope the authors will find useful as they go through the process of revision.

\section{Additional Emphasis}

To begin, I believe that certain concepts in the paper should be given more emphasis. First is mortality risk and, with it, the fear of outliving savings. Insurance products exist for this risk, but the variety of such products is limited. Second is unemployment risk and risky wages, especially in correlation with the market. For example, auto workers whose risk of unemployment is correlated with the performance of the auto market probably should not take equity risk in their stock portfolio. The traditional advice of having riskier investments early in a working career rather than later would probably be reversed in this case.

Another area for increased discussion is that of precautionary savings. The idea of having insurance markets for everything has a certain theoretical appeal, but the idea cannot work in practice because of the incentive problems involved. For example, if individuals have complete insurance protecting their wages such that they will receive the same income whether or not they are working, the majority of people will choose not to work. When such insurance is not available, life-cycle models indicate that precautionary savings arise as a form of self-insurance so people have a pool of money they can draw on when times are bad. This practice is inefficient compared with the unavailable first best, but it is part of the solution.

The fourth concept, contingent claims, has two main uses. It can be used as a form of hedging or insurance, but it can also be used to manage transaction costs and compensated risk - that is, establishing an appropriate trade-off among risk, return, and transaction costs.

Finally, although the authors acknowledge that prices matter, I would have liked to have seen more on this subject. For example, I have noticed a tendency for unsophisticated investors to equate a good company with a good investment. But investors should relate what they get to how much it costs. A good company with a price that is too high is not a good investment, but a terrible company with a price that is low enough can be a good investment. 


\section{Missing Topics: Marketing and Regulation}

In my view, two topics-both of which are related to implementation-were missing entirely: marketing and regulation. The discussion in the paper sounds like a plan for a wholesale contingent claims product to be marketed to sophisticated institutional investors and corporations. Marketing for such clients consists mainly of communicating accurately the features of the product and describing its benefits to the client. For retail products, however, marketing is a far more central element. Even if a retailer has a superior product, the seller has to be able to communicate with consumers and describe to them effectively the features and benefits of the product. So, I would like to see a discussion on retail marketing.

As for regulation, all financial products face certain regulatory restrictions, and financial services companies must either see that their products meet those regulations or have those regulations changed. For example, insurance companies have received favorable treatment for their products by lobbying successfully for special tax treatment and for exclusive domain over products whose economic function is conceptually no different from other hedging products. (Insurance textbooks assert why such products are different, but I say that is nonsense.) Thus, insurers have made it difficult for noninsurers to offer comprehensive products that include both insurance features and investment features. Similarly, ERISA restrictions are a tremendous issue for retirement plans. ERISA restrictions are rigid and old fashioned, and many of the specific rules are based on actuarial science from the 1970s and are at odds with financial principles. I realize that this is not news to the authors, but I would like to see a discussion of the topic in the paper.

\section{Conclusion}

This is a useful paper that makes the implications of life-cycle theory accessible to a broader audience. Most of us in financial education are proud of the fact that we have an actual impact on practice. In many cases, the time between discovery and practice is relatively small. This paper fits clearly with that tradition. We still have a lot of work to do before our recommendations are as easy to understand as "hold a more risky portfolio when younger"-reflecting the fact that the world is more complicated than such recommendations imply - but this paper is a step in the right direction. 


\section{Session 2: Laibson Presentation}

\section{Session 2 Comments by Jeffrey Brown}

Jeffrey R. Brown

William G. Karnes Professor of Finance

College of Business, University of Illinois at Urbana-Champaign Urbana, Illinois

The paper that David Laibson presented (summarized in the Overview by Zvi Bodie, pp. $x i x-x x)$ ties together a large and growing literature about the power of "default options" in retirement planning. (Default options are actions taken by a retirement plan if an individual does not actively choose for himself or herself.) Each of the articles summarized in the paper is convincing in its own right. And when the papers are evaluated as a collection, the evidence that defaults matter is overwhelming.

Furthermore, it is not just that defaults matter in some contexts and not others; rather, the evidence suggests that default options have a strong influence on individual behavior at every step along the way in the retirement planning process. Should I participate in a plan? If I am participating in a plan, how much should I contribute? If I am contributing, how should I allocate the money across the various investment options? If I leave the company and I have a choice of what to do with the money, what should I choose? When I retire, how do I take distributions from the plan? In each of these cases, the evidence shows that individual decisions are strongly influenced by the choice of the default option.

Having established that defaults matter, the authors then tackle the more difficult question of why they have such strong effects. A number of ideas are discussed in this paper, including the idea that default options help to cut through complexity and also help to circumvent the problem of procrastination. My assessment is that there is no single right answer but that a combination of factors comes into play.

The authors begin with an interesting discussion of the power of defaults in contexts ranging from organ donation to financial planning. They then make the important point that in the area of retirement planning, defaults are particularly important because the complexity facing an individual is immense. Most individuals do not have the financial knowledge required to make the complicated life-cycle calculations that are needed to optimally plan for retirement. They are not helped

Editor's Note: The paper that David Laibson presented, "The Importance of Default Options for Retirement Saving Outcomes: Evidence from the United States," by John Beshears, James J. Choi, David Laibson, and Brigitte C. Madrian, is forthcoming in Lessons from Pension Reform in the Americas, edited by Stephen J. Kay and Tapen Sinha, Oxford University Press. 
by the fact that much of the advice from the financial planning "experts" is often conflicting or in some cases just wrong. Furthermore, retirement planning is an area where there are limited opportunities to learn from one's mistakes. To paraphrase B. Douglas Bernheim of Stanford University, you only get to retire once. Certainly, people can reenter the workforce after retirement, but the general point is that if a person on the verge of retirement has made a mistake and has not saved enough, that person cannot go back in time and correct that mistake. Having poorly trained individuals working in a highly complex environment with no ability to learn from their own mistakes creates a situation in which the choice of default options is critically important.

My view, which differs only in a minor way from the authors', is that a default option always exists; the question is whether that default option has been clearly specified and thought through or whether it came about by happenstance. The key, therefore, is to choose that default wisely — as David Laibson said, to make sure that it is a good default option on average, even if it is not right for every individualand then give individuals the opportunity to opt out of that default.

The authors also discuss an alternative to default, which is to force someone to make an active decision, perhaps by annoying the person until he or she does so. But at some point, even in this case, there is a default for not making a decision. Thus, my general view, at least a first-order approximation, is that a default always exists, and the key is to design it intelligently.

In my work with Social Security and pensions, one of the things I discovered is that the discussion of default options brings together otherwise disparate views. Thaler and Sunstein (2003) have coined the phrase "libertarian paternalism," a concept that is relevant here. The idea is that defaults can appeal to those who value individual choice (libertarianism) and to those who believe that good policies can protect individuals who might not otherwise act in their own best interest (paternalism). This balance is struck by using defaults to guide the decisions that people "ought" to make while preserving the ability of individuals to opt out and make their own decisions.

This idea is beginning to catch on and is already influencing policy. For example, 10 years ago, the debate on having personal accounts for Social Security did not consider opt-in or opt-out decisions. Today, the "opt-in versus opt-out" decision is one of the key parameters that policymakers consider when designing a voluntary personal accounts plan. The U.S. Congressional Budget Office now uses opt-in/opt-out assumptions to understand what participation rates could be in such a scenario.

More recently, although the Pension Protection Act of 2006 was originally motivated by the need to address significant problems relating to the regulation of defined-benefit plans and the Pension Benefit Guaranty Corporation, the act also contains provisions about automatic enrollment in 401(k) plans, which may, in the 
long run, turn out to be the more important pieces of this legislation for retirement security. ${ }^{1}$ I am not necessarily condoning all aspects of the legislation, but it does attempt to make automatic enrollment and the power of default something that employers are more comfortable with. For instance, it clarifies that enrolling people in a plan by default does not conflict with state laws designed to prevent employers from garnishing wages. The legislation also allows some tax relief in the event that individuals get opted into a plan and then want out; they have some time to do that without tax penalties.

In addition, the U.S. Department of Labor was directed to issue new regulations covering default investment alternatives. ${ }^{2}$ Although the proposed regulations are currently in the comment stage, they specify life-cycle funds, balanced funds, and managed accounts as acceptable default investment options. One of the concerns I have is whether this definition of an appropriate default investment option is broad enough (Brown 2006). For example, the ideal investment option for some individuals might be a plan that allows the participant to buy annuity income that starts on a retirement date. A number of firms have such products under various names, and those products are important investment options that should not be omitted.

Although the future is always uncertain, from a policy standpoint, my sense is that automatic "everything" (enrollment, contributions, portfolio decisions, payout decisions, etc.) with the ability to opt out is an idea that most people can embrace. This certainly appears to be where private pensions are heading in the future.

From a research and policy standpoint, most of the attention to date has been focused on enrollment, contributions, and portfolio allocations. Given that these are the first three steps in the retirement planning process, this makes sense. But those who know my research agenda know that I care deeply about the payout phase. I often state that asset accumulation is only half the retirement security problem. To provide for lifelong retirement security, one must also consider the other half, the payout phase- - how to de-cumulate these assets in a sensible way.

Arguably, the biggest risk in the payout phase is longevity risk. Guaranteed lifetime income products are an answer to longevity risk, and yet there is very little annuitization taking place in the United States today outside of Social Security and the remaining defined-benefit plans. A major policy challenge is that the vast majority of 401(k) plans do not even offer an annuity payout option-that is, a lifetime guaranteed income option. Of course, the retiree can always choose to roll the $401(\mathrm{k})$ into an IRA and use the proceeds to buy a commercial annuity, but that is a multistep, complicated process that few individuals follow. Indeed, financially

1For more information on this legislation, see www.whitehouse.gov/news/releases/2006/08/ 20060817.html.

${ }^{2}$ See www.dol.gov/EBSA/pensionreform.html. 
unsophisticated individuals might not even know that it is an option, and if it is not presented to them, they are unlikely to pursue it. In other words, "not annuitizing" is the current default option, which, in my opinion, is not the right default option because it does not acknowledge the existence and importance of longevity risk.

The challenge in designing a default for the payout phase is that, although many people are underannuitized, it is clear that annuitizing all of a retiree's $401(\mathrm{k})$ balance is not optimal for everyone. There are many reasons for this conclusion, including the fact that some individuals have much shorter than average life expectancies (see Brown forthcoming 2007 for a more complete discussion of the issues involved). One of the difficulties is that these guaranteed income annuities are often irreversible and illiquid. If someone is defaulted into one and it turns out to be a bad decision, it is difficult or impossible to get out of. Policymakers may want to consider, instead, phased or laddered annuities that, for example, move onefifth of the account each year for five years into an annuity. If one-fifth of the account is annuitized in the first year of retirement and the individual decides that is not what he or she wanted, the worst case is that 20 percent of the account has been annuitized and the individual still has 80 percent to do something else with. Furthermore, even if 20 percent is annuitized, there is no reason that a company cannot design a product that allows some limited reversal period. Certainly, such a modification would affect the pricing of the products, but I suspect that the selection effects would be relatively small because there is a limit to how much new information people really receive about their mortality prospects over a six-month period.

In summary, policymakers should not just assume that they cannot default people into annuities because annuities are irreversible and might not make sense for some people. With a little creativity, we should be able to come up with a much better default option than no annuitization.

\section{REFERENCES}

Brown, Jeffrey R. 2006. "Re: Proposed Regulation on Default Investment Alternatives under Participant Directed Individual Account Plans." Comment letter submitted to the U.S. Department of Labor (13 November): www.dol.gov/ebsa/pdf/Brown111306.pdf.

Forthcoming 2007. "Understanding the Role of Annuities in Retirement Planning." In Improving the Effectiveness of Financial Education and Savings Programs. Edited by Annamaria Lusardi. Chicago: University of Chicago Press.

Thaler, Richard H., and Cass R. Sunstein. 2003. "Libertarian Paternalism.” American Economic Review, vol. 93, no. 2 (May):175-179. 


\section{Session 2 Comments by James Poterba}

\section{James Poterba}

Mitsui Professor of Economics and

Head of the Department of Economics

Massachusetts Institute of Technology

Cambridge, Massachusetts

This clear and interesting paper reviews a substantial literature, in which the authors' work features prominently, on how "default options" in 401(k) plans affect participation decisions of eligible workers as well as the contribution and asset allocation choices of participants. This research has been widely cited by behavioral economists as evidence that household saving decisions fail to satisfy simple postulates of rationality and that the framing of these saving decisions can substantially affect household choices.

Changing the default $401(\mathrm{k})$ enrollment option confronting new employees without altering the primitive structure of the saving plan should not affect employee choices in a standard neoclassical model because such a change affects neither the choice set nor the preferences of the prospective saver. Yet, empirical evidence overwhelmingly suggests that using "opt-out" (i.e., you are in unless you opt out) rather than "opt-in" enrollment defaults can significantly increase participation rates as well as the share of earnings contributed to $401(\mathrm{k})$ plans. Moreover, when a plan offers a default asset allocation mix — say, a lifestyle fund - a substantial percentage of participants adopt this mix.

Many researchers have concluded from this evidence that a significant percentage of households are not fully rational with regard to saving behavior. Some policymakers have used this evidence to justify paternalistic government policies that encourage household saving through workplace saving vehicles. Underlying these conclusions are two central questions: The first is whether households exhibit a fundamental irrationality in their saving behavior; the second is how best to use employer and government policies to improve choices about the amount to save and asset allocation. These questions will be the focus of my comments.

Although some view the evidence that default options affect saving decisions as a substantial refutation of neoclassical optimizing models of intertemporal consumer behavior, such a broad conclusion may overstate the case. Four considerations bear analysis. First, the word "substantial" is important in this context

Editor's Note: The paper that David Laibson presented, "The Importance of Default Options for Retirement Saving Outcomes: Evidence from the United States," by John Beshears, James J. Choi, David Laibson, and Brigitte C. Madrian, is forthcoming in Lessons from Pension Reform in the Americas, edited by Stephen J. Kay and Tapen Sinha, Oxford University Press. 
because households may make poorly considered choices for many low-stakes behaviors without necessarily making any errors that have important consequences for their lifetime utility.

In many of the $401(\mathrm{k})$ plans studied, the stakes associated with saving decisions may actually be relatively low. In the past two decades, payouts from 401(k) plans have not been the primary source of retirement income for most 401(k) participants. Many 401(k) plans began as thrift saving plans at large companies with definedbenefit plans. For participants in such plans, investment decisions within the 401(k) plan may be relatively inconsequential for the household's retirement security. For individuals with primary defined-benefit plan coverage and with the prospect of Social Security benefits in retirement, the risk of penury is small, no matter what they decide regarding their 401(k). The cash annuities associated with definedbenefit plans and Social Security, coupled with public health insurance coverage through Medicare and Medicaid, provide a consumption floor for the retirement period. If such a covered household saves relatively little, or nothing, in a 401(k) plan while working, any resulting drop in consumption after retirement may have only modest effects on lifetime utility.

One of the unresolved issues in the analysis of household financial behavior is the cost of mistakes. Few studies have been conducted on this issue. Calvet, Campbell, and Sodini (2006) studied the lack of diversification by some Swedish investors and, more generally, their failure to participate in equity markets. They found that the cost of these errors was modest. Poterba, Rauh, Venti, and Wise (2006) made a related point when they computed the expected utility of $401(\mathrm{k})$ wealth at retirement for risk-averse households with and without a Social Security life annuity.

Households that can rely on such an annuity as an income floor derive greater expected utility from risky investments than do households with similar preferences but no income guarantee. The presence of assured payouts in retirement removes the risk of facing very low consumption levels. If the household's decision about whether to participate in a $401(\mathrm{k})$ plan leads to only modest perturbations around the path of lifetime consumption, the utility consequences of the decision may be small.

Research in experimental economics suggests that decision makers behave more "rationally" on cognitive tasks, such as working out time value of money or remembering vocabulary words, when the stakes are greater. Smith and Walker (1993) and Camerer and Hogarth (1999) discussed this evidence, along with the view that computational costs may explain the observed pattern. They noted that higher stakes also reduce the variation in choices among participants. It is possible that as $401(\mathrm{k})$ plans become a more significant component of the retirement saving landscape, the rationality of participant decisions and the effort participants expend to learn about investment options and choose asset allocation profiles will increase. 
First, the pattern of participant behavior with respect to lump-sum distributions associated with job change is broadly supportive of this view. Those who leave a company with a large $401(\mathrm{k})$ balance are much more likely to roll the assets over to another $401(\mathrm{k})$, or to otherwise ensure that the assets remain in the retirement system, than are individuals with small 401(k) balances. If one views drawing the assets out of the retirement system as the irrational choice in this setting, the pattern of rollovers suggests that high-stakes decisions are different from low-stakes decisions.

Second, the most dramatic default effects are observed among new employees, and the magnitude of these effects declines as an employee's job tenure rises. A key feature of retirement saving decisions is that the cost of mistakes builds over time. Failure to participate in the plan for a single year has a much smaller impact on potential future consumption than failing to participate for a decade. Yet, we know relatively little about the long-term effects of defaults. Some of the evidence in Madrian and Shea (2001) points to such a convergence over time between default effects and job tenure and suggests that the "impact effect" of default options may overstate their long-term effect. This is an important item for future study.

Third, most of the research on default effects has relied on company administrative data provided by $401(\mathrm{k})$ benefits managers. These data are a rich source of information about participant behavior, but they suffer from some limitations as a general source of information on portfolio structure. Household balance sheets are complicated, and many households who participate in $401(\mathrm{k})$ plans have substantial asset holdings outside their 401(k) plans. The long-running debate on how 401(k) contributions affect private saving has emphasized the many ways in which households might offset behavior within their $401(\mathrm{k})$ plans. These include adjustments to financial assets outside the $401(\mathrm{k})$ and changes in net housing equity. Reducing consumption is not the only way to finance the higher level of defined-contribution plan saving induced by default plans. Studies of the net saving effect of $401(\mathrm{k})$ plans, such as those reviewed in Poterba, Venti, and Wise (2004), suggest that these other adjustments may be minor. Yet, future work should explore this issue for default plans.

Fourth, and finally, discussions of default effects should recognize the heterogeneity of households in the behavioral response to retirement plan innovations. Survey evidence as well as experimental evidence suggest that households differ widely. Ameriks, Caplin, Leahy, and Tyler (2007), for example, suggest that some households are most likely oversaving for their future years whereas other households are not saving enough, which raises the possibility that multiple decision-making biases may impinge on saving behavior. Their findings also suggest that differences across households are essential not only for analyzing the impact of existing default plans but also for determining the optimal structure of potential default rules.

Even if a substantial percentage of households makes poor decisions, the neoclassical optimizing framework may apply with some success to other households. This possibility complicates the design of default provisions, particularly ones that may affect both contribution rates and asset allocation patterns. It is not clear 
how to model the costs of deviating from the default option; the explicit cost of visiting a website or a benefits office are unlikely to capture the larger psychological costs of such decisions. If it is costly to undo the default, some households that would invest the time and effort to make an evaluation of the best choice for themselves may choose not to do so when there is a default option that reflects choices by an expert on retirement saving.

Taking as a given that some decision-making pathologies may be mitigated by the adoption of default plan provisions, what should the defaults be? The answer depends on the particular decision-making problem that the defaults are designed to solve, on the degree of heterogeneity in the household population, and on the default setter's relative concern about different groups of households. The authors of this paper make the important point that having a default can produce unintended consequences. A default asset allocation strategy may lead a significant group of 401(k) participants who would have made "good" decisions in the absence of a default to modify their behavior and make "passable" decisions by following the default. A poorly designed default may compound this problem.

One issue that must be resolved in default design is determining whether observed participant behavior is the result of poor information or of poor decision making by participants with good information. Existing research suggests that some 401(k) participants have limited information about the consequences of their choices, both with regard to contribution rates and asset allocation. Lusardi and Mitchell (2006) presented important information regarding the financial literacy of households who are approaching retirement age. They found that only half of their sample respondents over the age of 50 could correctly answer basic questions concerning inflation and interest compounding and that only one-third could answer questions involving diversification.

When households lack information but can be taught to make the relevant decisions, it is natural to consider educational programs as one policy response to apparently poor decisions. Yet, some of the decisions households must make in retirement planning are intrinsically complex and involve compound interest and long-term planning. In such contexts, households might want recommendations about how to manage their saving choices, not just purely factual information. Recent legislative changes that facilitate advice provision by retirement plan sponsors may have important consequences for the level of information and advice available to 401(k) plan participants, which may lead to changes in observed behavior.

One role that advice can play is to help households reduce the impact of decision-making biases on their choices. In some experimental game settings, it is possible to affect participant choices by asking them to use simple devices, such as imagining themselves in different settings or asking them to play the part of another agent in the game. There may be ways to use such methods in tandem with information about rates of return and other inputs to the saving decision to improve decision-making outcomes. 
The authors focus on default provisions that affect the share of salary contributed to a 401(k) plan as well as on defaults that affect the asset composition of the retirement portfolio. However, they do not discuss the rise of "life-cycle funds," which automatically change the bond/stock mix of the portfolio as participants age. These funds have been one of the most rapidly growing financial products of the past few years and have been increasingly popular as the default option in retirement plans. Studying them sheds light on broader issues that arise in default plan design.

Life-cycle funds provide $401(\mathrm{k})$ participants with an opportunity to purchase a product targeted for their retirement date and with asset allocation patterns that have ostensibly been selected by financial experts. Assets in these funds have increased more than tenfold since 2000. In 2006, the 2020 retirement date accounted for roughly one quarter of the assets. The life-cycle fund concept, in principle, removes the need to make decisions about asset allocation choices from the household. In practice, there is substantial heterogeneity across life-cycle funds, so investors still need to make choices.

Table 1 shows the evolution of the average asset allocation between stocks and bonds in life-cycle funds. There is a greater share of equity, on average, in long-dated funds than in those targeted at nearer-term retirees. Yet, there are also substantial differences across funds in the equity share for a given target date. Table 2 shows the dispersion in allocation percentages among funds that target 2015 and 2030 retirement dates. The table shows the three largest funds for each of these retirement dates. There are significant differences across funds in the equity share and in the role that assets other than stocks and bonds play in the portfolio, particularly for the long-dated (2030) funds. Thus, even within the class of life-cycle funds, it is clear that investors need to be attentive to the specific structure of the fund that they are purchasing.

Table 1. Weighted Average Asset Allocations for Target-Year Life-Cycle Mutual Funds, June 2006

\begin{tabular}{lllll}
\hline $\begin{array}{l}\text { Target } \\
\text { Retirement } \\
\text { Year }\end{array}$ & Stocks & Bonds & Cash & Other \\
\hline 2010 & $49.0 \%$ & $38.6 \%$ & $10.5 \%$ & $1.9 \%$ \\
2015 & 57.8 & 34.7 & 6.4 & 1.1 \\
2020 & 60.7 & 30.8 & 6.8 & 1.6 \\
2025 & 75.9 & 20.6 & 2.6 & 0.9 \\
2030 & 74.4 & 20.1 & 4.3 & 1.2 \\
2035 & 85.9 & 11.2 & 2.1 & 0.8 \\
2040 & 82.9 & 12.1 & 3.9 & 1.0 \\
2045 & 88.5 & 9.3 & 1.3 & 1.0 \\
\hline
\end{tabular}

Sources: Morningstar, updating information in Poterba, Rauh, Venti, and Wise (2006). 


\section{Table 2. Heterogeneity in Asset Allocation for \\ Same-Date Life-Cycle Funds}

\begin{tabular}{llcccc}
\hline $\begin{array}{l}\text { Target } \\
\text { Retirement } \\
\text { Year }\end{array}$ & \multicolumn{1}{c}{ Fund Name } & Stocks & Bonds & Cash & Other \\
\hline 2015 & Fidelity Freedom & $65 \%$ & $34 \%$ & $1 \%$ & $0 \%$ \\
2015 & T. Rowe Price Retirement & 70 & 23 & 6 & 1 \\
2015 & Vanguard Target Retirement & 65 & 34 & 1 & 0 \\
2030 & Fidelity Freedom & $71 \%$ & $23 \%$ & $4 \%$ & $1 \%$ \\
2030 & Principal Investment Lifetime & 67 & 23 & 6 & 4 \\
2030 & T. Rowe Price Retirement & 88 & 8 & 4 & 0 \\
\hline
\end{tabular}

Source: Morningstar.

The different levels of equity exposure in different life-cycle funds that target the same retirement date may not be surprising. There is no academic consensus on the optimal asset allocation pattern over the life cycle. Gollier and Zeckhauser (2002) discussed the long-standing theoretical debate on this issue, and Gomes and Michaelides (2005) reviewed much of the empirical literature. A number of important insights have emerged from academic research on this topic. The optimal agespecific equity share of the portfolio depends on factors including the household's risk tolerance, the correlation between the shocks to a household's labor income and the return on various financial assets, the household's flexibility in altering its labor supply to compensate for losses in financial markets, and the other types of risks facing the household. Social insurance programs - in particular, retirement income programs and retiree health insurance programs - also matter.

Differences across households in these factors are likely to lead to differences in desired levels of equity exposure and in life-cycle allocation patterns. This suggests that a single life-cycle fund is not likely to be ideal for all households. Default investment options that involve life-cycle funds are likely to be helpful for retirement plan participants who do not devote much attention to considering their asset allocation choices, provided that their costs are not too great. They are unlikely, however, to absolve households from the need to consider their investment options and to select such options in light of their own economic circumstances and investment preferences.

It is important to consider household heterogeneity in the design of retirement plan defaults and in public policy toward saving more generally. One useful approach to framing the default-design problem in this setting is the "asymmetric paternalism" paradigm developed by Camerer, Issacharoff, Lowenstein, O'Donoghue, and Rabin (2003). The key is to trade off the benefits that paternalistic policies offer for those who are prone to decision-making errors, and whose choices may be aided by such 
policies, with the costs that such policies impose on households whose decisions will be distorted in a utility-reducing way by paternalistic rules. The attraction of retirement plan defaults in this setting depends in part on the costs of opting out of default choices. Provided these costs are small, an informed or rational household that wanted to implement its own saving plan would be able to do so. At the same time, the defaults might prevent uninformed households or others who are prone to decision errors from making unattractive choices. The uninformed households might, therefore, be made better off with the defaults.

\section{REFERENCES}

Ameriks, John, Andrew Caplin, John Leahy, and Tom Tyler. 2007. "Measuring Self-Control Problems." American Economic Revieww, vol. 97, no. 3 (June):966-972.

Calvet, Laurent, John Campbell, and Paolo Sodini. 2006. "Down or Out: Assessing the Welfare Costs of Household Investment Mistakes.” NBER Working Paper 12030 (February).

Camerer, Colin F., and Robin M. Hogarth. 1999. "The Effects of Financial Incentives in Experiments: A Review and Capital-Labor-Production Framework." Journal of Risk and Uncertainty, vol. 19, no. 1-3 (December):7-42.

Camerer, Colin F., Samuel Issacharoff, George Lowenstein, Ted O'Donoghue, and Matthew Rabin. 2003. "Regulation for Conservatives: Behavioral Economics and the Case for 'Asymmetric Paternalism'.” University of Pennsylvania Law Review, vol. 151, no. 3 (June):1211-1254.

Gollier, Christian, and Richard J. Zeckhauser. 2002. "Horizon Length and Portfolio Risk." Journal of Risk and Uncertainty, vol. 24, no. 3 (May):195-212.

Gomes, Francisco, and Alexander Michaelides. 2005. "Optimal Life-Cycle Asset Allocation: Understanding the Empirical Evidence.” Journal of Finance, vol. 60, no. 2 (April):869-904.

Lusardi, Annamaria, and Olivia S. Mitchell. 2006. "Financial Literacy and Planning: Implications for Retirement Well-Being." Working Paper WP2006-01, Pension Research Council of the Wharton School, University of Pennsylvania.

Madrian, Brigitte C., and Dennis F. Shea. 2001. "The Power of Suggestion: Inertia in 401(k) Participation and Savings Behavior." Quarterly Journal of Economics, vol. 116, no. 4 (November): 1149-1187.

Poterba, James, Steven Venti, and David Wise. 2004. "The Transition to Personal Accounts and Increasing Retirement Wealth: Macro and Micro Evidence." In Perspectives on the Economics of Aging. Edited by David Wise. Chicago: University of Chicago Press.

Poterba, James, Joshua Rauh, Steven Venti, and David Wise. 2006. "Lifecycle Asset Allocation Strategies and the Distribution of 401(k) Retirement Wealth." NBER Working Paper 11974 (January). Forthcoming in Developments in the Economics of Aging. Edited by David Wise. Chicago: University of Chicago Press.

Smith, Vernon L., and James M. Walker. 1993. "Monetary Rewards and Decision Costs in Experimental Economics." Economic Inquiry, vol. 31, no. 2 (April):245-261. 


\title{
Session 3: Kotlikoff Presentation
}

\section{Is Conventional Financial Planning Good for Your Financial Health?}

\author{
Laurence J. Kotlikoff \\ Professor of Economics \\ Boston University \\ Boston
}

Economic theory predicts, and casual observation confirms, that households seek to maintain their living standards (smooth their consumption) as they age and face life's various contingencies. Seeking a stable living standard and actually achieving one, however, are two very different things. We cannot insure against aggregate shocks, including economic downturns, natural disasters, and epidemics, nor can we buy actuarially fair insurance against a range of individual shocks, such as job loss, excessive longevity, and disability. And we generally lack the self-control to save and insure adequately even given attractive opportunities to do so.

These concerns with consumption smoothing are well known and have been amply studied. ${ }^{1}$ But another problem-namely, the computation challenge posed by consumption smoothing-has received little attention, which is surprising because consumption mistakes could well swamp these other considerations. Certainly, the calculations required to minimize consumption disruptions over time and across states of nature are highly complex. Just consider the number and range of current and future variables involved in consumption smoothing: The list includes household demographics; labor earnings; retirement dates; federal, state, and local taxes; U.S. Social Security benefits; pension benefits; regular and retirement assets; borrowing constraints; rules for retirement account contributions and withdrawals; home ownership; mortgage finance; economies in shared living; the relative costs of children; changes in housing; choice of where to live; the financing of college and weddings; gifts made or received; inheritances; paying for one's dream boat; and so on. And each of these variables demands consideration under each and every survival contingency. ${ }^{2}$

\footnotetext{
1As an example, see http://post.economics.harvard.edu/faculty/laibson/papers.html for a long list of excellent papers by David Laibson and his colleagues contributing to the field of behavioral finance. ${ }^{2}$ Survival contingencies are distinguished by which spouse/partner dies and when he or she dies. The reason is that the survivor will inherit different amounts of wealth, collect different amounts of life insurance, and receive different levels of Social Security survivor and retirement benefits depending on the age at which his or her spouse/partner dies.
} 
Taxation by itself is a factor worthy of a high-speed computer processor. Figuring out the federal and state taxes when both spouses are alive and in each future survivor state (years in which one spouse is deceased) requires determining whether they will itemize their deductions, whether they will receive any of the many potentially available tax credits, whether they will have to pay the Alternative Minimum Tax, whether they will pay taxes on their Social Security benefits, whether they will be contributing to or withdrawing from retirement accounts, and whether they will be in high or low tax brackets. And as if this list were not bad enough, determining future taxes introduces a nasty simultaneity problem. We cannot figure out the future taxes until we know the current spending (which determines, in part, the future taxable capital income), but we cannot figure out the current spending without knowing the future taxes (which determines, in part, what the couple has available to spend).

Computing Social Security benefits is another nightmare. With 2,528 separate rules in the Social Security Handbook, figuring out what retirement, dependent, survivor, divorce, mother, father, and child benefits one will receive can be maddening, particularly in light of the system's complex average indexed monthly wage and primary insurance amount benefit formulae as well as its ancillary adjustments to the primary insurance amount. These adjustments include the earnings test, the early retirement reduction factors, the delayed retirement credit, the recomputation of benefits, the family benefit maximum, the windfall elimination and offset formulae for workers with noncovered employment, and the phase-in to the system's ultimate age 67 normal retirement age. ${ }^{3}$ How many households can even list all these interrelated factors, let alone process them accurately?

The standard fallback in economics is that households do not need to know all the details or have $\mathrm{PhDs}$ in math to make correct life-cycle decisions. Indeed, we economists view the mathematical formulation of optimal intertemporal choice as simply descriptive modeling. "Households," we tell ourselves, "do not do the math but act as if they do. Yes, households will make mistakes, but these mistakes will be small and average out."

\footnotetext{
${ }^{3}$ Unfortunately, the handbook is remarkably uninformative about many details of these adjustments, particularly the order in which they are applied. Several of the old-timers knocking about in the U.S. Social Security Administration's Office of the Actuary know these details, but when they go, this information may literally disappear. One might think that the computer code that generates the hundreds of billions of dollars worth of actual Social Security benefit payments would be easy to check regarding such matters. But this code is, as I have been told, documented very poorly and written in an ancient computer language, namely, COBOL, that no one at the Social Security Administration apparently understands. Furthermore, it cannot necessarily be reproduced from scratch because many Social Security rules were apparently made administratively.
} 
Unfortunately, studies of saving and insurance adequacy and portfolio diversification -including Kotlikoff, Spivak, and Summers (1982); Auerbach and Kotlikoff (1987, 1991); Bernheim, Carman, Gokhale, and Kotlikoff (2003); Bernheim, Forni, Gokhale, and Kotlikoff (2000, 2003); and Bernheim, Berstein, Gokhale, and Kotlikoff (2006) - belie this proposition. Vast numbers of households save, insure, and avoid risk either far too much or far too little. The fact that households make both types of mistakes and that, as a consequence, generate average behavior that, on its face, is not extreme offers little professional consolation. The medical community would not declare that heart disease has been cured if half of peoples' hearts beat too fast and the other half too slow.

The other professional fallback is that households that look financially sick are, in fact, financially healthy but simply have unusual preferences or prior beliefs about future events. Thus, a household that invests only in cash can be viewed as being extremely risk averse and also convinced that deflation is around the corner. Because preferences and priors are taken as economic primitives that are above reproach, there is no scientific basis for classifying extreme financial behavior as financial pathology. Imagine the medical profession declaring cancer a perfectly healthy manifestation of genetic free will.

Perhaps it is time to identify financial disease according to the financial pain it engenders. Based on this criterion, we are, generically speaking, financially quite sick. Indeed, the ravages of financial pathology are clearly seen among today's elderly, one-third of whom are wholly dependent or almost wholly dependent on Social Security.

Many households seek to cure their financial ills by turning to the financial planning industry for advice. In so doing, they effectively let financial planners or financial planning software decide what their preferences are and how they should be maximized. For such households, the study of their financial behavior may simply boil down to understanding what planners or software they are using and what these planners or programs are leading them to do.

If conventional financial planning corresponds closely to what economics prescribes, then households taking this advice will improve their financial health. But what if conventional financial planning generates recommendations that are far afield from proper consumption smoothing? In this case, "financial planning" will represent a cure-all, not real penicillin, and potentially leave one in worse financial shape.

In this paper, I examine one aspect of conventional financial planning: namely, the requirement that households set their own retirement and survivor spending targets. I show that from the perspective of consumption smoothing (the goal of achieving a stable living standard), even small targeting mistakes, on the order of 10 percent, can lead to enormous mistakes in recommended saving and insurance 
levels and to major living standard disruptions (on the order of 30 percent) at retirement. Given the computational difficulties involved in achieving proper consumption smoothing on one's own, targeting mistakes of 10 percent or greater appear inevitable.

In soliciting spending targets, the traditional approach asks households to tally up all of their current expenditures and to use this level of spending as a target for retirement and survivor spending with some adjustment for changes in spending needs. The goal here seems to be that of consumption smoothing (i.e., to achieve the same living standard before and after retirement and in survivor states).

The rub, however, is that the current level of spending, which underlies the targeting, may be higher or lower than the sustainable level. Given the computation problems referenced earlier, this is almost inevitable. If current spending is higher than the sustainable level, the targets will be set too high. In this case, households will be told to save and insure more than is consistent with consumption smoothing. If current spending is lower than the sustainable level, the targets will be set too low. In this case, households will be advised to save and insure less than is consistent with consumption smoothing.

If the target is set too high, the household will be told to oversave and overinsure and will end up with a lower living standard prior to retirement and a higher one after retirement and in survivor states. If the target is set too low, the household will be told to undersave and underinsure and will end up with a higher living standard prior to retirement and a lower one after retirement and in survivor states. Both types of targeting mistakes will lead to consumption disruption rather than consumption smoothing.

This conclusion depends, of course, on whether the household takes the advice being given. Telling households that are currently overspending to substantially cut their current living standard may lead them to ignore the advice, decide to retire later, or accept a much lower future living standard. And telling households that are currently underspending to start spending at what they perceive as crazy rates may lead them to discount financial planning altogether.

Why can small targeting mistakes lead to such bad financial advice and such large disruptions in living standard when the household retires or loses a head or spouse/partner? First, in the case of retirement, the targeting mistake is being made for roughly 30 years-from roughly age 65 to roughly age 95 . In the case of survivorship, the targeting mistake is being made for all of the survivor's potential remaining years. Second, spending more (less) than one should in retirement and survivor states means spending less (more) than one should prior to retirement in states when no one is deceased, which magnifies the living standard disruption (gap) beyond the original targeting mistake. Finally, the oversaving (undersaving) and overinsuring (underinsuring) associated with targeting for living standards that are 
too high (low) lead to higher (lower) taxes and insurance premium payments than would otherwise be paid. This induces further cuts (increases) in the preretirement living standard than would otherwise arise.

As I will show, targeted spending also underlies and undermines conventional financial planning's portfolio advice, potentially leading households to take on much more investment risk than is prudent. What households need to assess in considering risky investments is the variability of their future living standards. But standard planning assumes households will spend precisely their targeted amounts year after year regardless of the returns they receive unless and until they run out of money. This approach focuses attention on the probability of the plan (i.e., the target) working rather than on the spending consequences of it not. Because riskier investing can raise the probability of a plan's "success," households may be encouraged to take more risk than is appropriate. They may also get the idea that adjusting their portfolios rather than their lifestyle is the prudent response to low returns.

\section{Methodology}

Maximizing and preserving one's living standard is the hallmark of consumption smoothing - the economic approach to financial planning. Although conventional financial planning attempts to achieve consumption smoothing by having households set targets based on their current spending, this practice is essentially guaranteed to provide poor saving, insurance, and investment advice and to promote consumption disruption rather than consumption smoothing.

One might then wonder whether a better approach would be to use the conventional planning methodology but adjust the spending target to equalize living standards across one's working life, retirement, and widow(er)hood. Such target practice can, in theory, work. But doing so for any given set of assumptions could take hours, not seconds. The reason for the added complexity is that many, if not most, households are borrowing constrained, meaning that they or their financial planner would need to simultaneously set and adjust spending targets for each borrowing-constrained interval. ${ }^{4}$ When one adds to this picture return uncertainty, we are no longer talking hours but weeks because the household would need to solve not for one spending path but for all possible (and potentially borrowing-constrained) spending paths that would arise under each path of return realizations.

The only practical way to handle these problems mathematically is via dynamic programming, developed in the early 1950s by Richard Bellman. Specifically, one formulates a general plan for consumption smoothing in the last period (the maximum age of life), which I will call $T$. It then uses the period $T$ plan to formulate a plan for the next to last period (i.e., $T-1$ ). The $T-1$ plan is used to formulate

${ }^{4}$ Bernheim, Berstein, Gokhale, and Kotlikoff (2006) found that roughly three-fifths of Boston University participants in a study of saving and insurance adequacy were borrowing constrained. 
the $T-2$ plan and so forth, back to the current time period, which I will call 0 . This Time 0 plan is then used to determine how much to spend, save, and insure in the current year.

Although mathematicians, economists, and engineers are well versed in dynamic programming, the architects of traditional financial planning software are not. Or if they are, they are constrained by their superiors to keep things simple, which, in this context, means failing to elicit much of the information-such as the path of future labor earnings, prospective changes in housing, and plans for retirement account withdrawals—needed to generate an accurate dynamic program.

\section{Results}

A dynamic programming model, as described above, is used to generate sample consumption-smoothing results for a prototypical family. These results are then compared with those given by a conventional targeting approach. First, I will review some general features of the consumption-smoothing results.

The amount of recommended consumption expenditures needed to achieve a given living standard varies from year to year in response to changes in the household's composition. It also rises when the household moves from a situation of being liquidity constrained to one of being unconstrained (i.e., not needing or wanting to borrow). Finally, as mentioned, recommended household consumption will change over time if users intentionally specify that they want their living standard to change.

The simultaneity issue with respect to taxes mentioned earlier is just one of two such issues that needs to be considered. The second is the joint determination of life insurance holdings of potential decedents and survivors. Widows and widowers may need to hold life insurance to protect their children's living standard through adulthood and to cover bequests, funeral expenses, and debts (including mortgages) that exceed the survivor's net worth inclusive of the equity on her or his house.

But the more life insurance is purchased by the potential decedent, the less life insurance survivors will need to purchase, if one assumes they have such a need. Thus, survivors will pay less in life insurance premiums and have less need for insurance protection from their decedent spouse/partner. Hence, one cannot determine the potential decedent's life insurance holdings until one determines the survivor's holdings. But one cannot determine the survivor's holdings until one determines the decedent's holdings.

Dealing with the tax and life insurance simultaneity issues as well as the borrowing and nonnegative life insurance constraints all within a single dynamic program seems well beyond the computing power of a desktop personal computer, particularly given the speed required for a commercial product. 
The difficulty, time, and luck required to solve this simultaneous consumptionsmoothing, borrowing-constrained, saving, life insurance, and tax problem may explain why financial planning software producers have universally adopted the computationally trivial targeted-spending approach. As indicated, this approach puts the onus on the household heads and spouses/partners of doing literally millions of complex calculations in their heads in order to set their targets appropriately. Because none of us has computer chips implanted in our brains, let alone the right neuronware, the chance of making at least small targeting mistakes is extremely high.

\section{Consumption Smoothing vs. Mis-Targeting Spending}

Consider a middle-aged, middle-class, married household with two children. Both spouses are age 40 in 2005 . One child is age 10, and one is age 7 . The couple lives in California. The husband earns $\$ 75,000$ a year, and the wife, $\$ 50,000$. Neither spouse has a pension or a retirement account, but the couple does have $\$ 75,000$ in regular assets. The couple owns a $\$ 300,000$ home with a $\$ 125,00020$-year mortgage with monthly payments of $\$ 1,250$. Property taxes, homeowners' insurance, and maintenance total $\$ 6,000$ a year. The couple plans to spend $\$ 25,000$ in today's dollars on college tuition and other expenses for each child for four years. Each spouse will retire at age 65 and begin collecting Social Security benefits in that year. Past "covered" earnings (i.e., used to determine Social Security benefits) for the husband (wife) were $\$ 37,500(\$ 25,000)$ in 1987 when he (she) was 22 , and they grew by 4 percent each year through 2004. The couple expects inflation to run at 3 percent annually and to earn a 6 percent nominal rate of return on savings. The remaining inputs are the economies in shared living and the relative cost of children. Based on previous work, I assumed that two can live as cheaply as 1.6, that to provide the same living standard to a child as to an adult costs only 70 percent as much, and that taxes and Social Security provisions in the future are those suggested by current law.

Consumption Smoothing. Table 1 shows annual recommendations for selected years for the consumption-smoothing case. All values in these and other tables are in 2005 dollars. Note that the couple's living standard per equivalent adult, given in the last column, equals $\$ 31,337$. This amount remains constant through 2060, when each spouse reaches age 95, assuming they both live that long. The recommended total consumption expenditure, in contrast, initially equals $\$ 71,852$ but declines in 2014 and again in 2017 as the two children reach age 19 and are assumed to leave the household. In 2017 and thereafter, recommended total consumption expenditure equals $\$ 50,139$. For 2005 , the recommendation for consumption smoothing would be $\$ 484,947$ and $\$ 128,554$ in term life insurance holdings for the husband and wife, respectively. Over time, recommended holdings decline. 
Table 1. Consumption Smoothing Annual Recommendations (in constant 2005 dollars)

\begin{tabular}{lccccccc}
\hline Year & H's Age & W's Age & Consumption & Saving & $\begin{array}{c}\text { H's Life } \\
\text { Insurance }\end{array}$ & $\begin{array}{c}\text { W's Life } \\
\text { Insurance }\end{array}$ & $\begin{array}{c}\text { Living Standard } \\
\text { per Adult }\end{array}$ \\
\hline 2005 & 40 & 40 & $\$ 71,852$ & $\$ 1,440$ & $\$ 484,947$ & $\$ 128,554$ & $\$ 31,337$ \\
2006 & 41 & 41 & 71,852 & 1,678 & 479,364 & 131,024 & 31,337 \\
2007 & 42 & 42 & 71,852 & 1,906 & 467,677 & 132,826 & 31,337 \\
2008 & 43 & 43 & 71,852 & 2,117 & 452,332 & 135,409 & 31,337 \\
2009 & 44 & 44 & 71,852 & 2,309 & 435,512 & 139,488 & 31,337 \\
2010 & 45 & 45 & 71,852 & 2,458 & 425,461 & 144,822 & 31,337 \\
2011 & 46 & 46 & 71,852 & 2,597 & 415,998 & 151,089 & 31,337 \\
2012 & 47 & 47 & 71,852 & 2,701 & 407,888 & 158,198 & 31,337 \\
2013 & 48 & 48 & 71,852 & 2,767 & 401,155 & 166,140 & 31,337 \\
2014 & 49 & 49 & 61,455 & $-12,770$ & 388,883 & 169,766 & 31,337 \\
2015 & 50 & 50 & 61,455 & $-12,895$ & 377,052 & 173,952 & 31,337 \\
2016 & 51 & 51 & 61,455 & $-13,057$ & 365,666 & 178,683 & 31,337 \\
2017 & 52 & 52 & 50,139 & $-27,760$ & 333,541 & 165,914 & 31,337 \\
2018 & 53 & 53 & 50,139 & $-2,930$ & 301,025 & 152,962 & 31,337 \\
2019 & 54 & 54 & 50,139 & $-2,849$ & 268,095 & 139,801 & 31,337 \\
2020 & 55 & 55 & 50,139 & $-2,775$ & 234,700 & 126,405 & 31,337 \\
2021 & 56 & 56 & 50,139 & 22,250 & 207,122 & 112,783 & 31,337 \\
2022 & 57 & 57 & 50,139 & 22,525 & 179,143 & 98,908 & 31,337 \\
\hline
\end{tabular}

Note: $\mathrm{H}=$ husband; $\mathrm{W}=$ wife.

Table 2 details the couple's total spending, which includes consumption, special expenditures on college, life insurance premiums, and housing. Note that real housing expenditures (expenditures valued in 2005 dollars) decline over time as the assumed 3 percent rate of inflation reduces the purchasing power of nominal mortgage payments. Once the mortgage is fully paid off, housing expenses are $\$ 6,000$ a year. These expenses are property taxes, maintenance, and homeowners' insurance, all three of which remain fixed in real terms. Term life insurance premiums first rise and then fall as the household ages. This reflects the increase with age in premium per dollar of coverage as well as the decline over time in recommended life insurance holdings.

Table 3 displays selected years of the couple's regular asset balance sheet. It shows four things. First, households never exceed their debt limit, which in this case is zero. Second, all assets and income are spent (i.e., the household dies broke if the head and spouse/partner make it to their maximum ages of life). Third, a household's living standard per equivalent adult is smooth over any interval of years within which the household is not borrowing constrained. Fourth, if consumption, and thus the living standard, is increased in any year, the household will die in debt. This implies that the living standard is maximized. 
Table 2. Consumption Smoothing Total Spending (in constant 2005 dollars)

\begin{tabular}{|c|c|c|c|c|c|c|c|}
\hline Year & H's Age & W's Age & Consumption & $\begin{array}{c}\text { Special } \\
\text { Expenditures }\end{array}$ & $\begin{array}{c}\text { Housing } \\
\text { Expenditures }\end{array}$ & $\begin{array}{l}\text { Life Insurance } \\
\text { Premiums }\end{array}$ & $\begin{array}{c}\text { Total } \\
\text { Spending }\end{array}$ \\
\hline 2005 & 40 & 40 & $\$ 71,852$ & 0 & $\$ 20,563$ & $\$ 983$ & $\$ 93,398$ \\
\hline 2006 & 41 & 41 & 71,852 & 0 & 20,139 & 1,093 & 93,084 \\
\hline 2007 & 42 & 42 & 71,852 & 0 & 19,727 & 1,198 & 92,777 \\
\hline 2008 & 43 & 43 & 71,852 & 0 & 19,327 & 1,302 & 92,481 \\
\hline 2009 & 44 & 44 & 71,852 & 0 & 18,939 & 1,408 & 92,199 \\
\hline 2010 & 45 & 45 & 71,852 & 0 & 18,562 & 1,538 & 91,952 \\
\hline 2011 & 46 & 46 & 71,852 & 0 & 18,196 & 1,678 & 91,726 \\
\hline 2012 & 47 & 47 & 71,852 & 0 & 17,841 & 1,831 & 91,524 \\
\hline 2013 & 48 & 48 & 71,852 & 0 & 17,496 & 2,000 & 91,348 \\
\hline 2014 & 49 & 49 & 61,455 & 25,000 & 17,161 & 2,140 & 105,756 \\
\hline 2015 & 50 & 50 & 61,455 & 25,000 & 16,836 & 2,288 & 105,579 \\
\hline 2016 & 51 & 51 & 61,455 & 25,000 & 16,521 & 2,445 & 105,421 \\
\hline 2017 & 52 & 52 & 50,139 & 50,000 & 16,214 & 2,422 & 118,775 \\
\hline 2018 & 53 & 53 & 50,139 & 25,000 & 15,917 & 2,373 & 93,429 \\
\hline 2019 & 54 & 54 & 50,139 & 25,000 & 15,628 & 2,301 & 93,068 \\
\hline 2020 & 55 & 55 & 50,139 & 25,000 & 15,348 & 2,203 & 92,690 \\
\hline 2021 & 56 & 56 & 50,139 & 0 & 15,075 & 2,119 & 67,333 \\
\hline 2022 & 57 & 57 & 50,139 & 0 & 14,811 & 2,008 & 66,958 \\
\hline
\end{tabular}

Note: $\mathrm{H}=$ husband; $\mathrm{W}=$ wife.

Mis-Targeting Spending. Now suppose that in 2005, this household is spending not $\$ 71,852$ on consumption but 10 percent more (less), namely, $\$ 79,037$ $(\$ 64,667)$. Furthermore, suppose that this household uses its current consumption to set its retirement and survivor consumption spending levels but that in setting these targets, it appropriately adjusts for changes in the household's demographic over time and across survivor states. In this case, the household will specify a retirement consumption target that is 10 percent greater (smaller) than $\$ 50,139$, or $\$ 55,153$ (\$45,125). It will also specify survivor consumption spending targets that are 10 percent higher (lower), on a year-by-year basis, than those generated in this consumption-smoothing run.

How will these targeting mistakes affect the household's living standard, consumption expenditure, saving, life insurance holdings, assets, and taxes over its life cycle? The answers are provided in Tables 4 through 7. To start, the household's living standard is shown in Table 4. The fifth column, labeled CS for consumption smoothing, indicates that the household's living standard per equivalent adult is $\$ 31,337$ each year. This is the amount of consumption spending that a single adult would need to earn to enjoy the same living standard as she or he enjoys living in the household. 
Table 3. Consumption Smoothing Regular Asset Balance Sheet (in constant 2005 dollars)

\begin{tabular}{rccrrrrr}
\hline Year & H's Age & W's Age & Income & $\begin{array}{c}\text { Total } \\
\text { Spending }\end{array}$ & Taxes & Saving & $\begin{array}{r}\text { Regular } \\
\text { Assets }\end{array}$ \\
\hline 2044 & 79 & 79 & $\$ 51,191$ & $\$ 56,139$ & $\$ 3,783$ & $-\$ 8,732$ & $\$ 162,454$ \\
2045 & 80 & 80 & 50,937 & 56,139 & 3,686 & $-8,888$ & 153,566 \\
2046 & 81 & 81 & 50,678 & 56,139 & 3,584 & $-9,045$ & 144,521 \\
2047 & 82 & 82 & 50,415 & 56,139 & 3,479 & $-9,203$ & 135,317 \\
2048 & 83 & 83 & 50,147 & 56,139 & 3,369 & $-9,362$ & 125,955 \\
2049 & 84 & 84 & 49,874 & 56,139 & 3,257 & $-9,522$ & 116,433 \\
2050 & 85 & 85 & 49,597 & 56,139 & 3,140 & $-9,683$ & 106,750 \\
2051 & 86 & 86 & 49,314 & 56,139 & 3,020 & $-9,845$ & 96,905 \\
2052 & 87 & 87 & 49,028 & 56,139 & 2,896 & $-10,007$ & 86,898 \\
2053 & 88 & 88 & 48,736 & 56,139 & 2,768 & $-10,171$ & 76,727 \\
2054 & 89 & 89 & 48,440 & 56,139 & 2,637 & $-10,336$ & 66,390 \\
2055 & 90 & 90 & 48,139 & 56,158 & 2,502 & $-10,521$ & 55,869 \\
2056 & 91 & 91 & 47,833 & 56,253 & 2,363 & $-10,784$ & 45,085 \\
2057 & 92 & 92 & 47,518 & 56,338 & 2,219 & $-11,039$ & 34,046 \\
2058 & 93 & 93 & 47,197 & 56,392 & 2,070 & $-11,266$ & 22,780 \\
2059 & 94 & 94 & 46,869 & 56,368 & 1,917 & $-11,417$ & 11,363 \\
2060 & 95 & 95 & 46,536 & 56,139 & 1,760 & $-11,363$ & 0 \\
\hline
\end{tabular}

Note: $\mathrm{H}=$ husband; $\mathrm{W}=$ wife.

The fourth column presents the household's living standard path if it overtargets retirement and survivor spending by 10 percent and is thus directed to oversave and overinsure. The result is a $\$ 26,289$ living standard prior to retirement and a $\$ 34,439$ living standard after retirement. The ratio of the latter to the former amount is 1.31 , indicating that the targeting mistake causes a 31 percent disruption in living standard at retirement. This is a huge discrepancy given the maintained assumption that the household seeks to smooth its living standard.

In the case that the household undertargets retirement and survivor spending by 10 percent, it will spend more before retirement and less thereafter than in the consumption-smoothing case. But as Column 6 shows, the preretirement living standard for this household is not constant. Instead, it rises from $\$ 32,673$ to $\$ 39,109$ because of the binding of the household's liquidity constraint - the assumption is that the household cannot take on any debt beyond the original mortgage balance, which is a constraint that most households operate under. After retirement, the household's living standard drops to $\$ 28,159$. The ratio of $\$ 28,159$ to $\$ 39,109$ is 0.72 , indicating that the household suffers a 28.0 percent reduction in its living 
Table 4. Consumption and Saving Recommendations: Consumption

Smoothing vs. Mis-Targeting, Living Standard

(in constant 2005 dollars)

\begin{tabular}{lcccccccc}
\hline & & & \multicolumn{3}{c}{ Living Standard } & & $\begin{array}{c}\text { Percentage Difference in Living } \\
\text { Standard Relative to CS }\end{array}$ \\
\cline { 5 - 6 } Year & H's Age & W's Age & $+10 \%$ & CS & $-10 \%$ & & $+10 \%$ & $-10 \%$ \\
\hline 2005 & 40 & 40 & $\$ 26,289$ & $\$ 31,337$ & $\$ 32,673$ & & $-16.1 \%$ & $4.3 \%$ \\
2010 & 45 & 45 & 26,289 & 31,337 & 32,673 & & -16.1 & 4.3 \\
2015 & 50 & 50 & 26,289 & 31,337 & 32,673 & & -16.1 & 4.3 \\
2020 & 55 & 55 & 26,289 & 31,337 & 32,673 & & -16.1 & 4.3 \\
2025 & 60 & 60 & 26,289 & 31,337 & 39,109 & & -16.1 & 24.8 \\
2030 & 65 & 65 & 34,439 & 31,337 & 28,159 & & 9.9 & -10.1 \\
2035 & 70 & 70 & 34,439 & 31,337 & 28,159 & & 9.9 & -10.1 \\
2040 & 75 & 75 & 34,439 & 31,337 & 28,159 & & 9.9 & -10.1 \\
2045 & 80 & 80 & 34,439 & 31,337 & 28,159 & & 9.9 & -10.1 \\
2050 & 85 & 85 & 34,439 & 31,337 & 28,159 & & 9.9 & -10.1 \\
2055 & 90 & 90 & 34,439 & 31,337 & 28,159 & & 9.9 & -10.1 \\
2060 & 95 & 95 & 34,439 & 31,337 & 28,159 & & 9.9 & -10.1 \\
\hline
\end{tabular}

Notes: $\mathrm{H}=$ husband; $\mathrm{W}=$ wife. $\mathrm{CS}$ references consumption smoothing, +10 percent references a 10 percent positive targeting mistake; -10 percent references a 10 percent negative mistake.

standard with respect to its pre- and postretirement spending. Again, we see a major disruption at retirement in the household's living standard because of mis-targeting. 5

Because the overspending household was, by assumption, enjoying a 2005 living standard of $\$ 34,471$ (10 percent higher than $\$ 31,337$ ) when it visited its financial planner or used conventional financial planning software, it would have been advised to cut its current living standard by 23.7 percent $(1-26,289 / 34,471)$ to meet its target. The underspending household was enjoying a $\$ 28,203$ living standard (10 percent lower than $\$ 31,337$ ). It would have been told to raise its spending by 15.8 percent $(32,673 / 28,203-1)$. These are big adjustments. It is also ironic that the overspending household is being led to underspend and the underspending household is being led to overspend.

Clearly, adjusting upward is easier than adjusting downward. Hence, the underspending household is more likely than the overspending household to take the mistaken advice. Thus, the household that may be most concerned with maintaining its living standard in retirement will be led by standard financial planning to experience a 28.0 percent drop in its living standard when it retires-

$5 \mathrm{~A}$ small, but growing, body of research is examining living standard changes at retirement. Bernheim, Skinner, and Weinberg (2001), for example, provide evidence that living standards drop, on average, at retirement by 14 percent, with a median drop of 12 percent. 
precisely what it is trying so hard to avoid. Of course, households could well be making targeting mistakes from a situation of currently spending the correct amount: All they need to do is make mistakes in adding up their current expenditures or miscalculate the appropriate demographic adjustments. I refer here to the adjustment for the absence of children in retirement or the absence of a spouse in widow(er)hood. Adjusting for this change in the number and sizes of mouths to feed requires thinking through economies in shared living and the relative cost of children. These are not easy considerations even for very well educated households.

If \pm 10 percent mistakes occur with equal likelihood, the spread in preretirement living standards for two otherwise identical households could easily be 48.8 percentthe difference in the $\$ 26,289$ and $\$ 39,109$ preretirement living standards of households that set their spending targets 10 percent too high and 10 percent too low, respectively. The corresponding postretirement spread in living standards is 22.3 percent. For a source of age-specific consumption inequality, this seems like a good place to look.

Mistakes in Consumption, Saving, and Insurance Recommendations. Table 5 and Table 6 report saving and life insurance recommendations for the three cases. The proportionate consumption differences across the cases are the same as for the living standard differences just discussed. Hence, here I focus on saving and insurance recommendations. As one can quickly see, the differences are tremendous. In 2005, for example, the +10 percent saving recommendation is $\$ 11,955$ compared with $-\$ 810$ in the -10 percent case. At age 60 , the two saving recommendations are $\$ 38,818$ and $\$ 19,711$, respectively. At 75 , they are $-\$ 13,891$ and $-\$ 4,240$.

Life insurance recommendations in the \pm 10 percent cases are equally day and night. In 2005 , the +10 percent targeting mistake leads to a recommendation of $\$ 814,600$ in life insurance for the husband whereas the -10 percent targeting mistake leads to a recommendation of only $\$ 106,436$. Both of these values are far away from $\$ 484,947$ - the desired consumption-smoothing amount. For the wife, the +10 percent mistake leads to a $\$ 460,405$ term life insurance recommendation for 2005 . In contrast, the -10 percent mistake leads to a recommendation of zero life insurance. The recommended consumption-smoothing amount in this case is $\$ 128,554$. The dramatically higher level of life insurance in the +10 percent case entails dramatically higher life insurance premiums. For example, at age 50, the +10 , consumption-smoothing, and -10 households pay premiums of $\$ 4,017, \$ 2,288$, and $\$ 497$, respectively. Table 7 shows equally wild disparities in assets and tax payments across the three cases. At retirement, the household with the +10 percent targeting mistake holds $\$ 488,412$ in assets. This is 1.8 times the consumption-smoothing assets holdings of $\$ 270,715$ and 3.4 times the $\$ 144,405$ for -10 percent holdings. 
Table 5. Consumption and Saving Recommendations: Consumption Smoothing vs. Mis-Targeting, Saving (in constant 2005 dollars)

\begin{tabular}{|c|c|c|c|c|c|c|c|c|}
\hline \multirow[b]{2}{*}{ Year } & \multirow[b]{2}{*}{ H's Age } & \multirow[b]{2}{*}{ W's Age } & \multicolumn{3}{|c|}{ Recommended Consumption } & \multicolumn{3}{|c|}{ Recommended Saving } \\
\hline & & & $+10 \%$ & CS & $-10 \%$ & $+10 \%$ & CS & $-10 \%$ \\
\hline 2005 & 40 & 40 & $\$ 60,278$ & $\$ 71,852$ & $\$ 74,915$ & $\$ 11,955$ & $\$ 1,440$ & 810 \\
\hline 2010 & 45 & 45 & 60,278 & 71,852 & 74,915 & 13,146 & 2,458 & 520 \\
\hline 2015 & 50 & 50 & 51,555 & 61,455 & 64,074 & $-3,619$ & $-12,895$ & $-13,923$ \\
\hline 2020 & 55 & 55 & 42,062 & 50,139 & 52,276 & 4,798 & $-2,849$ & $-3,000$ \\
\hline 2025 & 60 & 60 & 42,062 & 50,139 & 62,575 & 38,818 & 31,423 & 19,711 \\
\hline 2030 & 65 & 65 & 55,102 & 50,139 & 45,054 & $-10,168$ & $-6,594$ & $-3,189$ \\
\hline 2035 & 70 & 70 & 55,102 & 50,139 & 45,054 & $-11,894$ & $-7,350$ & $-3,719$ \\
\hline 2040 & 75 & 75 & 55,102 & 50,139 & 45,264 & $-13,891$ & $-8,112$ & $-4,240$ \\
\hline 2045 & 80 & 80 & 55,102 & 50,139 & 45,054 & $-16,083$ & $-8,888$ & $-4,758$ \\
\hline 2050 & 85 & 85 & 55,102 & 50,139 & 45,054 & $-18,611$ & $-9,683$ & $-5,278$ \\
\hline 2055 & 90 & 90 & 55,102 & 50,139 & 45,054 & $-21,356$ & $-10,521$ & $-5,805$ \\
\hline 2060 & 95 & 95 & 55,102 & 50,139 & 45,054 & $-16,262$ & $-11,363$ & $-6,343$ \\
\hline
\end{tabular}

Notes: $\mathrm{H}=$ husband; $\mathrm{W}=$ wife. $\mathrm{CS}$ references consumption smoothing, +10 percent references a 10 percent positive targeting mistake; -10 percent references a 10 percent negative mistake.

\section{Table 6. Life Insurance Recommendations: Consumption Smoothing vs. Mis-Targeting, Life Insurance (in constant 2005 dollars)}

\begin{tabular}{|c|c|c|c|c|c|c|c|c|}
\hline \multirow[b]{2}{*}{ Year } & \multirow[b]{2}{*}{ H's Age } & \multirow[b]{2}{*}{ W's Age } & \multicolumn{3}{|c|}{ Husband's Life Insurance } & \multicolumn{3}{|c|}{ Wife's Life Insurance } \\
\hline & & & $+10 \%$ & CS & $-10 \%$ & $+10 \%$ & CS & $-10 \%$ \\
\hline 2005 & 40 & 40 & $\$ 814,600$ & $\$ 484,947$ & $\$ 106,436$ & $\$ 460,405$ & $\$ 128,554$ & $\$ 0$ \\
\hline 2010 & 45 & 45 & 690,432 & 425,461 & 112,015 & 414,861 & 144,822 & 0 \\
\hline 2015 & 50 & 50 & 582,515 & 377,052 & 119,611 & 384,669 & 173,952 & 0 \\
\hline 2020 & 55 & 55 & 399,515 & 234,700 & 9,982 & 296,195 & 126,405 & 0 \\
\hline 2025 & 60 & 60 & 220,819 & 92,366 & 0 & 186,569 & 55,269 & 0 \\
\hline 2030 & 65 & 65 & 63,139 & 0 & 0 & 85,191 & 0 & 0 \\
\hline 2035 & 70 & 70 & 85,191 & 0 & 0 & 63,139 & 0 & 0 \\
\hline 2040 & 75 & 75 & 45,822 & 0 & 0 & 45,822 & 0 & 0 \\
\hline 2045 & 80 & 80 & 32,261 & 0 & 0 & 32,261 & 0 & 0 \\
\hline 2050 & 85 & 85 & 22,807 & 0 & 0 & 22,807 & 0 & 0 \\
\hline 2055 & 90 & 90 & 17,603 & 0 & 0 & 17,603 & 0 & 0 \\
\hline 2060 & 95 & 95 & 0 & 0 & 0 & 0 & 0 & 0 \\
\hline
\end{tabular}

Notes: $\mathrm{H}=$ husband; $\mathrm{W}=$ wife. $\mathrm{CS}$ references consumption smoothing, +10 percent references a 10 percent positive targeting mistake; -10 percent references a 10 percent negative mistake. 
Table 7. Assets and Taxes: Consumption Smoothing vs. Mis-Targeting (in constant 2005 dollars)

\begin{tabular}{|c|c|c|c|c|c|c|c|c|}
\hline \multirow[b]{2}{*}{ Year } & \multirow[b]{2}{*}{ H's Age } & \multirow[b]{2}{*}{ W's Age } & \multicolumn{3}{|c|}{ Assets } & \multicolumn{3}{|c|}{ Taxes } \\
\hline & & & $+10 \%$ & CS & $-10 \%$ & $+10 \%$ & CS & $-10 \%$ \\
\hline 2005 & 40 & 40 & $\$ 89,205$ & $\$ 78,690$ & $\$ 76,440$ & $\$ 32,411$ & $\$ 32,411$ & $\$ 32,411$ \\
\hline 2010 & 45 & 45 & 152,732 & 89,159 & 76,548 & 34,100 & 33,114 & 32,916 \\
\hline 2015 & 50 & 50 & 186,022 & 71,558 & 51,470 & 36,735 & 34,776 & 34,421 \\
\hline 2020 & 55 & 55 & 176,192 & 22,188 & 0 & 38,540 & 35,812 & 35,403 \\
\hline 2025 & 60 & 60 & 335,873 & 144,250 & 66,660 & 42,868 & 39,309 & 38,082 \\
\hline 2030 & 65 & 65 & 488,412 & 270,715 & 144,405 & 7,078 & 4,737 & 2,640 \\
\hline 2035 & 70 & 70 & 423,520 & 235,480 & 126,865 & 6,542 & 4,488 & 2,674 \\
\hline 2040 & 75 & 75 & 367,143 & 196,448 & 106,706 & 5,914 & 4,136 & 2,623 \\
\hline 2045 & 80 & 80 & 291,190 & 153,566 & 83,951 & 5,188 & 3,686 & 2,493 \\
\hline 2050 & 85 & 85 & 203,311 & 106,750 & 58,602 & 4,442 & 3,140 & 2,290 \\
\hline 2055 & 90 & 90 & 101,868 & 55,869 & 30,633 & 3,421 & 2,502 & 2,018 \\
\hline 2060 & 95 & 95 & 0 & 0 & 0 & 1,839 & 1,760 & 1,679 \\
\hline
\end{tabular}

Notes: $\mathrm{H}=$ husband; $\mathrm{W}=$ wife. $\mathrm{CS}$ references consumption smoothing, +10 percent references a 10 percent positive targeting mistake; -10 percent references a 10 percent negative mistake.

Because higher asset levels imply higher taxable asset income, taxes are highest for the +10 percent household and lowest for the -10 percent household. At age 65 , the high, middle, and low tax payments are $\$ 7,078, \$ 4,737$, and $\$ 2,640$, respectively. As indicated, these discrepancies in tax and insurance premium payments exacerbate the consumption disruption at retirement and at widow(er)hood that arises from mis-targeting future retirement and survivor spending.

Sensitivity of Consumption Disruption to Assumptions. Consumption disruption caused by mis-targeted spending is likely to be greater for older households because they have fewer years over which to adjust their preretirement spending to avoid the difficulty of spending too much or too little in retirement. Households that are liquidity constrained are likely to set their spending targets too low because their current spending is limited by the availability of their liquid funds. If they retain these targets after their liquidity constraint is relaxed, they will, of course, be induced to undersave and underinsure for the future. Households earning low rates of return will experience larger consumption disruptions because larger adjustments to current spending will be needed to fund a given targeting mistake. Finally, households with higher maximum ages of life will face larger disruptions because one needs to fund targeting mistakes for more potential retirement and survivorship years. 


\section{Portfolio "Advice"}

Conventional planning's use of spending targets also distorts its portfolio advice. Given the household's retirement spending target and portfolio mix, conventional planning runs Monte Carlo simulations that determine the household's probability of running out of money. These simulations typically assume that households make no adjustment whatsoever to their spending as a result of doing well or poorly on their investments. But consumption smoothing dictates such adjustments and precludes letting oneself get into the position of completely running out of money (i.e., ending up with literally zero consumption). It is precisely the range of these living standard adjustments that households need to understand to assess their portfolio's risk. Conventional portfolio analysis not only answers the wrong question; it may also improperly solicit risk taking because riskier investments may entail a lower chance of financial exhaustion thanks to their higher mean.

To see this point in its starkest form, take, as an example, a single 60-year-old man named Joe whose only economic resource is $\$ 500,000$ in assets. Assume Joe's maximum age of life is 95 and that he faces no taxes of any kind. Suppose Joe sets his spending target at $\$ 30,000$ a year. Also assume that Joe holds only a properly laddered portfolio of TIPS-Treasury Inflation-Protected Securities (i.e., inflationindexed bonds)-yielding 2 percent after inflation. These bonds are essentially riskless and permit Joe to consume, at most and at least, $\$ 20,413$ in today's dollars each year. What is Joe's probability of meeting his target- $\$ 30,000$ - each year? It is zero, of course, because spending $\$ 30,000$ will drive Joe broke unless he fortuitously dies beforehand.

Now, suppose that Joe invests in an S\&P 500 Index fund of large-cap stocks rather than in TIPS. Since 1926, the real return on large caps has averaged 9.16 percent on an annual basis. 6 If Joe is able to earn this return for sure, he will be able to spend $\$ 48,264$ a year. But large-cap stocks are risky, with a standard deviation of, say, 20 percent. Nonetheless, there is still almost a 60 percent chance that Joe will be able to spend $\$ 30,000$ a year. So, if Joe uses a standard Monte Carlo portfolio analyzer, he will find that investing in TIPS fails completely to meet his goal but that investing in stocks gives him a chance to meet his goal. Joe may view this as a good bet given the way this investment outcome information is being presented.

Suppose then that Joe invests all his assets in large caps and then experiences in the next three years the large-cap returns (including dividends) recorded in 2000, 2001, and 2002-specifically, -9.1 percent,-11.9 percent, and -22.1 percent. Will Joe continue to spend $\$ 30,000$ a year and remain in the stock market given that his wealth after three years has dropped from $\$ 500,000$ to $\$ 238,013$ ? Probably not. At that point, Joe may well switch to holding just TIPS and be forced to live from that point on at about a third of his desired yearly spending rate. In not showing

6This is the average of annual real returns rather than the geometric mean, based on data in Ibbotson's 2005 yearbook. 
such large and sudden adverse potential living standard adjustments, standard financial planning seems to be encouraging more risk taking than is appropriate. This concern is heightened by the prospect of many households being induced as part of the same planning exercise to set their future spending targets at higher levels than are appropriate.

\section{Conclusion}

Economics teaches us that we save, insure, and diversify in order to mitigate fluctuations in our living standards over time and across contingencies. Although the goals of conventional financial planning appear consonant with such consumption smoothing, the actual practice of conventional planning is anything but. Conventional planning's disconnect with economics begins with its first step, namely, forcing households to set their own retirement and survivor spending targets. Setting spending targets that are consistent with consumption smoothing is incredibly difficult, which makes large targeting mistakes almost inevitable. But as shown here, even small targeting mistakes, on the order of 10 percent, can lead to enormous mistakes in recommended saving and insurance levels and to major disruptions (on the order of 30 percent) in living standards in retirement or widow(er)hood.

There are three reasons why small targeting mistakes lead to such bad saving and insurance advice and such large consumption disruptions. First, the wrong target spending level is being assigned to each and every year of retirement and widow(er)hood. Second, planning to spend too much (little) in retirement and widow(er)hood requires spending too little (much) before those states are reached, which magnifies the living standard differences. Third, both saving and insuring the wrong amounts affect tax and insurance premium payments, further exacerbating consumption disruption.

Conventional planning's use of spending targets also distorts its portfolio advice. Given a household's spending target and its portfolio mix, standard practice entails running Monte Carlo simulations to determine the household's probability of running out of money. These simulations assume that households make no adjustment whatsoever to their spending regardless of how well or how poorly they do on their investments. But consumption smoothing dictates such adjustments and, indeed, precludes running out of money (i.e., ending up with literally zero consumption). It is precisely the range of these living standard adjustments that households need to understand to assess their portfolio risk. Conventional portfolio analysis not only answers the wrong question; it may also improperly encourage risk taking because it focuses on the fact that riskier investments may entail a lower chance of financial exhaustion (thanks to their higher mean) rather than on the risk or worst-case scenario. 
Purveyors of financial advice have an ethical, if not a fiduciary, responsibility to ensure that the advice they provide is sound. Financially protecting one's family is a very serious business that requires careful analysis and a real commitment of time. It also requires posing and correctly answering the right question-namely, How can I preserve my family's living standard through time and in unforeseen, but not unforeseeable, circumstances?

Perhaps a final medical analogy will help explain the situation. None of us would go to a doctor for a 60-second checkup, nor would we elect surgery performed by a meat cleaver over surgery with a scalpel. And any doctor who provided such services would quickly be drummed out of the medical profession. Financial planning, like brain surgery, is an extraordinarily precise business. Small mistakes and the wrong tools can just as easily undermine as improve financial health.

\section{REFERENCES}

Auerbach, Alan J., and Laurence J. Kotlikoff. 1987. "Life Insurance of the Elderly: Adequacy and Determinants." In Work, Health, and Income among the Elderly. Washington, DC: The Brookings Institution.

- 1991. "The Adequacy of Life Insurance Purchases." Journal of Financial Intermediation, vol. 1, no. 3 (June):215-241.

Bernheim, B. Douglas, Jonathan Skinner, and Steven Weinberg. 2001. "What Accounts for the Variation in Retirement Wealth among U.S. Households?" American Economic Review, vol. 91, no. 4 (September):832-857.

Bernheim, B. Douglas, Solange Berstein, Jagadeesh Gokhale, and Laurence J. Kotlikoff. 2006. "Saving and Life Insurance Holdings at Boston University-A Unique Case Study." National Institute Economic Review, vol. 198, no. 1 (October):75-96.

Bernheim, B. Douglas, Katherine Carman, Jagadeesh Gokhale, and Laurence J. Kotlikoff. 2003. “Are Life Insurance Holdings Related to Financial Vulnerabilities?” Economic Inquiry, vol. 41 no. 4 (October):531-554.

Bernheim, B. Douglas, Lorenzo Forni, Jagadeesh Gokhale, and Laurence J. Kotlikoff. 2000. "How Much Should Americans Be Saving for Retirement?" American Economic Review, vol. 90, no. 2 (May):288-292.

- 2003. "Mismatch between Life Insurance Holdings and Financial Vulnerabilities—Evidence from the Health and Retirement Survey." American Economic Review, vol. 93, no. 1 (March):354-365.

Kotlikoff, Laurence J., Avia Spivak, and Lawrence Summers. 1982. "The Adequacy of Savings." American Economic Review, vol. 72, no. 5 (December):1056-1069. 


\section{Session 3 Comments by John Turner}

John Turner

Senior Policy Adviser, Public Policy Institute

AARP

Washington, $D C$

With the declining role of Social Security in providing retirement income-caused in part by the increase in its normal retirement age - and the declining role of employer-provided defined-benefit plans, individuals and families must rely more on their own investments to provide income in retirement. This shift of responsibility toward individuals has encouraged the development of retirement planning software to help people make financial decisions. A survey of federal government employees, however, showed that less than half of respondents had calculated how much they needed to save for a comfortable retirement (Barr 2006).

In recognition of the increasing importance of financial advice provided by computer programs, the Pension Protection Act of 2006 regulates the investment advice provided to pension participants by their employers using computer programs. Among other things, this legislation requires that computer models apply generally accepted investment theories. This legislative requirement does not apply to computer models that are not provided to pension participants by their employers.

Kotlikoff examines whether conventional financial planning software provides useful information to workers or whether the software, even when used properly, provides misleading results. Retirement planning has at least four major aspects: choosing the retirement age, accumulating adequate financial resources for retirement, choosing appropriate investments, and choosing appropriate payout mechanisms.

\section{Previous Studies}

Kotlikoff's paper is part of a small literature evaluating financial advice that people receive from financial planning software. In 2003, the Society of Actuaries participated in a major study of 19 computer programs for retirement planning: 6 programs were available for consumer use but did not include Kotlikoff's program, 11 programs were available for professional use, and 2 programs were proprietary programs developed by large financial planning firms (LIMRA and Society of Actuaries 2003). One of the primary conclusions of that study was that a tremendous variability exists among programs regarding when the participant runs out of assets, if at all. Because of this finding, the study recommends that people run multiple programs, use multiple scenarios within programs, and rerun the programs every few years to reassess their financial position.

Author's Note: This paper does not necessarily represent the views of AARP. 
Bodie (2003) examined the financial advice provided by retirement planning software available at four major websites (also not including Kotlikoff's program). $\mathrm{He}$ found a pro-equity bias in the advice. He also found that the programs advised reducing equity holdings as the participant's time horizon shortened. Bodie noted that a focus on the probability of a financial shortfall is not the best measure of success because it ignores the severity of the shortfall.

\section{Kotlikoff's Contribution}

Kotlikoff's retirement planning software differs from other programs in that instead of requiring users to provide the replacement income they desire, the software provides as an output their desired level of consumption in retirement. Kotlikoff focuses on the task workers face of accumulating adequate financial resources for retirement, given a particular retirement age.

Kotlikoff has used this software in the past to develop surprising findings concerning financial advice. In an earlier paper (Gokhale, Kotlikoff, and Neumann 2001), he and his co-authors found that for many workers, participating in a 401(k) plan actually raises their lifetime tax payments and thus they would be better off investing outside the plan. The increase in tax liability may occur for three reasons. First, marginal tax rates may be higher in the future. Second, reducing current marginal tax rates by participating in a $401(\mathrm{k})$ plan reduces the value of mortgage deductions. Third, raising future taxable income by postponing it to retirement may move the person into an income bracket where Social Security benefits are taxed.

Kotlikoff focuses on the computation challenge for financial planning software posed by consumption smoothing. He compares his software with other computer programs and finds his to be superior. His main criticism of traditional financial planning software is that it is based on the participant choosing a spending target in retirement. Kotlikoff argues that this approach has two problems. First, accurately determining a spending target is difficult; current consumption levels may be a poor guide for a future spending target if those levels are too high to be sustainable or if they are lower than the sustainable level. Second, even small errors in spending targets can lead to large errors in saving levels because both the savings accumulation period and the de-cumulation period are lengthy.

In evaluating the advice provided by four well-known, reputable financial services companies, Kotlikoff finds that they all advised dramatic oversaving compared with what would be needed to maintain a constant level of consumption. This finding makes an important contribution to our understanding of financial advice that U.S. workers receive. Kotlikoff's paper challenges not only standard financial planning software but also the replacement rates used in standard financial planning. 


\section{Kotlikoff's Critique}

Kotlikoff's critique of the difficulty of picking a target level of consumption in retirement also is a critique of the life-cycle model. He argues that "setting spending targets that are consistent with consumption smoothing is incredibly difficult to do, making large targeting mistakes almost inevitable." He argues further that empirical studies of savings show that vast numbers of households either save too little or too much.

Kotlikoff measures errors by the disruption of consumption in retirement, with that consumption easily being too large or too small by 30 percent. It would be interesting to take the analysis of errors a step further to assess the effect on lifetime utility of these errors. After all, if workers oversave for retirement, the loss of utility earlier in life would be offset to some extent by the higher utility provided by the higher consumption in retirement or by the ability to provide bequests. The effect on lifetime utility would presumably be a better measure of the effect of the error than the measure of disruption of consumption.

Because the date of death is unknown, having consumption smoothing into older ages may not be optimal. Some workers may decide that it is unlikely, although possible, that they will live to 95 . Thus, they may not want to plan for consumption smoothing into their 90 s but, rather, accept a lower standard of living at those ages, given the small probability they will live to be that old.

Although the topic of errors that workers make in financial planning is quite broad, my following comments focus on issues related to behavioral economics and the use of replacement rates as well as issues related to the interaction of life expectancy and financial planning.

\section{Replacement Rates}

Kotlikoff does not use the replacement rate concept with his planning software, but that concept is widely used in U.S. policy circles as a measure of the adequacy of retirement income. Replacement rates are often defined as income in the first year of retirement divided by the annual amount of an individual's income just prior to retirement. For decades, the replacement rate has been the primary measure used in the retirement planning process (see VanDerhei 2006). To determine the income needed in retirement, differences between working years and retirement years for savings, work-related expenses, and family composition are taken into account. Replacement rates also need to take into account the adequacy of postretirement health insurance.

Kotlikoff argues that it is exceedingly difficult for an individual to determine what his or her target consumption level in retirement should be. Behavioral economics teaches that when people face a decision that is conceptually difficult, they tend to rely on rules of thumb to simplify the decision-making problem. In this context, a replacement rate may be a useful concept as a simple rule of thumb. 
The concept of the replacement rate, however, has several shortcomings (see VanDerhei 2006). For example, if a person's retirement income is received entirely through a price-indexed annuity, then the replacement rate at retirement will continue throughout the retirement period. But if part of the income is received as a nominal annuity, as is typically the case through employer-provided pensions, then the person's income and replacement rate will fall over the retirement period.

Although, as I have said, Kotlikoff does not use the replacement rate concept in his software and criticizes the use of replacement rates in other retirement planning software, a replacement rate can be calculated from the figures he provides in his paper. Suppose we take as an example a married couple who are both 40 years old, who have children ages 7 and 10, and who have total family income before taxes of $\$ 125,000$. Kotlikoff would find that the optimal total consumption in retirement, under the assumption that both husband and wife live to age 95 , is $\$ 50,139$ in constant dollars. This amount produces a replacement rate relative to before-tax income at age 40 of 40 percent.

This low replacement rate may be an artifact, in part, of the assumption that both husband and wife live to age 95 . If the husband and wife were willing to risk a lower standard of living in very old age because of the low probability of living to that age, the feasible replacement rate would be higher. The low replacement rate for consumption smoothing is also a result of the assumptions that the mortgage is paid off, the children are out of college, and the couple no longer needs to save for retirement. If the replacement rate is measured shortly before retirement for families whose children are out of college but who still have a mortgage, a replacement rate of 40 percent is probably too low.

VanDerhei's (2006) findings concerning replacement rates include two important points. First, he found that, given differences in asset allocation of postretirement investments and the degree of annuitization of retirement wealth, as well as the complexity of retirement risks that need to be dealt with-longevity, old-age infirmity, and asset preservation - a single rule-of-thumb replacement rate target does not work for most U.S. workers. Second, VanDerhei's results indicate that much higher replacement rate targets are needed than generally are suggested, with replacement rates for some categories of workers being 100 percent or higher.

Replacement rates have been calculated a number of times by a joint project with Aon Consulting and Georgia State University. In the sixth and most recent iteration of this project, they calculated that target replacement rates should be in the 75-86 percent range (Georgia State University 2004).

If one accepts that replacement rates play a useful role as a rule of thumb, the question then arises as to what the replacement rate should be. As just indicated, wide differences of opinion exist as to what the target replacement rate should be. One aspect of this issue is whether consuming less than could have been consumed while working is viewed as equally a serious a problem as running out of money if 
one lives longer than expected. Financial planners generally have interpreted being conservative as ensuring that people do not run out of money at the end of a long life. With this in mind, the Society of Actuaries has recommended a high target replacement rate of 90 percent (LIMRA and Society of Actuaries 2003).

The subject of replacement rates is central to much financial planning, and it merits further consideration, especially given the wide variation in rates that are deemed to be appropriate by different experts.

\section{Life Expectancy Assumptions as a Source of Errors}

Many issues affect the accuracy of financial planning and financial planning software. An issue not addressed by Kotlikoff is the effect of errors concerning life expectancy. These errors can occur because either the software does not accurately represent the individual's life expectancy or the individual does not have an accurate expectation of his or her own life expectancy.

With improvements in life expectancy at older ages, ignorance as to changes in life expectancy may lead workers to systematically underestimate their own life expectancy. For those parents of Baby Boomers who reached age 65 in 1990, the life expectancy was 80.7 years for males and 84.0 years for females, but for Baby Boomers reaching age 65 in 2015, 25 years later, the projected life expectancy for males and females is 82.7 years and 85.2 years, respectively - an increase of 2.0 years for males and 1.2 years for females (see Social Security Trustees 2006). People who base their life expectancy on the experience of their parents and older relatives will underestimate their life expectancy.

With people being retired for roughly 20 years, an error of 2 years in life expectancy would amount to slightly less than a 10 percent error in the amount of money a person would need to save for retirement. The problem, however, is that individual heterogeneity in life expectancy is huge.

\section{Demographic Literacy}

A cause of undersaving for retirement may be that some workers underestimate their life expectancy. They may do so because they are unaware of how quickly life expectancy is improving at older ages and base their own life expectancy on that of their older relatives. The life-cycle theory as a tool for financial planning is based on the assumption that workers have an accurate assessment of their life expectancy. Workers could behave rationally otherwise but undersave if they underestimate their life expectancy. Thus, demographic literacy as well as financial literacy may be a source of problems in individuals' planning for retirement.

The Society of Actuaries conducted a study of demographic knowledge among individuals 45-80 years old (Society of Actuaries 2006). This study found that roughly 40 percent of preretirees underestimated life expectancy by five or more 
years and that 55 percent estimated the average life expectancy for their age and gender to be 80 or younger, which would be roughly three to five years too young. The findings indicate that a substantial portion of the population is underestimating life expectancy. An earlier study (Society of Actuaries 2004) found similar results.

A U.K. study found that, on average, people underestimated their life expectancy by 4.6 years for males and 6.0 years for females (O'Brien, Fenn, and Diacon 2005). Males who were 30-39 years old-ages when they may be considering employment as providing pension coverage- underestimated their life expectancy by 6.3 years; females in that age range underestimated their life expectancy by 6.5 years. These findings suggest that a substantial portion of the population may be considerably underestimating their life expectancy.

The topic of accuracy of life expectancy, however, is not settled. Another study found that a sample of males with an average age of 50 overestimated their life expectancy by three years, on average, and a similar sample of females overestimated theirs, on average, by about six months (Puri and Robinson 2005). A possible explanation for this finding is that it is based on mortality tables for people of a cross-section of ages rather than on cohort tables that project mortality rates into the future. Yet another study using the Health and Retirement Survey indicates that persons in or near retirement have, on average, fairly accurate expectations of life expectancy (Gong and Webb 2006).

\section{Heterogeneity in Life Expectancy}

Some financial planning software assumes that the worker has the average life expectancy for his or her birth cohort. This assumption solves the problem of people tending to underestimate their life expectancy. But it introduces a different problem in that it does not recognize the heterogeneity in the population concerning individual life expectancy. A person who expects to live substantially longer than the typical person will be advised to save too little, and a person who expects to live shorter than the typical person will be advised to save too much.

Financial planning software that does not take into account the heterogeneity in life expectancy will advise, relative to the advice given generally, single black males to save too much and single white and Asian females to save too little. People with family histories of early death will be advised to save too much, and people with family histories of longevity will be advised to save too little. Given that the U.S. population is becoming increasingly heterogeneous, both demographically and with a rise in the percentage of adults who are not married, these issues are increasing in importance. As well as there being heterogeneity in life expectancy between demographic groups, there are differences in life expectancy between smokers and nonsmokers and between the morbidly obese and people of healthy weight. 
The effects of heterogeneity on life expectancy may be limited in this context, however, because the relevant group is users of financial software, which is arguably a much less heterogeneous group than the population as a whole.

\section{Rules of Thumb}

A low-tech alternative to financial planning using dynamic programming is to use rules of thumb. An enhanced set of rules of thumb could provide useful, albeit imprecise, guidance for people planning for retirement. In that vein, I tentatively propose four.

Rule 1: You can expect to live $x$ (two or three) years longer than your parent of the same gender.

Rule 2: You can consume $x$ (5 or 6) percent of your assets every year in retirement as a conservative rule for not running out of money.

Rule 3: If you do not have a defined-benefit pension but only a 401(k) plan, your pension and retirement savings need to be $x$ (seven or eight) times your annual income if you plan on retiring at age 62.

Rule 4: You should have a target replacement rate of your income shortly before retirement of $x$ percent. The question raised by Kotlikoff's research is what that percentage should be.

\section{Conclusions}

Kotlikoff provides an important service by challenging standard approaches to financial planning and financial planning software. An implication of his paper is that the replacement rates used in standard financial planning software and in standard financial planning are considerably too high. This finding warrants further investigation because it has important implications for a number of aspects of retirement income policy.

Kotlikoff does not address a number of issues relating to life expectancy but, rather, takes a conservative approach by assuming a fixed age of death that is a number of years higher than life expectancy.

A low-tech alternative to financial planning using dynamic programming is an expanded set of rules of thumb. For example, people can expect to live two or three years longer than their parent of the same gender. 


\section{REFERENCES}

Barr, Stephen. 2006. "Survey Shows Half Have Not Calculated Retirement Needs." Washington Post (15 August):D04.

Bodie, Zvi. 2003. “An Analysis of Investment Advice to Retirement Plan Participants.” In The Pension Challenge: Risk Transfers and Retirement Income Security. Edited by Olivia S. Mitchell and Kent Smetters. Oxford, U.K.: Oxford University Press.

Georgia State University. 2004. "GSU \& Aon Release Updated RETIRE Project Report." RMI Report, vol. 13, no. 1 (Spring/Summer):8.

Gokhale, Jagadeesh, Laurence J. Kotlikoff, and Todd Neumann. 2001. “Does Participating in a 401(k) Raise Your Lifetime Taxes?” NBER Working Paper W8341 (June).

Gong, Guan, and Anthony Webb. 2006. "Mortality Heterogeneity and the Distributional Consequences of Mandatory Annuitization.” Center for Retirement Research at Boston College, CRR WP 2006-11 (May).

LIMRA International, Inc., and the Society of Actuaries. 2003. "Retirement Planning Software."

O'Brien, Chris, Paul Fenn, and Stephen Diacon. 2005. "How Long Do People Expect to Live? Results and Implications.” Research report, Centre for Risk and Insurance Studies, Nottingham University Business School (June):CRIS 2005-1.

Puri, Manju, and David Robinson. 2005. “Optimism and Economic Choice.” NBER Working Paper 11361 (May).

Social Security Trustees. 2006. "The Annual Report of the Board of Trustees of the Federal OldAge and Survivors Insurance and Federal Disability Insurance Trust Funds" (1 May): www.socialsecurity.gov/OACT/TR/TR06/.

Society of Actuaries. 2004. "2003 Risks and Process of Retirement Survey: Report of Findings" (January).

2006. "Longevity: The Fundamental Driver of Retirement Risks" (May).

VanDerhei, Jack. 2006. "Measuring Retirement Income Adequacy: Calculating Realistic Income Replacement Rates.” EBRI Issue Brief, no. 297 (September):1-36. 


\section{Session 3 Comments by George Chacko}

\section{George Chacko}

\section{Managing Partner, 6S Capital GmbH, Zug, Switzerland Managing Director, Trinsum Group, New York City Associate Professor, Santa Clara University, Santa Clara, California}

Kotlikoffs paper is an attempt to take a concept (dynamic programming) that has been in the academic world for more than 30 years and put it into practice for retirement planning. Dynamic programming attempts to solve a complex, multitime-period investment problem by starting at the end of the investment horizon and working backward in a sequence of single-time-period problems. In this context, the complex problem is saving enough for retirement, and this is one of the first software packages I have seen that does a good job of solving that investment problem-breaking it into small, solvable steps. Perhaps it should come as no surprise that a software package that takes into account the possibility that an individual might make changes in future consumption and investment decisions will generate more accurate results than other programs.

I do, however, have one concern, but it is not a criticism of the software per se. It is really a criticism of the state of the industry. When thinking about consumption smoothing, the objective function is very important. Suppose that instead of the usual power utility or mean-variance utility, we introduce a relative utility function. For example, suppose an individual would like to have a standard of living (inflation indexed) at the age of 65 that is actually higher than what he or she had at the age of 25-a habit-formation utility function. Most people think that is a reasonable expectation. But for a preference function like that, the consumption pattern is not flat. It is thus very different from the typical result from optimization programs that prescribe expected flat consumption paths. So, having consumption smoothing and also habit formation over time generates a different consumption-saving decision today from the one that would result without rising consumption. Such seemingly small changes can have a huge impact on the consumption-saving decision today.

Another set of assumptions that needs to be put in the software, and that, by definition, needs to be put into almost any software, is what are the expected returns that can be generated and how can we best protect against interest rate movements. For example, suppose you do everything perfectly (i.e., you make decisions to consumption smooth correctly according to your preferences), but when you reach age 65 , which is your retirement goal, lo and behold, interest rates are at historical lows, as they have been for the past few years. Thus, annuity prices are high. So, even though you saved up and accumulated exactly the right amount of wealth that 
20 or 30 years ago you thought you wanted to have, interest rates have moved, and thus annuity prices have moved. So, now you find that the retirement income stream that you thought you would have is a lot smaller.

There are actually two very important aspects to life-cycle planning: One is the consumption-saving decision, and the other is the investing decision. For the average person on the street, investing is difficult. Most people do not know how to do it, and if you asked them what their perfect investment product would be, they would (if they think about the question) say one that delivers $x$ dollars of income (inflation indexed) for life as soon as they retire. But how do they get to that amount? This is the problem that is solved by virtually every defined-benefit pension fund in the world because that is what they have to deliver. Pension funds are solving an asset/liability management problem. They have a liability income stream that has to be matched with their investments today.

That same asset/liability matching is what is needed for the individual because the individual is trying to target a lifetime retirement income stream that is inflation indexed. So, the individual actually needs to do some very sophisticated asset/ liability management to get that income stream. That is, the individual has to solve the same problem that pension funds do. The chances of an individual being able to do that, however, are nearly zero.

Therefore, after reading Kotlikoff s paper, I found myself still wanting to know how to solve this second piece of the puzzle - the whole investing part. Just targeting the retirement income stream is not enough. There has to be a piece attached to the software that manages the investing process for the individual.

Again, I do not intend this as a criticism of the paper or of the software. It is more a criticism of the industry. That is, as an industry, we seem to be saying that we want to be more accurate in terms of the consumption-saving decision. But then, we just leave people on their own for the investing, which does not really help much. So, we have to get much better on the investing side and then link that to the consumption-saving side and have this whole process automated. 


\title{
Session 4: Innovative Products Panel
}

\section{Perspective of the Retirement Income Industry Association}

\author{
François Gadenne, CFA \\ Co-Founder and Chairman \\ Retirement Income Industry Association \\ Boston
}

The retirement income challenge requires the cooperation of people who have been buried in individual industry, business, or product silos. Investment advisers need to talk to actuaries, who need to talk to asset managers, who need to talk to derivative specialists, and so on. The Retirement Income Industry Association (RIIA) was founded to give all interested parties an independent and objective place to facilitate such retirement income discussions.

If you were to classify the industry's consumers and its providers according to a $3 \times 3$ matrix, you would start with three horizontal bands of consumers: (1) the high-net-worth investors, which we can define as having investable assets, net of real estate, of $\$ 1.0$ million or more; (2) the affluent investors, with $\$ 100,000$ to $\$ 1.0$ million in assets; and (3) the mass market, defined as those having less than $\$ 100,000$ in investable assets. You would then build three columns to represent the types of financial services providers, differentiated by how they earn their money: (1) the "distributors," earning commissions on the sale and distribution of products manufactured by others; (2) the "intermediaries," such as financial planners and record keepers, earning fees for services; and (3) the "manufacturers," earning fees based on the dollar amount of assets under management or, in the case of insurance companies, earning premiums.

Given this matrix with nine cells, we can position participants in the industry by the type of customer they serve and the type of financial service they provide. UBS, for example, would be in the "Distribution/High Net Worth" cell. TIAA-CREF (Teachers Insurance and Annuity Association - College Retirement Equities Fund) would be in the opposite corner, the "Manufacturer/Mass Market" cell. Bank of America and similar institutions would be in the "Distribution/Mass Market" cell. And so on.

The purpose of RIIA is to bring together the decision makers who own the retirement income responsibility from all nine cells-to talk about retirement income issues without the conflicts of interest, biases, and other handicaps that one would have when advocating for a specific product or industry. 


\section{RIIA's Current Questions}

As an association, we seek to ask questions as we explore issues rather than make statements. RIIA sets its agenda with questions. As an example of RIIA's question-focused approach, this presentation will discuss five key questions that are explored in greater detail in a white paper titled "Innovative Retirement Income and Old-Age Insurance Products: The Perspective of the Retirement Income Industry Association."1

1. Is the market shift from asset accumulation to distribution for income generation real?

2. Will the "money-in-motion" reach trillions of dollars?

3. Do large market segments lack convenient access to the products, tools, and processes that match their needs?

4. Are existing asset accumulation products, tools, and processes likely to be inadequate for providing income generation?

5. Are existing income-generation products, tools, and processes likely to meet the entire volume of money-in-motion?

\section{Is the market shift from asset accumulation to distribution} for income generation real? To help answer this question, Figure 1 shows a framework organized around four phases of the life cycle of the investor (on the $x$-axis) and three generic types of financial solutions offered to the investor (on the $y$-axis). This framework makes it possible to illustrate two kinds of generic investment solutions - one providing "hopeful" accumulation and the other providing "reliable" income. Hopeful accumulation solutions are "best efforts." Best efforts manufacturers typically do not commit their own capital to guarantee the success of the investment; their fee or profit does not depend on the outcome actually delivered to the investor, and thus they can be generally described as providing investment products. Reliable income solutions are typically "guaranteed" products and thus can be generally described as insurance products.

The best efforts investment products (hopeful accumulation) and the guaranteed insurance products (reliable income) solutions are represented as nonoverlapping ovals in this framework, leading to yet another question: What might happen between these nonoverlapping generic solutions? We have named the gap between best efforts investments and guaranteed income "risk sharing."

What seemed hard to agree upon five years ago now seems to be close to the consensus opinion: The shift from hopeful accumulation to reliable income is increasingly real because of the aging demographics of the Baby Boomer generation. The industry's response may need to evolve in response to this shift. Between the development of more guaranteed income products and more best efforts investment products, we may see the emergence of a new category of risk-sharing products.

1This paper can be downloaded from the association's website, www.riia-usa.org. 
Figure 1. Generic Financial Solutions and the Investor Life-Cycle Phases

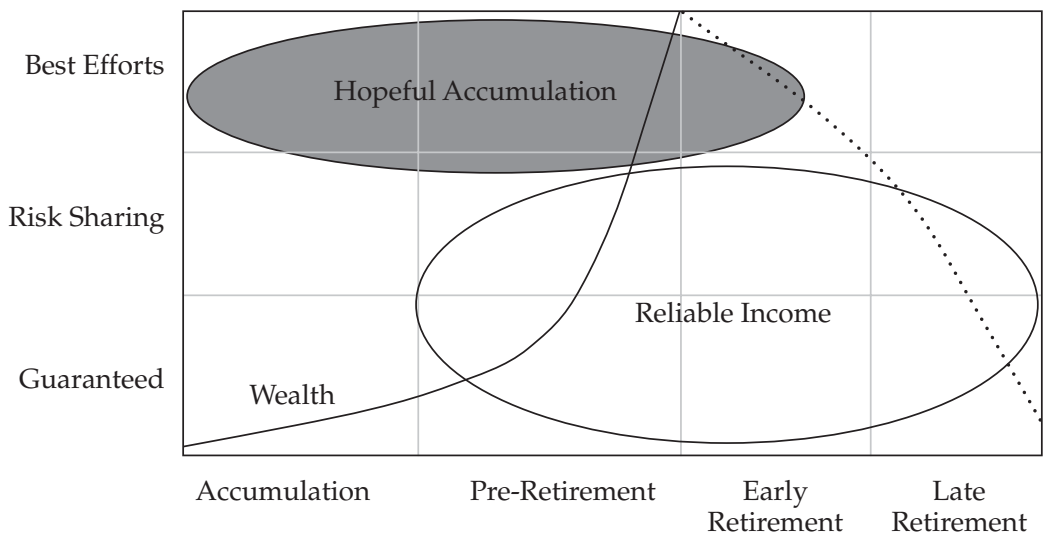

Source: Retirement Engineering, Inc.

\section{Will the money-in-motion reach trillions of dollars? Figure 2}

uses U.S. Federal Reserve Board flow-of-funds data to show the various vehicles holding household wealth in 2005 . The $x$-axis, as well as the circle size, shows the dollar amount of wealth in each vehicle-for instance, $\$ 12.7$ trillion in securities. The $y$-axis shows a five-year growth forecast for the various vehicles-for instance, 10 percent expected annual growth for IRAs.

According to these data, Americans held about $\$ 64$ trillion of wealth as of 2005 . Half of that amount was in financial assets, and about half was related to pension or retirement wealth. Pension or retirement wealth is housed in some of the fastergrowing investment vehicles. For instance, IRAs accounted for $\$ 3.7$ trillion in 2005, and their position at the top of the $y$-axis indicates that this segment is expected to grow faster than all other vehicles. Compare the IRA circle with the smaller (almost half as small) DB (defined-benefit) circle, which is not growing rapidly. Then, notice the DC (defined-contribution) plans, which are growing faster than DB plans. Finally, consider the insurance products: Variable annuities are about half the size of DB but are growing faster than DC, and fixed annuities are about half the size of variable annuities and growing at the rate of DB.

These large asset pools are mostly managed for hopeful accumulation. When they become mostly managed for reliable income, they will likely create large money flows. An interesting question is, How much of this business is going to be owned by the insurance industry? Considering the relative sizes of vehicles in Figure 2, how much more longevity risk will the insurance industry, in general, and a given insurance company, in particular, be able to add to its balance sheet? Remember that longevity risk has no reinsurance market; it is like mortgages before collateralized 
Figure 2. Household Wealth in 2005 by Vehicle and Expected Vehicle Five-Year Growth

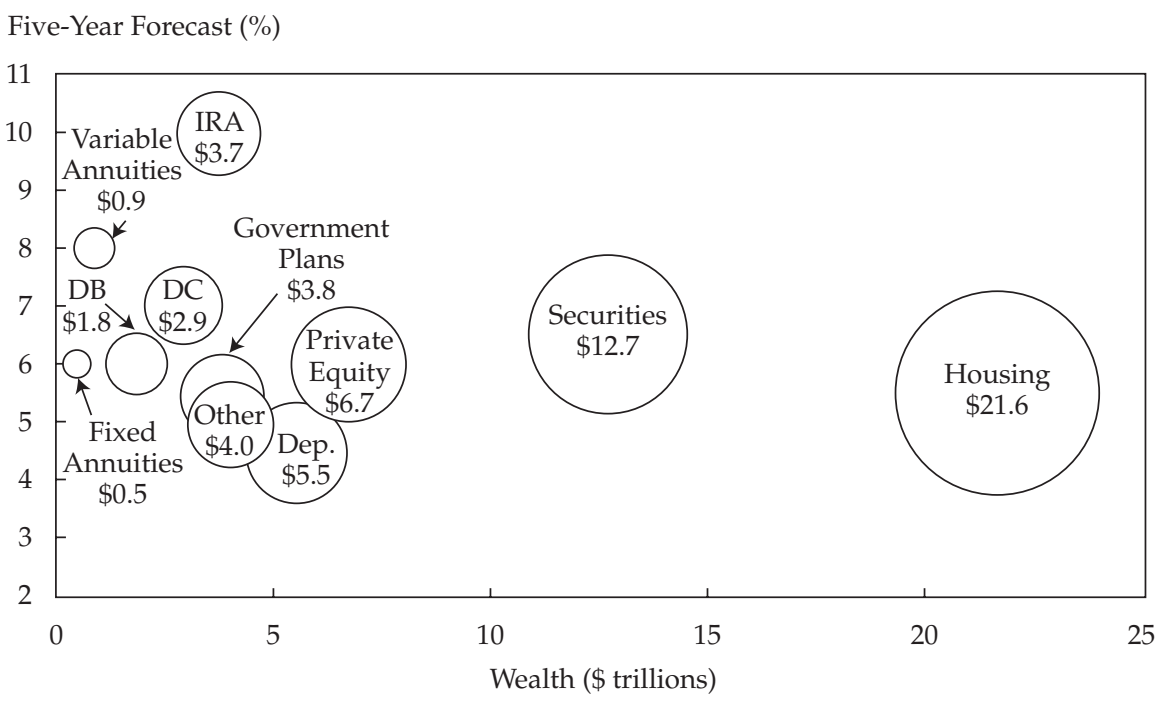

Note: Data in circles are trillions of dollars.

Sources: Based on U.S. Federal Reserve Board flow-of-funds data and information from Merrill Lynch and Retirement Engineering, Inc.

mortgage obligations. So, how much more longevity risk can each industry player add to its own balance sheet? Perhaps each will double the amount or triple it over the next 10-20 years. Looking at these data, one can see that the flows could be in the tens of trillions of dollars over the same period, which would involve much more than doubling or tripling the size of the insurance industry's balance sheet. This large amount of potential money-in-motion provides a great opportunity for both insurance companies and investment firms to create solutions that are no longer simply about best efforts investment products or guaranteed insurance contracts but that also include risk-sharing structured products.

\section{Do large market segments lack convenient access to the} products, tools, and processes that match their needs? Recall the two nonoverlapping ovals mapped across the life-cycle stages of the investor in Figure 1: hopeful accumulation and reliable income. Figure 3 extends the framework to show that the real-life picture may not be so binary. An old riddle goes as follows: In a lily pond, the size of the lilies doubles every day. The lilies cover half the pond. How many more days before the pond is covered? The answer is one day. It is amazing how many people get it wrong. This riddle helps explain Figure 3. 
Figure 3. Investor Life Phases and the Accumulation, Transition, and Distribution Periods

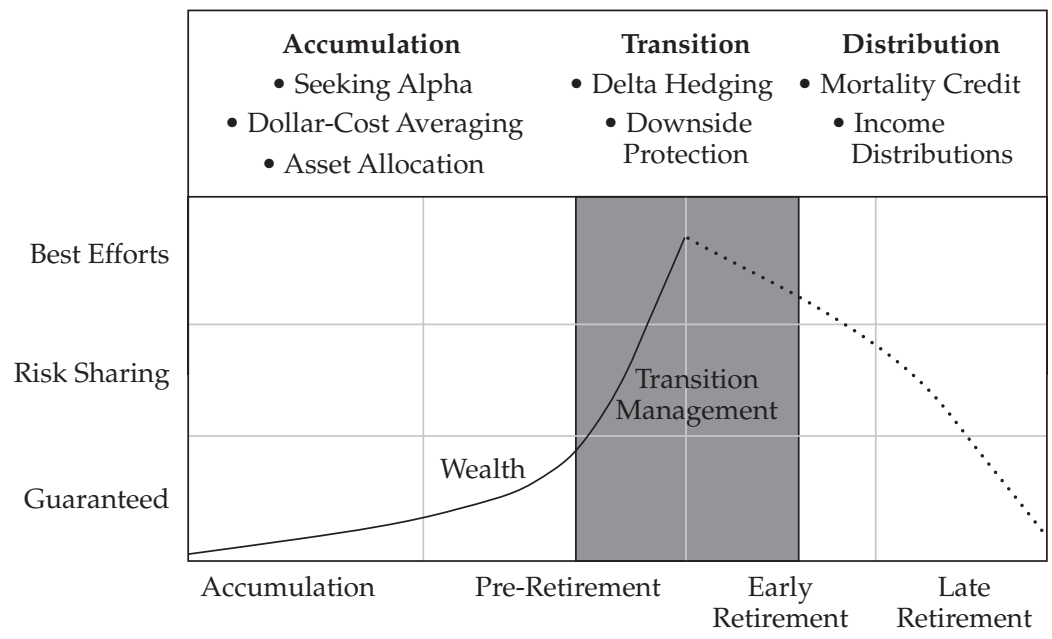

Source: Retirement Engineering, Inc.

Consider a person with a traditional 40 -year asset accumulation period. Assume that she is following the hopeful accumulation strategy with a 50/50 stock/bond strategy. The analogy with the lilies is that - at a fixed rate of compounding-she would experience half of her dollar accumulation in the last 8 years of that 40-year period. So, when people come close enough to retirement- say, eight years from retirement- they have half of their dollar wealth at stake. At that point, trying to maximize total return with naked exposure to the full volatility of the equity market, which may make sense in the early accumulation phase, may no longer make as much sense. At that point, transition management and downside protection start to look increasingly appealing to an increasing number of investors.

A similar pattern emerges in the first 8-10 years after retirement. As Milevsky (2006) and Milevsky and Abaimova (2006) have pointed out, the odds of portfolio ruin in retirement are highly sensitive to the returns the investor earns decade by decade. Path dependency matters greatly. As a conditional probability statement, the experience of zero returns (let alone negative returns) in the first decade in retirement may be 70-80 percent correlated with portfolio ruin (that is, running out of money before the retiree dies). The likelihood of ruin declines from decade to decade in retirement. Thus, there is a transition phase before and immediately after retirement when return maximization and risk taking may be considerably less 
desirable than downside protection for many investors. After that transition phase, in late retirement, some investors may need to focus on income distribution and "mortality credits."

We can now see a parallel between the emerging transition period and the emerging risk-sharing structures. New ideas, new products, and new companies will undoubtedly begin to appear to fill the opening market space.

4. Are asset accumulation products, tools, and processes likely to be inadequate for providing income generation? Recall the $3 \times 3$ matrix described earlier, and take a look at Figure 4. It shows our now familiar three market segments and three provider segments with a new twist: The $y$-axis is now scaled to show the relative number of households on the far left/first column and the relative assets under management (AUM) on the far right/last column. The middle column simply links one to the other. Table 1 provides the data. Thus, the left-most column - the sales and distribution sector of the industry, which is compensated by commissions - is now scaled for the number of households in the United States, out

\section{Figure 4. RIIA's Opportunity Matrix Scaled by Market Segments (households and AUM)}

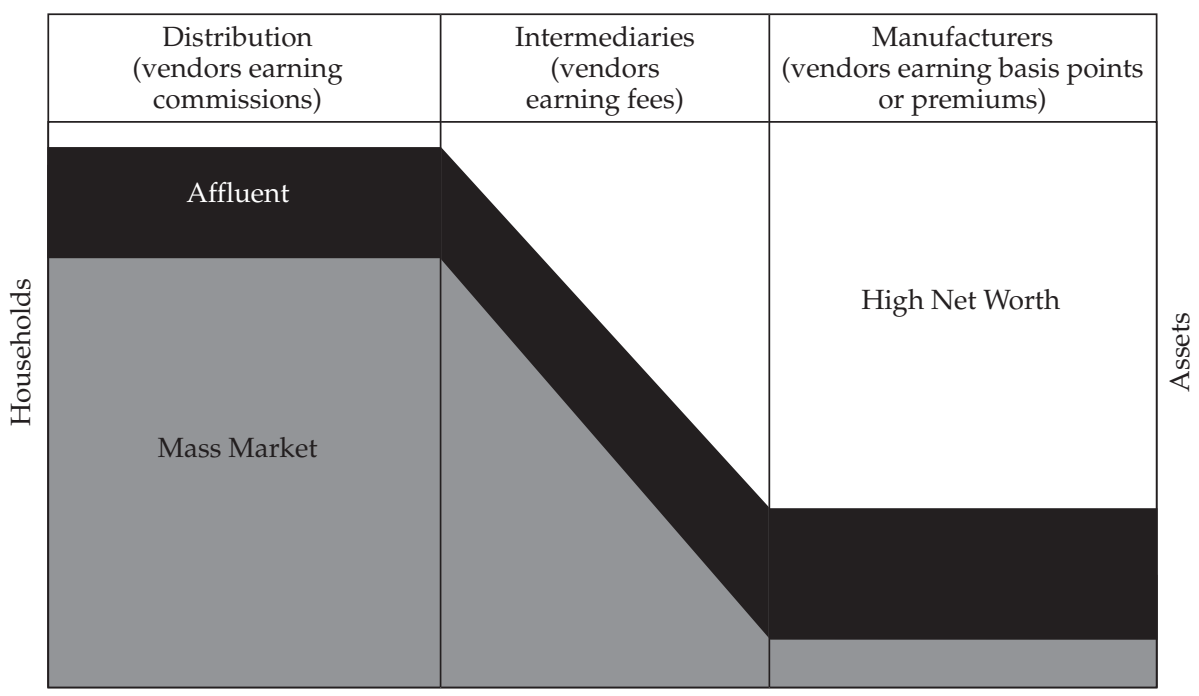

Sources: Based on data from FRC, Tiburon, and Retirement Engineering, Inc.

2In an annuity pool, the surviving annuitants receive some of the funds of the pool members who die earlier; this excess return is called the "mortality credit," and it hedges longevity risk. 
Table 1. Percentage of U.S. Households by Assets, 2004 Data

\begin{tabular}{lcc}
\hline & $\begin{array}{c}\text { Households as a } \\
\text { Percentage of } \\
\text { Total Households } \\
\text { (total }=\$ 108 \text { million })\end{array}$ & $\begin{array}{c}\text { Wealth as a } \\
\text { Percentage of } \\
\text { Total Wealth } \\
\text { (total }=\$ 30 \text { trillion })\end{array}$ \\
\hline $\begin{array}{l}\text { Household } \\
\text { High net worth }>1,000,000)\end{array}$ & $67 \%$ \\
$\begin{array}{l}\text { Affluent } \\
(\$ 100,000-\$ 1,000,000)\end{array}$ & 22 & 27 \\
$\begin{array}{l}\text { Mass market } \\
(<\$ 100,000)\end{array}$ & 74 & 6 \\
\hline
\end{tabular}

Sources: Based on data from Merrill Lynch, FRC, Tiburon Associates, and Retirement Engineering, Inc.

of a total of a little more than 100 million, that it serves. According to the definition of high net worth that we used for this figure (i.e., more than $\$ 1$ million in investable assets), 4 percent of the total U.S. households are high net worth. The right-most column shows the manufacturers. Manufacturers make their money by collecting fees based on assets under management. Thus, the right-most column is scaled for assets under management instead of the number of households.

Therefore, Table 1 and Figure 4 show that the 4 percent of high-net-worth households control 67 percent of investable assets. Many of the high-net-worth investors have assets that are large enough relative to their expense budgets (20-30 times their annual income budget or more) that this retirement income discussion is largely irrelevant to them. Most of what they need is continued efficient asset allocation. Hopeful accumulation continues to be a good fit for them.

For the affluent and the mass-market households and at the lower end of high net worth, however, this retirement income discussion is important. Before reliable income becomes a daily necessity, these market segments will need transition, risksharing products. Do you think that the current accumulation products are adequate for providing the risk-sharing transition, let alone the income generation?

\footnotetext{
5. Are early/traditional (insurance as well as investmentbased) income-generation products, tools, and processes likely to meet the entire volume of money-in-motion? We have seen earlier that the insurance industry manages a small fraction of investment assets. We have also seen that the investment industry controls most of the assets.

In order to adapt to the changes described earlier, as the center of gravity of the marketplace moves from hopeful accumulation and toward reliable income by way of a risk-sharing transition period, most players in the industry (insurance, brokerage,
} 
investment management, etc.) have sought to first try incremental changes to their existing business models. Following are some examples of insurance and investment products, tools, and processes:

- Insurance companies

- Deferred variable annuity

- Deferred fixed annuity

- Immediate annuity

- DC, income annuities

- Life insurance

- Investment products

- Target-date funds

- Lifestyle funds

- Income funds

- Managed accounts

- Tools and processes

- Accumulation-planning tools

- Distribution-planning tools

- Laddered distribution programs

- Systematic withdrawal plans

- Asset management platforms

As Figure 2 shows, insurance-based products might double or triple in asset size, but they would have to grow much more than that to absorb the money that is expected to be moving in the direction of needing income production and income guarantees. Thus, the market demand will probably not be entirely addressed by incremental changes. The industry will most likely need to create new traditional as well as nontraditional products, tools, and processes to meet the demand.

\section{Conclusion: RIIA's Key Statements}

- The market shift from asset accumulation to distribution is real.

- The money-in-motion will reach trillions of dollars-perhaps tens of trillions of dollars.

- Large market segments lack convenient access to the products, tools, and processes that match their needs - in particular, downside protection during the transition phase from hopeful accumulation to reliable income.

- Existing asset accumulation products, tools, and processes are likely to be inadequate for providing reliable income generation.

- Existing income-generation products, tools, and processes are not likely to grow enough to absorb the volume of money-in-motion. 


\section{REFERENCES}

Milevsky, M.A. 2006. The Calculus of Retirement Income-Financial Models for Pension Annuities and Life Insurance. New York: Cambridge University Press.

Milevsky, M.A., and A. Abaimova. 2006. "Risk Management during Retirement." In Retirement Income Redesigned: Master Plans for Distribution. Edited by H. Evensky and D. Katz. New York: Bloomberg Press. 


\title{
Innovative Retirement Income and Old-Age Insurance Products: Insurance and Income Annuity Solutions
}

\author{
Jerome S. Golden
}

\section{President, Income Management Strategies Division \\ MassMutual Financial Group \\ New York City}

The distribution of retirement savings must take into account not only the retiree but also the retiree's spouse, any children or other dependents, future caregivers, and other health providers. Thus, in developing a successful retirement solution, retirement plans must consider all risks.

First are the twin financial risks of longevity (outliving one's assets) and disability (needing long-term care) plus the increasing health care costs associated with aging. In addition, to reflect the changing life status of a retiree, a financial solution should integrate products that insure against these risks together with a diversified portfolio of investment products.

Of course, life or actuarial risks are not the only financial risks a retiree will face. In addition to the usual risks of managing a portfolio of investments-market, interest rate, and investment timing-inflation is a risk that must be managed to protect purchasing power over the remaining life of the retiree.

Moreover, an important risk not fully appreciated by the financial industry but keenly felt by real people is what might be called "planning risk" - the risk of being unable to carry out and complete a well-intentioned plan started in retirement. This inability may be the result of physical or mental disability. And of course, the adviser who helped set up the plan may not be around in the future.

To address these risks, the financial services industry is repackaging existing products, developing new ones, and combining products. Following is a partial list:

- Income annuities. This product is the only financial solution that can guarantee a stream of monthly income payments that cannot be outlived.

- Investment products. This element allows the participant to invest in a variety of mutual funds mainly focused on de-cumulation; some offer software to help manage withdrawal plans.

- Other insurance products. These include life insurance policies with special withdrawal features, variable deferred annuities with secondary income guarantees, and long-term care insurance.

- Combinations of products. Combinations may mix (1) investments with (2) income annuities plus (3) long-term care insurance. 
The focus of this presentation is on income annuities, which were probably first offered in the United States in the 19th century. MassMutual sold its first income annuity in 1917.1

\section{Income Annuities}

Although income annuities have been relatively unpopular compared with other products offered by the life insurance industry, they cannot be dismissed as unimportant. In fact, they may become one of the most important financial products in providing an income solution for retirees.

Income annuities vary in design as to how income is determined and where contract reserves are invested. The income guarantee may consist of a fixed nominal income, or it may provide for a cost-of-living adjustment (COLA).

In variable annuities, the assets are invested in variable subaccounts and the income depends on the performance of the funds selected. The insurance company may also provide a secondary guarantee of income.

Other variations in the design of income annuities include the following:

- When income starts. With most current designs, income starts immediately, although a few newer designs offer deferred income as a form of pure "longevity insurance."

- How premiums are paid. Most designs provide for a lump-sum premium payment, although new designs enable the annuitant to gradually fund a given annuity contract.

- Survivor benefits. Most designs have payout options for a spouse and/or other beneficiary (e.g., 75 percent to a survivor with "10 years certain"2). Newer designs permit the retiree to customize income benefits.

- Liquidity. Most designs do not provide access to reserve assets because of the risk of adverse selection based on mortality; that is, if annuitants who expect to die soon can leave the pool, the benefit of pooling is reduced or eliminated. Some new designs offer limited forms of liquidity.

- Additional income in case of incapacity. At least one design offers an option that creates higher income if the retiree becomes incapacitated during retirement. It is marketed as a "caregiver income benefit."

An income annuity contract can be structured to meet the specific income needs of a retiree and dependents. Table 1 illustrates the differences in monthly income of various combinations of benefit choices and age or retirement: level payments for life, an annuity with a COLA to protect purchasing power, and so on.

\footnotetext{
1Income annuities are sometimes called "payout annuities." See also Ibbotson, Milevsky, Chen, and Zhu (2007).

2The phrase "10 years certain" means that the survivor receives the benefit (at the 75 percent level) as long as she lives, but if she dies, then the heirs receive payments for 10 years from the original issue of the annuity.
} 
Table 1. Initial Monthly Annuity Income for a \$100,000 Rollover IRA in Various Combinations, as of 30 July 2006

\begin{tabular}{llcc}
\hline $\begin{array}{l}\text { Annuitant or } \\
\text { Combination }\end{array}$ & \multicolumn{1}{c}{ Type of Annuity } & $\begin{array}{c}\text { Initial Annual Income } \\
\text { as Percentage of } \\
\text { Amount Invested }\end{array}$ & Monthly Income \\
\hline $\begin{array}{l}\text { A. Male age 65 } \\
\text { M65 }\end{array}$ & Level life only & $7.9 \%$ & $\$ 662$ \\
M65 & COLA life only & 5.9 & 489 \\
M65, F62 & COLA; 75\% survivor & 4.9 & 407 \\
M65, F62 & COLA; 75\% survivor; 50\% legacy & 4.7 & 395 \\
M65, F62 & COLA; 75\% survivor; 50\% caregiver & 4.4 & 369 \\
B. Male age 75 & & & \\
M75 & Level life only & $10.8 \%$ & $\$ 897$ \\
M75 & COLA life only & 8.7 & 723 \\
M75, F72 & COLA; 75\% survivor & 6.8 & 567 \\
M75, F72 & COLA; 75\% survivor; 50\% legacy & 6.5 & 542 \\
M75, F72 & COLA; 75\% survivor; 50\% caregiver & 6.0 & 496 \\
\hline
\end{tabular}

Notes: $\mathrm{F}=$ female; $\mathrm{M}=$ male.

Income annuities can be purchased through insurance agents, registered representatives of brokerage firms, registered investment advisers holding insurance licenses, or directly from insurance companies. They can also be offered through institutional channels as a plan option in a $401(\mathrm{k})$ plan or as an "out of the plan" individual retirement annuity. Finally, income annuities can be offered as part of a rollover IRA.

\section{Pricing of Income Annuities}

The primary drivers for pricing income annuities are expectations of longevity, and for fixed annuities (including those with an inflation adjustment), the level of interest rates.

The longevity assumptions in annuities depend on the particular population of annuitants. For example, group annuities typically reflect shorter life expectancies than annuities issued to individual purchasers, primarily because the latter group is self-selecting and thus exhibits longer life expectancies. Thus, group annuities are offered at lower prices. A key additional question for the insurance company in all annuity markets is, How much of an increase in life spans is assumed in the pricing?

Insurance companies also face interest rate risk when issuing fixed annuities. A fixed annuity provides a lifetime income guarantee and thus an implicit lifetime interest rate guarantee, but the insurance company cannot purchase any investments 
that offer a fixed rate over the annuitant's lifetime. Thus, the insurance company bears significant investment risk. Most insurance companies mitigate this risk by one of the industry's primary disciplines—asset/liability matching. ${ }^{3}$

Despite the beginnings of a ground swell in the financial and academic press for including income annuities in the retirement mix, these products are not currently being used in large quantities. This situation is likely to change, however, as investment advisers and providers of retirement planning software see how the results are improved by adding income annuities to the retirement income equation.

\section{Effect of Annuities on Retirement Income}

Adding an income annuity to the retirement asset mix can improve the expected outcome for the retiree. But by how much? And what, if any, are the financial tradeoffs? The answers to these questions can be gleaned from the new planning software but depend on at least the following:

- Success criteria. Does the software define success in terms of when (or if) assets run out or in terms of how much lifetime income can be achieved?

- Participant's financial situation. Is the plan filling a large income gap for the retiree, or are there adequate assets, and thus the plan is designed to balance income and bequest objectives?

- Source of funding. Are the assets that are intended for purchasing the income annuity coming from tax-deferred savings or from taxable personal assets?

- Methodology. Does the planning software use Monte Carlo simulation ${ }^{4}$, deterministic methods, or other methods?

- Assumptions. What assumptions does the economic model make as to market returns, interest rates, inflation, and so on?

For example, for MassMutual's planning software, we determined that of all the millions of paths to designing a retirement distribution plan, the most important decisions were, first, to ascertain whether income annuities were included in the mix and, second, if so, to determine how much income was purchased and over what period. These decisions appeared to us to be more important than subtle changes in asset allocation.

Three strategies that a typical retirement adviser who is designing an income plan for a retiree with purchasing power protection will consider are (1) investment only (no income annuity is purchased); (2) purchase of a COLA income annuity up front with, say, one-third of the available investment funds; and (3) investment

\footnotetext{
${ }^{3}$ Asset/liability matching is the holding of assets in the investment portfolio that are matched, in terms of their cash flows or durations, with the liabilities.

${ }^{4}$ Monte Carlo statistical analysis, also known as the Monte Carlo simulation technique, is a mathematical process used to implement complex statistical methods that chart the probability of meeting specific financial goals at certain times in the future.
} 
with gradual purchase of a COLA income annuity until the lifetime income goal is reached (a "laddered" approach). In today's conditions, and with the assumptions and methodology used in the MassMutual model, the laddered strategy of gradual funding results in the most favorable distribution of income risk. Individuals, of course, have different needs and circumstances that require an individualized strategy to achieve success.

The bottom line is that by adding protection products to traditional investments, retirees should be able to manage more of the life and financial risks after retirement than they can without them.

\section{REFERENCES}

Ibbotson, Roger G., Moshe A. Milevsky, Peng Chen, and Kevin X. Zhu. 2007. Lifetime Financial Advice: Human Capital, Asset Allocation, and Insurance. Charlottesville, VA: Research Foundation of CFA Institute.

\section{Disclaimer}

Guarantees for living benefit, death benefit, and lifetime income are based on claims-paying ability of the issuing company.

Annuities do not provide additional tax advantages when used to fund a qualified plan, and investors who purchase annuities should do so for the annuity's additional features, such as lifetime income payments.

The MassMutual RMA is an investment advisory program and an IRA (Account). This retirement income program enables you, with the help of your advisor, to produce inflation-protected monthly payments from your qualified retirement savings.

Before investing in any of the Oppenheimer funds, investors should carefully consider a fund's investment objectives, risks, charges, and expenses. Prospectuses for the funds available in the mutual fund model portfolios contain information about the investment objectives, risks, charges, and expenses and other information about the funds and may be obtained from your advisor. Please read the prospectuses carefully before investing.

Program Sponsor: Massachusetts Mutual Life Insurance Company, Investment Advisor

Co-advisors: Massachusetts Mutual Life Insurance Company and MML Investors Services, Inc. 


\section{Sustaining Retirement Income- Barriers and Dreams}

\section{Anna Rappaport \\ President \\ Anna Rappaport Consulting \\ Chicago}

The payout period is an increasingly important aspect of the retirement income system. When many Americans were covered by traditional defined-benefit (DB) plans, the payout period was not a major issue, largely because DB plans paid out monthly life income. In the retirement system that is evolving, few plans automatically pay out monthly lifetime income and many do not include an option for such income, so voluntary allocation of resources for use over a lifetime has become important. The variability of life spans and the possibility of living to 100 years old and beyond, however, make this allocation challenging.

In this brief article, I first discuss why the generation of lifetime income outside traditional DB pension plans has proven so difficult. I do so by identifying the barriers faced by each of the stakeholders in retirement benefit delivery. I then reveal some of my "dreams" for making lifetime income more of a reality in the future than it is today.

\section{Barriers to Lifetime Benefit Delivery}

The system for delivering retirement income includes several groups of stakeholders that interact with and influence each other:

- individuals, including employees and the public,

- employers (who sponsor retirement and other benefit plans, offer advice and education to employees, and can give employees access to the group purchase of financial products),

- financial institutions of various kinds (investment management firms, insurance companies, and so forth),

- advisers, and

- regulators.

This section addresses the barriers to focusing on risk management in retirement from the perspectives of these stakeholders.

Individual Perspective. Barriers vary for different individuals. Some do not have enough funds to purchase a meaningful guaranteed life income or may believe that Social Security is all the life income they need. For other individuals, the most important barrier to receiving retirement income as an annuity is the lack 
of flexibility once they have purchased the annuity. Because of this lack of flexibility, individuals must very carefully decide when and if to purchase an annuity, whether to purchase guaranteed life income or an arrangement for installment payments or regular withdrawals without any life guarantee, and how much of the portfolio may be used to buy annuity income. The entire portfolio should not be annuitized.

Research from the Society of Actuaries provides insights about how people think about management of retirement assets:

- The focus of many individuals (and their advisers) is on investment management, not risk transfer or risk management.

- The planning horizon is very short for many people, and the approaches that are used to think about retirement tend to be intuitive rather than based on sophisticated analysis. Sometimes, they are not based on any quantitative analysis at all.

- Reducing spending is the most popular risk-reduction strategy.

- Control of assets is an important issue, but at the same time, many people are not able to exercise the control well.

In addition, individuals tend to be overly optimistic about how long selfmanaged resources will last and what return they can get by investing themselves; they underestimate how long the resources will be needed, or they do not consider the longer term at all. Furthermore, many individuals have difficulty understanding how much spending power can be generated over a lifetime by a specific pool of assets.

Focus group research conducted in 2005 for the Society of Actuaries indicated the following:

- Retirees tended to plan on a short-term, not a long-term, basis.

- Retirees commonly determined whether they could afford to retire by assuming that 6 percent of assets was a sustainable annual withdrawal rate and then comparing that amount, plus income from other sources, with current expenses without adjusting for change over time.

- Most of the retirees in the groups did not have an organized, comprehensive risk management program. Rather, they took each day at a time and dealt with situations as they occurred.

- Many of the retirees did not carry out formal retirement planning.

- Awareness of long-term care insurance was high, but few bought it, and some thought it was too expensive.

- Awareness of annuities was low.

- A lot of what people think they know is misguided or false. 1

1The full report of the focus groups and the 2005 Risks and Process of Retirement Survey can be found at www.soa.org. 
The population of those in need of retirement income can be divided into segments by resource level. At the lower end are people with limited financial assets and little income beyond Social Security. Purchasing guaranteed income is not an option for them. At the higher end are people who have investment income that will more than cover their regular expenses in retirement. They do not need to purchase guaranteed income. It is the people in the middle without defined plan income who need to focus on regular income over life and who could benefit from some form of annuitized retirement income.

Employer Perspective. Traditionally, employers offered income through DB plans. With the shift to defined-contribution (DC) plans, however, most employees receive lump sums upon retirement, often with no lifetime income option. And those who have the option rarely elect it. Thus, the time has come to discuss the importance of managing DC assets to produce income for life and to think about new distribution strategies.

Employers are reluctant to offer annuity options directly because of spousal consent requirements, fiduciary and reporting responsibilities, and "safest annuity rule" issues. This last rule is expressed by U.S. Department of Labor Interpretive Bulletin 95, which makes clear that "the selection of an annuity provider . . . is a fiduciary act. ... [P]lan fiduciaries must take steps calculated to obtain the safest annuity available." 2 The Pension Protection Act of 2006, however, opens the way to an easing of the safest annuity rule.

Instead of offering an annuity payout option directly, therefore, some companies, such as IBM, have begun offering annuity options outside the plan but with competitive shopping and institutional pricing through a third-party IRA rollover program. In a third-party program, the annuity can be purchased at retirement, later, or in steps over time.

Satisfactory postretirement results will also depend on employees and retirees receiving understandable advice about alternative strategies in an efficient and unbiased manner. Employers could play a key role in this essential process because employees look to them as a source of information. Thus, employers could offer information and advice, offer income-based distribution options in plans, and contract with providers of products offering group pricing for more effective purchase of risk protection.

Perspective of Financial Services Providers. Barriers and challenges to annuity and other risk-protection products differ depending on whether the perspective is that of product design (and the willingness of consumers to buy the products), the distribution system (and the willingness of agents to sell them), or the risks relating to the financial structure of the products and their guarantees.

2From a U.S. Department of Labor Advisory Opinion from 18 December 2002 (available at www.dol.gov/ebsa/regs/aos/ao2002-14a.html). 
Marketing. Selling immediate annuities is not attractive to most sales agents/representatives. The commissions are often not as great as those they can earn by selling other products, and selling the products requires specialized knowledge. This barrier can be overcome through the use of specialist wholesalers who can provide product knowledge and support the individual agent.

In addition, finding a target market that has both the interest in annuity and other retirement risk-protection products and the ability to pay for them is challenging. For many agents, the middle market, as identified in the "Individual Perspective" section, is not the most attractive place to be because sales (and thus commissions) are not large. To make this market profitable, a culture will have to be built that focuses on the importance of the distribution period. In addition, many companies are likely to develop new products for retirement resource management.

Product design and cost. Buyers would prefer a product that does not require an immediate irrevocable choice. Some such products are on the market, and various alternatives are being explored for management of the postretirement-period assets. In addition, to truly protect lifetime income, inflation protection is necessary; fixed nominal annuities do only a part of the job. Inflation protection is also expensive, so few inflation-protected products are available. At the same time, the insurer needs to be able to match investments to liabilities to minimize risk, and few inflation-protected investments exist that match the liabilities.

Another challenge is designing a product that appeals to a broad risk pool. If only healthy people buy a product, adverse selection drives up the cost of the product and reduces sales. Products that combine some long-term care coverage with annuity income would, as discussed by Mark Warshawsky, reduce adverse selection with respect to mortality risk and improve the risk pool. ${ }^{3}$

Yet another issue relates to guarantees and their cost. The buyer wants guarantees against outliving assets, investment risk, and inflation but tends to underestimate their value and thus may not be willing to pay adequately for them. Innovative ideas are included in a few products and are under consideration today that offer some such guarantees, including combination products, partial liquidity provisions, longevity insurance, inflation-indexed benefits (i.e., cost-of-living adjustments), and reverse mortgages with lifetime guarantees included.

Finally, as with other financial products, tax considerations often drive product structures. Federal law requires that individuals with retirement plan assets and IRAs start taking minimum distributions by 1 April following the year they reach age $70 \frac{1}{2}$. Failure to do so results in a stiff tax penalty. This minimum distribution rule has been cited as one of the barriers to product innovation because it often tends to dominate the strategy for using retirement assets.

${ }^{3}$ See Warshawsky's presentation in this book. 
Regulatory Issues. I have already mentioned some regulatory issues, but when the intersecting regulatory issues facing all the stakeholders are considered, the total impact of the regulations has a restraining effect on the use of income options in DC plans. Two examples of regulatory challenge in addition to those mentioned earlier are (1) conflict with regard to unisex rates and (2) the minimum distribution rules.

Employer plans are not permitted to use sex-based rates for determining benefits or pricing distribution options, but virtually all annuity contracts are priced according to sex-based rates. In addition, the minimum distribution rule makes it difficult to purchase annuities over time on a staggered basis and to combine annuity income and long-term care in the same insurance product if it is to be linked to a retirement benefit or an IRA. Annuities and long-term care are both heavily regulated but by different rules, which is another barrier to combining them. Provisions of the Pension Protection Act, however, have opened the way to more combination products in the future, but there are still barriers to the use of these arrangements with pension plans.

Employers often choose DC plans as a way to escape extensive DB plan regulation, but DC plans also have complex rules. The more helpful an employer tries to be in addressing postretirement issues, the more rules the company has to follow.

\section{The Dream}

Based on my ideas and discussions with colleagues, following are some approaches that would allow individuals better paths to regular guaranteed lifetime income, either through employer offerings or directly by purchase of a financial product. These ideas may require changes in law, employer practice, and market offerings. They are dreams for the future, and several of them are not feasible today.

Unify and rationalize the regulatory environment. With pensions in the United States regulated by the U.S. IRS, Department of Labor, Pension Benefit Guaranty Corporation, Financial Accounting Standards Board, and sometimes the U.S. SEC, and with annuities regulated by state insurance departments and sometimes the SEC, a huge mass of complicated regulations faces employers sponsoring benefit plans, product providers, and purchasers. In addition, income tax rules often influence when using a risk-protection product, such as an annuity, is attractive and when it is not. These regulations create fiduciary risk for plan sponsors and complicate for all those concerned what would otherwise be much simpler strategies. Unified and balanced regulation would help open the way to simple, logical solutions.

Improve the default distribution options in 401(k) plans. Today, lump sums are the most common default for savings distribution, and lifetime income options are often not available. Annuitizing all assets is a bad idea, and annuitizing immediately on leaving employment is also often not the right strategy. An example of a better default distribution would be to leave the money in the plan until age 70 
and pay out 4 percent a year in regular installments until that time. At age 70 and for each of the next four years, 10 percent of the balance would be annuitized on a 100 percent joint and survivor basis. The retiree would be able to opt out of this default option for any funds not yet annuitized. The advantages of this option include the following:

- It forces the participant to consider an annuity.

- It gives the participant time to think before making irrevocable decisions.

- It uses dollar-cost averaging.

- It approaches the matter from a portfolio point of view.

- It provides for annuity purchase at a good time to buy annuities.

Note that this type of default option is not possible under current law.

Implement a tiered, flexible account product. A tiered, flexible account would allow gradual annuitization of all or part of the retirement assets. Gradual or phased annuitization is a means of dollar-cost averaging and offers a route to inflation protection. Such an account would also allow for leaving funds in traditional investments with regular monthly installment withdrawals and one-time withdrawals to meet special needs. A variation on this theme would be to provide a laddered plan with different "buckets." The first bucket might be used to provide a relatively high level of income for ages 65 to 85 . The second bucket might consist of longevity insurance and provide a lower level of income after age 85. A third bucket might provide premiums to pay for long-term care insurance.

Expand product innovations. Ideas for innovations include the following:

- Combination annuity and long-term care products. From the point of view of managing risks, combining various product offerings or offering them as a package would be ideal. In a package, they would reduce adverse selection, could be priced more effectively, and would help people manage multiple risks through a single product purchase. (Several companies have started combination products that include long-term care.)

- Special annuity products for people in poor health. These products, called "substandard" annuities, offer individuals who have shorter-than-average life expectancies a level of payout that is larger than that provided by standard immediate annuities. (Several companies do currently offer substandard annuities.)

- Longevity insurance. This product is a deferred annuity (without cash value or death benefits on early death) that pays benefits starting at a high age, such as 85. (Some companies have introduced such a product.)

- Reverse mortgages and other programs to use housing wealth. These alternatives need much more evaluation and discussion than they are receiving. Financial institutions and advisers need to be sure that products are well matched to needs, and then they need to help people understand which, if any, of the approaches are most likely to be effective in a particular situation. 
- Unbundled retirement annuities. Unbundling annuity assets would facilitate thinking of annuities in a manner similar to how the market thinks about universal life insurance. Universal life unbundles life insurance by separating out the accumulation amount (the investment component) from the cost of life insurance (the death benefit component). An annuity could similarly be unbundled by setting it up as an accumulation account with an added "dividend" paid to survivors to reflect the mortality credits that have been earned (the value of survivorship). That is, the accumulation for those who die is redistributed to those who continue as participants. This structure would help open the way to other innovations.

Offer risk protection. A rider to allow withdrawal from the annuity for medical premiums or for medical expenses in case of medical or other emergencies could be made available. A similar rider could provide for long-term care premiums or for payment of expenses offering direct coverage. Such riders would offer some risk protection and could be made available through a withdrawal account in the postretirement asset management account that includes an annuity and risk protection.

Recognize the employer as the ideal way to reach the middle market. The middle market is difficult to reach through one-on-one interactions between financial professionals and buyers. The workplace is the best route to reach this market, and the employer who offers advice needs to be protected from litigation and legal penalties in connection with the advice. The variety and number of legal and fiduciary requirements make it challenging and risky for the employer to offer advice on retirement income generation to participants in DC plans. In light of the need to involve employers in retirement income planning, policymakers and regulators should revisit these requirements to give employers more certainty regarding what they can and cannot do. With this certainty, the employer segment has great potential for helping to meet the needs of the middle market. 


\section{The Life Care Annuity}

\section{Mark J. Warshawsky \\ Director of Retirement Research \\ Watson Wyatt Worldwide Arlington, Virginia}

A life care annuity (LCA) is the combination of a life annuity and long-term care insurance (LTCI). In return for the payment of a premium (either in a lump sum or collected over time), the LCA provides a stream of fixed-income payments for the lifetime of the named annuitant. ${ }^{1}$ In return for higher premium charges, a coannuitant, usually the spouse, can be added; payments in this case would continue until the death of the second-to-die co-annuitant. In addition, the LCA provides an extra stream of payments if the annuitant (and/or the co-annuitant) requires long-term care. The annuitant qualifies for the long-term care payment if he or she is cognitively impaired or is unable to perform at least two of the six recognized activities of daily living (ADLs), such as walking or eating without substantial human assistance. These ADL triggers are the same triggers used in the LTCI policies qualified under current tax law.

Because this second segment of the LCA is intended to function as comprehensive LTCI, the additional layer of payments to the disabled annuitant must be sufficient to cover the extra expenses incurred for home health care or nursing home care, generally as soon as possible after the disability commences and for as long as those care needs continue. For that reason, the inclusion of yet another layer of "pop-up" disability payments in the LCA may be advisable in case a disability is severe (e.g., impairment in four ADLs) or lasts a particularly long time (e.g., two years). When the extent of needed care is great, costs will increase. Moreover, longterm care costs have been increasing more rapidly than consumer prices in general, and LTCI should reflect this fact.

The desired level of payments in the first segment of the LCA (the life annuity segment) will depend on the financial resources of the annuitant; on the existence and size of other life annuity income, such as a defined-benefit (DB) pension and Social Security; and on the annuitant's desired standard of living in retirement. And importantly, the amount devoted to the life annuity should consider the investor's risk tolerance and personal preferences for bequests, inter vivos gifts, and other needs and desires for which a life annuity is not the best-suited vehicle. ${ }^{2}$

\footnotetext{
1The income payments may be fixed in nominal or real terms; a real annuity is the more expensive form. 2 Guarantee periods (in which the annuity will be paid to beneficiaries for a fixed period of time even if the annuitant dies), cash refunds, and various liquidity features of many individual life annuity products currently marketed may, however, meet some of these preferences and needs.
} 
What is the motivation for the integration of a life annuity and LTCI-separate insurance products that are widely available and have been marketed for decades? The integration is intended to address inefficiencies in the separate markets for those products. For example, empirical research has shown that immediate life annuities are as much as 10 percent more expensive than they would be without adverse selection (Friedman and Warshawsky 1990; Mitchell, Poterba, Warshawsky, and Brown 1999). Adverse selection exists because individuals with long life expectancies seek to purchase life annuities whereas other individuals tend not to. A large improvement in utility could be achieved by the annuitization of assets at fair actuarial value in retirement rather than at the prices distorted by adverse selection.

At the same time, according to Kemper, Murtaugh, and Spillman (1995), current underwriting practices prevent 25 to 33 percent of the retiring population (ages 65 to 75) from purchasing individual LTCI policies. That is, individuals with impaired health, or with lifestyles perceived by the insurer to be unhealthy, cannot purchase LTCI. 3 The conclusion is that if LTCI were easier to purchase, it would be much more widely held. Brown and Finkelstein (2004) demonstrated, using simulation analysis, substantial demand by individuals above the lowest two or three wealth deciles to pay for actuarially fairly priced private LTCI coverage on top of Medicaid. (Of course, Medicaid coverage itself provides significant consumer welfare because of its LTCI coverage.)

Finally, the LCA combination is motivated by the observed positive correlation between mortality and poor health and lifestyle.

These observations and findings led to the proposal for an integrated product that would offer a life annuity and an LTCI policy at a lower cost, and with wider eligibility, than could be provided by the two types of policies offered separately. The LCA blends the longevity risk of annuity buyers with the morbidity/disability risk of those desiring, but denied access to, LTCI coverage. The product thus appeals to two populations simultaneously. The proposal is an application of economic theory - a practical attempt to produce a self-sustaining pooling equilibrium that is superior to the separate equilibrium currently in existence.

The proposal rests on three hypotheses that we tested:

1. The life expectancy of voluntary purchasers of an integrated product will be less than that of voluntary purchasers of life annuities.

2. The population eligible for, and most likely to be attracted to, the integrated product will be larger than the populations attracted to and eligible for the two products issued separately.

3. With minimal medical underwriting, the cost of the integrated product will be less than the sum of the costs of the two products sold separately. ${ }^{4}$ Note that

${ }^{3}$ This finding is corroborated by observation in the insurance industry of the high rejection rate of applications for LTCI policies by older applicants.

${ }^{4}$ For more details, see Murtaugh, Spillman, and Warshawsky (2001). 
"minimal underwriting" means that only those who would go immediately into

claim status for LTCI benefits (e.g., those who are already nursing home residents) would be rejected for the LCA. 5

The basic integrated product that we modeled was an immediate LCA that paid $\$ 1,000$ (nominal) a month for the lifetime of a 65-year-old individual (of either sex) with a 10-year guaranteed period. The disability payment was an additional $\$ 2,000$ (nominal) a month if 30 days had passed after the annuitant had two ADL impairments or had been cognitively impaired for at least 90 days plus another $\$ 1,000$ (nominal) a month if the annuitant had four ADL impairments. The balance between the life annuity and LTCI segments is important in achieving the pooling equilibrium; few people rejected for LTCI would want to buy pure life annuity products, but a guaranteed period added to the annuity component of the LCA makes it more attractive to this population.

We found that for this basic integrated product, the single-payment premium at age 65 would be $\$ 156,326$. As Table 1 shows, that price is about $\$ 5,000$ less than the two products sold separately.

\section{Table 1. Premiums at Age 65 for Income Annuity with Disability Benefits: Current LTC Underwriting Practice vs. Minimal Underwriting}

\begin{tabular}{lcccc}
\hline & $\begin{array}{c}\$ 1,000 \text { Monthly } \\
\text { Life Annuity Only }\end{array}$ & $\begin{array}{c}\$ 2,000 \text { Monthly } \\
2-3 \text { ADL } \\
\text { Disability Benefit }\end{array}$ & $\begin{array}{c}\text { \$1,000 Monthly } \\
\text { 4+ ADL } \\
\text { Disability Benefit }\end{array}$ & $\begin{array}{c}\text { Combined } \\
\text { Premium }\end{array}$ \\
\hline All persons & $\$ 139,098$ & $\$ 15,950$ & $\$ 3,155$ & $\$ 158,203$ \\
Prospective purchasers & & & & \\
Current LTC underwriting & $\$ 145,041$ & $\$ 13,900$ & $\$ 2,843$ & $\$ 161,784$ \\
Minimal underwriting only & 139,827 & 13,723 & 2,777 & 156,326 \\
Nonpurchasers & & & & \\
Current LTC underwriting & $\$ 119,051$ & $\$ 22,866$ & $\$ 4,207$ & $\$ 146,124$ \\
Minimal underwriting only & 104,147 & 122,764 & 21,293 & 248,203 \\
\hline
\end{tabular}

Note: All numbers are without inflation protection.

Source: Murtaugh, Spillman, and Warshawsky (2001).

This proposal also has a public policy context. On the annuity side, employer provision of retirement income support for workers has moved toward the definedcontribution plan form, in which a life annuity distribution is not required-indeed, is not often offered. Therefore, the individual plan participant must search in the voluntary individual annuity market if he or she is interested in coverage by a life

5 An alternative formulation would allow coverage for even these people, but it would have to be delayed two or three years for them. 
annuity at retirement. Even for those workers covered by a DB pension plan, mandatory annuitization has become less common; therefore, the scope of adverse selection has increased. Moreover, mandatory annuitization is not featured in many Social Security reform proposals.

On the long-term care side, the U.S. Congress, concerned about apparent abuses of the Medicaid spend-down requirement and by the runaway cost of the program to the federal and state governments, has recently tightened eligibility for the long-term care benefits of Medicaid. Indeed, research by Brown and Finkelstein (2004) demonstrated that, even without considering concerns about gaming the Medicaid system, Medicaid has had a substantial crowding-out effect on private LTCI coverage. Hence, as Medicaid eligibility is tightened, the need for private LTCI coverage will increase among lower and lower ranges of the income and wealth distribution. Despite the need, the preferred solutions of the insurance industry have been sales of individual LTCI policies at young ages or employer provision of the benefit, where underwriting is not a significant factor. These approaches, however, have not taken deep root.

Moreover, in the life-cycle planning of a household, there is a natural focal point for the LCA — namely, when the household is approaching or has just begun retirement and is seriously considering, given finite resources, the rest of the household's financial future.

New product designs in the private sector should respond to changing private and public factors in pragmatic ways. And the product providers need to be accommodated and perhaps encouraged by public policy. The LCA is a step in the right direction.

\section{REFERENCES}

Brown, Jeffrey R., and Amy Finkelstein. 2004. "The Interaction of Public and Private Insurance: Medicaid and the Long-Term Care Insurance Market.” NBER Working Paper No. 10989 (December).

Friedman, Benjamin, and MarkJ. Warshawsky. 1990. "The Cost of Annuities: Implications for Saving Behavior and Bequests.” Quarterly Journal of Economics, vol. 105, no. 1 (February):135-154.

Kemper, Peter, Christopher Murtaugh, and Brenda Spillman. 1995. "Risky Business.” Inquiry, vol. 32, no. 3 (Fall):271-284.

Mitchell, Olivia, James Poterba, Mark J. Warshawsky, and Jeffrey R. Brown. 1999. "New Evidence on the Money's Worth of Individual Annuities." American Economic Review, vol. 89, no. 5 (December):1299-1318.

Murtaugh, Christopher, Brenda Spillman, and Mark J. Warshawsky. 2001. "In Sickness and in Health: An Annuity Approach to Financing Long-Term Care and Retirement Income." Journal of Risk and Insurance, vol. 68, no. 2 (June):225-254. 


\title{
Session 5: Munnell Presentation
}

\section{The Role of Government in Life-Cycle Saving and Investing}

\author{
Alicia H. Munnell
}

Peter F. Drucker Professor of Management Sciences, Boston College Carroll School of Management Director, Center for Retirement Research at Boston College Boston

It is a good time to consider government's role because the players in life-cycle saving in the United States have dropped from three-government, employers, and the individual - to two-government and the individual. A partnership is necessary because, in an industrialized society, individuals need to accumulate resources while working to support themselves in retirement, and most lack the foresight and discipline to do so in the absence of institutionalized savings arrangements. The withdrawal of employers from these arrangements is troublesome because business used to provide both structure and resources that allowed individuals to smooth lifetime income and retire in an orderly fashion. To fill the gap, the role of government in life-cycle saving needs to change. This paper explores how the government could help restore the structure and resources formerly provided by employers.

As a prelude to defining the new role for government, this paper begins by explaining the complex financial decisions that individuals face in an industrialized economy. The second section describes the role that government currently plays in fostering life-cycle savings. The third section explores why and how the role of employers has changed, and the fourth section lists other factors that one might want to take into account when designing the revised role of government- the increasing retirement span, the contracting retirement-income system, the importance of the house as a retirement asset, the drain of college payments on retirement assets, and the need for people to work longer. Finally, the fifth section lays out the additional tasks that, in the wake of the withdrawal of employers, now fall to government-improving access to annuities and reverse mortgages, encouraging continued employment of older workers and their orderly withdrawal from the labor force, and possibly introducing a new tier of life-cycle saving. 


\section{Player \# 1: The Individual}

In the beginning, there was the individual. During the preindustrial period, the individual typically did not rely on help from employers or government in retirement saving because the elderly generally continued to work for as long as they could. They took on less taxing jobs as their strength or acuity declined and stopped working only when no longer able. Well into the 19 th century, three of four elderly Americans still worked. ${ }^{1}$ The elderly in preindustrial economies also often owned property that provided an income. Family farms and handicraft businesses were natural vehicles for accumulating wealth as part of a worker's normal routine, and many elderly people were able to retire from active labor by selling or leasing these assets. ${ }^{2}$ The minority of the elderly who could no longer work and had little or no property would often rely on their children or local community for economic support.

Two developments - urbanization and industrialization — transformed the economics of aging in the 19th century. Urbanization concentrated the population in the large labor and product markets, which undermined the traditional sources of family or communal assistance. Industrialization transferred production from the household to larger and more rationally organized enterprises. The outcome was an enormously productive economy. But it also undermined the ability of the elderly to support themselves through work or the ownership of income-producing assets. Industrialization separated the process of gaining a livelihood from the process of acquiring income-producing property. To build up such assets, industrial workers had to consciously set aside a portion of their earnings and invest those funds.

The saving and investing process requires a good deal of foresight, discipline, and skill. The life-cycle model of saving is based on the assumption that people have the knowledge to forecast their needs decades in the future and then the discipline and skill to act on those forecasts. To properly forecast retirement needs and how much they should save each year, people need to predict their earnings over their lifetime, how long they will be able to work, how much they will earn on their assets, and their life expectancy. Recent surveys suggest that-even todaypeople are not very good at planning for retirement. In 2005, only 24 percent of respondents indicated that they were very confident that they had put aside enough for retirement, 30 percent had not saved anything for retirement, and 58 percent had not even tried to figure out how much they might need. ${ }^{3}$ A recently released

\footnotetext{
1 Much of the historical background comes out of conversations with or earlier work by Steven Sass, primarily Sass (1997), and from our joint work, Munnell and Sass (2006) and Munnell, Sass, and Soto (2006). Steven Sass has been extraordinarily generous in allowing me to appropriate many of his ideas and much of his and our language for use here.

2U.S. Bureau of the Census and the Social Science Research Council (1960); Sass (1997); Thane (2000). ${ }^{3}$ Helman, Copeland, and VanDerhei (2006). Similarly, in a survey of 10,000 workers in a single firm, 68 percent responded that their saving was too low; they should have been saving 14 percent but were only saving 6 percent (Choi, Laibson, Madrian, and Metrick 2001).
} 
National Retirement Risk Index indicated that 43 percent of today's households will be unlikely to maintain their preretirement living standards in retirement. ${ }^{4}$ The number would be even higher if retirement were assumed to occur at 63 , the current average retirement age for men, rather than 65 .

The current work in behavioral finance, which brings together economics, finance, and psychology, has tried to identify some of the factors that lead to poor preparation for retirement. Not surprisingly, one problem is myopia - that is, people are absorbed in their daily routines, or prefer not to think of their own old age, and fail to see what lies in the future. This myopia is enhanced by the fact that saving and investment decisions are complicated.

A second problem is the low value many people seem to place on their future well-being. One explanation offered by psychologists and economists is that people are "hyperbolic" discounters, in that their near-term discount rates are much higher than their long-term discount rates. 5 In the case of saving, a dollar put aside today is seen as growing fast in the short run but slowly thereafter, so benefits more than a short period away have very little value. In old age, of course, such people would say they consumed far too much and saved far too little when young.

A third issue is self-control. 6 That is, many people say they should be saving for retirement but find it very difficult to act on that knowledge. Inertia and procrastination are major components of the discipline problem with regard to saving behavior. Researchers find that making decisions about retirement is one area where workers are likely to procrastinate. In fact, even today, one common response of workers as to why they do not participate in saving plans is, "I never get around to it." Some reasons that people never get around to it are obvious: A secure retirement tomorrow involves sacrificing consumption today, postponing the start of saving has no immediate penalty, and the process is complicated.

Because of lack of discipline, workers often need commitment devices to ensure that they put money aside. ${ }^{7}$ Employer-based plans that automatically take money out of the paycheck are one sort of device. The simple Christmas Club is another, where a group of people bind together and commit to putting aside so much money per month. Financial planners often urge clients to "pay yourself first" as a discipline for saving. Others purposely have their employers over-withhold on their personal income tax so they will get a large refund at tax time, even though they have given the government an interest-free loan in the meantime.

\footnotetext{
${ }^{4}$ See Center for Retirement Research (2006). Earlier studies had come to similar conclusions. Moore and Mitchell (2000) found only 30 percent of the population was prepared for retirement, another 30 percent was likely to close the savings gap before age 65 -leaving 40 percent that would never be prepared. 5 See Laibson, Repetto, and Tobacman (1998).

6Thaler and Shefrin (1981).

${ }^{7}$ See Laibson (1997). A recent commitment device is the Thaler and Benartzi (2004) "Save More Tomorrow" program. Under this plan, individuals who want to save more-but indicate that they cannot do so now-make a commitment to increase their contributions at some time in the future.
} 
At the beginning of the industrialization process, the fact that workers had no role models intensified the effect of these psychological impediments to saving. Their parents and grandparents had not actively saved for retirement and had rarely "retired" from work for any significant length of time. Thus, retirement saving probably did not seem like a necessary undertaking and the penalties for not saving were not immediately obvious.

But the failure to save caught up with these early industrial workers. Around the turn of the century, the labor force participation of older men dropped sharply, in large measure because of their inability to find work at a reasonable wage. ${ }^{8}$ The elderly became the subject of public and private charity. And the federal government greatly expanded Civil War pensions to include all veterans, not just the sick and disabled, and the availability of these pensions significantly expanded the retirement of Northern native-born men. ${ }^{9}$

The response to a growing number of distressed older workers in every industrial nation, not just the United States, was the creation of retirement income programs by large employers and national governments. The earliest programs were pension plans set up by large employers - first governments, then railroads and public utilities, then large manufacturers and service-providing enterprises. (These will be discussed later.) But by the 1930s, employer-sponsored plans in the United States covered only 15 percent of the workforce. Therefore, the responsibility fell to government.

\section{Player \#2: The Government}

The U.S. government, like governments in virtually all developed countries, supports household life-cycle saving directly through social insurance programs for income and health benefits and indirectly through tax incentives to encourage lifecycle saving through employer-sponsored plans or by individuals themselves. It also defines the retirement age, which separates the period of saving from that of drawing down assets. And it regulates financial intermediaries through which people accumulate retirement assets and purchase de-cumulation vehicles.

\section{Direct Support of Life-Cycle Saving: The Social Security} Program. The United States created its Social Security program in 1935, in the midst of the Great Depression. It was one of the last industrialized countries to do so. The severe economic downturn, combined with a surge in the supply of older workers, dramatically worsened the employment and income problems of the

\footnotetext{
8 According to Moen (1987), the labor force participation rate for men 65 and over declined from 73.8 percent in 1890 to 65.4 percent in 1900 to 58.1 percent in 1910.

${ }^{9}$ For an extensive description of the evolution of retirement, see Costa (1998).
} 
elderly. $10 \mathrm{~A}$ critical need for financial support thus emerged at a political moment especially conducive to major institutional innovation. The legislation enacted in 1935 had two components. The first addressed the immediate crisis with a meanstested program called Old-Age Assistance. The second addressed the continuing problem of providing income for the elderly who could no longer work with a program called Old-Age Insurance, what we now think of as Social Security.

The elderly nevertheless remained a distinctly poor population. The critical 1950 Social Security Amendments substantially expanded coverage and restored benefits that had been seriously eroded by inflation during the war, but replacement ratesbenefits relative to preretirement earnings - remained at 30 percent for the model average worker. Given the widespread acceptance of retirement as a legitimate period of rest after a lifetime of work and the low level of government benefits, a significant expansion of the retirement income system was essential. ${ }^{11}$ Although employer plans did expand, it eventually became clear they were never going to fill the gap.

In 1972, Congress sharply increased Social Security benefits, to roughly a 40 percent earnings replacement rate for the benchmark average earner. The expansion of Social Security and employer-sponsored pensions during the long postwar boom allowed the elderly, on average, to maintain a reasonable approximation of their preretirement living standard for the first time in history.

Soon after Social Security's expansion, however, it became clear that the cost of pay-as-you-go government plans would dramatically rise in the future. Rapid population aging would require a drastic increase in payroll tax rates to finance benefits. Moreover, the program faced a short-term funding crisis. In response, the National Commission on Social Security Reform, headed by Alan Greenspan, presented a series of reforms that enabled the system to pay immediate benefits and supposedly restored solvency over the 75-year horizon. One component of the 1983 reform package that will have important implications going forward is the extension of the normal retirement age (NRA) from 65 to 67 because if people do not work longer, they will see a cut in their Social Security replacement rates.

10Some experts also contend that the desire to remove older workers from the labor force was another motivating factor, but DeWitt (1999) makes a persuasive case against such a motivation.

11 Social Security benefits were available at age 65 , the program's "normal retirement age," and were granted only if the worker withdrew from the labor force. They also came with a "take it or lose it" feature that intentionally or not encouraged retirement: Benefits were not increased if claimed at a later age, so the compensation of a worker age 65 or over was effectively reduced by the amount of the foregone benefit. The availability of government pensions, the definition of 65 as the "normal" age of retirement, and the incentives to leave work at that age led to the widespread acceptance of "retirement." 
Despite the 1983 increase in revenues and reduction in benefits, deficits appeared almost immediately after the legislation and increased sharply in the early 1990s. ${ }^{12}$ At this point, Social Security can pay full benefits through 2040.13 Thereafter, payroll taxes are sufficient to cover only about 70 percent of commitments. The financing shortfall means that the American people will have to choose between an increase in taxes and a further reduction in benefits or some combination of the two.

But today, government-sponsored social insurance is a key component of lifecycle saving in the United States. As shown in Figure 1, households in the bottom third of the older population get 86 percent of their income from Social Security; those in the middle third, 71; and those in the top third, almost 40 percent. The provision of these benefits through a national social insurance program counterbalances the wide-spread myopia with regard to retirement income needs and ensures those with the lowest level of income enough to survive in retirement.

\section{Figure 1. Sources of Nonearned Income for Households by Tercile: Age 65 and Older, 2005}

\section{A. Bottom Tercile}

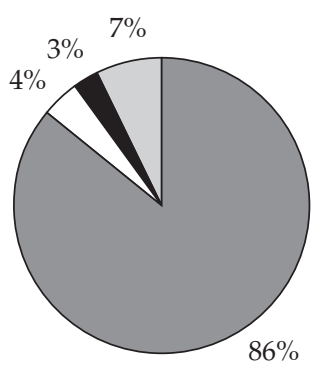

B. Middle Tercile

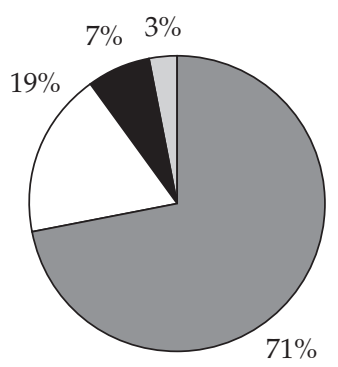

Social Security

Assets
C. Top Tercile

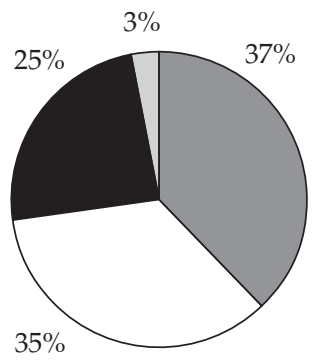

Note: Earnings not included.

Sources: Author's calculations based on U.S. Bureau of Labor Statistics and U.S. Bureau of the Census (2005).

12Why did the balance deteriorate? Leading the list is the impact of changing the valuation period. That is, the 1983 report looked at the system's finances over the period 1983-2058; the projection period for the 2005 report is 2005-2079. Each time the valuation period moves out one year, it picks up a year with a large negative balance. This is the reason policymakers now insist on looking beyond the 75-year projection period when considering ways to restore solvency.

13U.S. Social Security Administration (2006b). 


\section{Direct Support of Life-Cycle Saving: The Medicare Program.}

Another mechanism for life-cycle saving is the Medicare program, which was enacted in 1965. The hospital insurance part of the program fits perfectly into the life-cycle saving model of social insurance. Workers and their employers contribute payroll taxes over their work lives and are entitled to payments to cover the cost of hospital care once they reach age 65 . Physician services and drugs are also covered by Medicare. The part of this latter benefit financed by general revenues can be thought of as life-cycle saving in that people pay taxes over their work lives to qualify for payments toward physician and drug expenditures in retirement.

Indirect Support of Life-Cycle Saving: Tax Expenditures. For middle- and higher-income individuals, the government encourages life-cycle saving in employer-sponsored programs through favorable tax provisions. ${ }^{14}$ The tax code allows businesses and individuals to take an immediate deduction for contributions to either a defined-benefit or defined-contribution plan and does not levy a tax until the monies are paid out in retirement. As a result, employees pay significantly less tax on compensation received in the form of deferred pension benefits than in the form of cash wages. The approach of federal pension policy as far back as the 1940s has been to provide tax incentives that will encourage highly paid employees in higher marginal tax brackets to support the establishment of employer-provided pension plans and then to use regulations to assure that the tax incentives apply only to plans that also benefit the rank and file.

Policymakers have never defined exactly what sort of pension coverage they expected to occur as a result of the favorable tax treatment of pensions. The issue of who belonged to the "rank and file" was not very clearly defined until 1986 legislation set an upper income limit for this group, which, indexed for inflation, reached $\$ 98,000$ in 2006.15 But the rank and file as defined by pension policy has never included those who end up in the bottom third of the income distribution after retirement. In 2004, pensions accounted for only 4 percent of the retirement income of the lowest third of the over-65 households.

The cost of these favorable tax provisions is very high. After deducting the present value of future tax payments on benefits, the revenue loss to the Treasury is an estimated $\$ 184$ billion for 2006 (see Table 1). 16 This amounts to 20 percent of federal income tax revenues and more than 30 percent of payroll taxes collected to support the old-age portion of Social Security.

14The government also provides tax incentives for life-cycle saving for the self-employed and individuals themselves through Keogh Plans and Individual Retirement Accounts, respectively.

15 For a fuller discussion, see Halperin and Munnell (2005).

16These provisions, which permit tax deferral on both contributions and the earnings on those contributions, are equivalent to exempting from taxation the earnings on the money that would have been invested after tax, assuming the employee remains in the same tax bracket. 
Table 1. Tax Expenditures for Public and Private Pensions, 2006

\begin{tabular}{lc}
\hline Type of plan & $\begin{array}{c}\text { Expenditures } \\
\text { (billions) }\end{array}$ \\
\hline Employer plans & $\$ 81.2$ \\
401(k) plans & 102.6 \\
Total & $\$ 183.8$ \\
\hline
\end{tabular}

Notes: These numbers are the present value of tax expenditures- that is, the revenue effects net of future tax payments for pension contributions and earnings in 2006. Estimates include plans that cover both public and private civilian employees. Additional tax expenditures for Individual Retirement Accounts and Keogh Plans amounted to $\$ 4.5$ billion and $\$ 3.2$ billion, respectively.

Source: U.S. Office of Management and Budget (OMB) (2005).

In addition to pensions, the tax system also favors another form of savingsaving by purchasing a house and paying off the mortgage. Traditionally, retirees have not tapped their home equity to support themselves in retirement but, rather, used it to cover health crises late in life or to bequeath to their children. ${ }^{17}$ In the future, however, in the face of a contracting retirement income system discussed later, many people are going to have to turn to their home as a source of support. Housing is treated very favorably under the personal income tax. Imputed rent is not included in taxable income, but some of the expenses of owning a home, such as mortgage interest and property taxes, are deducted. Moreover, the first $\$ 250,000$ of capital gains ( $\$ 500,000$ for a couple) is tax exempt. These two provisions are estimated to cost the government $\$ 117$ billion in 2006 according to the tax expenditure budget (see Table 2).

\begin{tabular}{lc} 
Table 2. & $\begin{array}{l}\text { Tax Expenditures for Owner-Occupied } \\
\text { Housing, } 2006\end{array}$ \\
\hline Provision & $\begin{array}{c}\text { Expenditures } \\
\text { (billions) }\end{array}$ \\
\hline Deductibility of mortgage interest & $\$ 62.2$ \\
Deductibility of state/local property taxes & 19.1 \\
Capital gains exclusion on home sales & 36.0 \\
Total & $\$ 117.3$ \\
\hline
\end{tabular}

Source: OMB (2005).

${ }^{17}$ See Venti and Wise (2001). 
Defining the Retirement Age. The government has also played a major role in defining the retirement age, which in a life-cycle-saving context determines the period for saving and for dis-saving. When Congress established 65 as the age of eligibility for Social Security benefits, it was following precedents set internationally and by employer-sponsored plans. Thus, Congress was institutionalizing an existing norm. But in 1956, Congress lowered Social Security's earliest eligibility age (EEA) for women to 62.18 The introduction of an EEA for men followed in 1961, primarily in response to a recession that left many older workers without employment.

The early retirement benefits are actuarially reduced, and the reduction is designed to be "age neutral." That is, two people with average life expectancy-one who claims benefits at 62, the other at 65-receive equal lifetime Social Security benefits. ${ }^{19}$ The existence of the EEA means that most Americans have an important choice to make once they turn age 62: Claim reduced Social Security benefits right away or delay until some further date and receive a larger benefit. The result is that most people now claim benefits well before age 65 (see Table 3). In 2004, 59 percent of women and 54 percent of men claimed benefits at age 62 . The claiming of benefits coincides with the average retirement age, which is now 63 for men and 62 for women. ${ }^{20}$ By introducing the earliest eligibility age for Social Security benefits, the government appears to have endorsed age 62 as the nation's retirement age.

Table 3. Percent Distribution by Age of Initial

Social Security Benefit Awards, 2004

\begin{tabular}{lcc}
\hline Age & Women & Men \\
\hline 62 & $59.1 \%$ & $53.8 \%$ \\
63 & 7.7 & 8.1 \\
64 & 10.2 & 11.2 \\
65 & 17.3 & 23.2 \\
66 and over & 5.9 & 3.7 \\
Total & $100 \%$ & $100 \%$ \\
\hline
\end{tabular}

Sources: U.S. Social Security Administration (2006a) and author's calculations.

18 The change was made primarily to help younger widows and to allow wives, who were presumed to be two to three years younger than their husbands, to claim benefits at the same time as their husbands. Because it seemed unfair to require women workers to wait until a later age for benefits than women nonworkers, the EEA was introduced for all women. See Congressional Budget Office (1999).

${ }_{19}$ More specifically, benefits are reduced by 5/9th of 1 percent for each month they are received prior to the normal retirement age (NRA) up to 36 months and 5/12th of 1 percent for each month thereafter. This is equivalent to a 6.67 percent reduction for the first three years prior to the NRA and 5 percent thereafter. With an NRA of 65 , a person who claims benefits at age 62 receives monthly benefits 20 percent lower than the full amount. The scheduled increase in the NRA from age 65 to 67 raises the actuarial reduction for claiming benefits at age 62 from 20 percent to 30 percent.

20 The average retirement age is defined as the age that 50 percent of the cohort is out of the labor force. 
Social Security's retirement age for full benefits is scheduled to increase from 65 to 67 by 2022.21 But under current law, the EEA remains unchanged at 62 . Raising the NRA, however, will increase the actuarial reduction for claiming benefits at age 62 from 20 percent to 30 percent. Because people's claiming behavior and retirement decision appear more sensitive to the availability of benefits than to benefit amounts, age 62 is likely to remain the nation's official retirement age. 22

Regulation of Financial Intermediaries. Financial intermediaries play a significant role in life-cycle saving. Institutions such as banks and securities firms connect those who want to build up retirement assets through saving with those who want to increase their current spending through borrowing. Life insurance companies provide annuities to insure against outliving resources in retirement. It is important that these institutions follow sound financial practices and deal honestly with the public.

To this end, a variety of agencies at both the state and federal levels regulate financial intermediaries in order to prevent fraud, abuse, and instability. Although regulatory activity in several countries has been consolidated, in the United States, agencies specialize in specific categories of financial intermediaries, such as banks, securities firms, or insurance companies. Both federal and state agencies regulate the banking industry, whereas agencies at the federal level, principally the SEC, are the primary regulators of the securities industry. Regulation of insurance companies remains at the state level, with coordination through the National Association of Insurance Commissioners. Although regulation remains fragmented, the government has been fairly successful in ensuring that people's accumulated assets are there when they need them in retirement.

In short, throughout most of the second half of the 20th century, the provision of retirement income was the joint product of a national social insurance program and employer-sponsored defined-benefit plans, subsidized through favorable treatment under the personal income tax, and protected by federal and state regulation of financial intermediaries.

\section{Player \#3: Employers-The Rise and Fall of Employer Pensions}

Retirement income systems in industrialized countries evolved in two very different ways after World War II. The nations on the European continent, with private industry devastated by the war and with a strong tradition of publicly provided

21The increase began with individuals born in 1938, for whom the NRA is 65 plus two months, and increases two months per year until it reaches age 66. Then, after a 12-year hiatus, the NRA again increases by two months per year until it reaches age 67 for individuals born in 1960 or later.

22 Studies showing the availability of benefits as the major effect on retirement include Burtless and Moffitt (1984), Hurd (1990), and Gruber and Wise (1998). 
welfare, opted for generous government-provided pensions. The United States and other "Anglo-Saxon" nations, such as the United Kingdom, Australia, and Canada, which were spared the worst ravages of war and which held a far more restrictive view of the role of the state, maintained a mixed government-employer system that provided basic social insurance and supplemental employer pensions.

Employer pensions had evolved over the course of the 19th century. Large U.S. employers, which came to have huge numbers of permanent employees, introduced pensions as instruments for shaping their relationship with their workforce. Pensions helped develop career employees and managers, to whom large employers increasingly delegated authority to oversee their operations. Such workers had to invest in organization-specific skills and relationships, make decisions in the best interest of the organization, and do so with limited oversight. Pensions paid a comfortable benefit, pegged to salary and years of service, to those white-collar workers who remained with the employer to the specified retirement age. Workers who left early typically got only a return of their own contributions. The pension thus functioned as an incentive to remain with the organization, do good work, and rise in the ranks.

Pensions also proved valuable in shaping relationships with blue-collar workers. Organizations in industries such as railroads, urban transit, and manufacturing employed very large numbers of blue-collar workers to operate their capitalintensive, high-throughput operations. These employers typically paid high market wages to attract better workers, win their loyalty, and fend off unions. But beyond a certain point, employers found it more effective to provide "industrial insurance" rather than ever-higher wages. This insurance protected workers and their families against the loss of earnings caused by accident, death, illness, or age.

Finally, by the end of the 19th century, many large employers saw their offices, machine shops, and locomotives increasingly staffed by older workers whose productive abilities had clearly declined. So, beginning at the turn of the century in the United States, large employers began to mandate retirement at a specified age. To remove older workers without damaging relations with the rest of the workforce, or the public at large, they retired these workers on pension.

By the end of the 1930s, employer pension plans had become standard in mature big businesses. They were critical personnel tools for strengthening, then severing, relationships with workers. As noted above, employer plans covered about 15 percent of the workforce when the Social Security program began.

After World War II, Social Security benefits remained low, so the AngloSaxon approach to the provision of retirement income required a significant expansion of employer plans. And employer plans did expand in the United States 
(see Figure 2) and other Anglo-Saxon nations.23 These plans had become an essential component of corporate personnel systems, so coverage grew as corporate big business blossomed.24 The special tax treatment of employer pensions also became significantly more valuable in the face of mass income taxation. 25 And unions, which had gained powerful collective bargaining rights, made pensions a standard component of labor agreements throughout the unionized sector in the decade that followed.26

Business participation in the provision of old-age income had taken root by the mid-1960s. In combination with Social Security, employer-sponsored definedbenefit plans provided long-service workers a secure and comfortable retirement. Costs were low because employer plans generally got sophisticated financial advice and did not incur significant administrative or marketing expenses. They were also funded to a significant extent with high-yielding equities, with market fluctuations smoothed over time by the long-lived corporate sponsor. Nevertheless, employer plans covered at best half the workforce. Many covered workers would quit or lose their jobs before gaining a pension. Others would see their plans go bust and their benefits lose much or all of their value.

In response to these shortcomings, Congress enacted the Employee Retirement Income Security Act (ERISA) of 1974 to make employer pensions a more secure and widely distributed component of the national retirement income system. ERISA did that by imposing vesting, funding, and governance requirements (which have subsequently been tightened) and required employers to purchase insurance from the new Pension Benefit Guaranty Corporation (PBGC).

Just as demographic shifts undermined the government's Social Security program soon after its expansion, structural economic shifts seriously weakened employer plans soon after the enactment of ERISA. Beginning in the early 1980s, globalization and sharp increases in the educational attainment of the labor force, in the technical level of production, and in the employment of married women had various corrosive effects. First, these forces undermined the power of unions, a major

23For a fuller discussion of the role of employer plans in Anglo-Saxon countries, see Munnell and Sass (2006).

24The long big-business boom was largely driven by giant mass-production mass-distribution enterprises - in industries ranging from autos, steel, and consumer goods to telecommunications, banking and insurance, transport, and public utilities.

25 Favorable tax provisions had a limited effect on coverage before the war because less than 10 percent of the adult population typically paid tax, and even those who did, paid low rates. But the postwar growth of mass income taxation made pensions far less costly to employers and workers and encouraged their spread.

26The big industrial unions won generous pension benefits in 1949 and 1950 as part of a political settlement that included long-term labor agreements, controls on labor militancy, and the passage of the 1950 Social Security Amendments. 
Figure 2. Percent of U.S. Private Sector Wage and Salary Workers Covered by Employer Plans, 1940-1995

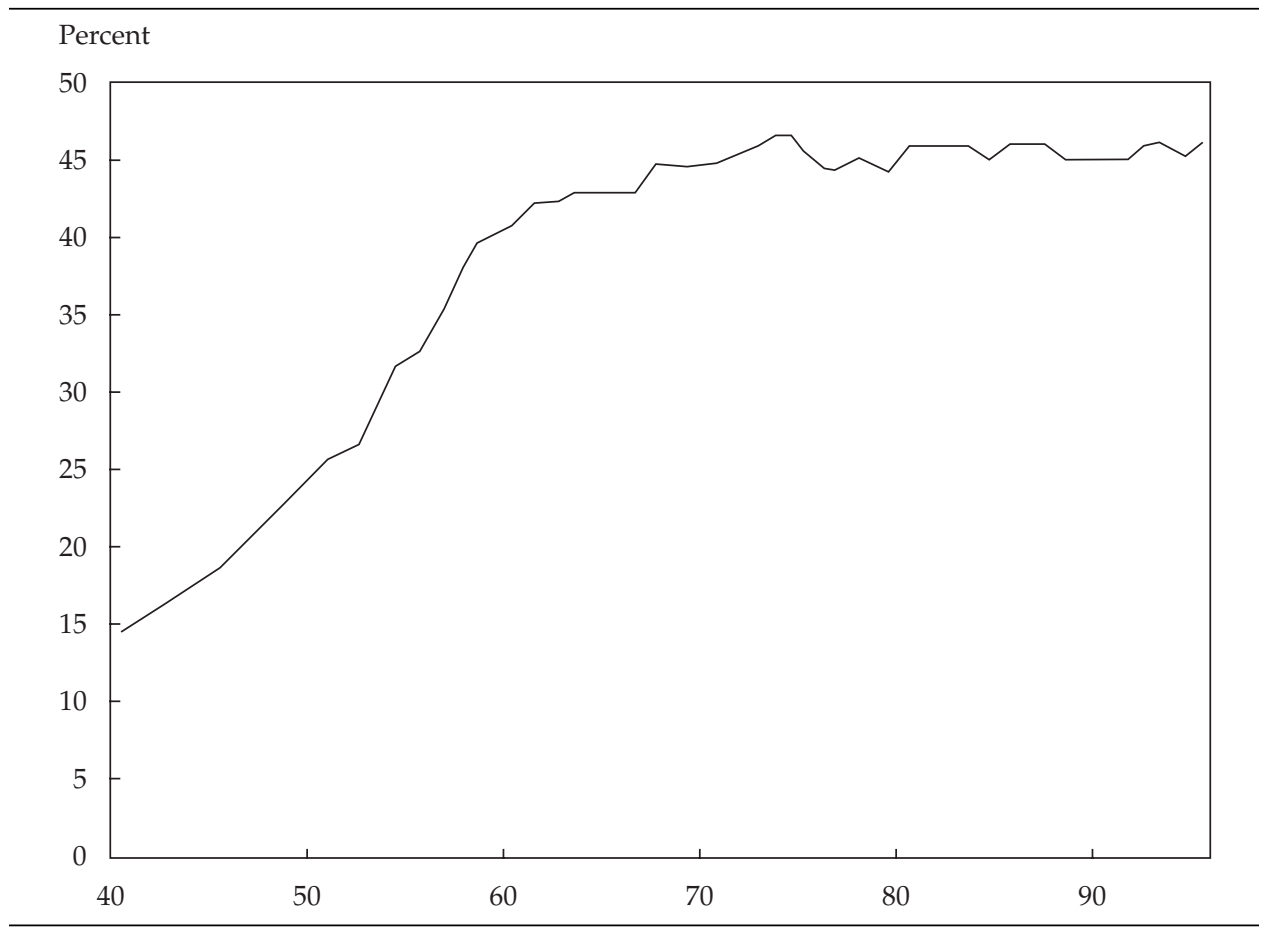

Sources: Skolnik (1976); U.S. Department of Labor (1999 and 2006).

factor in the postwar expansion of employer plans. Second, these forces undermined the financial stability of large corporate employers, making the assumption of longterm pension obligations a more risky undertaking. Finally, the changing labor force-more female, educated, and young-diminished the appeal of life-long careers, especially for the higher-paid workers that employer plans primarily serve. So, employers started to back away from defined-benefit plans as a tool of personnel management. As new companies adopted 401(k) plans and employment in industries with defined-benefit plans declined, overall pension coverage shifted to $401(\mathrm{k}) \mathrm{s} .{ }^{27}$

Just as employers had increasingly little to gain by offering pensions, the costs of such benefits also began to rise. Workers were living longer, making life annuities increasingly expensive. The reduction in inflation in the 1980s and 1990s raised the

27Most of the movement to $401(\mathrm{k}) \mathrm{s}$ since 1981 occurred as a result of three developments: (1) the addition of 401(k) provisions to existing thrift and profit-sharing plans; (2) a surge of new 401(k) plan formation in the 1980s; and (3) the virtual halt in the formation of new defined-benefit plans. Until recently, the only companies closing their defined-benefit pension plans were those facing bankruptcy or struggling to stay alive. 
real cost of un-indexed lifetime payments. The imposition of new government regulations made it increasingly expensive to operate a defined-benefit plan. In lessthan-fully-funded plans, a dramatic increase in the number of retirees required large contributions relative to the size of the company. Finally, because employer plans held a significant portion of their assets in equities, large maturing plans produced significant volatility in company earnings and cash flow, with large losses and a spike in required contributions emerging in recessions, when sponsors were stressed.

In the 1980s, major economic shocks hit key U.S. industries-specifically steel and airlines - that had pension plans with large unfunded liabilities left over from the past. These shocks led to large pension insolvencies, major deficits at the PBGC, and the imposition of tougher funding requirements, primarily on sponsors of weak defined-benefit plans. In 2000, the nation's now enormous pension plans had a dramatic effect on the finances of their sponsors. The slump in the equities markets (producing a fall in the value of pension fund assets) and the decline in interest rates (producing a sharp rise in the present value of future plan obligations) required employers to nearly triple their contributions from $\$ 33$ billion in 2000 to $\$ 96$ billion in 2003.28 This financial pressure intensified employer interest in exiting definedbenefit commitments. Finally, in the past few years, even large healthy companies with well-funded pensions have begun to either close their plans to new entrants or end pension accruals for current as well as future employees. 29

As shown in Figure 3, coverage has shifted dramatically from defined-benefit plans, which pay lifetime benefits based on salary and years of service, to 401(k) plans, which are essentially savings accounts. 30 In 1980, 83 percent of private sector workers with pension coverage had either a defined-benefit plan only or a definedbenefit plan and a supplementary defined-contribution plan. By the early 1990s, that percentage had declined to 57 percent, and in 2004, it was 39 percent. Most workers today rely on 401(k) plans, where the employee bears the risk and responsibility for life-cycle saving, as their only source of employer-sponsored retirement saving. Employers have adopted some provisions, such as automatic enrollment, automatic escalation of default contribution rates, life-cycle funds, and managed accounts, to make these plans easier and more automatic. But employers are no longer interested in having the responsibility for, and bearing the risks of, their employees' life-cycle saving.

28These numbers come from the Department of Labor's Form 5500. See Buessing and Soto (2006). 29 See Munnell, Golub-Sass, and Varani (2005).

${ }^{30}$ The annuity under a defined-benefit plan might be a dollar amount per month for each year of service, say $\$ 50$; so workers with 20 years of service would receive $\$ 1,000$ per month at age 65 . The benefit could also be a percentage of final salary for each year of service, say 1.5 percent; so workers with 20 years would receive 30 percent (20 years at 1.5 percent) of final salary for as long as they live. The employer finances these benefits by making pretax contributions into a pension fund, holds the assets in trust, directs the investments, and bears the risk. 
Figure 3. Private Sector Workers with Pension Coverage by Pension Type, 1980, 1992, and 2004

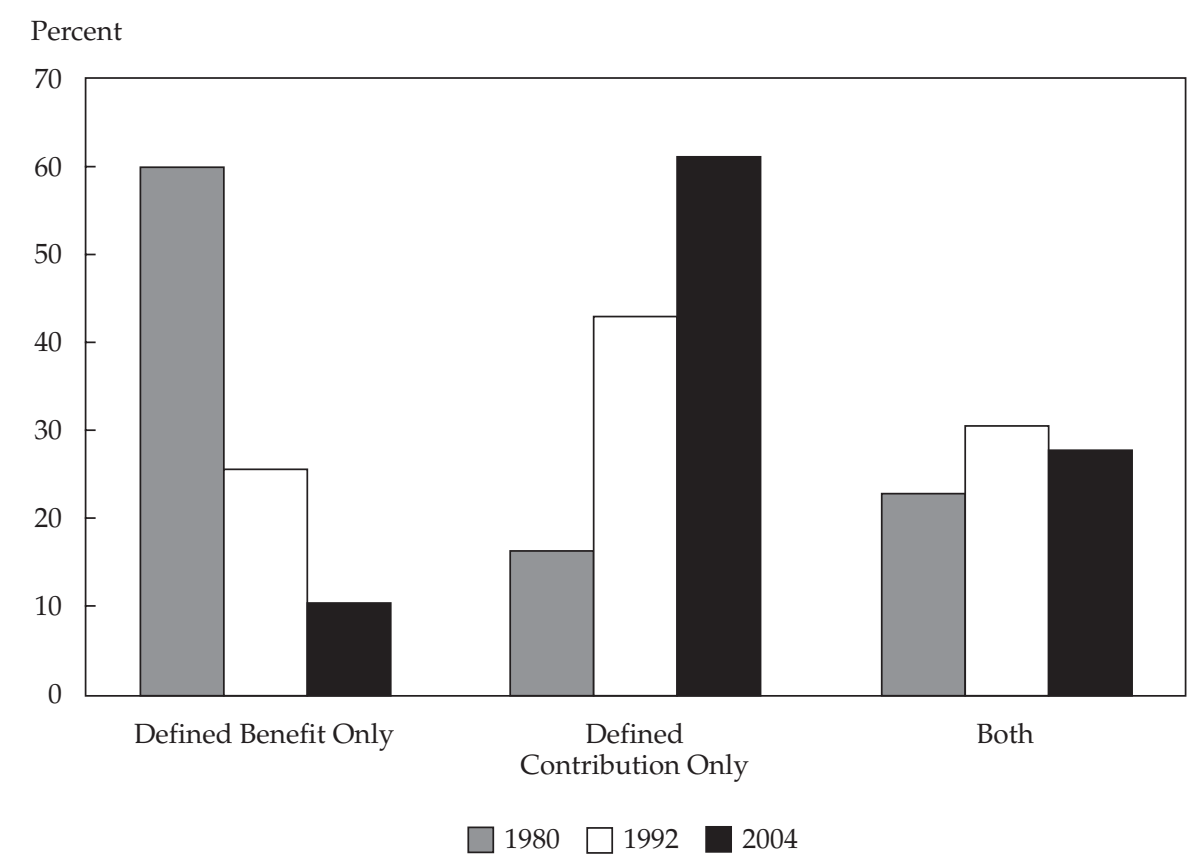

Note: Although these calculations adjust for double-counting, some overestimation of coverage may still remain.

Sources: U.S. Department of Labor (2004) and author's calculations from U.S. Department of Labor (2006).

The preceding discussion has focused on the withdrawal of employers from life-cycle saving in the form of cash benefits. Employers have also cut back on their provision of postretirement health care benefits, which is another way that employers helped spread resources over the life cycle. Between 1988 and 2006, the percent of large firms offering postretirement health care benefits dropped from 66 percent to 35 percent (see Figure 4). The decline in participating firms actually understates the extent of the cutback because the generosity of the benefits has also been reduced. In response to the rising costs of health care, employers have increased retiree contributions to premiums, increased retiree coinsurance or co-payments, raised deductibles, and increased out-of-pocket limits. ${ }^{31}$ Moreover, many of those providing postretirement health benefits today have terminated such benefits for new retirees. Thus, workers need to save more on their own today than they did in the past to cover health care costs that were previously borne by the employer.

${ }^{31}$ Kaiser/Hewitt (2005). 
Figure 4. Percentage of Employers Offering Retiree Health Benefits (Large Firms with 200+ Workers)

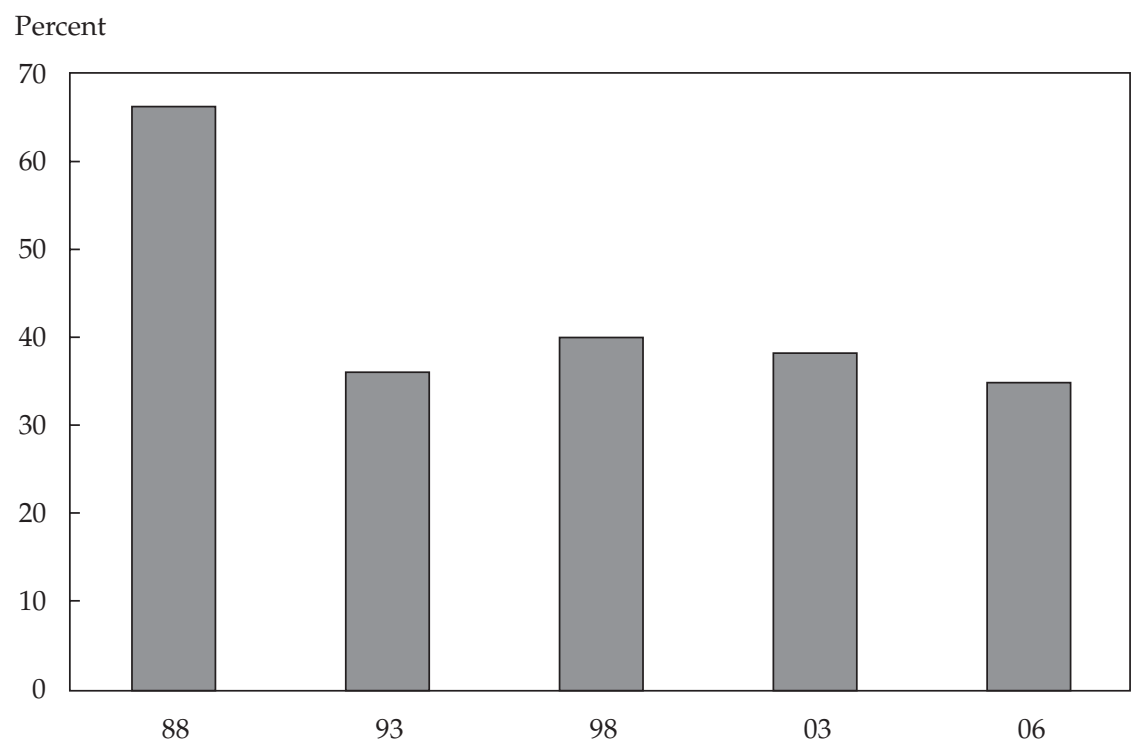

Source: Kaiser/Health Research and Educational Trust (2006).

\section{Other Developments Affecting Life-Cycle Saving}

Before considering the role of government in a world without significant employer participation in life-cycle saving, it is useful to look at a number of other factors that might shape that role. These include the increase in the period that people are spending in retirement, the contraction of the retirement income system, the assets of people as they enter retirement, the drain that college payments impose on many families trying to save for retirement, and the wild card created by potential expenditures on health care and long-term care.

Retirement Spans Are Increasing. Despite a recent uptick in the labor activity of older people, the length of the retirement span has increased significantly and, without any change in behavior, will increase in the future (see Figure 5). Two factors determine the retirement span-the average age at retirement and life expectancy at that time. Until the mid-1980s, both factors played a role; the average retirement age was declining substantially, with early retirement available under both defined-benefit plans and Social Security. In the mid-1980s, the retirement age stabilized at about 62 for women and 63 for men. Since then, the increase in the retirement span reflects improved life expectancy. The typical person retiring today will spend about 20 years in retirement, and many will face longer spans. In 
Figure 5. Retirement Period of Males, 1950-2050

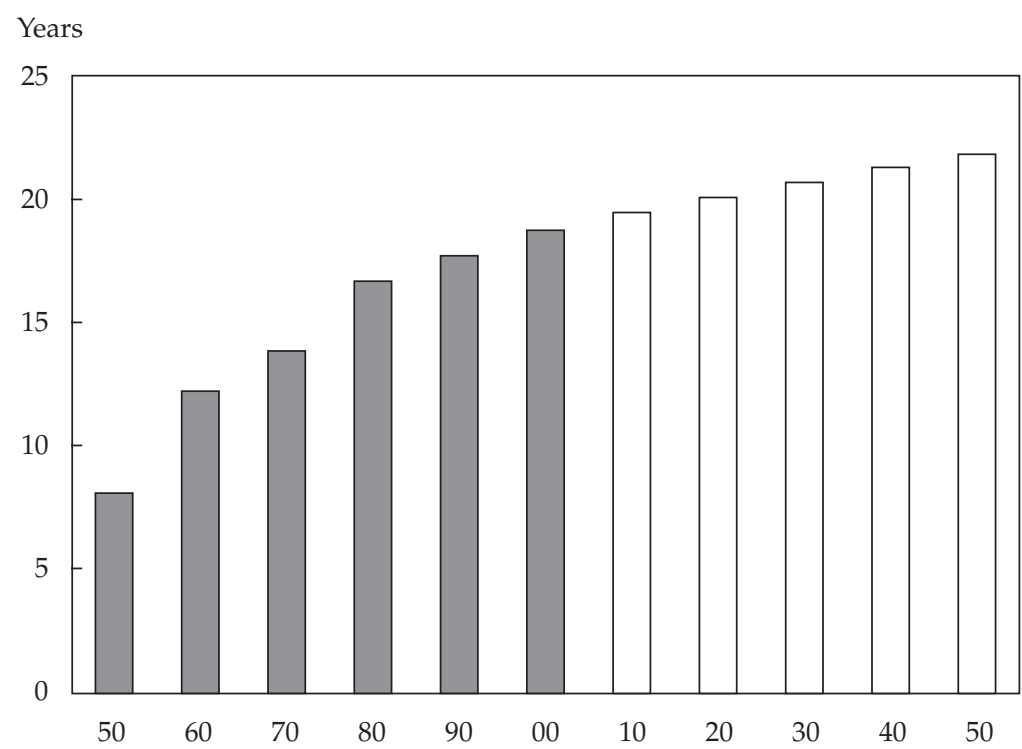

Sources: U.S. Bureau of Labor Statistics and U.S. Bureau of the Census (1962-2005) and author's calculations based on U.S. Social Security Administration (2006b), Table VA.4.

fact, a couple retiring today faces a 50 percent chance of having at least one member live to 92.32 Therefore, people face the prospect of having to support themselves for a long time on their accumulated retirement assets.

Retirement Income System Is Contracting. At the same time that retirement spans are increasing, the retirement income system is contracting. Social Security will replace less of preretirement earnings in the future than it does today because of the extension of the NRA from 65 to 67, the deduction of Medicare premiums, which are taken out before the check goes in the mail, and the increased taxation of benefits under the personal income tax. As shown in Figure 6, the net Social Security replacement rate-benefits as a percent of preretirement earningswill decline from 39 percent today for the median worker to 30 percent in 2030.

And as discussed in the previous section, pension coverage in the private sector has shifted from defined-benefit to defined-contribution plans-primarily 401(k)s. When 401(k) plans began to spread rapidly in the early 1980s, they were viewed mainly as supplements to employer-funded pensions and profit-sharing plans. Because $401(\mathrm{k})$ participants were presumed to have their basic retirement-income security needs covered by an employer-funded plan and Social Security, they were

${ }^{32}$ Society of Actuaries (2006). 


\section{Figure 6. Social Security Replacement Rates for the Medium Earner, 2002 and 2030}

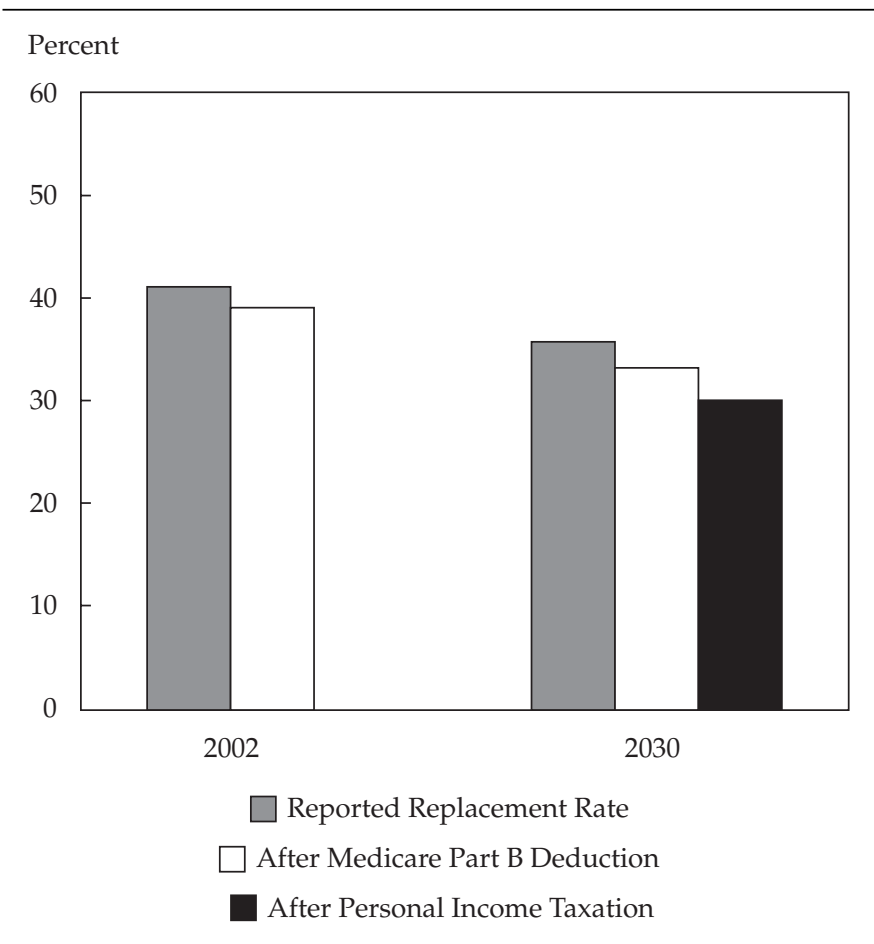

Note: 2030 incorporates extension of NRA.

Source: Author's calculations based on Munnell and Sundén (2004).

given substantial discretion over 401(k) choices, including whether to participate, how much to contribute, how to invest, and when and in what form to withdraw the funds.

Even though most workers covered by an employer plan now rely on 401(k)s, these plans still operate under the old rules. Payouts must commence at age $701 / 2$, reflecting tax policy rather than retirement income policy. Spouses have no protected survivor benefits, as ERISA required in defined-benefit plans. Nor are $401(\mathrm{k})$ plans subject to the same prudent investment management rules. Workers continue to have almost complete discretion over whether and how much to contribute, how to invest, and how and when to withdraw the funds.

In theory, workers should be able to accumulate substantial balances in $401(\mathrm{k})$ plans, but in practice, most participants make mistakes at every step along the way. A quarter of those eligible to participate choose not to do so. Over half fail to diversify their investments. Many overinvest in company stock. Almost no participants rebalance their portfolios as they age or in response to market returns. Most importantly, many cash out when they change jobs. And at retirement, very few 
annuitize. The basic problem is that financial decisions are difficult. Most participants lack sufficient financial experience, training, or time to figure out what to do. As a result, in 2004 median 401(k)/IRA balances for a head of household approaching retirement were only $\$ 60,000$ (see Figure 7). 33

\section{Figure 7. 401(k)/IRA Actual Accumulations by Age Group, 2004}

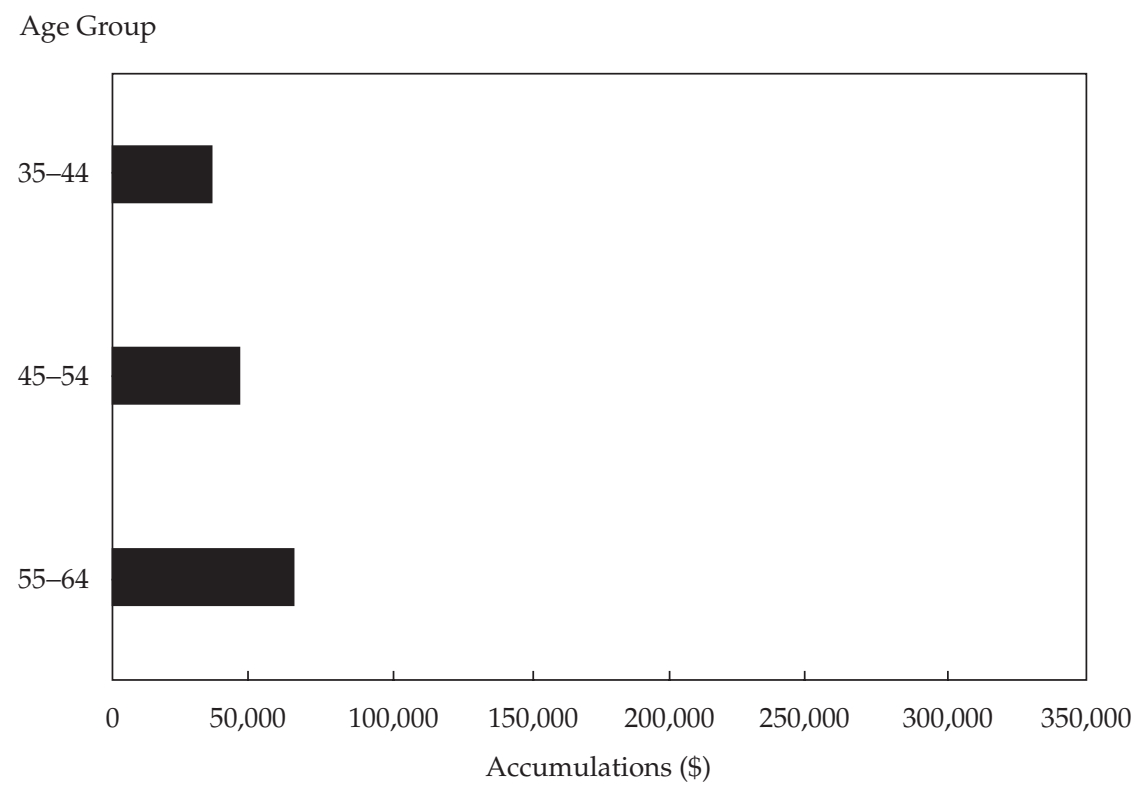

Sources: Munnell and Sundén (2004) and author's calculations from U.S. Board of Governors of the Federal Reserve System (2004).

College Expenses Hinder Retirement Saving. A new issue resulting from the shift from defined-benefit to $401(\mathrm{k})$ plans is that households are forced to make explicit choices in how to budget for retirement saving versus other uses of funds, a dilemma that did not exist when employer sponsors of defined-benefit plans controlled the retirement assets. A critical choice, for example, is how to finance college tuition, given an ability to tap 401(k) balances prior to retirement. Parents who use $401(\mathrm{k})$ assets for college expenses, or who reduce their contributions to $401(\mathrm{k}) \mathrm{s}$ because they are paying for college, could find their retirement threatened.

33IRA balances are included in the total because most of the money in IRAs is rolled over from employer-sponsored plans. The Investment Company Institute (2006), the national association for mutual fund companies, reported that 94 percent of the money flowing into traditional IRAs was rolled over from employer-sponsored plans over the period 1997-2003. 
Most People's Major Nonpension Asset Is Their House. Given the projected decline in Social Security, the diminished availability and increased uncertainty surrounding employer-sponsored defined-benefit pensions, and the low balances in 401(k) plans, one might have expected to see increased personal saving among those of working age. But the U.S. National Income and Product Accounts (NIPA) personal saving rate, which includes both employer and worker contributions and investment earnings in pension plans, hovers around zero. Of course, as economists have frequently pointed out, the NIPA personal saving rate is not an ideal statistic for measuring the extent to which people are preparing for retirement because it does not include capital gains, which could help finance postretirement consumption. ${ }^{34}$ More importantly, and less noticed, NIPA saving combines the saving of the working-age population with the dis-saving of retirees. And with retirees becoming an increasing portion of the population, their dis-saving imposes an increasing downward pull on the national saving rate.

Eliminating retirees from the saving calculation reveals two interesting facts. First, personal saving by the working-age population is significantly higher than the reported national rate (see Figure 8). 35 The pattern of saving over time is also easy to understand. The saving rate for the working-age population remains more or less steady until the last half of the 1990s. It then declines, presumably in response to the run-up in the stock market. When the bubble burst, the saving rate rebounded because people no longer had capital gains to spend.

Second, most of the time between 1980 and 2003, pension saving accounted for essentially all of personal saving. Today, saving outside of pensions is negative for the working-age population. Thus, other than employer contributions to defined-benefit plans, employee and employer contributions to $401(\mathrm{k}) \mathrm{s}$, and the investment income generated by these pension assets, the working-age population appears to be accumulating very little in the form of financial wealth.

The pattern observed in the NIPA is reflected in the holdings of people as they approach retirement. As shown in Table 4, the nonpension financial assets of the typical household approaching retirement amount to $\$ 42,000$. If a 65 -year-old couple used this amount to purchase an immediate annuity, the annuity would increase their retirement income by $\$ 250$ per month. That is not very much money, and inflation will erode its value over time. Moreover, the typical amount of financial assets even for those who are in the top quintile of the income distribution as they

34For example, see Gale and Sabelhaus (1999). Two other often cited flaws with NIPA personal saving include the following: (1) Consumer durables that generate services over an extended period of time (such as automobiles and dishwashers) are treated as consumption rather than investment, and (2) interest income and outlays are not adjusted for inflation. To the extent that capital gains result from a decline in investment returns and discount rates, the positive effect on retirement income security is offset by greater difficulty in drawing income out of those assets.

35 Allocating a portion of business saving - a proxy for capital gains-to working-age households further raises their saving rate. 
Figure 8. NIPA Personal Saving Rate: Working-Age Population with and without Pensions, 1980-2003

Percent

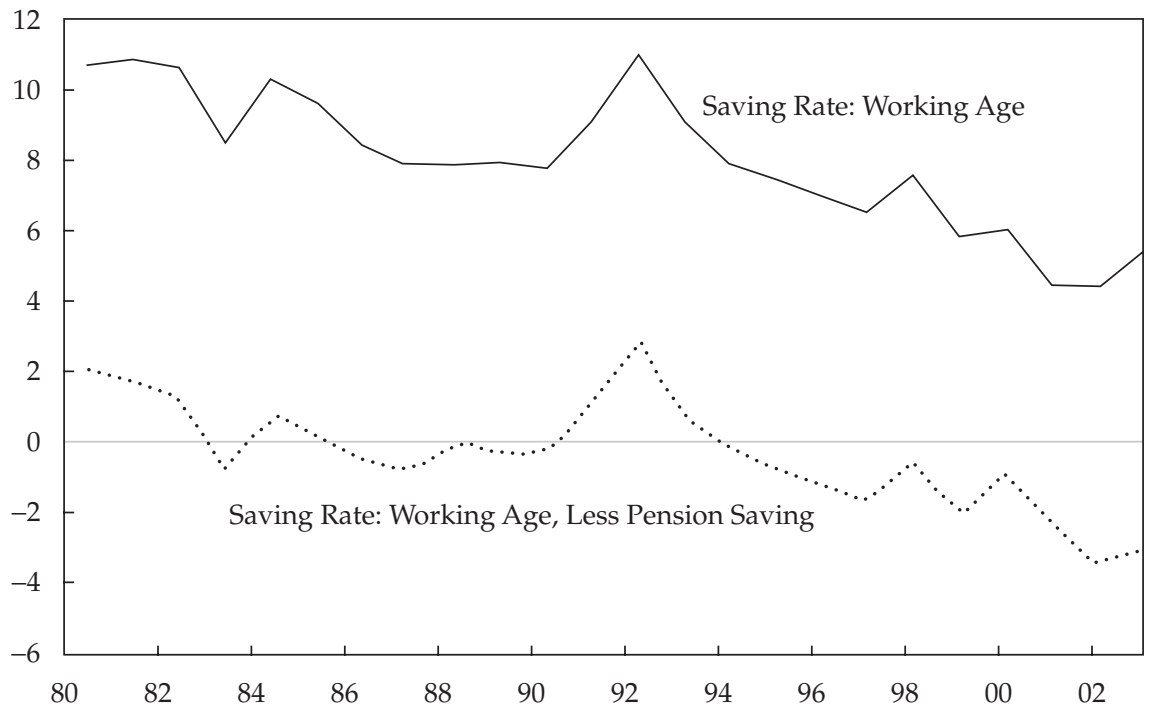

Source: Munnell, Golub-Sass, and Varani (2005).

Table 4. Wealth Holdings of a Typical Household Prior to Retirement, 2004

\begin{tabular}{lrc}
\hline Source of Wealth & Amount & Portion of Total \\
\hline Primary house & $\$ 125,208$ & $21 \%$ \\
Business assets & 10,370 & 2 \\
Financial assets & 42,014 & 7 \\
Defined contribution & 45,244 & 8 \\
Defined benefit & 96,705 & 16 \\
Social Security & 251,983 & 42 \\
Other nonfinancial assets & 26,402 & 4 \\
Total & $\$ 597,926$ & $100 \%$ \\
\hline
\end{tabular}

Note: The "typical household approaching retirement" refers to the mean of the middle 10 percent of the sample of households headed by an individual aged 55-64.

Source: Center for Retirement Research at Boston College calculations from U.S. Board of Governors of the Federal Reserve System (2004). 
approach retirement is only $\$ 155,000.36$ Therefore, households are not undertaking their life-cycle saving through the accumulation of nonpension financial assets.

The place where households are building up resources that could be used in retirement is their house. Typically, households purchase homes early in their lives financed by a substantial mortgage. Even though they may trade up to a larger house as their family grows and perhaps take on additional debt, the plan is often to end up mortgage free at retirement. Entering retirement, virtually all couples and a high percentage of single people own their home. In 2004, about 60 percent of homeowners were mortgage free (see Table 5). And for those who still had a mortgage, the outstanding amount had been substantially reduced. Thus, housing equity is the main nonpension source of life-cycle saving, and households will likely be forced to draw on this asset in the future. The question is, What is the most efficient and effective means to access this equity and what can government do to help?37

Table 5. Homeownership and Mortgage Debt by Age of Household Head, 2004

\begin{tabular}{lcccc}
\hline $\begin{array}{l}\text { Age of } \\
\text { Household Head }\end{array}$ & $\begin{array}{c}\text { Percentage of } \\
\text { Homeowners }\end{array}$ & $\begin{array}{c}\text { Median Value } \\
\text { of Home }\end{array}$ & $\begin{array}{c}\text { Percentage of } \\
\text { Homeowners } \\
\text { with Mortgage }\end{array}$ & $\begin{array}{c}\text { Median Value } \\
\text { of Mortgage }\end{array}$ \\
\hline $35-44$ & $68.3 \%$ & $\$ 160,000$ & $92.0 \%$ & $\$ 110,000$ \\
$45-54$ & 77.3 & 170,000 & 83.7 & 97,000 \\
$55-64$ & 79.1 & 200,000 & 64.4 & 83,000 \\
$65-74$ & 81.3 & 150,000 & 39.5 & 51,000 \\
$75-84$ & 85.8 & 120,000 & 26.1 & 30,000 \\
$85+$ & 83.5 & 141,000 & 8.9 & 40,000 \\
\hline
\end{tabular}

Source: Author's calculations from U.S Board of Governors of the Federal Reserve System (2004).

Health Care Costs Are Rising. Finally, health care costs have been on the rise and are projected to continue to increase. Even older Americans who have Medicare to cover a large share of their medical bills have seen out-of-pocket expenditures increase significantly. Long-term care also looms as a possible expense

36Figure comes from the 2004 Survey of Consumer Finances.

${ }^{37} \mathrm{~A}$ question also arises whether this bulwark of middle-class saving could be at risk. The housing boom of the last decade has led many people to believe that they need not acquire housing equity through diligently repaying their mortgage loan but, rather, that they can rely on the capital gains associated with housing appreciation. As a result, "interest-only mortgages" have gained enormous popularity in recent years. In addition, the low interest rates and heavy advertising by financial institutions have encouraged many to access their home equity long before retirement. As a result, even though most households enter retirement either mortgage free or with only a small balance, that percentage has declined over time. Many of those with mortgages also have higher housing wealth than in the past, but the mortgage payment represents an additional claim on their monthly income not experienced by earlier generations. Moreover, the housing equity that they can draw on in retirement has been reduced by the amount of the mortgage. 
for many households. The rising cost of health care relative to Social Security (see Figure 9) means that people will need to undertake more life-cycle saving during their work lives than in the past to maintain their standard of living in retirement.
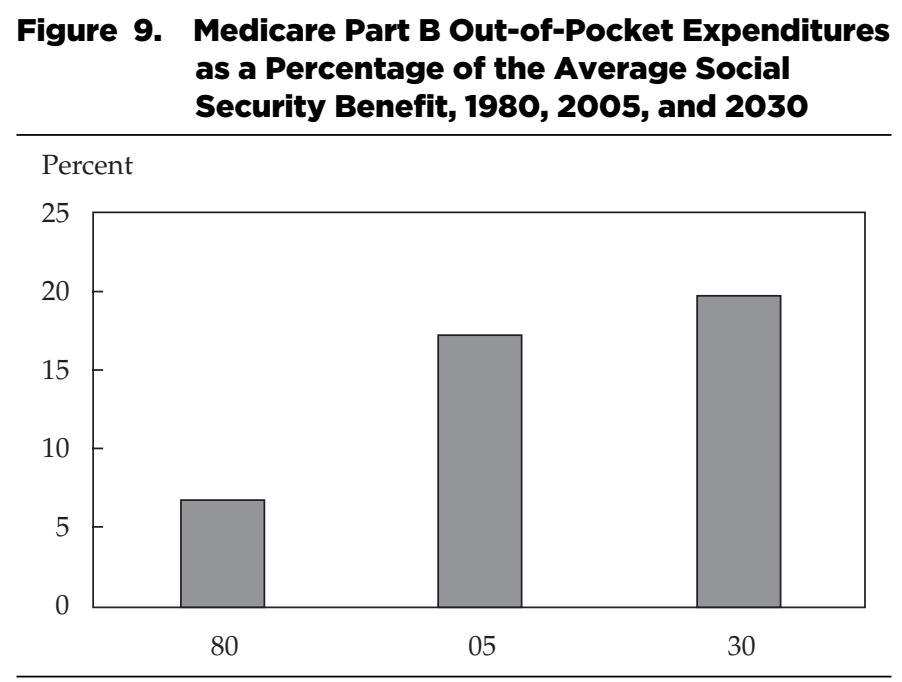

Source: Foster and Clemens (2005).

\section{The New Role for Government in Life-Cycle Saving}

The departure of employers from life-cycle saving, combined with a lengthening retirement span and the contraction of Social Security, suggests a different role for government going forward. Workers without participation in employer-sponsored retirement plans will have to rely solely on diminished government benefits. Those who do participate must rely on these diminished benefits and their 401(k) accumulations. Both groups will most likely turn to their housing equity as a source of retirement income. To make 401(k) plans work better as a vehicle for retirement income saving, the government may need to revamp the way it regulates such plans and introduce a variety of new initiatives, such as improving the market for annuities. To help people access their housing equity as a source of cash income, the government may want to improve the market for reverse mortgages.

The rise in life expectancy and the contraction of conventional retirement income sources also means many people are going to have to work longer to gain a reasonably secure and comfortable retirement. Continued work means that the employee must recognize the need to stay in the labor force and the employer must be willing to hire the older worker. In this regard, the government may play a role in two ways. First, it may be time to reconsider the desirability of offering early 
Social Security benefits at age 62 . The government would send out the message that withdrawal at this age is not the "norm" and cannot be financed with public pensions. Second, in the absence of the incentives to retire embedded in definedbenefit plans, employers are going to need some orderly way to retire superannuated workers or else they simply may not take the risk of hiring older workers.

Finally, even with continued employment, well-functioning 401(k) plans, and access to housing equity, people may still not have enough to maintain their standard of living in retirement. This raises the question of whether further cutbacks in the already diminished Social Security system make sense and whether we need to add another layer of life-cycle saving to the nation's retirement income system. The following section discusses each of these issues in more detail.

Improve Markets for Financial Instruments That Facilitate De-Cumulation of Retirement Assets. The withdrawal of employers from the provision of life-cycle-saving plans has two implications. First, workers will no longer receive their retirement income in the form of a lifetime annuity but, rather, will receive a lump sum at retirement. Lump-sum payments mean that individuals will have to decide how much to withdraw each year. They face the risk of either spending too rapidly and outliving their resources or spending too conservatively and consuming too little. These risks could be eliminated with the purchase of annuities, but the annuity market in the United States is small. Thus, one role for government is to improve the annuity market. The second implication of the withdrawal of the employer-combined with the contraction of Social Security - is that individuals will have to turn to their housing equity as a source of retirement income. A promising vehicle for accessing housing equity is the reverse mortgage, but today the market is miniscule and fees are high. Thus, a second role for government is to enhance the market for reverse mortgages.

Annuities. Very few retirees buy annuities today. They are expensive for the average person because of administrative and marketing costs and adverse selection. 38 Moreover, Social Security and defined-benefit plans have annuitized a considerable portion of the wealth of today's retirees. Married couples achieve some degree of risk sharing within the family. People may also want to hold on to their wealth for a bequest or in anticipation of large health-related expenses. Basically, too few individuals understand the risk of outliving their resources or appreciate the higher level of income that annuities offer. They instead view an annuity as a gamble with the insurance company, in which the company wins if they die early. But as Social Security benefits decline and employer defined-benefit pensions grow scarce, such attitudes will need to change.

38For an analysis of why people may not buy annuities, see Brown and Poterba (2000), Brown (2000), Kotlikoff and Spivak (1981), and Mitchell, Poterba, Warshawsky, and Brown (1999). 
If the goal is to encourage annuitization, the annuity must be made as cheap, easy, and safe as possible. Voluntary individual annuities are riskier as well as costlier than defined-benefit annuities. 39 Participants must now worry about the following when they purchase an annuity: Should they do it immediately upon retirement or later when they have a better sense of their health and income needs? Moreover, annuity payments are highly sensitive to interest rates, which means that different cohorts of retirees who annuitize will likely end up with different monthly benefits for the same total accumulations. 40 Under traditional defined-benefit plans, workers were insulated from these fluctuations.

One further issue that no one had to think about in the past is the safety of the insurance company. To date, few annuitants have taken a loss on fixed annuities, but it has happened. Two relatively large insurance companies ended up paying only 70 cents on the dollar after they got into trouble as a result of bad investments. 41 The main purchasers of annuities to date, moreover, have been large sophisticated sponsors of defined-benefit pension plans, not millions of relatively unsophisticated consumers. If individuals have to shop for annuities on their own, they will have to consider the health of the insurance company as well as all the other factors that play into the decision about allocating their $401(\mathrm{k})$ funds at retirement.

Various government initiatives could help make the private provision of individual annuities less expensive, complex, and risky. Government could lower administrative costs if it could pool large numbers of participants. To the extent that lowering administrative costs increases participation, it would also reduce adverse selection and thereby further improve the payout per dollar of premium. The government is also the most likely entity to provide inflation-indexed annuities at a reasonable cost in a short period of time. Finally, the government is in a much better position to absorb interest rate risk than the individual. It could smooth out payments over time so that different cohorts did not end up with dramatically different benefits for the same accumulations. It might also make sense to shift the regulation of insurance companies from the state to federal level to enhance confidence in these institutions as providers of annuities.

${ }^{39}$ Individuals cannot purchase on their own the same annuity that they would have received under a traditional defined-benefit plan. First, the voluntary nature of annuitization under a $401(\mathrm{k})$ plan creates a major adverse selection problem, which significantly increases the cost per dollar of annuity income. Second, administrative and marketing costs are significantly higher when annuities are purchased one by one rather than in bulk. Third, the explosion of $401(\mathrm{k})$ plans greatly changed the relative price of annuities for women and men.

40 The variation is substantial. A $\$ 1,000$ premium would have purchased a monthly income of $\$ 9.50$ in 1989 , when the yield on a 10-year Treasury note was about 8.5 percent; the monthly payment in March 2003 was about $\$ 6.69$ per $\$ 1,000$ because 10 -year Treasury note yields fell below 4 percent.

41U.S. Government Accountability Office (2004). 
The government could take a number of approaches. The most aggressive would be to set up a government agency that received premiums from individuals, invested the money, and paid the monthly benefits. That is, the government would take on the full administrative, underwriting, and investment responsibilities. An alternative approach would be for the government to specify a standard type of annuity, perhaps including inflation indexing, and issue requests for proposals to private sector insurers. If the private insurance companies could satisfy these requirements, the government could serve as a clearinghouse and direct consumers to companies that offered these standard annuities. The government could also act as a purchaser or reinsurer of the approved annuity sold by private companies. The goal would be to establish a public-private partnership that provides $401(\mathrm{k})$ participants with the annuities they need at retirement.

Reverse Mortgages. Housing equity is the most important asset for the vast majority of Americans. According to the 2004 Survey of Consumer Finances, 15.3 million households age 65 and over own their home free and clear. Homeowners could access their equity by selling their house or they could take out a home equity loan. Selling is generally not a desirable option because, to date, most retirees have chosen to remain in their current home. $42 \mathrm{~A}$ home equity loan allows the retiree to remain in the house but requires regular payments of interest (and sometimes principal). In contrast, a reverse mortgage enables a household to consume some of its housing equity without the obligation to make periodic loan payments. ${ }^{43}$ Yet this market is extremely small-about 1 percent of qualified homeowners have a reverse mortgage.

The most widely used reverse mortgage currently on the market is the Home Equity Conversion Mortgage (HECM). The HECM program emerged from the National Housing Act of 1987. HECM loans, which are federally insured, are available to most homeowners age 62 and older who own their primary residence free and clear or who can pay off their mortgage easily with the proceeds of the loan. From the outset, Fannie Mae agreed to purchase all HECM loans and today is still the sole purchaser.

Despite some recent growth, the current market for reverse mortgages faces a lot of limitations. First, the home value used in computing the loan amount for HECM reverse mortgages cannot exceed the Federal Housing Administration's insurance limits (which currently range from $\$ 200,160$ to $\$ 362,790$ based on geographical

42 For an extensive analysis of homeownership behavior at older ages, see Venti and Wise (2001). 43With reverse mortgages, households borrow against the equity in the home, and the loan plus accumulated interest is repaid when the individual dies, moves out, or sells the house. Because the amount repayable is capped at the sale proceeds, the maximum loan is always going to be less than the current value of the property. The loan can be taken as a lump sum, line of credit, lifetime income, or as a payment for a specified period. To date, the line of credit has been the most popular option. 
area). 44 Second, up-front fees are high. Unlike in the case of forward mortgages, HUD (the U.S. Department of Housing and Urban Development) does not offer a "no points, no fee" option, so these costs may look out of line to many potential borrowers. ${ }^{45}$ Third, the amount that can be borrowed depends crucially on interest rates. 46 Not too long ago, when long-term Treasury bond rates approached 3 percent, a 65 -year-old homeowner could borrow about half the value of the house, but as recently as 1999, when interest rates were higher, that portion was as low as 29 percent (see Figure 10). Interest rates have begun to climb once more, lowering the percentage of house value that can be borrowed. Finally, despite substantial government subsidies and protections to date, many originators have been unable to generate sufficient volumes to justify the costs of maintaining a trained staff for this specialized product and have exited the market. 47 The challenge for government, therefore, is to help make a viable market for reverse mortgages. This may involve creating a secondary market for non-HECM mortgages as well as other initiatives.

Foster Environment for Continued Employment of Older Workers. A key aspect of life-cycle saving and investing is establishing the divide between the period over which the saving occurs — that is, the work life - and the period during which assets are drawn down-the retirement span. The current divide occurs at too young an age. If men continue to retire, on average, at age 63 and women at age 62, older people will not receive enough income from the contracting Social Security system and modest 401(k) balances to maintain their preretirement standard of living in retirement. One solution to the income security challenge with a potentially enormous payoff is for individuals to work longer. Achieving this goal, however, will likely require changes not just by individuals but by government as well. Two important issues are what individuals and employers perceive as the "normal" retirement age and some orderly process that enables employers to retire superannuated workers.

The Retirement Age. The "normal" retirement age plays two roles. For workers, it provides a government-sanctioned age when it is appropriate for them to withdraw from the labor force. For employers, it signals how long they can expect older workers to remain in their employ. In a defined-benefit world, the

44U.S. Department of Housing and Urban Development (2006).

45In addition, although servicing fees are paid over the life of the loan, the expected present value of these fees is subtracted from the amount borrowed. Thus, closing costs may be perceived as even larger than they really are, especially when compared with the value of the loan.

46Interest payments are added to the loan principal over the life of the loan. The higher the interest rate, the more rapidly the outstanding balance will increase. Accordingly, at higher interest rates, lenders will offer a smaller proportion of the value of the house.

47Low origination fees, the risk that elderly borrowers will not maintain their homes, and other uncertainties are additional possible explanations why lenders might withdraw from the market. 
Figure 10. Percentage of House Value That Could Be Borrowed at Ages 65, 75, and 85, 1975-2005

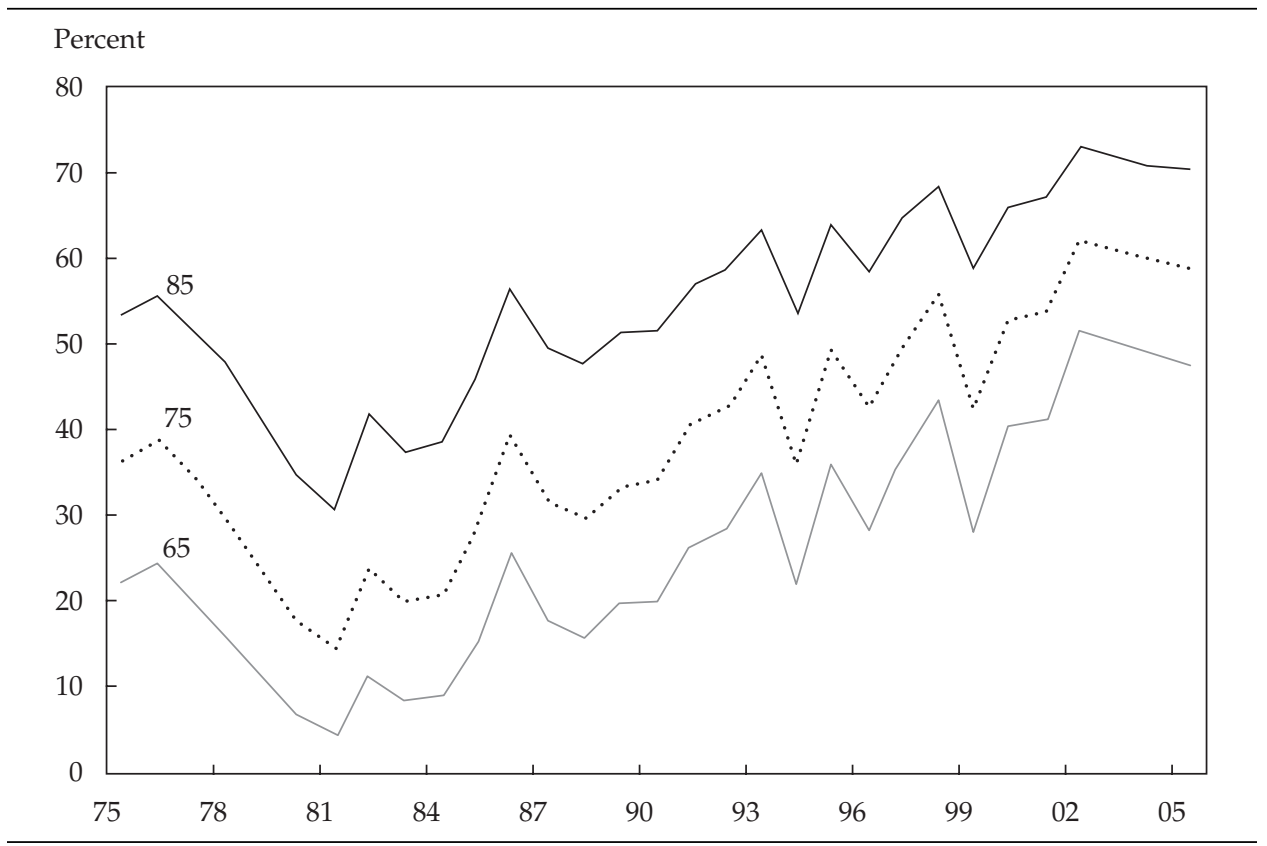

Notes: This figure assumes a $\$ 200,000$ house, a 1.5 percent lender's margin, and the closing cost estimates used in AARP's online reverse mortgage loan calculator. HECM loans have been available only since 1990, so amounts for 1975 to 1989 represent the percentages that could have been borrowed had they been available. Source: Eschtruth, Sun, and Webb (2006).

employer controlled the retirement age, first through the imposition of mandatory retirement rules and then, once mandatory retirement was abolished, through incentives in the defined-benefit plans themselves. ${ }^{48}$ The system was designed so workers could have an orderly withdrawal with money when their productivity fell below their compensation.

The only retirement age signal in a 401(k) world is the earliest eligibility age (EEA) under Social Security. Evidence that this signal has an important impact is the large proportion of workers who claim benefits as soon as they become available. Raising the EEA to 64 would likely encourage people to work longer by raising the sanctioned "normal" retirement age and by removing the opportunity to get benefits earlier. A later "normal" retirement age will also enhance the willingness of employers to hire older workers.

48 Amendments to the Age Discrimination in Employment Act outlawed mandatory retirement before age 70 in 1978 and effectively abolished it altogether in 1986. 
It should be noted that many individuals (perhaps as many as one-third) are unable to work past age 62 either because they are in poor health, their jobs are physically demanding, or they have been displaced later in life and cannot find work at their age (Table 6). ${ }^{49}$ Therefore, raising the EEA would inevitably involve some expansion of the disability program for older workers. Another problem is that a higher EEA would reduce lifetime Social Security wealth for those with lowerthan-average life expectancies. Because African Americans and low-wage workers have lower-than-average life expectancies, a higher EEA might be considered unfair. So, raising the EEA should be part of a larger package of reforms that includes provisions that offset such losses to particular groups. 50

\section{Table 6. Reason for Retiring of Those Retired by Age 65}

\begin{tabular}{lc}
\hline Reason & Portion \\
\hline Retired voluntarily & $65.2 \%$ \\
Poor health & 18.0 \\
Laid off & 7.3 \\
Business closed & 5.7 \\
Family reasons & 3.7 \\
\hline Sources: University of Michigan (1993-2003) and author's calculations.
\end{tabular}

Retirement Structure. Another aspect of the employer/employee relationship in a 401(k) world is how retirement will occur. With mandatory retirement, both parties knew that as of a certain age, the relationship would end. Employers also used traditional defined-benefit plans to structure an orderly departure. No such structure exists in a $401(\mathrm{k})$ environment. Employers face the prospect of workers with declining productivity and inadequate $401(\mathrm{k})$ balances hanging on much longer than desirable. The government needs to ensure that employers have the tools they need to manage an older workforce. Without such tools, employers will avoid older workers. The tool could take the form of flexibility in the ability to offer a "carrot,"

${ }^{49}$ Similarly, a recent survey by Prudential Financial of a nationally representative sample found that 38 percent of retirees claimed they had retired involuntarily.

50Raising the EEA does little to improve Social Security finances because benefits are actuarially adjusted. Those who continue working will contribute some additional payroll taxes, but these amounts are relatively small compared with the size of the financing gap. An increase in the EEA could help set the stage for future increases in the normal retirement age, one option for maintaining the solvency of the Social Security program. An EEA of 62 makes any additional increase in the NRA highly unlikely because a higher NRA would produce an even steeper reduction in benefits at age 62 . A higher EEA, by signaling that retiring in one's early 60s is no longer economically feasible, would prepare the way for a higher NRA. 
such as a generous retirement package, or the availability of a "stick," such as some form of mandatory retirement. Of course, the latter would be extremely controversial, but it is important to recognize that in the absence of employer defined-benefit plans, the structure that eased employees into retirement no longer exists.

Add New Mechanisms for Life-Cycle Saving. Assume that all possible steps are taken to make the existing life-cycle saving mechanisms work as well as possible: $401(\mathrm{k})$ plans with automatic provisions boost participation and contributions. Retirees have attractive and efficient ways to draw down their financial and housing wealth. Individuals recognize the need to work longer and plan to extend their careers. Employers are open to retaining and hiring older workers because they believe that older workers will stay for a meaningful period of time and they have the tools to retire those workers when they are no longer productive. It is very likely even in this optimistic scenario that people will not have enough income to maintain their living standards once they retire. One-third of households will have nothing but Social Security, and Social Security replacement rates are scheduled to decline even under current law. The remainder will have 401(k) accounts, but the pressure to spend $401(\mathrm{k})$ balances on college costs and other pressing needs is likely to produce modest balances.

With a diminished Social Security program, uncertain outcomes from 401(k) plans, and one-third of households with no pensions at all, it might be worth considering the introduction of an additional tier of retirement income. This is not a new idea. The President's Commission on Pension Policy recommended in 1981 a mandatory universal pension system (MUPS).

Under this proposal, every employer would contribute a minimum of 3 percent of payroll to a tax-deferred defined-contribution pension plan. 51 If employers did not want to administer their own plans, they could send their contributions to a clearinghouse under the authority of the Social Security Administration to be invested in private capital markets.

The cost of such a mandatory savings program would presumably be borne by workers, not their employers. ${ }^{52}$ Reducing wage growth in exchange for future retirement benefits is probably a reasonable trade-off for middle-income workers. But people with a lifetime of low wages are often not in a position to sacrifice current consumption for additional retirement income. Nor do they derive benefits from the tax favors accorded such contributions because they typically do not pay tax.

\footnotetext{
51 All employees over age 25 with one year of service would participate; vesting would be immediate; and benefits would not be integrated with Social Security. Mandatory universal pension system plans would be managed as company plans are today — through pension trusts, insurance companies, and other financial institutions.

52 Another cost is the forgone revenues to the federal government because an expansion of the pension system would increase the tax expenditure numbers reported in the introduction. To compensate for this loss, the government would have to raise additional revenues through increased taxes to maintain its current level of expenditures.
} 
Other designs have been proposed for an extra tier of mandatory retirement savings. 53 The purpose of this discussion is not to generate a particular recommendation. The point is that more life-cycle saving programs will most likely be needed, and a government-supported second tier offers the flexibility of providing automatic credits for low-income workers without affecting their wages. Such plans would be funded, and assets managed, by the private sector. The question is whether such programs should be voluntary or mandatory. At a minimum, given all that is known about the power of defaults, automatic participation with a potential to opt out might be the least controversial approach. The important message, however, is that more life-cycle saving will probably be needed for people not to suffer a decline in their standard of living when they retire.

\section{Conclusion}

This paper argues that employers have withdrawn from the provision of retirement income in the United States. The proportion of the workforce covered by traditional defined-benefit plans has declined sharply and will probably slip further as more companies freeze their plans and most new businesses opt for 401(k)s. The fact that employers sponsor $401(\mathrm{k})$ s is not a trivial contribution, however, because institutionalized saving invariably encourages employees to save money that they might not have saved otherwise. But employers have backed away from the comprehensive package of accumulating assets on behalf of their employees and providing lifetime benefits in retirement. Employers are also withdrawing from the provision of postretirement health care benefits.

This withdrawal has occurred just as the task of accumulating adequate retirement income has gotten harder. The Social Security program, the backbone of the nation's retirement system, will, under current law, provide less relative to previous earnings because of the extension of the NRA from 65 to 67, the deduction of Medicare Part B and D premiums, and increased taxation under the personal income tax. The shift in coverage to $401(\mathrm{k})$ s has placed all the risk and responsibility for retirement saving on the individual, and to date, the process has produced modest balances. Although retirement income is getting harder to come by, the period over which people have to support themselves has gotten longer.

53 An alternative approach is a program like the USA (Universal Savings Account) proposal, introduced by the Clinton administration. Under this proposal, the government would make an automatic contribution in the form of a refundable tax credit deposited directly to each individual's account. As proposed, the tax credit for workers and their spouses in low- or moderate-income households would be $\$ 300$ a year, and the automatic credit would be phased out for higher-income families. Individuals could make additional contributions to their USA accounts, and the government would match their contributions up to a certain amount. Workers would not need to shift out of private sector plans because the government would pay these matching contributions either to USA accounts or 401(k) plans. Individuals would also be able to invest their accounts in a retirement plan similar to the federal Thrift Savings Plan or with private sector fund managers. 
The withdrawal of employers and the increasingly treacherous retirement income landscape mean that government will have to assume new tasks. The decumulation phase from 401(k) plans will make the accumulation phase look like child's play. Annuities are going to have to play a role in this exercise, and the government could improve the market for these instruments. Similarly, with the contraction of other resources, most retirees will likely have to rely on their housing equity to support some of their consumption in retirement. Government could play a role in clarifying the options for accessing housing equity and perhaps further supporting the market for reverse mortgages.

The contraction of the retirement income system and increases in life expectancy suggest that most people are going to have to stay in the labor force longer. Increasing the earliest eligibility age under Social Security would improve the incentives for older workers to remain in the labor force and the willingness of employers to hire them. Of course, increasing the early retirement age would require an expansion of other programs for the significant portion of the population for whom continued work is not a viable option.

Even if all the recommended changes occurred, however, Americans need more institutions for life-cycle saving. These arrangements will not develop without the impetus of government. Moreover, Americans need an additional tier of retirement saving.

The final point pertains to the future of Social Security. Social Security will remain, in its diminished form, the principal source of support for a large fraction of the elderly population. Thus, solving Social Security's financing problem should be framed in terms of life-cycle saving needs, not as a budgetary hole that needs to be plugged.

The author would like to thank Steve Sass for sharing his insights and material, Andy Eschtruth for providing editorial guidance at an early stage, and Jerilyn Libby for excellent research assistance.

\section{REFERENCES}

Brown, Jeffrey R. 2000. "How Should We Insure Longevity Risk in Pensions and Social Security?" Issue in Brief, no. 4. Center for Retirement Research at Boston College (August).

Brown, Jeffrey R., and James M. Poterba. 2000. "Joint Life Annuities and Annuity Demand by Married Couples." Journal of Risk and Insurance, vol. 67, no. 4 (December):527-553.

Buessing, Marric, and Mauricio Soto. 2006. “The State of Private Pensions: Current 5500 Data.” Issue in Brief, no. 42. Center for Retirement Research at Boston College (February). 
Burtless, Gary, and Robert A. Moffitt. 1984. "The Effect of Social Security Benefits on the Labor Supply of the Aged." In Retirement and Economic Behavior. Edited by Henry J. Aaron and Gary Burtless. Washington, DC: Brookings Institution.

Center for Retirement Research at Boston College. 2006. "Retirements at Risk: A New National Retirement Risk Index" (June).

Choi, James, David Laibson, Brigitte Madrian, and Andrew Metrick. 2001. "Defined Contribution Pensions: Plan Rules, Participant Decisions, and the Path of Least Resistance.” NBER Working Paper 8655 (December).

Congressional Budget Office. 1999. "Raising the Earliest Eligibility Age for Social Security Benefits" (January).

Costa, Dora L. 1998. The Evolution of Retirement: An American Economic History, 1880-1990. Chicago: The University of Chicago Press.

DeWitt, Larry. 1999. “The History and Development of the Social Security Retirement Income Test.” Special Study No. 7. Social Security Administration.

Eschtruth, Andrew D., Wei Sun, and Anthony Webb. 2006. "Will Reverse Mortgages Rescue the Baby Boomers?" Issue in Brief, no. 54. Center for Retirement Research at Boston College (September).

Foster, Richard S., and M. Kent Clemens. 2005. "SMI Out-of-Pocket Expenses as a Percentage of Illustrative Social Security Benefit." Memorandum to the Committee on Ways and Means. Centers for Medicare and Medicaid Services, Office of the Actuary.

Gale, William G., and John Sabelhaus. 1999. "Perspectives on the Household Saving Rate.” Brookings Papers on Economic Activity, vol. 1:181-224.

Gruber, Jonathan, and David Wise. 1998. "Social Security and Retirement: An International Comparison." American Economic Review, vol. 88, no. 2:158-163.

Halperin, Daniel I., and Alicia H. Munnell. 2005. "Ensuring Retirement Income for All Workers." In The Evolving Pension System: Trends, Effects, and Proposals for Reform. Edited by William G. Gale, John B. Shoven, and Mark J. Warshawsky. Washington, DC: Brookings Institution Press.

Helman, Ruth, Craig Copeland, and Jack VanDerhei. 2006. "Will More of Us Be Working Forever?: The 2006 Retirement Confidence Survey.” EBRI Issue Brief, no. 292. Employee Benefit Research Institute (April).

Hurd, Michael D. 1990. "Research on the Elderly: Economic Status, Retirement, and Consumption and Saving." Journal of Economic Literature, vol. 28, no. 2 (June):565-637.

Investment Company Institute. 2006. “The U.S. Retirement Market, 2005.” Research Fundamentals, vol. 15 , no. 5 (July).

Kaiser/Health Research and Educational Trust. 2006. "Employer Health Benefits: 2006 Annual Survey" (www.kff.org/insurance/7527/upload/7527.pdf).

Kaiser/Hewitt. 2005. "Prospects for Retiree Health Benefits as Medicare Prescription Drug Coverage Begins: Findings from the Kaiser/Hewitt 2005 Survey on Retiree Health Benefits" (www.kff.org/ medicare/upload/7439.pdf).

Kotlikoff, Laurence J., and Avia Spivak. 1981. "The Family as an Incomplete Annuities Market.” Journal of Political Economy, vol. 89, no. 2 (April):372-391. 
Laibson, David I. 1997. "Golden Eggs and Hyperbolic Discounting." Quarterly Journal of Economics, vol. 112, no. 2 (May):443-477.

Laibson, David I., Andrea Repetto, and Jeremy Tobacman. 1998. "Self-Control and Saving for Retirement." Brookings Papers on Economic Activity, no. 1:91-196.

Mitchell, Olivia, James M. Poterba, Mark J. Warshawsky, and Jeffrey R. Brown. 1999. "New Evidence on the Money's Worth of Individual Annuities." American Economic Review, vol. 89, no. 5 (December):1299-1318.

Moen, Jon R. 1987. "Essays on the Labor Force and Labor Force Participation Rates: The United States from 1860 through 1950.” Unpublished PhD dissertation, University of Chicago.

Moore, James F., and Olivia S. Mitchell. 2000. "Projected Retirement Wealth and Saving Adequacy." In Forecasting Retirement Needs and Retirement Wealth. Edited by Olivia S. Mitchell, P. Brett Hammond, and Anna M. Rappaport. Philadelphia: University of Pennsylvania Press.

Munnell, Alicia H., and Steven A. Sass. 2006. Social Security and the Stock Market: How the Pursuit of Market Magic Shapes the System. Kalamazoo, MI: Upjohn Institute.

Munnell, Alicia H., and Annika Sundén. 2004. Coming Up Short: The Challenge of 401(k) Plans. Washington, DC: Brookings Institution Press.

Munnell, Alicia H., Francesca Golub-Sass, and Andrew Varani. 2005. "How Much are Workers Saving?" Issue in Brief, no. 34. Center for Retirement Research at Boston College (October).

Munnell, Alicia H., Steven A. Sass, and Mauricio Soto. 2006. "Employer Attitudes towards Older Workers: Survey Results.” Issue in Brief, Series 3, Work Opportunities for Older Americans. Center for Retirement Research at Boston College (June).

Sass, Steven A. 1997. The Promise of Private Pensions: The First Hundred Years. Cambridge, MA: Harvard University Press.

Skolnik, Alfred. 1976. "Private Pension Plans, 1950-1974.” Social Security Bulletin, vol. 39, no. 6 (June):3-17.

Society of Actuaries. 2006. “Annuity 2000 Mortality Table.” In "Longevity: What You Need to Know.” Fidelity Investments (https://communications.fidelity.com/fria/longevity.html?fca_id=20063599).

Thaler, Richard H., and Shlomo Benartzi. 2004. "Save More Tomorrow ${ }^{\mathrm{TM}}$ : Using Behavioral Economics to Increase Employee Saving." Journal of Political Economy, vol. 112, no. S1 (February): S164-S187.

Thaler, Richard H., and H.M. Shefrin. 1981. “An Economic Theory of Self-Control.” Journal of Political Economy, vol. 89, no. 2 (April):392-406.

Thane, Pat. 2000. Old Age in English History: Past Experiences, Present Issues. Oxford, U.K.: Oxford University Press.

University of Michigan. 1993-2003. Health and Retirement Study. Ann Arbor, MI: Institute for Social Research.

U.S. Board of Governors of the Federal Reserve System. 2004. Survey of Consumer Finances. Washington, DC: U.S. Government Printing Office. 
U.S. Bureau of the Census and the Social Science Research Council. 1960. Series F 10-21, Historical Statistics of the United States, Colonial Times to 1957. Washington, DC.

U.S. Bureau of Labor Statistics and U.S. Bureau of the Census. 1962-2005. Current Population Survey. Washington, DC.

U.S. Department of Housing and Urban Development. 2006. "HUD Announces Higher FHA Home Loan Limits to Help More American Families Become Homeowners.” News Release No. 06-001.

U.S. Department of Labor. 1999. Private Pension Plan Bulletin: Abstract of 1995 Form 5500 Annual Reports. Washington, DC: U.S. Government Printing Office.

- 2004. Private Pension Plan Bulletin: Abstract of 1999 Form 5500 Annual Reports. Washington, DC: U.S. Government Printing Office.

2006. Annual Return/Report Form 5500 Series for Plan Year 2004. Washington, DC: U.S. Government Printing Office.

U.S. Government Accountability Office. 2004. "Financial Regulation: Industry Changes Prompt Need to Reconsider U.S. Regulatory Structure.” Report to the Chairman, Committee on Banking, Housing, and Urban Affairs, U.S. Senate. Washington, DC.

U.S. Office of Management and Budget (OMB). 2005. Analytical Perspectives: Budget of the United States Government, Fiscal Year 2006. Washington, DC: www.gpoaccess.gov/usbudget/fy06/pdf/spec.pdf.

U.S. Social Security Administration. 2006a. Annual Statistical Supplement, 2005. Washington, DC: U.S. Government Printing Office.

2006b. The 2006 Annual Report of the Board of Trustees of the Federal Old Age, Survivors and Disability Insurance Trust Funds. Washington, DC: U.S. Government Printing Office.

Venti, Steven F., and David A. Wise. 2001. “Aging and Housing Equity: Another Look.” NBER Working Paper 8608 (November). 


\section{Session 5 Comments by John Shoven}

John B. Shoven

Charles R. Schwab Professor of Economics

Stanford University

Stanford, California

Munnell's paper was excellent, although she could have, and should have, gone further in her policy prescriptions. She described some ways in which retirement behavior and life expectancy have changed, but she did not emphasize that the average length of retirement for men is up 50 percent since 1965. That increase has a lot to do with the crisis in pensions; people are just retired for a lot longer. Some people know that, on average, men are retiring three years earlier than they did, and some people know that people in their 60s are living three years longer. But not many people add the two together to get six extra years of retirement being funded since 1965 .

I also suggest that we reconsider how we measure age. A mother will say that her infant is 15 months old; a two-year-old will say that she is two and a half; but an adult will say that he is 32 . Although some of these measures are more precise than others, they are all still time since birth. This is not the only way one could measure age. In fact, my view is that the most fundamental measure of age is mortality risk. If you face a high degree of mortality risk-measured, say, as the probability of dying in the next year-you are old; if you face low mortality risk, you are not old. By this measure, 59-year-old men in 1970, 65-year-old men today, and 70-year-old women today are all the same "age" because they have the same risk of dying within one year. This method gives quite a different picture of who is old and who is not from the one based on years since birth.

Munnell emphasizes the big switch from defined-benefit (DB) to definedcontribution (DC) plans and mentions a number of problems with the latter: nonparticipation, lack of diversification, failure to "roll over" existing balances into new tax-deferred accounts, failure to rebalance, and lack of annuity payouts. She then argues for an expanded government role, partly on the grounds that employers have been withdrawing from life-cycle saving. But I think Munnell exaggerates the extent to which employers have withdrawn. They certainly have changed the nature of their offerings, but as Robert Merton has asserted, employers remain a very interested party in pensions and in the ability of their workers to retire. 1

I would say, however, that when you propose a government policy, you always have to worry about unintended consequences. Merton also mentioned mispricing as a cause of the big switch from DB to DC, and I think he was onto somethingthat employers thought DB plans would be cheaper than they turned out to be.

${ }^{1}$ See Professor Merton's presentation in this proceedings. 
Another view of the DB plan crisis is that for a while, employers did not see the plans as transferring risk from the employee to the employer but instead thought that somehow risk was just disappearing. When it became obvious to employers that there had been a large transfer of risk to them, they did not like it so much.

But that was not the only cause of the switch. One has to at least also look at the fact that the formation of new DB plans stopped at almost exactly the same time that ERISA was passed (1974) and at the time that Social Security benefits were increased dramatically (1972). As a result of ERISA, the cost to small employers of offering a DB plan went up dramatically. ERISA was designed to strengthen DB plans, but one could make a case that it actually killed them. And the 2006 Pension Protection Act-which, again, is designed to strengthen DB plans-probably will accelerate their demise. So, one has to be very careful when designing such government policy.

Munnell's proposal has four components. The first is to raise the Social Security early retirement eligibility age from 62 to 64 . Her second proposal involves another layer of savings - government-sponsored, or at least government-organized, savings. I will probably irritate her by calling them "add-on individual accounts," but it is only a matter of labeling. Third, she wants to encourage reverse annuity mortgages, and fourth, she wants to strengthen ordinary life annuities as well.

I think raising the Social Security early eligibility age is a very good idea, although I agree that it is politically tough to do and that it has to be done gradually. As Munnell points out, if people work longer, it improves not only the finances of the retirement system but also the finances of the government overall and GDP. If we regard Social Security and Medicare as programs to transfer GDP from workers to retirees, then these programs will be a lot better off if GDP is bigger. One way to make it bigger is to work harder, and the way to work harder is to work longer.

Regarding add-on individual accounts, I want to welcome Munnell to the support club for that proposal. As for reverse annuity mortgages, they are tough to implement. They are immediate life annuities and have serious adverse selection problems. Nobody will take out a reverse annuity mortgage who has a history of cancer or recently had a heart attack. Another problem is the moral hazard: Why maintain the house for the 20-year life of the mortgage after effectively selling the residual claim? The temptation, obviously, is to let the house deteriorate. The problems with annuity markets that economists have thought about for a long time are present in reverse annuity mortgages - and they are present in a big way. So, these markets tend not to work very well. In general, we need ideas on how to strengthen the annuity markets because they have fundamental problems. One idea is the deferred annuity, which gets around some of these problems in a nice way.

Munnell, however, stops short of doing everything she could, given the problems she has identified. Government policies could encourage people to work longer. Some U.S. economists think that Europeans were wrong to believe that 
getting older workers out of the workforce would create more jobs for younger workers; it has not worked that way in Europe. And then these economists say that the United States does not do that. But when you look at the details, we do it too. We have many policies that encourage people to get out of the workforce, as Paul Samuelson mentioned in his presentation. ${ }^{2}$ Social Security was instituted partly for that reason: Get older workers out and give those jobs to younger people. But it is not appropriate to do that now. In fact, we want to do the opposite. For instance, we have had 35 years of work counting toward the Social Security benefit calculation for a long time. Why not raise that to 40 ? And that could be done without cutting average benefits-just increase the number of years you need to work to get them. This number could then be indexed further based on life expectancy.

Some people may not know the modal age at which males reach 35 years of work experience. It is 52-much younger than one might have thought. For women, the corresponding age is higher because, typically, women depart from the workforce for a few years during their careers. But even among women, this age is less than 60. Thus, I advocate raising the years of work experience from 35 to 40 .

We should also consider a new category within the entitlement programs-a category well known to insurance policies-namely, "paid-up." You have paid enough; you are out; you are done; no more taxes. And I would propose that after 40 years there be no more benefit accruals but also no more taxes. If people want to work a 41st, 42nd, or 43rd year, more power to them. But as far as Social Security is concerned, they would be paid up after the 40th year.

Right now, the nonlinearity of the Social Security PIA (primary insurance amount) formula means that individuals accrue more benefits when they work for their 11th, 12th, and 13th years than they do when working for their 31st, 32nd, and 33rd years. All years do not count the same. That situation could easily be changed: Make all years count the same so that people who are approaching the 40-year mark have an incentive to keep working.

Changes to Medicare would also help the retirement situation. Those who have reached age 65, and thus qualify for Medicare, largely do not get the Medicare benefit if they continue to work. Their employer has to pay their health care benefits, and Medicare takes the position that it is the secondary payer, so it does not pay (or it pays only a small amount). We could switch that so that Medicare pays whether an individual works or not. Employers may suddenly find these 65-yearolds with Medicare to be very desirable employees because employers do not have to pay nearly as much health care cost.

Our laws define a number of ages that are important to the retirement system and to the would-be retiree. At 591/2, an individual can begin to take money out of pensions without a tax penalty. This threshold has been $59 \frac{1}{2}$ as long as I can

2See Professor Samuelson's presentation in this proceedings. 
remember, and I can remember a long time. Why not raise that age-maybe by two years, as Munnell is suggesting, on the early eligibility age for Social Security (i.e., to $\left.61 \frac{1}{2}\right)$ - and then index it after that?

The normal retirement age (i.e., the age for collecting the "normal" level of Social Security benefits) is being gradually increased to 67, and I do not think we should accelerate that. But once it gets to 67 , it is supposed to stay at 67 forever, according to the law. We were stuck at 65 for 65 years. We cannot afford to be stuck at 67 for 65 years. We should index that number for changes in life expectancy.

A number of things happen at or around age $701 / 2$. At that age, an individual has to start taking his or her money out of tax-deferred annuities and 401(k) plans. If the individual does not, he or she faces a gigantic penalty. At age 70, Social Security stops rewarding the deferral of retirement. That is, if a worker retires at age 68 or 69 , he or she gets a little more benefit for waiting. But after age 70, the worker not only stops getting more benefit but also has to begin taking his or her Social Security benefits. Why do that? We should let people continue to work even beyond age 70 and either accrue more benefits or be exempt from the Social Security tax.

In conclusion, for the most part, I agree with Munnell. I think long careers and more savings are the answer to financing the entitlement programs in the future. We should index all the key ages in the pension and tax laws for life expectancy. As Munnell suggests, we should raise the early eligibility age by two years and, I would add, then index it. We should remove the disincentives that Social Security and Medicare create to having long careers. We should make sure that those extra years count in terms of benefits. Or if those extra years do not count, then they should not be taxed. And finally, we need to work on the details of add-on individual accounts (or whatever name is used to describe them). 


\section{Session 5 Reply by Alicia Munnell}

\section{Alicia H. Munnell \\ Peter F. Drucker Professor of Management Sciences, Boston College Carroll School of Management Director, Center for Retirement Research at Boston College Boston}

I would like to thank the discussants and add just a few comments. The fact that employers have been withdrawing from defined-benefit (DB) plans does not make them bad guys. It was no longer in their interest. Because of changes in the workforce and changes in technology, career paths changed. The idea of staying with one company and working your way up the ladder just disappeared. So, for personnel management reasons, DB plans were no longer that valuable. Furthermore, the costs of DB plans changed with regulation and the decline in inflation, although I do not think regulation is as big a deal as Shoven does. And note that globalization also puts pressure on costs. So, there are rational reasons why traditional pension plans have declined. Business made the right decision not to continue to provide DB plans. The problem is that although we have seen DB plans fade for 25 years now, we have not developed any other institutions. So, we have a big hole. That is the problem.

Another issue is that we have to be careful about changing the stated retirement age if it does not have the effect of keeping people in the workforce. In other words, if the eligibility age is increased but people still stop working and claim partial benefits, we have not done anything other than cut the benefit. They will not be working longer and will not continue to contribute to GDP.

In terms of doing more, I agree. There are many issues that we should think about when we engage in Social Security and tax reform. We should be careful not to make pensions unattractive in terms of their tax treatment. And I want to re-emphasize the fact that we do have employment-based life-cycle finance mechanisms through 401(k) plans. But we need to design new institutions, and I think that is what this conference is about - to find how we are going to respond to employers' withdrawal from the original, defined-benefit retirement income system. 


\title{
SESSion 6: What Everyone SHOULD KNOW ABOUT . . . PANEL
}

\section{Introduction}

\author{
Paul Solman
}

\section{Business and Economics Correspondent The NewsHour with Jim Lehrer Boston}

When it comes to reflecting not only on what everyone should know about saving and investing but also on what most people believe they know, the data-both the hard data and the anecdata-are grim. For example, the audience that I address every couple of weeks for The NerwsHour with Jim Lehrer is by all accounts the most sophisticated TV audience in the United States-about the top 1 percent of TV viewers. Yet, the most common comment I have received over 20-plus years on that show is, "You make it so simple even I can understand it." So, even the top 1 percent of viewers find these critically important investment concepts difficult to follow.

Who, then, have elite PBS viewers turned to for investing advice over the years? Louis Rukeyser and his stock tipsters and now Robert Kiyosaki. It should come as no surprise, therefore, that David Laibson estimates that people tend to use a 30 percent per year discount rate in determining their propensity to save versus their propensity to consume. A 30 percent discount rate is so inflationary it would make Weimar Germany look like a stable economy. No wonder people do not save.

How, then, do we educate people? How do we help them understand what everyone should know about saving and investing? To address that question, this panel discussion begins with David Blitzstein summarizing and reflecting on the topics discussed and lessons learned at this conference, while giving special attention to the saving needs of low- and moderate-wage workers. After that, Dallas Salisbury will discuss the vital importance of Social Security and Medicare. Jeffrey Diermeier will discuss the role played by CFA Institute in investor education and the preparation of ethical and well-informed financial advisers. Finally, Zvi Bodie will leave us with some concluding thoughts about the challenges facing investor education.

Editor's Note: Paul Solman served as moderator of this session. 


\section{The Crisis in Retirement Plans}

\section{David Blitzstein}

Special Assistant for Multiemployer Plans

United Food and Commercial Workers International Union Washington, $D C$

The United Food and Commercial Workers International Union (UFCW) represents 1.3 million workers in the retail food and food manufacturing industries in the United States and Canada. Traditionally, the UFCW has sponsored and negotiated defined-benefit plans. Two-thirds of our members, specifically in retail food, are covered by multiemployer plans, and the remaining one-third are covered by single-employer defined-benefit and defined-contribution plans. I would estimate that less than 10 percent of UFCW members participate in both definedbenefit and defined-contribution plans. Demographically, our members are younger than the national averages for the workforce, and their wages range between $\$ 20,000$ and $\$ 40,000$ a year. A significant majority of our members are what I would call "career part-timers."

Such low- and moderate-wage workers deserve the attention of researchers. These people represent a substantial portion of the workforce who have low coverage rates in private retirement plans and cannot afford to contribute the necessary salary to $401(\mathrm{k})$ plans. Low- and moderate-wage workers need special consideration on both the saving and investment side of the retirement equation. This group consists of tens of millions of workers who are most at risk for having inadequate financial resources upon retirement. If policymakers and retirement system stakeholders are going to make a difference in reforming the retirement system, the needs of low- and moderate-income workers must be considered.

\section{Flaws in the Current Retirement System}

The papers presented at this conference and many of the discussants' reports have helped crystallize the reasons why the U.S. retirement system is failing workers. I remain skeptical about the application of life-cycle savings and retirement theory, especially as it is being practiced in our retirement system today. I do not argue with its theoretical underpinnings as presented in the paper by Bodie, Treussard, and Willen, but the principles and the insights they have developed are not appearing in the products that are being sold to workers. One reason for this disjuncture of theory and practice is that the current retirement system is replete with principal-agent conflicts that undermine best practices and lead to unacceptable economic rents. 
Following this line of argument, Kotlikoff raises in his paper important questions about the accuracy of financial advice offered by retirement market intermediaries, such as mutual funds. He focuses on consumption smoothing and demonstrates how small mistakes in setting spending targets in retirement magnify errors in targeting saving rates. Such errors can, in turn, distort portfolio investment advice, exposing workers' retirement security to unacceptable risks. Kotlikoffs discussion parallels the topic of the Employee Benefit Research Institute (EBRI) Issue Brief in which Jack VanDerhei (2006) offered a new look at replacement income analysis by layering in investment performance, longevity, and health risk factors. The EBRI study generates replacement income requirements significantly higher than those recommended by prevailing research, especially as one seeks a probability of retirement benefit adequacy higher than 50 percent. The study further accentuates the challenges that low-income individuals, in particular, face in achieving adequate retirement income. Finally, the EBRI study demonstrates the importance of annuitization as a risk management tool that can dampen the need for higher replacement income.

The paper that David Laibson presented provides empirical support for the importance of default options in defined-contribution plans and should be required reading for employers who are considering adopting the new default provisions under the recently legislated Pension Protection Act. The Laibson paper demonstrates that plan design can make a difference in a worker's saving rate. For example, the research casts doubt on the commonly held concern that more employees will opt out if default contribution rates are high. To the contrary, the research indicates that participation rates under automatic enrollment are virtually identical, whether the contribution rates are 3 percent or 6 percent.

Laibson and his co-authors also observe that automatic enrollment decouples the savings plan participation decision from the contribution rate and asset allocation decisions and has a bigger impact on young, less tenured workers (who often have little knowledge of retirement plans). Laibson and his co-authors, however, cannot explain why 50 percent of participants fail to maximize the full contribution match available from their employer. Finally, the paper's discussion of optimal defaults needs to be tested more thoroughly as it applies to low-income workers. The discussion ignores the important question of whether it is possible to design an optimal savings plan enrollment mechanism for a given workforce in a given industry.

The paper that Alicia Munnell presented discusses retirement savings from a policy perspective and offers numerous insights. Munnell is troubled that employers may be in the process of withdrawing from the retirement social contract. My response is that corporate America has never been committed to sponsoring retirement plans, demonstrated by the fact that less than 50 percent of the workforce has any pension plan coverage today. The experience of single-employer plans in the post-1970 ERISA period does not engender confidence that company plans are stable and secure delivery platforms for retirement benefits. Emily Kessler of the 
Society of Actuaries has noted that the life cycle of a corporation in a dynamic capitalist system is a bad fit with the life-cycle phases of a worker's retirement accumulation and de-cumulation. This does not mean that employers do not have a role to play in the retirement system but that their role may best be limited to a financing source.

Munnell identifies the critical, but often ignored, role that Social Security plays in life-cycle savings and retirement. Two-thirds of the retired population depend on Social Security for more than 70 percent of their income. Even the top one-third of wealthiest retirees depend on Social Security for 40 percent of their income. (As an aside, note that according to Robert Shiller's [2004] study of President George W. Bush's default investment option for privatized Social Security accounts, lifecycle portfolios fall short of traditional systems' returns 71 percent of the time.) Munnell also points out that Social Security benefits as a percentage of preretirement income will decline from 39 percent for median workers today to 30 percent in 2030 because of the extension of the normal retirement age. How will we fill in this declining funding gap and replacement income?

Munnell's succinct summary of the life-cycle model of saving and investing raises a series of troubling questions. Her model assumes that people have the knowledge to forecast their needs decades into the future while also having the discipline and skill to act on their forecasts. But when 35 percent of those who are eligible to participate in plans opt out, when half of those who do participate in plans fail to diversify their portfolios, when few participants rebalance their portfolios, and when few participants annuitize their retirement benefits, it becomes clear that a majority of the workforce cannot navigate the life-cycle model. If we treat the median $401(\mathrm{k}) / \mathrm{IRA}$ account balance in 2004 , which was $\$ 60,000$, as a scorecard of the life-cycle model, we have system failure. Human foibles seem to defeat the life-cycle savings and investment model.

Life-cycle savings and investment discussions too often ignore or discount the fact that retirement is an expensive proposition. In a recent presentation, David Walker (2005), comptroller general of the United States and director of the U.S. Government Accountability Office, demonstrated that a 35-year-old would have to save between 8 percent and 12 percent of gross salary on top of Social Security payroll taxes to meet retirement goals. Life-cycle investment theory does not matter if contributions earmarked for retirement are too few.

\section{Strategies That Benefit Retirement Savings}

In regard to the realistic cost of retirement, Munnell identifies several untapped sources of wealth that can contribute to retirement. One source of potential retirement wealth that requires much more attention from policymakers and researchers is home equity. Developing a cost-effective reverse mortgage market as suggested by Munnell is an important start to tapping this retirement resource. 
Mark Iwry (2005) of the Retirement Security Project has proposed several initiatives that attempt to leverage existing tax policy on behalf of low- and moderate-income workers. His proposals include

- expanding the savers' credit and making it permanent,

- encouraging workers to save tax refunds by allowing workers to split refunds and make direct deposits into a pension plan, and

- changing asset tests on means-tested programs to remove punitive treatment of retirement savings.

I would add to this list the expansion of one of the most successful antipoverty programs, the Earned Income Tax Credit, which could also be used to enhance savings for low- and moderate-income workers.

I also support Munnell's proposal for introducing an additional tier of retirement income. This tier does not have to be a government program. Every employer that does not already offer a retirement plan with a minimum employer contribution should be required to pay a mandated contribution of 3-6 percent of salary into an authorized, private, multiemployer pension plan. Such plans could be organized by industry, sector, geographical region, union, employer association, or any mix of the above. These authorized multiemployer plans would provide professional investment management at low cost and a large pool for annuitization of benefits at retirement. In order to minimize agency issues, such plans should be governed by boards of professionally certified trustees representing all system stakeholders.

\section{Insights from Peter Drucker}

In a series of recent newsletters (The Ambachtsheer Letter), the Canadian pension strategist Keith Ambachtsheer revisited an important retirement idea proposed by Peter Drucker (1976) in his book The Unseen Revolution: How Pension Fund Socialism Came to America. Drucker later described the book as his most prescient and most ignored work. In it, Drucker explored two related themes: (1) that aging and longevity would become dominant socioeconomic issues and (2) that pension funds would become dominant owners of the means of production. Drucker concluded that pension plans can maximize their legitimacy and accountability by operating as single-purpose, arm's length organizations, defeating natural political agency issues. Following from this conclusion, Drucker determined that pension plans represent multiple stakeholder interests that should be recognized in their governance structure.

Drucker also explored the property rights issues related to retirement plans. He concluded that pension plans are risk-bearing arrangements and that, therefore, the risks entailed in pension plans should be made transparent to all stakeholders. He recognized that pension risk bearing is highly complex in theory and practice. As a result, Drucker favored collective pension contracts that have both individual capital accumulation and annuitization features. Admirers of Drucker, such as 
Ambachtsheer (who currently leads the University of Toronto International Centre for Pension Management), have focused needed attention on the issues of pension governance, pension contract issues, agency issues, and investment belief systems that are fundamental to any successful retirement system.

In my opinion, the life-cycle savings and investment debate should occur within the context of this larger, structured, integrated retirement framework, not within an isolated "silo," to use a famous Drucker term.

\section{REFERENCES}

Drucker, Peter. 1976. The Unseen Revolution: How Pension Fund Socialism Came to America. New York: Harper \& Row.

Iwry, Mark. 2005. "The Saver's Credit: Expanding Retirement Savings for Middle- and LowerIncome Americans.” Retirement Security Project Policy Brief No. 2005-2 (March).

Shiller, Robert J. 2004. "Life-Cycle Portfolios as Government Policy.” Economists' Voice, vol. 2, no. 1 (December):1-8.

VanDerhei, Jack L. 2006. "Measuring Retirement Income Adequacy: Calculating Realistic Income Replacement Rates.” EBRI Issue Brief No. 297 (September).

Walker, David M. 2005. "Is Social Security's Financial Future in Jeopardy?” Paper presented at forum sponsored by Centrists.org and the Alliance for Worker Retirement Security (21 January). 


\section{The Need to Save More}

\section{Dallas L. Salisbury \\ President and CEO \\ Employee Benefit Research Institute Washington, $D C$}

The primary messages I take away from this conference are that (1) U.S. Social Security and Medicare are vitally important, (2) employers help some people supplement their Social Security benefits, (3) most people have always had to supplement their Social Security benefits with savings, and (4) if people are going to accrue enough savings, they have to be required to do so or tricked into it.

Some critics may argue that Social Security was created so that individuals would not have to save; others will say that it was created to encourage individuals to leave the labor force. But the essential lesson is that at the point in U.S. history when Social Security was introduced, the life-cycle saving model had proven to be a failure, not because it failed to describe how people should behave but because it failed to describe how people actually do behave. As for Medicare, whether or not health savings accounts are eventually established, most individuals would be far deeper in trouble without Medicare than they are today.

One should note, however, that the defined-benefit pension system has never been available for more than a relatively small proportion of workers. Similarly, although the decline of employment-based retiree medical coverage is certainly regrettable, relatively few individuals (in proportion to the entire population) have ever had such coverage in the first place.

If a crisis exists in retirement benefits, it has little to do with what employers have stopped doing and far more to do with what individuals have never done and what institutions have not done for them. Individuals have never saved much. As for requiring workers to save or tricking them into saving, the relatively low income of most Americans today and the stress that would be caused by reducing their current income to provide savings probably preclude trickery or required saving. The average $401(\mathrm{k})$ balance of $\$ 60,000$ and even the nearly $\$ 200,000$ balance for those in their 60s with 30 years of tenure show that, relative to the value of Social Security and Medicare, we are not doing very well.

Furthermore, the median defined-benefit pension annuity from the private sector is only $\$ 6,200$ a year. Calculating the present value of that annuity stream, even most defined-benefit pension annuities do not come close to matching the value of Social Security, let alone the value of Medicare. 


\section{Need for Financial Literacy}

Considering current conditions and realities, if we do not begin teaching U.S. workers basic financial literacy through mandatory workplace education-such as that provided by the California Public Teachers' Retirement System, with its oneon-one counseling for every worker - then our citizens will not have sufficient capital to retire. To become fully aware of financial realities, all individuals must learn to

- build a budget,

- save first,

- use debt minimally (if at all),

- spend less than they earn,

- understand the magic of compound interest,

- $\quad$ set goals, and

- save more rather than counting on excess investment returns.

\section{Facing Statistical Realities}

The workforce in the United States has always been mobile, and that mobility is one of the reasons that so few workers have extensive retirement benefits. As shown in Figure 1, although the job tenure of workers in the two older age groups (ages 45-54 and 55-64) shows a marked decrease since the 1990s (topping out at 10 years in 2004), even before that period, job tenure never averaged above 15.3 years, and in 1951, job tenure averaged only 9.3 years.

For a more specific example, consider the actuarial assumptions of AT\&T, which until its breakup was one of the most stable of all U.S. private employers. AT\&T assumed that for every 100 people it hired, no more than 10 would actually retire from the company. Its defined-benefit pension plan, with long deferrals of vesting, was intended, therefore, to provide adequate retirement income for no more than 10 percent of its workforce. The federal government, another stable employer by most measures, uses the actuarial assumption that 23 percent of those hired will retire from the government after at least 20 years of service. The mobility issue is something we have always faced and is an important reason that so few workers have adequate benefits.

Retirees' dependence on Social Security benefits has been relatively stable as of late. A study that compared sources of retirement income in 1977 and 2004 found that Social Security was somewhat less important at the earliest retirement ages (60-64) but more important at the older retirement ages for both years. This result emerges because of the longevity effect and the fact that Social Security is indexed whereas most other programs are not. For those age 65 and older, the proportion of retirement income provided by Social Security was just above 40 percent in 1977 and 2004. Asset income and postretirement employment each provided about 20 percent of income in both years. In fact, asset income showed a slight decline 


\section{Figure 1. Male Prime-Age (25-64) Workers' Median Tenure, by Age, 1951-2004}

Tenure (years)

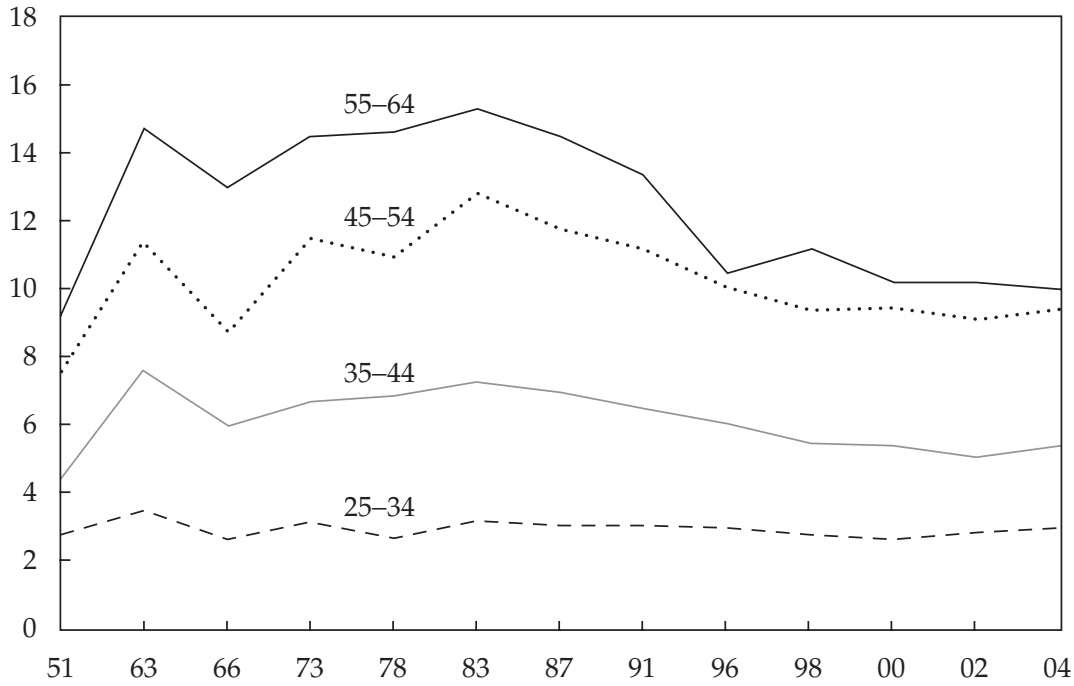

Sources: Data for 1951, 1963, 1966, 1973, and 1978 are from the Monthly Labor Review for September 1952, October 1963, January 1967, December 1974, and December 1979, respectively. Other data are from press releases from 1983, 1987, 1991, 1996, 1998, 2000, and 2002 from the U.S. Department of Labor, Bureau of Labor Statistics, and from Employee Benefit Research Institute estimates of the January 2004 Current Population Survey.

between 1977 and 2004. Interestingly, for both years, the contribution to retirement income from defined-benefit and defined-contribution plans was roughly 10 percent. Thus, such plans have never provided more than a small proportion of retirement income throughout the entire post-World War II period.

When I compare the sources of retirement income for the top and bottom quartiles of the U.S. workforce (not including government employees), I find a huge discrepancy in the importance of Social Security. In 2004, the top quartile of workers relied on Social Security for 21 percent of their income and the bottom quartile of workers, 86 percent. The portion of retirement income provided by pensions for the top quartile in 2004 equaled 25 percent - an improvement over the 19 percent in 1975 but still only part of a balanced array of retirement income sources for that group of workers. In contrast, the bottom quartile of workers in 2004 received only 2 percent of their retirement income from pensions, up from a meager 1 percent in 1975.

Even if 401(k) plans do the same job as defined-benefit plans for the minority of the labor force that spends 25 years or more with one employer, for the vast majority of workers who change jobs many times during their working lives, 
accumulations are greatly reduced. One way to improve accumulations is to change not only the administrative requirements of $401(\mathrm{k})$ plans but also the way such plans are marketed. Examples of such changes include the following:

- Require mandatory rollover of lump-sum distributions upon every job change.

- Eliminate loan provisions.

- Eliminate hardship withdrawal provisions.

- Stop marketing 401(k) plans as a way to save for children's education, medical emergencies, or down payments on a home.

Unfortunately, the U.S. Congress has shown no sign of doing any of these things. In fact, during the last legislative cycle, Congress expanded the number of circumstances under which people could get money out of IRAs and other vehicles without the payment of penalty taxes. But if we are serious about bolstering retirement income, we need to make such changes to encourage saving among people who change jobs frequently. Furthermore, compounding the problem is the fact that many workers change jobs with very small distributions, which, the data suggest, workers are unlikely to roll over until the distributions exceed $\$ 15,000$ or so. Because approximately 50 percent of $401(\mathrm{k})$ participants have account balances today of less than $\$ 10,000,50$ percent of $401(\mathrm{k})$ participants have a high probability of not rolling over their accumulations if they change jobs. If we do not redesign programs to deal with the highly mobile worker, we will not help a large percentage of workers.

\section{Effect of Fast Vesting}

Earlier in the conference, someone said that regulation was overrated as an explanation of the shift in employer sponsorship of pension plans. I would assert that regulation was the primary driver of that shift. The introduction of fast vesting, which has gotten faster as the years have passed, was a major factor in changing employer behavior. Consider again the example of AT\&T's pension planning, in which it assumed that it would need to provide adequate retirement income for 10 percent of the people it hired. Such actuarial assumptions made it reasonably inexpensive to sponsor a plan. But current vesting regulations essentially eliminate such a strategy. Today, a defined-benefit plan has to provide a retirement income for everyone who stays with a company for five years plus a day. So, a huge amount of money goes into a defined-benefit plan to flow out to individuals who will not use it to generate meaningful retirement income.

This change in defined-benefit plans began in 1978 when Atlantic Richfield Company altered its plan to offer lump sums as an alternative to annuities. In the first year of that offer, 92 percent of employees took the lump sum. The most recent data show that in a defined-benefit plan offering a lump sum, 96 percent of workers take the lump sum and only 4 percent take the annuity, despite the tremendous efficiency advantage of a sponsor-provided annuity over anything currently available for individuals to buy in the private market. 


\section{Additional Realities Affecting the Retirement Picture}

I will conclude by identifying several realities that anyone concerned with retirement planning must consider.

First, approximately 40 percent of those who retire early do so for medical and disability reasons. They could not work even if they wanted to.

Second, ERISA forced employers to shift their retirement plans by redefining the system and, in effect, saying that we do not want pension plans to provide only retirement income. We want, in essence, a fair economic distribution. Economists tell us that this is all deferred income, so we want everyone to get a piece of the pie. That change in regulation was the beginning of the end for defined-benefit plans, and it will continue to cause defined-benefit plans to decrease in importance.

Third, although de-cumulation strategies, such as reverse mortgages, are important for those older people who have savings, the primary need for the broad population, which does not have savings, is to learn to stop borrowing and start saving. Despite the apparent inefficacy of exhorting workers and teaching them basic financial literacy, I believe such efforts should continue, at least until policies change and required vehicles, such as add-on accounts, are mandated.

Finally, Baby Boomers are actually in pretty good shape. It is the children of the Baby Boomers, the young workers, who face the biggest challenges in the decades ahead. For their sake, we must all try to convince policymakers that even though the real crisis will not appear in the data for another 20-25 years, we must start dealing with it today. 


\section{The Role of CFA Institute}

\section{Jeffrey J. Diermeier, CFA \\ President and CEO \\ CFA Institute \\ Charlottesville, Virginia}

I will build on some of the topics discussed so far, but I will first emphasize four guiding thoughts to keep in mind:

1. A hole in economic education today means an economic hole in retirement later.

2. Proverbs (29:18) says, "Where there is no vision, the people perish." Similarly, I would say that where there is no adviser, the people perish.

3. Unreasonable expectations equal unacceptable outcomes.

4. Some believe that if all else fails, the government will be the residual owner of the problem. If that is the case, we will all pay.

\section{Importance of Investor Education}

Almost all individuals will at some point become investors. What they need, therefore, is investor education. Yet, our educational system treats investor education and, more broadly, economic education as a second thought - an elective course at best. High school students are not taught the rules of the economic game. They learn about the political systems but very little about the economic system. So, when they step into adult life and begin working at a job that is generated by a company functioning in an economy, they have no idea how that job was generated or how it fits into the economic picture.

At this job, they are then typically offered the opportunity to participate in a defined-contribution plan. But they have no basis for addressing even the most elementary questions they are required to answer. And unfortunately, lack of education leads to lack of participation:

- 33 percent of workers fail to participate in retirement savings plans;

- 20 percent of those eligible for employer matching fail to contribute enough to get full matching; and

- 25 percent of employees hold half or more of their assets in employer stock.

Furthermore, many investment educators question how much information the average U.S. investor can absorb. Before it was disbanded, the Investor Education Group concluded that investor information should be limited to the following guiding principles: save, plan, diversify, understand the costs, and plan again. Education that goes any deeper than that, the Investor Education Group believed, would likely lose its audience. Certainly, these principles seem like low expectations. 
Finally, most investors do not understand the difference between fiduciary responsibility and salesmanship - a difference embodied in the phrase "buyer beware." Yet, they certainly understand this phrase when making other decisions, such as buying a house or buying a car. For example, most consumers know to what extent they should trust an automobile salesman. At the very least, they know how to drive a car well enough to have passed a driver's test, and they probably have some other knowledge, perhaps obtained from consumer magazines. I think that in investing, a comparable base level of education can be attained.

\section{Role of Investment Advisers}

Besides education, investors need guidance, and the advisory model for investors is shifting from an institutional environment-in which, for example, a definedbenefit pension plan committee oversees the investment process and mediates between investment managers and the end user-to an environment in which crucial asset allocation decisions are made by the individual. The individual may be assisted by an adviser or, as provided for in the Pension Protection Act of 2006, by a committee of professionals that provides some input into the process. The individual also benefits from the work of asset managers, who still select a portfolio's specific securities. But many crucial decisions are made by the individual investor, who is too often ill prepared to make such decisions.

Although the old-style pension plan committees had their flaws, they also did some useful things, and we should question whether the current advisory model provides adequate assistance. We have all criticized pension committees for using return assumptions that are too high, but considering the political and earnings pressures they are typically under, they have set relatively reasonable expectations. Moreover, traditional pension plan sponsors do a wonderful job of negotiating management fees that most individuals would consider a tremendous bargain. Plan sponsors can monitor managers and replace underperforming managers with better ones. Finally, defined-benefit plans have automatic enrollment, which is a feature that responds to one of the problems identified during the conference- that when individuals are not required to save for retirement, they often do not.

\section{Economic Realities and Unreasonable Costs}

In a paper I wrote with Larry Siegel and Roger Ibbotson (Diermeier, Ibbotson, and Siegel 1984) that builds on Irving Fisher's notion of the real rate of interest, we noted that long-term real returns, all other things being equal, are governed by the ability of the real economy to produce goods and services. Thus, on a long-term basis (if some equilibrium assumptions hold), 3-4 percent real global economic growth translates into an after-tax rate of return of $3-4$ percent that the global capital 
markets can generate. By diversifying globally and through asset classes, the investor can claim a share of this global growth, diversifying away idiosyncratic risk. Furthermore, investors need to understand that they are dealing with small percentages and should set their expectations at a more realistic level.

Unfortunately, much real growth potential is lost through a host of leakages, the most obvious ones being asset management fees, legal fees, accounting fees, and commissions. In The Bogleheads' Guide to Investing (Larimore, Lindauer, and LeBoeuf 2006), the authors estimated that such leakages come to about 3 percent annually for an actively managed equity mutual fund, which means that the intermediary structure is taking away most of the growth from the investor. Such a situation must ultimately change.

Consider this situation from an individual investor's point of view. Assume she has a $\$ 50,000$ retirement account and is paying total annual costs of 2 percent, or $\$ 1,000$. When people go to the mall, they think long and hard about spending $\$ 100$. Yet, here is an investor who is probably not even aware that she is spending $\$ 1,000$ on fees and other costs for her retirement account. Fees should be so transparent that paying them should be like writing a check out of a checkbook. When I write a check, I look at all the other items I am writing checks for and ask myself, Is this a good expenditure of my money? Without such transparency, investors have no idea how to make good choices.

\section{Role of CFA Institute}

CFA Institute has a vital role to play as a long-term advocate for investors of all types by providing them with guidance that will help them understand the realities of saving and investing. Therefore, CFA Institute is intent on creating a cadre of investment professionals who meet a high standard of ethical awareness and objective investment knowledge. We have 94,000 members worldwide who are expected to

- $\quad$ act with integrity, competence, diligence, and respect;

- $\quad$ lace the interests of the client before their own personal interests;

- use reasonable care and exercise independent professional judgment;

- practice in a professional and ethical manner;

- $\quad$ promote the integrity of and uphold the rules governing capital markets; and

- maintain and improve their professional competence through lifelong learning. CFA Institute has a long history of building a general investment body of knowledge and is working to create a similar body of knowledge for private wealth. It also has a long history of testing the competency of a large population of investment advisers and is using that expertise to consider developing an investor IQ test for individuals. 


\section{Summary}

If we fail to meet our obligations to the investor who is planning for retirement, four fates await us. We will see

- compound ignorance rather than compound interest,

- irrational expectations that lead to disappointing outcomes,

- individual investor blindness and a lack of adviser vision, and

- a centralized government solution.

\section{REFERENCES}

Diermeier, Jeffrey J., Roger G. Ibbotson, and Laurence B. Siegel. 1984. "The Supply of Capital Market Returns.” Financial Analysts Journal, vol. 40, no. 2 (March/April):74-80.

Larimore, Taylor, Mel Lindauer, and Michael LeBoeuf. 2006. The Bogleheads' Guide to Investing. Hoboken, NJ: John Wiley \& Sons. 


\section{The Challenges of Investor Education}

\section{Zvi Bodie}

\section{Norman and Adele Barron Professor of Management Boston University \\ Boston}

Finance is an applied science like medicine or engineering, and best practices evolve as scientific knowledge advances. But there are some core principles of rational financial decision making that remain constant. Those principles should be taught in a way that is consistent with the basic concepts and definitions of economics. They should be presented as simply as possible-but not too simply.

We need institutional innovation to address the problem of investor education. Most people have honorable intentions, but we all want to make a living. In that respect, we are all salesmen to some extent. The trick, therefore, is getting people to serve the public interest while they are serving their own interests. Starting with my own profession, I believe that educators have not done enough to educate the public about finance, so I have visited investor education websites to learn what educators could do better.

When such websites started to appear as a result of the defined-contribution revolution, I thought they would be great places to find cases to use in my investments class. I would look at real world cases, see what professionals were telling people to do, and then discuss them in class. What I discovered was a real eye opener for me and my students. The advice the websites offered was pretty much the opposite of what I was teaching them. I determined then to learn why this was happening and what should be done about it.

First, I believe that regulators are not doing their job. In fact, the U.S. Securities and Exchange Commission (SEC) is part of the problem. The educational materials distributed by financial services firms and by the SEC are often misleading and biased in favor of products that may not be suitable for large numbers of consumers. Regulators should be wary of disseminating or endorsing these materials because doing so gives them the appearance of validity and objectivity.

The current situation is a classic example of what Nobel Prize winning economist George Stigler called regulatory capture. He observed that regulation does not so much help consumers as help organize the industry being regulated by restraining competition and keeping prices high and quality low. This result occurs because the regulated companies are profoundly affected by regulators and have a much greater incentive to influence the regulators than do the consumers, whose interests are diffuse. I think this insight into regulation has a great deal of explanatory power. 
Therefore, universities and professional associations should cooperate in designing, producing, and disseminating objective financial education that is genuinely trustworthy. In doing so, we have to distinguish between marketing materials and bona fide education. The first order of business is to purge the popular literature of concepts and terminology that are not what we teach or believe to be true. For example, much popular literature, including the SEC website, states that saving is for the short run and investing is for the long run. In reality, the distinction between saving and investing has nothing to do with the time horizon. Both are for the long run and both are for the short run. Saving refers to the difference between income and consumption. Investing refers to the construction of a portfolio of assets. This is the way economists have always defined saving and investing.

More than that, the popular literature appears to have defined safe investing out of existence- a clever trick from a marketing point of view but a great disservice to financial education. According to the conventional wisdom promoted in popular literature, stocks become safe in the long run because of time diversification. This conventional wisdom assumes that time diversification always works, which, in turn, means that the investor is certain to earn the equity risk premium. But if the risk premium is the payoff for bearing the uncertainty of risk, how can the payoff be certain? The popular view contradicts the principles of economics. Stocks are never a safe way to achieve a specific inflation-protected target at any future date. Popular literature encourages the belief that the only way to reduce risk is to diversify, but the reality is that the simplest way to reduce risk is to hold safe assets. The ex ante cost of achieving a future objective cannot be reduced by investing in stocks.

Economics and personal finance are not separate fields. Investors need to understand the basic economic foundations of personal finance. I believe the 10 principles listed below will help them do so:

- frame choices in terms of objectives and constraints,

- do not waste resources,

- do not be fooled by inflation,

- distinguish between saving and safe investing,

- do not judge the risk of an asset in isolation,

- stocks are not safe even in the long run,

- a security's price is a fair estimate of its value,

- beware of survivorship bias in evaluating investment managers,

- consider taxes, fees, and other transaction costs when evaluating investments, and

- $\quad$ seek expert advice from impartial sources.

Finally, let me emphasize one more point. I believe that the labels we give things are not a secondary matter; they represent a matter of primary importance. For example, when I make my point about redefining saving and investing to a group 
of financial planners, they tell me I am quibbling over words. But I say this is not quibbling. The way we define things shapes the way we think about them and, therefore, the way we use or interact with them.

Consider a health savings account. As defined today, a health savings account is simply an investment account. But by labeling it a health savings account, we are implying to ordinary consumers that if they contribute money to such an account, they should then be able to pay their health expenses. Similarly, consumers might well assume that if they invest in a tuition savings account as recommended, they will be able to pay for their children's college tuition. But a tuition savings account with a target date is merely a commitment to a certain asset allocation strategy. No consumer protection is offered, no guarantees-so too with a retirement account. The consumer may, in fact, experience a tremendous shortfall with such products.

As a consumer, I expect products to provide what their labels imply. Labels are important. 


\section{POSTCONFERENCE SUMMARIES}

\section{The Future of Life-Cycle Saving and Investing: A Review}

Jim Finnegan, CFA

\section{Dear Readers,}

I had the wonderful opportunity to attend a conference titled "The Future of LifeCycle Saving \& Investing" held at the Boston University School of Management from 25 to 27 October 2006. The event was sponsored by Boston University with cosponsorship by the U.S. Federal Reserve Bank of Boston's Center for Behavioral Economics and the Research Foundation of CFA Institute. The rationale for holding this conference included the following:

1. We live in a time of great changes in the way Americans save, invest, and manage the risks of protecting their standards of living in their retirement years.

2. The Baby Boom generation (the leading edge-born in 1946-is now within five years of the traditional retirement age) is the most prosperous, healthiest, and longest-lived generation ever. ${ }^{1}$ And this generation (median age 51 ) faces an unprecedented number of choices and challenges regarding their retirement saving and investing.

3. With the revolution in financial markets and technology since the early 1970s and advances in research on behavioral finance since the early 1990s, we finally have the intellectual foundations to create a new field of science for life-cycle saving and investing.

The conference was fascinating both in the diversity of participants who attended and the shared sense of urgency among attendees that new theories, concepts, models, tools, and (ultimately) financial products and services will be necessary to address the needs of a huge segment of the population (over 20 percent of the total population in the United States alone) who hope to retire comfortably within the next 25 years.

1The Baby Boom is typically defined in the United States as the period from 1946 to 1964, when approximately 75 million children were born.

Editor's Note: This letter from the editor was originally published by Financial Engineering Nerws (www.fenews.com) and is republished here with permission. 
Among the participants were senior representatives of the insurance industry, the investment management industry, the commercial banking industry, a major international trade union, several retirement policy and advocacy groups (e.g., the American Association of Retired People, or AARP, and the Employee Benefit Research Institute), the U.S. Department of Labor (Employee Benefits Security Administration), the actuarial science profession, and many senior academics in finance and economics (including Nobel Laureates Professor Paul A. Samuelson of MIT and Professor Robert C. Merton of Harvard University, each of whom provided a keynote address at the dinners over this three-day event).

Professor Zvi Bodie of Boston University (co-author of Worry-Free Investing ${ }^{2}$ ) was a key figure in organizing the conference and encouraging all attendees to participate in the lively debates that followed the presentation of papers. The conference sessions included "Can Personal Investing Be Rational?"; "Innovative Retirement Income and Old-Age Insurance Products"; "The Role of Government in Life-Cycle Saving and Investing"; and "The Theory of Optimal Life-Cycle Saving and Investing." (Most of the papers from the conference can be downloaded at http://smg.bu.edu/exec/elc/lifecycle/.)

\section{The Need for a New Approach to Retirement Planning}

Many of the post-World War II working generation accepted an implicit lifetime employment contract with their employers (often large corporations). They exchanged lifetime loyalty to the employers in return for defined-benefit retirement plans. The benefits were largely determined in the last three to five years of employment prior to retirement and tied to a formula based on the number of years of service and the wages/salary in the last years of employment. And there were significant penalties for violating this implicit contract, including forfeiting all future benefits if one left prior to a defined "vesting period" of up to 10 years as recently as the early 1980s.

Today, significantly fewer of the pool of future retirees (including those aging Baby Boomers) are offered this option. And current participation in defined-benefit pension plans also continues to decline as many companies terminate these plans and shift current employees into defined-contribution plans, where their past, accrued, and vested defined benefits are converted into a monetary value along with the promise of future employer contributions that the employee is now responsible for managing. As for Social Security, this defined-benefit plan run by an agency of the U.S. government will come under increasing pressure as the ratio of employed contributors to retired beneficiaries declines over the next three decades.

2Zvi Bodie and Michael J. Clowes, Worry-Free Investing: A Safe Approach to Achieving Your Lifetime Financial Goals (London: Financial Times Prentice Hall, 2003). 


\section{An Excellent Start to a Difficult Challenge}

The conference was a start-and an excellent one-for tackling the future challenges and problems millions of people face with this tectonic shift in responsibility for retirement security from employers to employees. And the current challenges are great indeed. This brave new world for retirement planning rests on two critical decisions by individuals: (1) How much should one save for retirement over the course of his/her working career? and (2) How should he/she invest these retirement savings in order to ensure a secure and comfortable retirement?

In terms of individual retirement saving decisions, David Laibson's presentation of a paper by Beshears, Choi, Laibson, and Madrian ${ }^{3}$ (based on a confidential analysis of recent employee participation rates in defined-contribution retirement plans) indicated that employee participation in these plans is not rational based on current economic theory. Many employees forgo making contributions to companysponsored defined-contribution retirement plans - sometimes for 3-10 years-and despite the promise of employer matching contributions (on a tax-free basis). And from a behavioral finance standpoint, many participating employees in these defined-contribution plans opt for legally required "default" options for minimum matching employer contributions-currently 2 percent-when higher employee contribution rates would be matched dollar for dollar on a tax-free basis. Clearly, this form of economic incentive for employees is not working.

In terms of individual investing decisions, Professor Bodie argued that some retirement investment advice currently being offered is wrong. As an example, consumers are being told that the way to protect themselves against inflation in retirement is to invest in stocks. In fact, Treasury Inflation-Protected Securities are a far better hedge against the risk of inflation. Indeed, the reason given by the U.S. Treasury in 1997 for starting to issue these bonds was to provide consumers with a safe way to invest for retirement. Many investment companies offer these bondscalled TIPS - as a choice in their 401(k) plans.

Underlying all the discussion on saving and investing for retirement was the recurring question of life expectancy, which has historically increased in the United States. Future advances in medical technology could possibly have a dramatic effect on future life spans, even among those now 50 and over. And so, the brave new world of individual responsibility for retirement security includes making an accurate estimate of one's life span (in addition to other important factors, like retirement investment returns, future expenses in later years, and increases in the cost of living).

3John Beshears, James J. Choi, David Laibson, and Brigitte C. Madrian, "The Importance of Default Options for Retirement Savings Outcomes: Evidence from the United States," NBER Working Paper 12009 (February 2006). 
Is there a role for financial engineering in this new world of employee- and household-managed retirement planning? I certainly think so, and I think it is a critical role. In his speech at the conclusion of the first day of the conference, Robert C. Merton, 1997 Nobel Laureate in economics, analyzed and forecasted the likely directions for the next stage of financial innovation in life-cycle products for consumers. He cited the accelerating pace of technological progress in finance during the decades since Paul Samuelson and he published their 1969 companion articles on optimal life-cycle consumption and portfolio choice, and he expressed his strong conviction that the innovations that have revolutionized the practice of finance in banking and international trade already exist and can be adapted to satisfy consumer financial needs over the life cycle. Finally, he gave several examples of how new consumer financial products can be designed and produced to overcome some of the obstacles that lead to blatantly irrational or suboptimal behavior.

So, stay tuned: An exciting new application for financial engineering-with tremendous social and economic benefits-is beginning to take shape. 


\section{An Actuary's View of the Future of Life Cycle Saving and Investing: A Report and Some Discussion on Key Issues Anna Rappaport}

President

Anna Rappaport Consulting

Chicago

This is a time of major change to the American retirement landscape. Are we ready to meet the challenges?

I recently attended a very interesting conference, The Future of Life-Cycle Saving and Investing, sponsored jointly by the Federal Reserve Bank of Boston, Boston University, and the Research Foundation of CFA Institute. The conference was attended by a diverse group: several important academics, economists and experts on finance, members of the Federal Reserve bank, actuaries, policymakers and regulators, attorneys, representatives of the financial services industry, CFA charterholders, and people in advisory roles.

The topics included discussion of the life-cycle model, findings from behavioral finance, a discussion of managing risks post-retirement, a discussion of the role of government, some discussion on software, and some perspectives on the future. The full program, papers, and presentations can be found on the conference website, http://smg.bu.edu/exec/elc/lifecycle/. I recommend the papers to you.

I found a lot of overlap between the topics covered there with recent research within the actuarial profession and with the topics discussed at Retirement 20/20, a major project of the Society of Actuaries. This article will link some of the content to topics of interest to actuaries and to some of the work that actuaries have been doing and raise questions and perspective. For a summary of the content, look at the summary provided by Zvi Bodie, a professor of economics and finance and conference organizer. That summary can be found on the website referenced above.

\section{Challenges to Traditional Ideas}

Challenges to traditional investment ideas were central to the discussion. Bodie has collected numerous examples of ideas that he views as false that are in the public domain and presented as correct information on the websites of large and highly

Copyright 2007 by the Society of Actuaries, Schaumburg, Illinois. Reprinted with permission. 
regarded institutions. Bodie identifies three notions he suggests purging from the popular literature along with three replacement ideas from the discipline of financial economics that are, in contrast, worthy of wide promotion (see Table 1).

He raises an important issue with regard to equity investment and causes us to ask the question, "When is it appropriate for individuals to invest in stocks?" I find it very interesting that well-schooled financial people, including economists, actuaries, and others, have very different views about the appropriateness of stock investment in different circumstances. Divergent views exist within each of these professions. I also think some of the discussion about stock investment, while appropriately focusing on the risk, fails to recognize that stock investment is a form of ownership and gives people a chance to participate in the growth of the economy. I am not prepared to take a position on the question of who is right and who is wrong in these many discussions.

\section{Table 1.}

Popular Literature

Financial Economics

Saving is for the short run. Investing is for the long run.

Saving means income minus consumption; investing means selecting your portfolio of assets.

The only way to reduce risk is to diversify. The simplest ways to reduce risk are to hedge, insure, or hold safe assets. A safe way to achieve a future consumption target is with CPI-linked bonds.

Stocks become safe in the long run due to Stocks do not become safe even in the long run. If they did, "time diversification." they would not have a risk premium.

\section{Perspectives on Consumption Targets}

The key paper, "The Theory of Optimal Life-Cycle Saving and Investing" by Zvi Bodie, Jonathan Treussard, and Paul Willen, sets the stage for the dialogue. The authors review the theory and point out that there are gaps between theory and practice. In her discussion, Deborah Lucas, from Northwestern University, raised practical issues about the use of this model. She cautioned us to realize that people have many different life paths and that an exclusive focus on phases of the life cycle tends to oversimplify for many people. She also focused on the importance of contingent events and emphasized the importance of such decisions as marriage, divorce, and family size and the fact that uncertainty surrounding them limits the ability to make forecasts with precision.

Another paper, by Laurence Kotlikoff, introduced practical models and focused us on consumption smoothing. Life-cycle saving and investing are linked to consumption smoothing or some other method of reallocating consumption over the life cycle. A common way of focusing on income needed after retirement is through the use of replacement ratios. Actuaries have commonly used replacement ratios in thinking about pension plan design and measuring benefit adequacy. Some 
of the models of life-cycle financial planning presented focused on lifetime consumption smoothing (inflation adjusted so that consumption is smoothed on a real basis). Although this is appropriate for some people, many others will have different ideas. It is hoped that actuaries can have some dialogue on this issue, focusing on different approaches to determining what is needed and wanted in retirement, how they differ and how they are the same. I see actuaries as being able to add to the discussion in several key areas:

- Identification of risks together with information about what risks can be transferred effectively in the current marketplace and how this happens.

- Very good participants in a discussion about how the marketplace may evolve.

- Practical knowledge of how retirement systems work and regulations interact with each other. Many actuaries have hands-on experience working within the system. The combination of hands-on experience and theoretical knowledge is very valuable as we think about these issues.

My opinion about life-cycle consumption as we think about retirement needs and wants is as follows: A way to link traditional replacement ratios and consumption targets is to make an implicit assumption that income is consumed except for the amount saved and paid in taxes, and what does not need to be replaced is savings, Social Security payroll taxes, and/or work-related expenses.

For example, an individual who was saving about 10 percent of income prior to retirement and consuming all the rest of current income, and who no longer does paid work and therefore no longer pays Social Security payroll taxes, can probably continue his or her standard of living with about 70 percent to 80 percent of preretirement income plus the increased cost of medical premiums. This links traditional replacement ratios with consumption targets.

That amount would be adjusted in some common situations. For example, a family saving more than 10 percent would need a lower amount relative to preretirement income. When a family pays off their mortgage at time of retirement, the income needed to maintain consumption post-retirement is reduced by the reduction in current housing cost. Similarly, a family that had heavy college expenses in the years before retirement will not need to count that money in consumption that will continue into retirement.

During retirement, consumption may be higher early on as people pursue their retirement dreams, such as travel for example.

Consumption levels may also change. Some people may want to stay in the same house and geographical area, whereas others want to move, perhaps to lowercost housing to enable earlier retirement. Others may want to spend more on housing and become snowbirds or have multiple-type dwellings for different uses. People who have larger homes are ultimately likely to downsize, even if they do not have to for economic reasons. The problem of caring for larger homes can be substantial later in life. 
Medical costs and the need for care are likely to increase in retirement. When an individual not eligible for Medicare exits an employer paid health plan, costs for insurance are likely to increase greatly.

Consumption varies over working adult life, and the new retiree probably will want to continue or modify spending based on consumption just before retirement.

We can think about income as representing a bare minimum, plus added amounts to do things we want to do. We might think about the need for guaranteed income as linked to the bare minimum.

In my view, neither consumption smoothing nor traditional replacement ratios properly address the issue of changing needs during retirement by focusing on the one-time transition from pre-retirement to retirement. The premise of consumption smoothing is a good start, however, by recognizing at least the reality of fluctuations due to the occurrence of different events over time.

Part of the discussion about consumption smoothing over the life cycle included the idea of borrowing early in life. If borrowing goes beyond student loans and a home mortgage, I do not think it is a good idea. We do not really know what our ultimate income will be.

I also find that inadequate focus on risk management is a failure of both consumption smoothing and traditional replacement ratio analysis.

\section{The Role of Defined-Benefit Plans}

Most of the conference was focused on challenges with regard to providing retirement security and income in personal savings accounts and defined-contribution (DC) plans. These systems do not usually provide lifetime income and offer significant challenges with regard to lifetime security. These challenges do not exist in traditional defined-benefit (DB) plans, which are a natural way to provide income. Although most of the discussion in "The Future of Life-Cycle Saving and Investing" relates to individual saving and DC plans, we need to remember that DB plans work very well in the appropriate setting.

These plans are facing many challenges today. A key question is whether it is worth trying to meet those challenges and continue to use DB plans. Public sector employers are generally continuing DB plans, although state legislatures are increasingly challenging them and some plans have moved to defined contribution. The number of private sector employers offering these plans is shrinking markedly. The paper by Alicia Munnell provides trend data on the overall use of various plan types in the private sector. The discussion by Deborah Lucas focuses on the importance of DB plans.

I believe that $\mathrm{DB}$ plans are a direct and easy way to provide lifetime income and that they remain valuable. There are many threats to these plans, and the existing designs are not attractive to plan sponsors in the U.S. accounting and regulatory environment. There are different views of how to move forward. Some 
people are seeking ways to strengthen and preserve these plans; some are seeking new plan models; and others have essentially given up on DB plans as a part of the future retirement income delivery system. I strongly encourage not giving up on DB plans but, rather, seeking out models that can work in the evolving environment.

\section{Risks and Risk Management}

The primary focus of the conference was on life-cycle saving and investing, with a lot of focus on consumption smoothing. At the same time, speakers recognized that risk management and, particularly, lifetime income are part of the picture. My paper focused on post-retirement risks and risk management issues. Mark Warshawsky focused on long-term care risk and how packaging long-term care with a life annuity may be a good way to manage both risks. Jerry Golden talked about income annuities and how their price might vary depending on the risk management decisions the buyer made. He showed the difference in cost for a single life annuity versus a joint and survivor annuity and then showed the effect of lifecare provisions, indexing, inflation, and some other features. I believe that one of the primary weaknesses of much personal financial planning is an inadequate focus on risk and how to manage it.

\section{The Role and Importance of the Employer}

The conference discussed the employer's role and (several times) the importance of the employer, although there was no panel specifically focused on that topic. I feel that there was inadequate focus on the importance of the employer. It was clear from the discussion that individuals are not managing well enough on their own and that some combination of government programs, employer programs, and mandates are essential for financial security. There was no way to conclude from the discussion what the preferred mix was by the group in total. However, from the panel on the role of government, it was clear that some presenters preferred mandates to plans voluntarily established by employers.

Traditionally, employers offer income through DB plans, and although they offer a reliable source of life income, most private sector plans in the United States do not include inflation indexing, leaving a gap in income protection. However, most DC plans offer lump sums and not life income, and as these plans are growing, it is important to consider issues surrounding life income in DC plans. These plans that have evolved are more often the primary retirement vehicle, and in the last few years, there has been a growing focus on results produced by these plans. For instance, default options are now recognized as critically important since many employees stay with them and do not make an active choice. The paper presented by David Laibson made clear just how important default options are and how much they influence the results produced by plans. Common defaults today include autoenrollment, auto-increases, and investment defaults using balanced and life-cycle 
funds. It is uncommon to find benefit distribution defaults in defined contribution other than a lump sum. This is an area for further development, and default options for payment of benefits were discussed in several different panels.

The distribution of benefits and making funds last during retirement are important issues in achieving success and meeting life-savings-plan goals and employer-plan goals. Satisfactory results post-retirement will depend on having good methods for providing advice and life income to employees and retirees in an efficient and unbiased manner. Employers could play a key role in selecting the providers that would offer group products for risk protection through the employer.

Plan sponsors are reluctant to offer annuity options directly because few people choose them and, in addition, regulatory issues - such as joint and survivor annuity and spousal consent requirements, the implications of the Norris decision, "safest annuity rule issues," and/or fiduciary responsibilities, etc.-create more work and uncertainty. It should be noted that the regulatory climate tends to offer incentives to employers not to offer income. The employer who offers only a lump sum option does not need to get spousal consent for plan distributions. In contrast, the employer who offers an annuity option must offer a joint and survivor annuity and must get spousal consent in order for someone to elect out of the option. One of the other complexities is linked to the Norris decision: Although annuities are usually priced using different rates for males and females, employers are prohibited from using sex-based rates or features inside of DC pension plans. A third complexity is the minimum distribution rules. The most desirable form of annuity option would be one that allows purchase in several chunks over time, but the minimum distribution rules fight against this. The safest annuity rule also opens the employer up to fiduciary liability.

Instead of offering income directly through the DC pension plan, companies such as IBM are beginning to offer annuity options outside of the plan, but with institutional pricing through a third-party IRA rollover program. Under one thirdparty program now being used by some large companies, the annuity is shopped using an automated process to get a good price; it can be purchased at retirement or later and in steps over time. A group of employers is also working on an annuity purchasing coalition using institutional pricing of the product. Note that the Pension Protection Act opens the way to an easing of the safest annuity rule issues. Working through the employer is one way to deal effectively with the distribution system issues. It will, however, have a chance only if the regulatory issues are dealt with to make it easier.

\section{Regulatory Issues and the Role of Government}

Alicia Munnell presented a paper on the role of government in life-cycle saving and investing. That paper focused on longer-term options for the role of government. The author recognizes that there are limitations on the effectiveness of 
individual efforts and she recommends mandated saving as a second layer on top of Social Security. Such a mandate is similar to the MUPS, recommended by the President's Commission on Pension Policy in the Carter administration, or to addon private accounts in Social Security. There was also a discussion from the Netherlands. That discussion advocated mandatory personal accounts invested in a type of multi-employer arrangement. The use of a "non-profit" insurance company is advocated, and it is proposed that the government issue longevity bonds to assume the mortality risk.

These structures offer alternatives for reconfiguring the retirement income system. Within the present system, there are regulatory issues that create roadblocks to payment of retirement funds as income. These regulations are important in understanding the functioning of the current system, and modifying them offers a path to improving income delivery aspects of the system. In addition to the issues mentioned above, the intersection of regulations affecting the insurer and plan sponsor must also be considered. When the regulatory issues facing all of the stakeholders in the retirement system are merged, the total impact of the regulations is overwhelming. Two of the most serious issues are the conflicts with regard to unisex rates and issues surrounding minimum distribution rules. Employer plans are not permitted to use sex-based rates, whereas virtually all annuity contracts are priced using sex-based rates. The minimum distribution rules require that qualified plan funds be distributed beginning after age 70 -and-a-half. Their structure creates complexity for purchasing annuities over time on a staggered basis and for combination products that put annuity and long-term care into the same insurance product. Both annuities and long-term care are heavily regulated, but by different rules, and the regulations make it hard to combine them. Provisions of the Pension Protection Act open the way to combination products in the future.

There are also regulatory complexities in products sold to individuals. Some of these products require compliance with both securities and insurance law.

\section{Conclusion}

This is a time of major change and challenge to the American retirement landscape. This conference set forth many interesting ideas and perspectives. The way of thinking about the ideas is quite different from much of what we have traditionally done. It helped me to think more about benefit adequacy, replacement ratios, and the retirement system-ideas that I have lived with for many years. My concerns about the discussion were as follows:

Lifetime consumption smoothing is unrealistic. However, when taken together with replacement ratios, a focus on consumption adds to our understanding of retirement needs.

Risk management needs to be much more prominent in our thinking about this topic. 
The employer is a very important part of the retirement system, and we need to encourage and value employer sponsorship of plans.

Regulation is often a roadblock to doing some things that are desirable.

I plan to bring these ideas back to the Committee on Post Retirement Needs and Risks. One of the issues that needs work, which the committee identified over the last few years, is retirement needs and more understanding of spending. We have a paper-call out on that topic. It is hoped that this article will also encourage you to think about these issues, read the papers, and add to the dialogue.

Anna Rappaport, FSA, MAAA, is chair, Society of Actuaries Committee on Post Retirement Needs and Risks and owner of Anna Rappaport Consulting. She can be contacted at anna@annarappaport.com. 